\title{
MR imaging of coronary atherosclerosis
}

Citation for published version (APA):

Gerretsen, S. C. (2010). MR imaging of coronary atherosclerosis. [Doctoral Thesis, Maastricht University]. Datawyse / Universitaire Pers Maastricht. https://doi.org/10.26481/dis.20101210sg

Document status and date:

Published: 01/01/2010

DOI:

10.26481/dis.20101210sg

Document Version:

Publisher's PDF, also known as Version of record

\section{Please check the document version of this publication:}

- A submitted manuscript is the version of the article upon submission and before peer-review. There can be important differences between the submitted version and the official published version of record.

People interested in the research are advised to contact the author for the final version of the publication, or visit the DOI to the publisher's website.

- The final author version and the galley proof are versions of the publication after peer review.

- The final published version features the final layout of the paper including the volume, issue and page numbers.

Link to publication

\footnotetext{
General rights rights.

- You may freely distribute the URL identifying the publication in the public portal. please follow below link for the End User Agreement:

www.umlib.nl/taverne-license

Take down policy

If you believe that this document breaches copyright please contact us at:

repository@maastrichtuniversity.nl

providing details and we will investigate your claim.
}

Copyright and moral rights for the publications made accessible in the public portal are retained by the authors and/or other copyright owners and it is a condition of accessing publications that users recognise and abide by the legal requirements associated with these

- Users may download and print one copy of any publication from the public portal for the purpose of private study or research.

- You may not further distribute the material or use it for any profit-making activity or commercial gain

If the publication is distributed under the terms of Article $25 \mathrm{fa}$ of the Dutch Copyright Act, indicated by the "Taverne" license above, 


\section{MR imaging of coronary atherosclerosis}


CC Copyright S. Gerretsen, Maastricht 2010

ISBN 9789052789859

Cover design: Susanne Frints, Barrakuda Image studio

Met dank aan Emilia Hauser voor het ter beschikking stellen van haar schilderijen "Vrijthof" en "oude brug II" voor het ontwerp van de uitnodigingen.

Lay out: Ine Kengen

Printed by Datawyse / Universitaire Pers Maastricht 


\title{
MR imaging of coronary atherosclerosis
}

\author{
PROEFSCHRIFT \\ ter verkrijging van de graad van doctor aan de Universiteit Maastricht, \\ op gezag van de Rector Magnificus, Prof mr. G.P.M.F. Mols \\ volgens het besluit van het College van Decanen, \\ in het openbaar te verdedigen \\ op vrijdag 10 december 2010 om 10.00 uur \\ door \\ Suzanne Carina Gerretsen \\ Geboren op 22 februari 1978 te 's Gravenhage
}

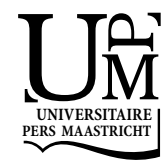




\title{
Promotor
}

Prof. dr. J.M.A. van Engelshoven

\section{Copromotores}

\author{
Dr. T. Leiner \\ Dr. M.E. Kooi
}

\section{Beoordelingscommissie}

Prof. J. Wildberger (voorzitter)

Dr. Ir. W. Backes

Prof. dr. M.J.A.P. Daemen

Prof. dr. B. Mochtar

Prof. dr. M. Stuber (University of Lausanne, Switzerland)

The work described in this thesis was partially funded by NWO (Veni grant number 916.46.034) and Bayer Schering Pharma

Additional financial support for publication of this thesis was generously provided by:

- Philips Healthcare

- Bayer Schering Pharma

- Boston Scientific Nederland BV 


\section{Contents}

$\begin{array}{lll}\text { Chapter } 1 & \text { General introduction } & 7\end{array}$

Chapter 2 Magnetic resonance imaging of atherosclerosis 15

Chapter 3 Magnetic resonance imaging of the coronary arteries 41

$\begin{array}{lll}\text { Chapter } 4 & \text { Detection of coronary plaques using MR coronary vessel } & 71\end{array}$ wall imaging: validation of findings with intravascular ultrasound

Chapter 5 Visualization of coronary wall atherosclerosis in asymptomatic subjects and patients with coronary artery disease using magnetic resonance imaging

Chapter 6 Time-efficient black blood coronary vessel wall imaging at 109 3T using Improved Motion Sensitized Driven Equilibrium (iMSDE): Feasibility and reproducibility

Chapter 7 Cardiac cine MRI: Comparison of 1.5T, non-enhanced 3.0T and blood pool enhanced 3.0T imaging

Chapter 8 General discussion

Summary

Samenvatting

Dankwoord

Curriculum vitae

List of publications

Color figures 

Chapter 1

General introduction 
$-8-$ 


\section{Atherosclerosis and coronary artery disease}

Atherosclerosis is a chronic inflammatory disease of the large and medium sized arteries and remains one of the most important causes of morbidity and mortality worldwide, despite advances in diagnosis and treatment ${ }^{1,2}$. The term atherosclerosis is derived from latin and means gruel-like (athero) hardening (sclerosis) of the arteries. It is characterized by the build-up of cholesterol, fibrous tissue and inflammatory cells in the arterial vessel wall ${ }^{3-5}$. In early stages of atherosclerosis, the vessel wall exhibits positive, outward or Glagovtype remodeling ${ }^{6}$. This process is characterized by expansion of the elastic lamina but maintenance of luminal diameter. In later stages, negative, inward remodeling can take place, which leads to luminal narrowing ${ }^{7}$.

Complications of atherosclerosis can occur when there is lumen obstruction due to plaque rupture or erosion with thrombus formation or after embolization of a formed thrombus ${ }^{4,5,8}$. In the coronary arteries, this leads to transient myocardial ischemia or myocardial infarction. These complications occur not only in severely stenosed vessels, but also in arteries with mild to moderate stenoses ${ }^{9,10}$. In these mild to moderate stenotic arteries, there are often plaques demonstrating outward remodeling, a big necrotic core, a thin and inflamed fibrous cap, proliferation of the adventitial vasa vasorum and intraplaque neovascularization and intraplaque hemorrhage, and are therefore considered vulnerable for rupture ${ }^{8,11}$.

\section{Burden of Disease}

By any measure cardiovascular disease remains one of the foremost causes of morbidity and mortality. In the Netherlands in 2007, 41.355 (31\%) of all 132.752 deaths were due to cardiovascular diseases like ischemic heart disease, stroke, heart failure etc ${ }^{12}$. In subjects presenting with cardiovascular diseases, $29 \%$ of deaths and $26 \%$ of clinical admissions in hospitals were due to ischemic heart disease. Total healthcare costs in the Netherlands in 2005 were $€ 68.5$ billion of which $€ 5.5$ billion (8\%) were spent on cardiovascular disease, which is the second most expensive group of diseases after psychological disorders. Of the $€ 5.5$ billion, $23 \%$ ( $€ 1.3$ billion) was spent on patients with coronary artery disease ${ }^{13}$. More recent data from the US also demonstrate the large financial burden on society: the estimated costs for the USA 
for 2010 associated with coronary heart disease are approximately \$177.1 billion ${ }^{1}$.

Complications of atherosclerosis often arise unexpectedly. In 30-50\% of asymptomatic subjects, the first indicator of coronary atherosclerosis is a heart attack, which is often fatal ${ }^{14} .80 \%$ of all individuals who suffer sudden cardiac death have coronary artery disease ${ }^{15}$, and about $20-25 \%$ of all sudden cardiac deaths occur in subjects without prior clinical evidence of coronary artery disease ${ }^{16}$. However, due to ongoing improvement in prevention and treatment, there is a decrease in deaths in the western world ${ }^{2}$.

\section{Imaging of the coronary arteries and vessel wall}

Visualization of the coronary arteries is usually done with X-ray coronary angiography. Although this is a highly invasive technique it remains the standard of reference for imaging coronary artery luminal narrowing because of its unmatched spatial and temporal resolution. However, because X-ray coronary angiography can only be used to depict the arterial lumen, earlier and subtler forms of coronary atherosclerosis such as atherosclerotic plaques in positive remodeled arteries can be underestimated or even remain undetected.

Excellent techniques for imaging of the arterial vessel wall are intravascular ultrasound (IVUS) $)^{17-20}$ and optical coherence tomography (OCT $)^{21-23}$. These techniques both give detailed information about both the coronary lumen and vessel wall, although OCT is currently mainly used in research studies whereas IVUS is already implemented in clinical practice in some institutions. IVUS is a highly reliable technique for vessel wall imaging as has been demonstrated in many studies, and can even give information about certain plaque characteristics that might be related to risk for complications of atherosclerosis, ${ }^{10,24-26}$. However, due to risks and high costs, IVUS cannot justifiably be used for serial imaging in asymptomatic subjects. This dilemma has sparked the search for alternative modalities which are capable of unmasking occult coronary atherosclerotic plaques in a patient-friendly way,

Nowadays many investigators are researching magnetic resonance imaging (MRI) and computed tomography (CT) as potential alternatives to X-ray angiography and IVUS as these modalities can also be used to visualize atherosclerosis in coronary arteries ${ }^{27-31}$. Both MRI and CT offer the promise for noninvasive imaging of the coronary arteries and vessel wall and their use may lead to improved individualized risk assessment because of direct visualization 
of coronary plaque burden. Despite the technical challenges, MRI ultimately is the more attractive of the two methods, as it holds not only the promise of coronary plaque detection, but also of characterization, without the use of contrast media or ionizing radiation. Especially these latter two properties take away significant hurdles to widespread application in asymptomatic, otherwise healthy individuals.

\section{Objective of this thesis}

The objective of this thesis was to evaluate the potential of MRI for detection of coronary artery disease by visualization of the coronary vessel wall in humans.

Specific questions are:

1. How accurate is MR coronary vessel wall imaging in comparison to IVUS, the established standard of reference, for detection of coronary wall thickening?

2. Can differences in wall characteristics and thickness be detected between patients and healthy volunteers with MR coronary vessel wall imaging?

3. How can MR coronary vessel wall imaging be technically optimized?

4. What are the issues associated with migration from $1.5 \mathrm{~T}$ to $3 \mathrm{~T}$ for cardiac imaging, and how can some of the problems be solved?

\section{Outline of the thesis}

In Chapter 2 an overview is provided of MR techniques for imaging of atherosclerosis.

In Chapter 3, the use of MRI for imaging the coronary arteries is discussed as well as the role of $\mathrm{MRI}$ in relation to recent developments in coronary $\mathrm{CT}$.

In Chapter 4 the ability of MRI of the coronary vessel wall to detect coronary artery disease is validated by comparing MRI to intravascular ultrasound.

In Chapter 5, MRI-derived characteristics of the coronary vessel wall from a sample of healthy subjects are compared to a control group of patients with angiographically confirmed coronary artery disease. 
In Chapter 6 a novel and more time efficient MR technique is presented for coronary vessel wall imaging which will facilitate improved image quality.

In Chapter 7 some of the problems associated with migration from 1.5T to 3T for cardiac imaging are discussed and a solution is presented to address issues with cine imaging of the heart.

Finally, in chapter 8 the findings of these thesis will be placed in a broader perspective. Ongoing and future developments are discussed, including the role of MRI for coronary imaging in everyday clinical practice compared to the currently booming CT-techniques.

The research for this thesis was performed at the departments of Radiology and Cardiology of the Maastricht University Medical Center, the Cardiovascular Research Institute Maastricht (CARIM) and the Vascular Imaging Laboratory at Washington University, Seattle, Washington, USA, and in collaboration with the Department of Radiology, Division of Image Postprocessing (LKEB) at Leiden University Medical Center in Leiden, the Netherlands.

Funding was provided by the Netherlands Organisation for Scientific Research (NWO, VENI-scheme, grant 916.46.034) and Bayer Schering Pharma 


\section{References}

1. Lloyd-Jones D, Adams RJ, Brown TM, Carnethon M, Dai S, De Simone G, Ferguson TB, Ford E, Furie K, Gillespie C, Go A, Greenlund K, Haase N, Hailpern S, Ho PM, Howard V, Kissela B, Kittner S, Lackland D, Lisabeth L, Marelli A, McDermott MM, Meigs J, Mozaffarian D, Mussolino M, Nichol G, Roger VL, Rosamond W, Sacco R, Sorlie P, Thom T, WasserthielSmoller S, Wong ND, Wylie-Rosett J. Heart disease and stroke statistics--2010 update: a report from the American Heart Association. Circulation. 2010;121:e46-e215.

2. Mackay J, Mensah GA. The atlas of heart disease and stroke. 1st ed. Geneva: World Health Organization; 2004.

3. Lusis AJ. Atherosclerosis. Nature. 2000;407:233-241.

4. Ross R. Atherosclerosis--an inflammatory disease. N Engl J Med. 1999;340:115-26.

5. Virmani R, Kolodgie FD, Burke AP, Farb A, Schwartz SM. Lessons from sudden coronary death: a comprehensive morphological classification scheme for atherosclerotic lesions. Arterioscler Thromb Vasc Biol. 2000;20:1262-75.

6. Glagov S, Weisenberg E, Zarins CK, Stankunavicius R, Kolettis GJ. Compensatory enlargement of human atherosclerotic coronary arteries. N Engl J Med. 1987;316:1371-5.

7. Libby P. Inflammation in atherosclerosis. Nature. 2002;420:868-874.

8. Naghavi M, Libby P, Falk E, Casscells SW, Litovsky S, Rumberger J, Badimon JJ, Stefanadis C, Moreno P, Pasterkamp G, Fayad Z, Stone PH, Waxman S, Raggi P, Madjid M, Zarrabi A, Burke A, Yuan C, Fitzgerald PJ, Siscovick DS, de Korte CL, Aikawa M, Juhani Airaksinen KE, Assmann G, Becker CR, Chesebro JH, Farb A, Galis ZS, Jackson C, Jang IK, Koenig W, Lodder RA, March K, Demirovic J, Navab M, Priori SG, Rekhter MD, Bahr R, Grundy SM, Mehran R, Colombo A, Boerwinkle E, Ballantyne C, Insull W, Jr., Schwartz RS, Vogel R, Serruys PW, Hansson GK, Faxon DP, Kaul S, Drexler H, Greenland P, Muller JE, Virmani R, Ridker PM, Zipes DP, Shah PK, Willerson JT. From vulnerable plaque to vulnerable patient: a call for new definitions and risk assessment strategies: Part I. Circulation. 2003;108:1664-72.

9. Falk E, Shah PK, Fuster V. Coronary plaque disruption. Circulation. 1995;92:657-71.

10. Schoenhagen P, Ziada KM, Kapadia SR, Crowe TD, Nissen SE, Tuzcu EM. Extent and direction of arterial remodeling in stable versus unstable coronary syndromes : an intravascular ultrasound study. Circulation. 2000;101:598-603.

11. Narula J, Strauss HW. The popcorn plaques. Nat Med. 2007;13:532-4.

12. Vaartjes I, Peters RJG, van Dis SJ, Bots ML. Hart- en vaatziekten in Nederland 2008, cijfers over ziekte en sterfte. In. Den Haag: Nederlandse Hartstichting; 2008.

13. Poos MJJC, Smit JM, Groen J, Kommer GJ, Slobbe LCJ. Kosten van Ziekten in Nederland 2005 - Zorg voor euro's. In. Bilthoven: RIVM; 2008.

14. Naghavi M, Falk E, Hecht HS, Jamieson MJ, Kaul S, Berman D, Fayad Z, Budoff MJ, Rumberger J, Naqvi TZ, Shaw L, Faergeman O, Cohn J, Bahr R, Koenig W, Demirovic J, Arking D, Herrera VL, Badimon J, Goldstein JA, Rudy Y, Airaksinen J, Schwartz RS, Riley WA, Mendes RA, Douglas P, Shah PK. From vulnerable plaque to vulnerable patient--Part III: Executive summary of the Screening for Heart Attack Prevention and Education (SHAPE) Task Force report. Am J Cardiol. 2006;98:2H-15H.

15. Zipes DP, Wellens HJ. Sudden cardiac death. Circulation. 1998;98:2334-51.

16. Myerburg RJ, Kessler KM, Castellanos A. Sudden cardiac death: epidemiology, transient risk, and intervention assessment. Ann Intern Med. 1993;119:1187-97.

17. Nissen SE, Gurley JC, Grines CL, Booth DC, McClure R, Berk M, Fischer C, DeMaria AN. Intravascular ultrasound assessment of lumen size and wall morphology in normal subjects and patients with coronary artery disease. Circulation. 1991;84:1087-99. 
18. Siegel RJ, Chae JS, Maurer G, Berlin M, Fishbein MC. Histopathologic correlation of the three-layered intravascular ultrasound appearance of normal adult human muscular arteries. Am Heart J. 1993;126:872-8.

19. Gussenhoven WJ, Essed CE, Frietman P, Mastik F, Lancee C, Slager C, Serruys P, Gerritsen $\mathrm{P}$, Pieterman $\mathrm{H}$, Bom N. Intravascular echographic assessment of vessel wall characteristics: a correlation with histology. Int J Card Imaging. 1989;4:105-16.

20. Mintz GS, Nissen SE, Anderson WD, Bailey SR, Erbel R, Fitzgerald PJ, Pinto FJ, Rosenfield K, Siegel RJ, Tuzcu EM, Yock PG. American College of Cardiology Clinical Expert Consensus Document on Standards for Acquisition, Measurement and Reporting of Intravascular UItrasound Studies (IVUS). A report of the American College of Cardiology Task Force on Clinical Expert Consensus Documents. J Am Coll Cardiol. 2001;37:1478-92.

21. Jang IK, Bouma BE, Kang DH, Park SJ, Park SW, Seung KB, Choi KB, Shishkov M, Schlendorf K, Pomerantsev E, Houser SL, Aretz HT, Tearney GJ. Visualization of coronary atherosclerotic plaques in patients using optical coherence tomography: comparison with intravascular ultrasound. J Am Coll Cardiol. 2002;39:604-9.

22. Fujimoto JG, Boppart SA, Tearney GJ, Bouma BE, Pitris C, Brezinski ME. High resolution in vivo intra-arterial imaging with optical coherence tomography. Heart. 1999;82:128-33.

23. Yabushita H, Bouma BE, Houser SL, Aretz HT, Jang IK, Schlendorf KH, Kauffman CR, Shishkov M, Kang DH, Halpern EF, Tearney GJ. Characterization of human atherosclerosis by optical coherence tomography. Circulation. 2002;106:1640-5.

24. Yamagishi M, Terashima M, Awano K, Kijima M, Nakatani S, Daikoku S, Ito K, Yasumura Y, Miyatake K. Morphology of vulnerable coronary plaque: insights from follow-up of patients examined by intravascular ultrasound before an acute coronary syndrome. J Am Coll Cardiol. 2000;35:106-11.

25. Fujii K, Mintz GS, Carlier SG, Costa JR, Jr., Kimura M, Sano K, Tanaka K, Costa RA, Lui J, Stone GW, Moses JW, Leon MB. Intravascular ultrasound profile analysis of ruptured coronary plaques. Am J Cardiol. 2006;98:429-35.

26. Fujii K, Carlier SG, Mintz GS, Wijns W, Colombo A, Bose D, Erbel R, de Ribamar Costa J, Jr., Kimura M, Sano K, Costa RA, Lui J, Stone GW, Moses JW, Leon MB. Association of plaque characterization by intravascular ultrasound virtual histology and arterial remodeling. $A m$ J Cardiol. 2005;96:1476-83.

27. Botnar RM, Stuber M, Kissinger KV, Kim WY, Spuentrup E, Manning WJ. Noninvasive coronary vessel wall and plaque imaging with magnetic resonance imaging. Circulation. 2000;102:2582-7.

28. Kim WY, Stuber M, Bornert P, Kissinger KV, Manning WJ, Botnar RM. Three-dimensional black-blood cardiac magnetic resonance coronary vessel wall imaging detects positive arterial remodeling in patients with nonsignificant coronary artery disease. Circulation. 2002;106:296-9.

29. Achenbach S, Moselewski F, Ropers D, Ferencik M, Hoffmann U, MacNeill B, Pohle K, Baum U, Anders K, Jang IK, Daniel WG, Brady TJ. Detection of calcified and noncalcified coronary atherosclerotic plaque by contrast-enhanced, submillimeter multidetector spiral computed tomography: a segment-based comparison with intravascular ultrasound. Circulation. 2004;109:14-7.

30. Leber AW, Becker A, Knez A, von Ziegler F, Sirol M, Nikolaou K, Ohnesorge B, Fayad ZA, Becker CR, Reiser M, Steinbeck G, Boekstegers P. Accuracy of 64-slice computed tomography to classify and quantify plaque volumes in the proximal coronary system: a comparative study using intravascular ultrasound. J Am Coll Cardiol. 2006;47:672-7.

31. Achenbach S, Raggi P. Imaging of coronary atherosclerosis by computed tomography. Eur Heart J. 2010; Epub ahead of print. 


\section{Chapter 2}

\section{Magnetic resonance imaging of atherosclerosis}

T. Leiner, S.C. Gerretsen, R.M. Botnar, E. Lutgens, V.C. Cappendijk, M.E. Kooi, J.M.A. van Engelshoven 


\section{Abstract}

Abundant data now link composition of the vascular wall rather than the degree of luminal narrowing with the risk for acute ischemic syndromes in the coronary, central nervous system and peripheral arterial beds. Over the past years, magnetic resonance angiography has evolved as a well established method to determine the location and severity of advanced, lumen encroaching atherosclerotic lesions. In addition, more recent studies have shown that high spatial resolution, multi-sequence MRI is also a promising tool for noninvasive, serial imaging of the aortic and carotid vessel wall, which potentially can be applied in the clinical setting. Because of the limited spatial resolution of current MRI techniques characterization of coronary vessel wall atherosclerosis, however, is not yet possible and remains the holy grail of plaque imaging. Recent technical developments in MRI technology such as dedicated surface coils, the introduction of 3.0T high-field systems and parallel imaging as well as developments in the field of molecular imaging such as contrast agents targeted to specific plaque constituents are likely to lead to the necessary improvements in signal-to-noise ratio, imaging speed and specificity. These improvements will ultimately lead to more widespread application of this technology in clinical practice. In the present review the current status and future role of MRI for plaque detection and characterization are summarized. 


\section{Introduction}

Despite advances in treatment and prevention, clinical manifestations of advanced atherosclerosis such as myocardial infarction and stroke remain the primary cause of death in the Western world. The most recent figures published by the American Heart Association estimated 700.000 new and 500.000 recurrent heart attacks and 500.000 new and 200.000 recurrent strokes in 2003, in the United States alone. The costs associated with coronary heart disease and stroke in 2004 are expected to total over $\$ 180$ billion ( $€ 144$ billion) ${ }^{1}$.

Abundant data now link composition of the vascular wall rather than the degree of luminal narrowing with the risk for acute ischemic syndromes in the coronary, central nervous system and peripheral arterial beds ${ }^{2,3}$. However, in the absence of a clinically reliable method to characterize atherosclerotic plaque composition, current clinical decision making is still largely based on location and degree of stenosis, as determined with color Doppler ultrasonography ${ }^{4}$, magnetic resonance angiography (MRA) ${ }^{5}$ and intra-arterial digital subtraction angiography (IA-DSA) - the last of these is currently still widely considered to be the standard of care. Recent studies have shown that MRI now has the ability to differentiate plaque components in addition to accurate quantification of location and degree of luminal narrowing ${ }^{6}$. In addition, evidence is emerging that multiple detector row CT may also be suitable for plaque characterization ${ }^{7}$.

In the present review the current status and future role of MRI for plaque detection and characterization are summarized.

\section{Atherosclerotic plaque composition and development}

Atherosclerosis is considered to be a chronic inflammatory disease of the large arteries. The disease already starts at an early age, and remains clinically silent for decades.

The initiation of atherosclerosis is characterized by upregulation of leukocyte adhesion molecules, subsequent adhesion and migration of monocytes into the arterial neointima and differentiation of these monocytes in macrophages $^{2}$. Once macrophages are present in the arterial intima, they are able to ingest unlimited amounts of modified lipoproteins. Accumulations of these 
lipid filled macrophages are the major component of the first macroscopically visible, but clinically silent, atherosclerotic plaque: the intimal xanthoma or fatty streak ${ }^{8}$.

When atherosclerotic lesions progress, more and more (inflammatory) cells enter the lesion. Besides accumulations of lipid filled macrophages, increased amounts of T-lymphocytes, smooth muscle cells and (myo)fibroblasts enter the atherosclerotic plaque and form a 'pathological intimal thickening' ${ }^{8}$. When this process advances, (myo)fibroblasts and vascular smooth muscle cells migrate further into the atherosclerotic lesion, deposit extracellular matrix, and form a fibrous cap that overlies the atherosclerotic plaque. In the mean time, the center of the plaque is deprived of oxygen, and a necrotic core develops. The necrotic core contains extracellular lipids, cholesterol crystal esters, and sometimes calcification ${ }^{2,9}$. Apoptosis of vascular smooth muscle cells may be a key factor in this process ${ }^{10}$. Moreover, activation of angiogenic pathways results in an increased number of neo-vessels in the plaque ${ }^{11}$. Atherosclerotic lesions containing a fibrous cap and/or a lipid core are called 'atheromata' ${ }^{8}$. With the progression of atherosclerosis, the arterial wall reshapes. When atherosclerotic plaques encroach the lumen, the circumference of the artery increases, thereby partially or totally maintaining the original luminal diameter, a process called 'outward remodeling'. Therefore, luminal arteriography often masks the severity of atherosclerosis ${ }^{12}$. Although there are multiple modalities which are capable of assessing plaque morphology, $M R I$ is at present the sole non-invasive modality with the potential to detect outward remodeling in asymptomatic subjects ${ }^{13}$.

Depending on their composition, atheromata are subdivided in 'fibrous cap atheromata' and 'thin fibrous cap atheromata' (fibrous cap thickness $<65$ $\mu \mathrm{m})^{8}$. The latter are characterized by large lipid accumulations, large lipid cores, increased amounts of inflammatory cells and intra-plaque capillaries and thin fibrous $\mathrm{caps}^{8}$. These atherosclerotic lesions are designated 'vulnerable plaques' ${ }^{2}$ and are considered precursors for the lesions that are responsible for the majority of cardiovascular complications of atherosclerosis: the ruptured atherosclerotic plaque. When atherosclerotic plaques rupture, thrombogenic components of the atherosclerotic plaques come into contact with the blood and a thrombus develops that can occlude the artery, thereby resulting in myocardial infarction, stroke or renal infarction, depending of the arterial bed affected. Morphologically, plaque rupture is defined as 'an area of fibrous cap disruption whereby the overlying thrombus is in continuity with the lipid core' ${ }^{8}$. 
Factors correlated with plaque vulnerability and plaque rupture are increased activity of inflammatory (e.g. leukocyte adhesion molecules, chemokines and cytokines) and proteolytic pathways (e.g. matrix-metalloproteinases and cathepsins $)^{14}$. Other factors associated with plaque vulnerability and plaque rupture are increased thrombogenicity and an increased angiogenesis.

It is important to realize that plaque rupture does not always imply a fatal event. In patients who died of non-cardiovascular causes, plaque rupture was present in $10 \%$ of atherosclerotic lesions ${ }^{15}$. Non-fatal lesions can contain areas of (repeated) plaque rupture and thrombosis. If a thrombus remains mural rather than occlusive and its lysis is incomplete, re-endothelialization followed by fibrous thrombus organization results in accelerated plaque growth. Besides true plaque ruptures, intra-plaque hemorrhage is described as a phenomenon in lesions that are not necessarily associated with plaque rupture. In figure 1 the process of plaque development is schematically shown.

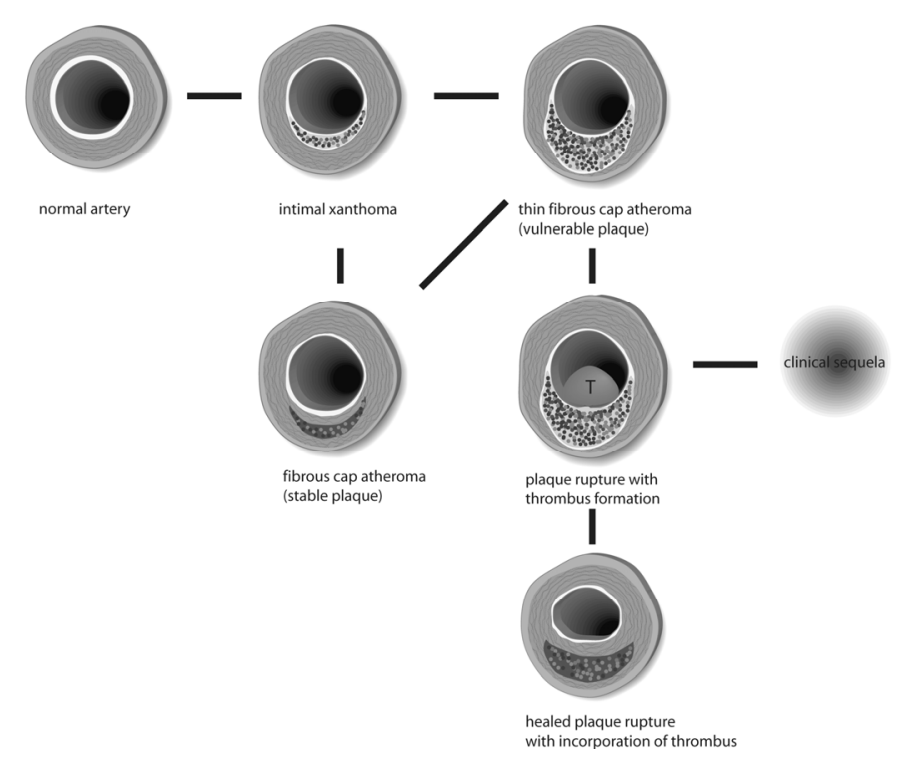

Figure 1. Different stages of plaque development (see text for description). Black lines denote transitions between different stages. T signifies thrombus.

Recently, it has been stated that plaque rupture does not occur as an isolated phenomenon, but rather as a systemic disease. In this view, it is preferable to refer to the 'vulnerable patient' instead of a patient with a localized vulnerable atherosclerotic plaque. 'Vulnerable patients' often present with multiple ruptured plaques. In an angiography study of patients with an acute coronary 
syndrome (ACS), $39.5 \%$ of the patients had multiple complex plaques that were associated with an increased incidence of recurrent $\mathrm{ACS}^{15}$. In another study using IVUS, $79 \%$ of the patients presenting with an ACS had multiple ruptured plaques at sites other than the culprit lesion that caused the clinical symptoms ${ }^{16}$. It can therefore be postulated that the occluding thrombus at the culprit lesion determines the clinical presentation, but is only a focal manifestation of an underlying systemic disease process that includes several rupture prone or vulnerable lesions. Systemic factors that are correlated with plaque rupture are altered blood rheology, increased coagulability, increased systemic inflammation and recurrent infections ${ }^{14}$.

\section{MRI characteristics of atherosclerotic plaques}

In 1996, Toussaint and co-workers were among the first to demonstrate that MRI is able to differentiate lipid core, fibrous cap, calcifications, intraplaque hemorrhage, normal intima, and adventitia in vivo in human atherosclerotic plaques. They showed that in T2-weighted sequences the atheromatous core has low signal intensity relative to the fibrous cap and outer layers of the vessel wall, and that areas of the plaque that contain calcified tissue exhibit very low signal intensity due to low water proton content. Calcified tissue also exhibited low signal intensity on T1-weighted sequences ${ }^{17}$. Intraplaque hemorrhage exhibits bright signal intensity on T1-weighted sequences ${ }^{18-20}$ because of the presence of methemoglobin, a breakdown product of hemoglobin, which is formed about 12 hours after the hemorrhage. This produces a shortening of $\mathrm{T} 1$ and hence an increase in signal intensity in T1-weighted images ${ }^{21}$. Although it is known that signal intensity of intracerebral hemorrhage changes over time because of changes in hemoglobin structure and oxidation state ${ }^{21}$, not much is known about the development over time of the MR signal intensity of hemorrhage in human atherosclerotic plaque.

By combining different MRI weightings ( $T 1, T 2$, proton-density (PD), and time-of-flight (TOF)) it has been possible to determine the location and composition of advanced atherosclerotic plaques. Shinnar et al. and Yuan et al. definitively established that multi-sequence MRI is capable of identifying different plaque components with high sensitivity, specificity and accuracy ex $v_{i v o}{ }^{22}$ as well as in vivo ${ }^{23}$. Serfaty et al. have demonstrated that T2-weighted MR imaging of human carotid atherosclerotic plaque specimens can accurately identify type $\mathrm{Vb}$ fibrocalcific plaques on the basis of the American Heart 
Association classification ${ }^{24}$. In table $1, \mathrm{MRI}$ signal intensity criteria to identify different plaque components are listed.

Table 1. Relative MRI signal intensities for identification of different plaque components

\begin{tabular}{|c|c|c|c|c|}
\hline \multirow[b]{2}{*}{$\begin{array}{l}\text { Plaque } \\
\text { component }\end{array}$} & \multicolumn{4}{|c|}{ MRI weighting } \\
\hline & $\mathrm{T} 1$ & $\mathrm{~T} 2$ & Proton Density & $\begin{array}{l}\text { Time-of- } \\
\text { Flight }\end{array}$ \\
\hline Lipid core & hyperintense & hypointense & iso- / hyperintense & $\mathrm{N} / \mathrm{A}$ \\
\hline Fibrous cap & iso- / hyperintense & iso- / hyperintense & iso- / hyperintense & low* \\
\hline Calcification & hypointense & hypointense & hypointense & $\mathrm{N} / \mathrm{A}$ \\
\hline $\begin{array}{l}\text { Intraplaque } \\
\text { hemorrhage }\end{array}$ & variable / hyperintense & variable & iso- / hyperintense & $\mathrm{N} / \mathrm{A}$ \\
\hline
\end{tabular}

In a recent landmark paper, Cai et al. demonstrated that in-vivo multi-contrast high resolution MRI is capable of classifying intermediate to advanced atherosclerotic lesions and is also capable of distinguishing advanced lesions from early and intermediate atherosclerotic plaque, in accordance with the classification used by the American Heart Association (table 2) ${ }^{25}$.

Table 2. AHA classification of atherosclerotic plaques as modified for MRI*

\begin{tabular}{|c|c|c|c|c|}
\hline \multirow[b]{2}{*}{ Type I } & \multirow{2}{*}{$\begin{array}{l}\text { AHA classification } \\
\text { Initial lesion with foam } \\
\text { cells }\end{array}$} & \multicolumn{2}{|c|}{ Modified AHA classification for MRI } & \multirow{2}{*}{$\begin{array}{l}\text { Sensitivity/ } \\
\text { Specificity } \\
67 \% / 100 \%\end{array}$} \\
\hline & & Type I-II & $\begin{array}{l}\text { Near-normal wall thickness, no } \\
\text { calcification }\end{array}$ & \\
\hline Type II & $\begin{array}{l}\text { Fatty streak with multiple } \\
\text { foam cell layers }\end{array}$ & & & \\
\hline Type III & $\begin{array}{l}\text { Preatheroma with } \\
\text { extracellular lipid pools }\end{array}$ & Type III & $\begin{array}{l}\text { Diffuse intimal thickening or small } \\
\text { eccentric plaque with no } \\
\text { calcification }\end{array}$ & $81 \% / 98 \%$ \\
\hline Type IV & $\begin{array}{l}\text { Atheroma with a } \\
\text { confluent extracellular } \\
\text { lipid core }\end{array}$ & Type IV-V & $\begin{array}{l}\text { Plaque with a lipid or necrotic core } \\
\text { surrounded by fibrous tissue with } \\
\text { possible calcification }\end{array}$ & $84 \%$ / 90\% \\
\hline Type V & Fibroatheroma & & & \\
\hline Type VI & $\begin{array}{l}\text { Complex plaque with } \\
\text { possible surface defect, } \\
\text { hemorrhage, or thrombus }\end{array}$ & $\begin{array}{l}\text { Type VI } \\
\text { s }\end{array}$ & $\begin{array}{l}\text { Complex plaque with possible } \\
\text { surface defect, hemorrhage or } \\
\text { thrombus }\end{array}$ & $82 \% / 91 \%$ \\
\hline Type VII & Calcified plaque & Type VII & Calcified plaque & $80 \% / 94 \%$ \\
\hline Type VIII & $\begin{array}{l}\text { Fibrotic plaque without } \\
\text { lipid core }\end{array}$ & Type VIII & $\begin{array}{l}\text { Fibrotic plaque without lipid core } \\
\text { and with possible small } \\
\text { calcifications }\end{array}$ & $56 \% / 100 \%$ \\
\hline
\end{tabular}

* As modified from ${ }^{25}$ 
Because preoperative MRI correlated well with paraffin section histology of carotid endarterectomy specimens, this study essentially demonstrated the feasibility of non-invasive 'biopsy' of carotid atherosclerotic plaques. Except for the previously mentioned study, most investigations to date were performed on advanced atherosclerotic plaques and it remains to be determined if very early plaques exhibit similar MRI characteristics.

\section{Magnetic Resonance techniques for imaging atherosclerosis}

Because of the versatility of currently available pulse sequences, the superior ability to differentiate different soft tissues, and MRI's non-invasive nature, $\mathrm{MRI}$ is uniquely suited for serial imaging of both the arterial lumen and the vessel wall. The basic MRI sequence requirements for vessel wall imaging are high spatial resolution, high contrast between different plaque components, and suppression of extrinsic motion, as well as signal from flowing blood.

In vivo vessel wall imaging is commonly performed using fast spin-echo sequences with multiple contrast weightings ${ }^{6,26}$. Several investigators have reported promising results using gradient echo sequences ${ }^{18,20}$. The minimum field strength at which vessel wall imaging can be performed clinically is 1.5T. To suppress motion artifacts, data are commonly acquired using cardiac triggering. In addition, fat-saturation prepulses are used to suppress signal from subcutaneous and perivascular fat. This does not affect the MR signal of plaque because lipids in subcutaneous and perivascular fat are predominantly made up of triglycerides as opposed to lipids in plaques which predominantly consist of cholesteryl esters and free cholesterol ${ }^{27}$.

Successful clinical use of plaque imaging demands the use of dedicated phased-array radiofrequency coils that provide high signal-to-noise of different vessel wall components, good signal penetration for imaging arteries deep within the body, and excellent homogeneity over the entire region of investigation $^{28-31}$.

In phantom studies Schär et al. have demonstrated that at least one pixel is needed across the different tissue layers of the vessel wall in order to characterize different vessel wall components reliably ${ }^{32}$. In the same study these authors demonstrated that differentiation of the thin fibrous cap from the adjacent lipid core required $\geq 2$ pixels across these two tissues. While these boundary conditions can be met with state-of-the-art imaging protocols for 
large arteries like the aorta and carotid artery, it is currently very difficult to do so for the coronary arteries.

To maximize signal enhancement at the shortest possible imaging time it is preferably that multi-element (i.e. multi-channel) phased array surface coils with parallel imaging capabilities are used. Parallel imaging is a technique to speed up data acquisition by using an array of multiple reception coils, which exhibit strongly inhomogenous, mutually distinct spatial sensitivity ${ }^{33}$. With parallel imaging, acquisition times can theoretically be decreased by a factor equal to the number of coil elements. This is beneficial considering the relatively long imaging times of current MRI vessel wall sequences which are in the order of several minutes for each weighting.

Recently, the first intravascular coils for vessel wall imaging have been described $^{34,35}$, including coils with parallel imaging capabilities ${ }^{36}$. The obvious drawback of this approach lies in its invasiveness. Another exciting concept of intravascular MRI employs stents as intravascular RF antennas for high resolution MR imaging ${ }^{37}$. Stents can be used as reception coils using a coaxial cable attached to the scanner, but by using the principle of inductive coupling they can also be used as intravascular signal amplifiers whose signal can be detected non-invasively from the outside ${ }^{38}$. For overviews of coil requirements, different coils that have been used for imaging the vessel wall and parallel imaging technology, we refer to the excellent review articles by Quick et al. ${ }^{31}$ and Weiger et al. ${ }^{39}$.

\section{Non-enhanced MRI techniques}

As discussed above, multiple contrast weightings using both black blood and bright blood acquisition schemes are necessary to identify different plaque components.

Black blood techniques are designed to suppress the signal from flowing blood $^{40}$ with the aim of improving visualization and delineation of the atherosclerotic plaque from the arterial lumen. The most commonly used technique to achieve flow suppression is double inversion recovery $(\mathrm{IR})^{41}$. The double IR pulse consists of a nonselective inversion radiofrequency (RF) pulse to invert the longitudinal magnetization in the entire body, immediately followed by a slice selective RF pulse that reinverts the longitudinal magnetization in the imaging slice of interest ${ }^{41}$. Placement of the double IR pulse (determined by the delay time or inversion time) is such that the longitudinal magnetization from blood is zero during readout, and is determined by heart rate and the T1 value of arterial blood ${ }^{42}$. Signal from the vessel lumen is suppressed by placing 
a double IR prepulse before a period of fast flow, and acquiring data during slow flow. In this way flow suppression of intraluminal signal due to outflow is maximized and artifacts due to vessel motion are minimized ${ }^{43}$. The disadvantage of double IR imaging is that acquisition duration is relatively lengthy. Recently, several investigators have introduced optimized IR techniques to increase scan efficiency by introducing simultaneous multi-slice acquisitions and combining this strategy with parallel imaging ${ }^{44-47}$. A second technique to suppress the signal from flowing blood is by RF spatial saturation. The major problem with this technique, however, is that slow and complex flow patterns may lead to residual blood signal within the lumen, suggestive of wall thickening and atherosclerotic plaque ${ }^{48}$. Therefore this technique is infrequently used today.

Bright blood techniques are used to visualize intimal calcifications and to assess fibrous cap thickness and integrity. Hatsukami ${ }^{49}$ and Mitsumori et al. ${ }^{50}$ demonstrated that by using a time-of-flight sequence they could differentiate intact, thick fibrous caps from intact thin and from ruptured fibrous caps in vivo in human carotid arteries. Intact, thick fibrous caps appear as a uniform dark band between bright lumen and gray plaque core. Conversely, in sites with ruptured caps, the dark band bordering the lumen is absent and a hyperintense bright region is seen adjacent to the lumen (figure 2$)^{49,50}$.
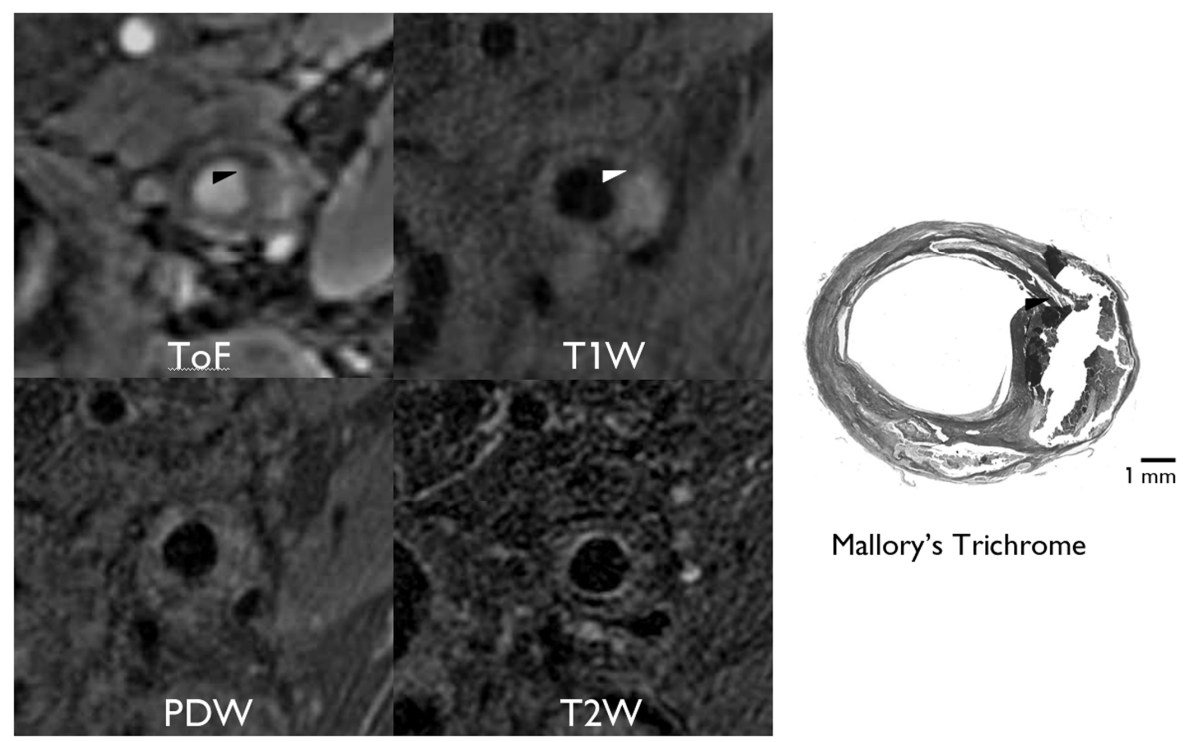

Mallory's Trichrome

Figure 2. Example of a luminal contour abnormality. A focal concavity of the luminal surface (arrowhead), best depicted on the ToF and T1-weighted images, correlates with an unstable, ruptured cap on the corresponding histologic section. Reproduced with permission from (50). 


\section{Contrast-enhanced MRI techniques}

Contrast-enhanced MRI techniques using commercially available extracellular contrast agents have been extremely well received for the depiction of the vascular lumen in the neurovascular, upper and lower extremity vascular beds ${ }^{5}$. Recently, they have also been shown to be useful for improving plaque characterization. In two studies in patients scheduled for carotid endarterectomy, Yuan et al. and Wasserman et al. demonstrated that after injection of $0.1 \mathrm{mmol} / \mathrm{kg}$ of a $0.5 \mathrm{M}$ extracellular agent, improved differentiation of atherosclerotic tissue types was possible compared to non-enhanced imaging. In addition, Yuan et al. found that the degree of enhancement correlated significantly with the degree of neovasculature ${ }^{51,52}$. Further work by the same group revealed that kinetic modeling of dynamic contrast-enhanced MRI not only provides an indication of the location but also of the amount of neovasculature in carotid artery plaques ${ }^{53,54}$.

Although injection of extracellular contrast agents improves plaque characterization, the use of new, high-relaxivity agents will necessitate novel MRI methods to optimally take advantage of the contrast properties. A disadvantage of injecting these agents is that they pose significant difficulties for double IR post-contrast black-blood imaging because of their prolonged T1shortening effects. In an effort to overcome this problem Yarnykh et al. added an additional double IR preparatory pulse to the standard double IR sequence (i.e. quadruple IR) to effectively null the signal from blood after injection of contrast medium. By addition of a second double IR preparatory pulse the longitudinal magnetization of blood basically becomes T1-independent over a wide range of contrast medium concentrations ${ }^{55}$. Another way to suppress intravascular signal over a wide range of blood T1-values after contrast injection is by adding a diffusion flow-nulling preparatory pulse to the double IR module ${ }^{56}$. The diffusion module consists of 3 rectangular RF pulses, separated by diffusion gradients in the readout, phase-encoding and slice directions ${ }^{57}$. In the implementation by Sirol, the first $90^{\circ}$ nonselective pulse flips the magnetization into the transverse plane; the diffusion gradients, which follow, suppress the magnetization of the flowing spins. After the $180^{\circ}$ refocusing nonselective pulse, the last $90^{\circ} \mathrm{RF}$ pulse restores the initial magnetization of the stationary spins ${ }^{56}$. 


\section{MRI of atherosclerosis in different vascular beds}

MRI has been used to image the human carotid ${ }^{58}$, aortic ${ }^{59}$ and coronary vessel wall $^{60,61}$. At present it has not been definitively established if plaque development is similar in different vascular beds, and if the 'vulnerable plaque' concept applies in a similar fashion.

\section{MRI of human carotid atherosclerosis}

The carotid artery has proven to be an extremely fruitful model to validate multi-contrast vessel wall imaging techniques because of its superficial location, straight course, absence of gross motion, relatively large size, and routine availability of histologic correlation after carotid endarterectomy. It must be kept in mind that carotid endarterectomy is only proven to be advantageous in cases of high grade stenosis (more than $70 \%$ luminal narrowing), and therefore only MRI of advanced, lumen encroaching plaques has been validated in humans. Toussaint et al. were among the first to demonstrate that MRI could differentiate carotid plaque components based on differences in T2-value ${ }^{62}$. The technique was subsequently greatly refined and thoroughly validated in a series of studies by Yuan and co-workers. With these studies they demonstrated that an MRI protocol with multiple contrast weightings is a valid tool to detect and characterize different plaque components such as lipid/necrotic core, fibrous tissue, calcifications, thrombus, the presence of neovasculature and the integrity of the fibrous cap in vivo ${ }^{23,53,63,64}$. In perhaps the most significant work, Yuan ${ }^{65}$ and Mitsumori ${ }^{50}$ demonstrated that MRI is able to correctly identify fibrous cap status with high sensitivity and specificity (i.e. intact, thick fibrous cap, or 'ruptured' cap), and that MRI identification of ruptured fibrous cap is highly associated with a recent history of transient ischemic attack or stroke. These results are the first to suggest that MRI can enable recognition of a vulnerable plaque prior to the development of an ischemic event. Recent work by our group has demonstrated that for carotid arteries only a limited number of sequences is needed to identify different plaque components. We found that T1-weighted TFE (segmented gradient echo) and T2-weighted TSE are essential to characterize the plaque (figure 3). In addition, an arbitrary pair of the sequences partial T2-weighted TSE, proton density-weighted TSE, and T1-weighted TSE is needed to identify calcified tissue $^{66}$. 

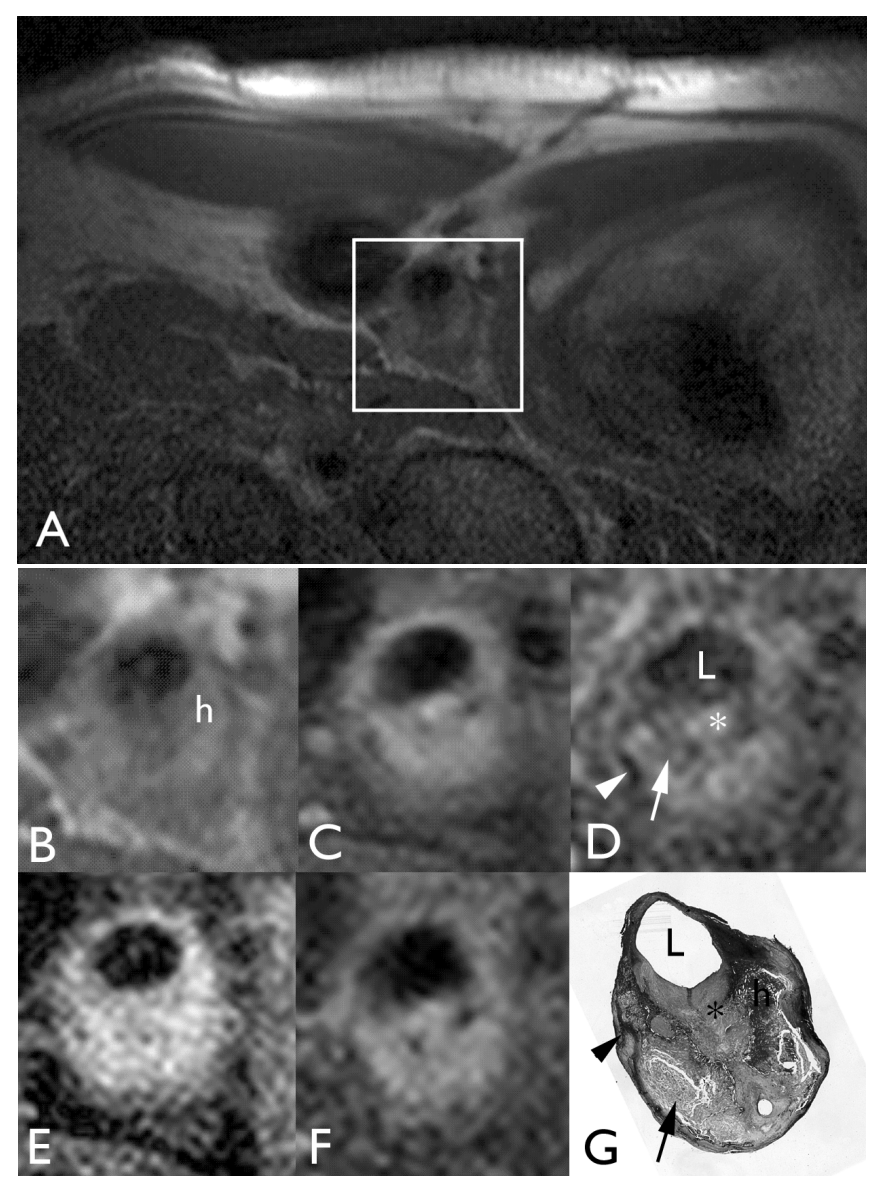

Figure 3. Carotid atherosclerotic plaque imaging with multisequence MRI. (A) T1-weighted TFE overview of the right side of the neck. The box is placed around the internal carotid artery. Different MRI weightings are: T1-weighted TFE (B); PD-weighted TSE (C); T2-weighted TSE (D); T1-weighted TSE (E); and Partial T2-weighted TSE (F). The corresponding haematoxylin-eosin stained histological slice (magnified 12.5x) is shown in (G). For the T1-weighted TFE sequence (B), the in-plane resolution was $0.39 \times 0.49 \mathrm{~mm}$ with a slice thickness of $3.0 \mathrm{~mm}$ and no slice gap. For the other sequences, the in-plane resolution was $0.39 \times 0.39 \mathrm{~mm}$ with a slice thickness of 2.5 $\mathrm{mm}$ and a slice gap of $0.5 \mathrm{~mm}$. Hemorrhage (h) was well differentiated from fibrous (asterisk) tissue (high and iso-intense relative signal intensity, respectively) on the T1-weighted TFE image (B). On the T2-weighted TSE image (D) fibrous tissue (asterisk) has high signal intensity, while calcification has very low signal intensity (arrowhead). Calcification also has very low signal intensity on PD-weighted TSE (C), T1-weighted TSE (E) and Partial T2-weighted TSE (F). Lipid core has low signal intensity on T2-weighted TSE (D; arrow) and is low/iso-intense on T1weighted TFE. 
MRI of human aortic atherosclerosis

Several authors have demonstrated that MRI is an accurate tool to probe for and characterize ascending and descending aortic atherosclerosis. Fayad et al. were the first to succeed in characterizing aortic plaque using multi-contrast MRI. Plaque composition, extent and size were assessed from black blood T1-, T2-, and proton density-weighted images and correlated highly with transesophageal echocardiography ${ }^{59}$.

As a foundation for determining the potential clinical utility of MRI as a tool for tracking plaque development over time, Chan et al. demonstrated that the reproducibility of MRI assessment of aortic lumen area, lumen circumference, and plaque area is high ${ }^{67}$. In addition, Jaffer et al. showed that non-invasive assessment of aortic atherosclerosis in 318 asymptomatic subjects with MRI correlates strongly with more traditional cardiovascular risk measures such as the Framingham Coronary Risk Score ${ }^{68}$.

\section{MRI of human coronary atherosclerosis}

Despite obvious difficulties such as cardiac and respiratory motion, tortuous course and small size of the coronary arteries, it is possible to image the coronary vessel wall for the detection of coronary atherosclerosis using MRI (figure 4). In landmark studies Botnar and Fayad were the first to demonstrate that MRI with submillimeter in-plane resolution is able to non-invasively assess the location of increased coronary artery wall thickness in patients with coronary artery disease using both free-breathing ${ }^{61}$ and breath-hold approaches ${ }^{60}$. Although the studies were performed in a limited number of subjects, both authors demonstrated that coronary artery wall thickness is significantly higher in patients with advanced, lumen encroaching $C A D^{60,61}$ as opposed to healthy adult subjects. In perhaps an even more important study, Kim recently demonstrated that free-breathing MRI with isotropic resolution can detect increased coronary wall thickness in patients with non-significant coronary artery disease, when the coronary lumen is still normal (figure 5$)^{13}$, i.e. before the development of symptoms. The latter study opens up the tantalizing possibility to non-invasively track coronary wall thickness in asymptomatic subjects and correlate the progression over time with clinical events. Despite these promising studies, it has, however, not been possible yet to identify the different components in coronary atherosclerotic plaques because of the limited in-plane resolution that was used. 


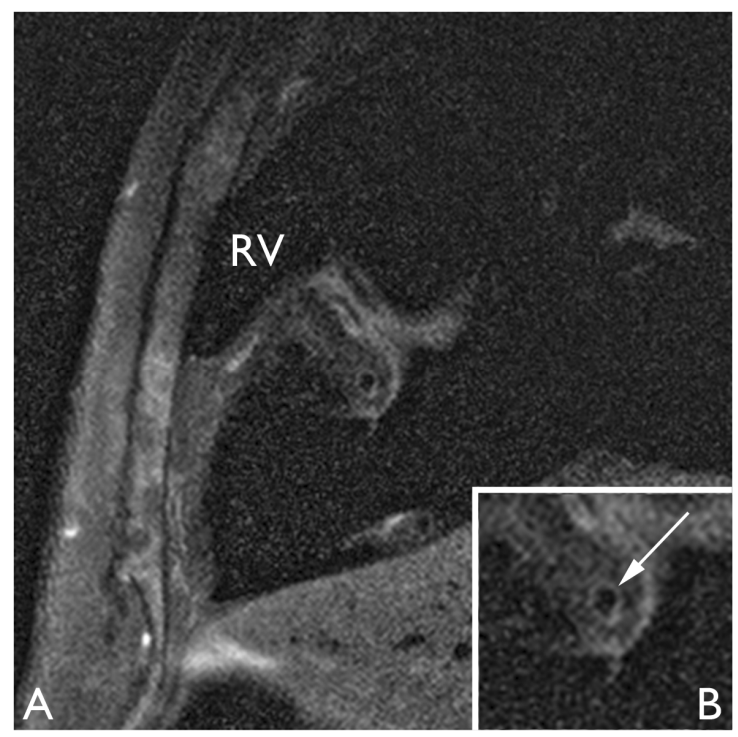

Figure 4. Cross-sectional (A) and corresponding magnified (B) view of RCA wall of a patient with coronary artery disease, revealing lumen as dark and wall as bright signal area. Wall can readily be distinguished from sur-rounding epicardial fat and coronary blood (arrow).

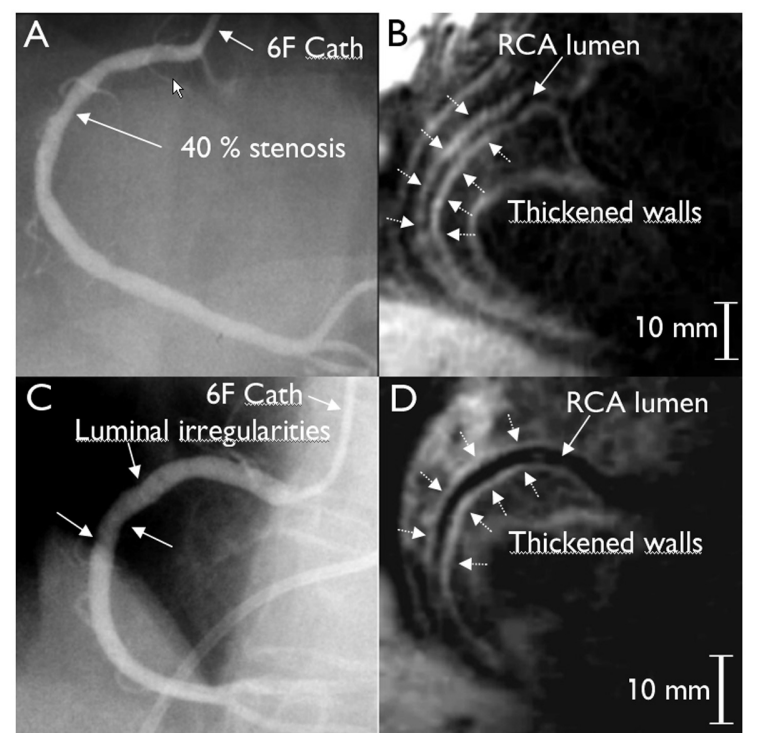

Figure 5. X-ray angiography in 2 patients with $(A)$ a focal $40 \%$ stenosis (white arrow) and (C) minor ( $10 \%$ stenoses) luminal iregularities (white arrows) of the proximal RCA. The corresponding blackblood 3D CMR vessel wall scans ( $B$, D) demonstrate an irregularly thickened RCA wall ( $>2 \mathrm{~mm}$ ) indicative of an increased atherosclerotic plaque burden. The inner and outer RCA walls are indicated by the white dotted arrows. The catheter size for the $\mathrm{x}$-ray was 6F. Reproduced with permission from (13).

\section{Clinical applications: is MRI of atherosclerosis ready for routine clinical use?}

As has become clear over the past years, MRI is the potential imaging modality of choice for non-invasive and serial evaluation of atherosclerosis. However, prior to incorporation in the clinical setting a number of issues still have 
to be clarified. Many of the validation studies that have been published to date and discussed above were done on imaging slice level, and not on patient level. In addition, in most publications MRI images that were nonevaluable because of artifacts were excluded from the analyses. Although reasonable in the context of the studies that were performed, this limitation must be kept in mind when the clinical utility of these techniques is assessed.

Despite these issues, MRI of atherosclerosis is now ready for clinical use and provides unprecedented opportunity to track plaque modification over time in the aorta and the carotid arteries. In a study in 21 asymptomatic patients with hypercholesterolemia, Corti et al. demonstrated that MRI could be used to measure the effect of lipid lowering treatment with simvastatin ${ }^{69}$. The significance of this study is that it demonstrated that plaque regression as measured with MRI could perhaps be used as a surrogate clinical endpoint for lipid lowering drugs like 3-hydroxy-3-methylglutaryl coenzyme A reductase inhibitors ('statins'). Prospective, randomized efficacy studies of these drugs have traditionally necessitated enormous trials with inclusion of thousands of patients in treatment and control arms. Given the fact that plaque morphology is highly correlated with subsequent clinical events and the ability of MRI to track plaque progression over time, such large studies might no longer be needed in the near future.

MRI of atherosclerosis has the potential to fundamentally change how this disease is managed in humans. Current clinical practice is to treat risk factors such as abnormal glucose, hypercholesterolemia and hypertension which affect atherosclerotic lesions that modulate clinical sequela of atherosclerosis. In case an event has already taken place, impaired flow is remedied and risk factors are treated aggressively. It makes sense that in the future, prevention of (additional) clinical events can be improved by knowledge of the presence of high-risk plaques as identified in vivo with non-invasive imaging modalities such as MRI.

Another promising imaging modality for plaque characterization is computed tomography (CT). Although detailed discussion of the relative merits and shortcomings of $\mathrm{CT}$ is beyond the scope of this article, early experience with single slice scanners was disappointing ${ }^{70}$. However, the recent introduction of multiple detector row $\mathrm{CT}$ scanners has yielded encouraging results with regards to atherosclerotic plaque characterization ${ }^{71,72,73}$. Future studies will have to determine the respective clinical contributions of both modalities. 


\section{Future developments}

In the short term, advances in image analysis and quantification will lead to improved, observer-independent plaque characterization. For instance, Yuan and Kerwin proposed the development of algorithms to characterize plaque components automatically based on T1- and T2-maps on the individual pixel level ${ }^{74}$.

Current non-invasive MR techniques for imaging plaque are mainly limited by the available signal-to-noise ratio in clinically feasible imaging times. With the introduction of improved receiver coils and whole body ultra-high fieldstrength magnets such as 3.0T and 7.0T this issue might be overcome. Preliminary data obtained at 3.0T demonstrated the feasibility of imaging the coronary vessel wall ${ }^{75}$, which should allow for improvements over 1.5T protocols (figure 6). Different contrast mechanisms such as diffusion weighting may also help to improve plaque characterization, although at present imaging times are still prohibitively long ${ }^{76}$.

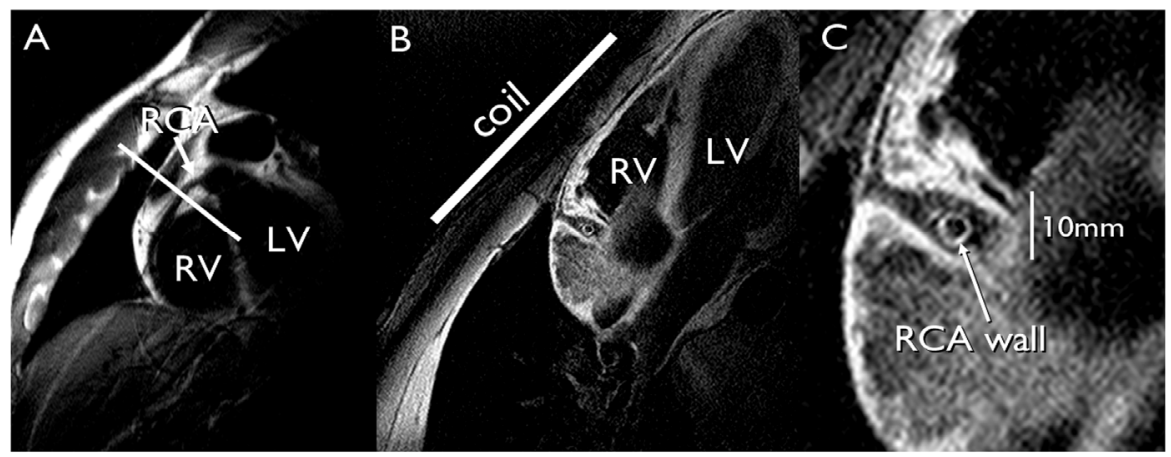

Figure 6. Coronary vessel wall imaging at 3.0T. The vessel wall scan (B) was planned from a double oblique view (A) of the right coronary artery (RCA). The RCA vessel wall is readily visible on a magnified view (C). RA: right atrium, RV: right ventricle, LV: left ventricle. Reproduced with permission from (75).

Newer contrast agents that will soon become commercially available may further improve plaque characterization. In a study intended to demonstrate the feasibility of steady-state MRA for the detection of aortoiliac peripheral arterial occlusive disease using the intravascular contrast agent MS-325, Maki et al. found equilibrium phase enhancement of the arterial wall in diseased aortoiliac vessels. To explain this finding the authors hypothesized that MS325 enters the vessel wall by way of newly formed, leaky plaque capillaries and vessel wall enhancement is consequently observed because MS-325 ex- 
periences strong relaxation enhancement after binding to albumin, which is known to be present in the wall of atherosclerotic arteries in concentrations correlating with disease severity. Thus, injection of MS-325 might possibly allow quantification of vessel wall inflammation ${ }^{77}$.

\section{Targeted contrast agents}

One of the most exciting and promising developments is the use of contrast agents with the ability to target specific plaque components or even specific cell surface receptors or other proteins ('molecular imaging'). Examples of promising target molecules are vascular cell adhesion molecule 1 (VCAM-1) and $\mathrm{P}$ - and E-selectin, because endothelial cells express these molecules selectively in areas prone to atherosclerotic lesion formation ${ }^{3}$. The attraction of MR molecular plaque imaging is the combination of the potential for sensitive disease detection because of the relatively high spatial resolution and noninvasiveness as well as the widespread availability of whole body clinical MR imaging systems. Currently, several of such agents are under investigation, mostly in animal models, but also in humans. An overview of different agents as well as their mechanism of action is listed in table 3.

Although the exact mechanism is still unknown, Sirol et al. found that the lipophilic gadolinium chelate complex gadofluorine specifically targets the lipid core of atherosclerotic plaques in hyperlipidemic rabbits ${ }^{56}$. In another recent study by our group, we found that the ultra-small particulate iron oxide (USPIO) agent Sinerem was taken up by and allowed localization of macrophages in carotid plaques of patients with a recent history of transient ischemic attack (figure 7$)^{78}$.

Another set of studies has been performed to investigate the feasibility of direct thrombus visualization. $\mathrm{Yu}^{79}$ as well as Flacke ${ }^{80}$ demonstrated that MRI can detect human thrombi by using gadolinium loaded lipid-encapsulated perfluorocarbon nanoparticles targeted to fibrin. Using a novel gadoliniumlabeled peptide, Botnar et al. also demonstrated the feasibility of detecting acute and subacute thrombosis in a rabbit model of aortic atherosclerosis ${ }^{81}$, and in a pig model of coronary thrombosis ${ }^{84}$. Potential clinical applications of these agents include rapid, noninvasive thrombus detection and localization in patients with acute coronary syndromes and stroke. 
Table 3. Contrast agents

\begin{tabular}{lll}
\hline Class & Agent & Mechanism \\
\hline (U)SPIO & $\begin{array}{l}\text { Sinerem (Ferumoxtran-10, } \\
\text { Guerbet, Aulnay sur Bois, France) }\end{array}$ & $\begin{array}{l}\text { (Ultra-) small particles of iron oxide; } \\
\text { phagocytosed by macrophages; signal } \\
\text { voids on gradient-echo sequences }\end{array}$ \\
Gd-chelate & $\begin{array}{l}\text { Gadofluorine (Schering, Berlin, } \\
\text { Eermany) }\end{array}$ & $\begin{array}{l}\text { Eccumulation in atherosclerotic plaques } \\
\text { unknown; predominantly localized in lipid } \\
\text { core; T1-weighted enhancement }\end{array}$ \\
Perfluorocarbon & $\begin{array}{l}\text { Gadolinium-loaded lipid- } \\
\text { nanoparticle }\end{array}$ & $\begin{array}{l}\text { Fibrin binding by addition of anti-fibrin } \\
\text { carbon nanoparticles }\end{array}$ \\
Small molecule & $\begin{array}{l}\text { EP-1873 (Epix Pharmaceuticals, } \\
\text { T1-weighted enhancement }\end{array}$ & $\begin{array}{l}\text { Fibrin binding; T1-weighted enhancement } \\
\text { peptide derivative }\end{array}$ \\
\hline
\end{tabular}

Targeted MRI contrast agents currently under investigation and mechanism of contrast generation Based on ${ }^{56,78-80 ~ 81,84}$
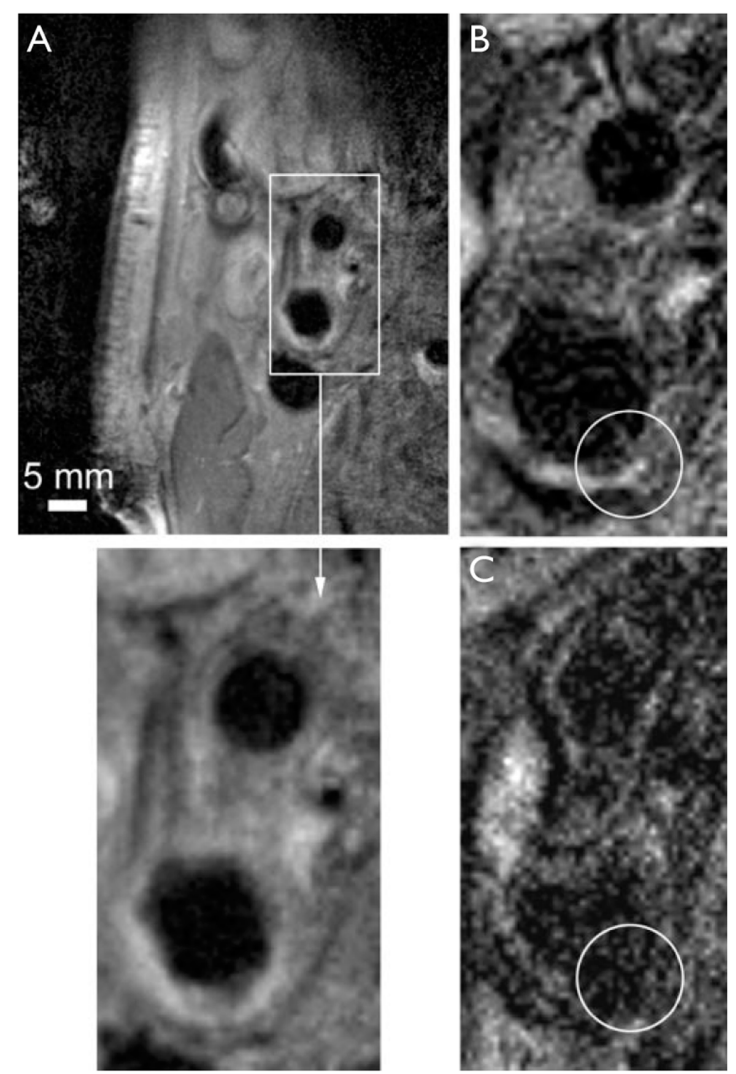

Figure 7. Corresponding in vivo MR images of the external (above) and internal (below) carotid artery. (A) PDw fast spin echo MR image; (B) $\mathrm{T} 2{ }^{*} \mathrm{w}$ gradient-echo $\mathrm{MR}$ image before administration of ferumoxtran-10; (C) $\mathrm{T} 2 * \mathrm{w}$ gradient-echo MR image 24 hours after administration of ferumoxtran-10. A signal decrease can be observed on the postcontrast $\mathrm{T} 2 * \mathrm{w}$ MR image (circle) in the part of the vessel wall that showed a large number of Fe-positive cells in the corresponding histological section. Perl's reading in the lower quadrants was many and very many iron positive cells, respectively, whereas it was hardly any for both the upper quadrants. Reproduced with permission from (78). 


\section{Conclusions}

After having been extensively validated, MR imaging of atherosclerosis is currently being introduced in the clinical setting. Future studies will have to demonstrate the feasibility of multi-sequence MRI for coronary plaque characterization and whether targeted contrast agents will improve plaque characterization and can safely be used in humans. In addition, prospective studies in asymptomatic patients are needed to determine the predictive value of the presence of different plaque components as visualized with MRI for risk of subsequent ischemic events. One of the most important questions remains whether MRI guided treatment will improve outcome in patients with symptomatic and asymptomatic carotid, peripheral and coronary atherosclerosis.

\section{Acknowledgements}

The authors thank Geertjan van Zonneveld and Dr. Sylvia Heeneman, PhD of the Audiovisual Department and Department of Pathology, Maastricht University Hospital for assistance with preparation of figures 1 and 3. In addition, the authors would also like to express their gratitude to Drs. Lee Mitsumori, $\mathrm{MD}$ and Chun Yuan, PhD of the Department of Radiology, University of Washington, Seattle, WA, USA, for contributing figure 2 and to Dr. Won Yong Kim of the MR-Center and Department of Cardiology, Aarhus University Hospital and Skejby Sygehus, Aarhus, Denmark for contributing figure 5. Financial support of The Netherlands Organization for Scientific Research (NWO VENI Grant 916.46.034) and The Netherlands Heart Foundation (Project number 2000.173) is gratefully acknowledged. 


\section{References}

1. Association AH. Heart disease and stroke statistics - 2004 update. Dallas, TX: American Heart Association; 2003.

2. Lusis AJ. Atherosclerosis. Nature. 2000;407(6801):233-241.

3. Libby P. Inflammation in atherosclerosis. Nature. 2002;420(6917):868-874.

4. Rose SC, Nelson TR. Ultrasonographic modalities to assess vascular anatomy and disease. $J$ Vasc Interv Radiol. 2004;15(1 Pt 1):25-38.

5. Yucel EK, Anderson CM, Edelman RR, Grist TM, Baum RA, Manning WJ, Culebras A, Pearce W. AHA scientific statement. Magnetic resonance angiography : update on applications for extracranial arteries. Circulation. 1999;100(22):2284-2301.

6. Fayad ZA, Fuster V. Characterization of atherosclerotic plaques by magnetic resonance imaging. Ann N Y Acad Sci. 2000;902:173-186.

7. Fayad ZA, Fuster V, Nikolaou K, Becker C. Computed tomography and magnetic resonance imaging for noninvasive coronary angiography and plaque imaging: current and potential future concepts. Circulation. 2002;106(15):2026-2034.

8. Virmani R, Kolodgie FD, Burke AP, Farb A, Schwartz SM. Lessons from sudden coronary death: a comprehensive morphological classification scheme for atherosclerotic lesions. Arterioscler Thromb Vasc Biol. 2000;20(5):1262-1275.

9. Ross R. Atherosclerosis--an inflammatory disease. N Engl J Med. 1999;340(2):115-126.

10. Trion A, van der Laarse A. Vascular smooth muscle cells and calcification in atherosclerosis. Am Heart J. 2004;147(5):808-814.

11. Kwon HM, Sangiorgi G, Ritman EL, McKenna C, Holmes DR, Jr., Schwartz RS, Lerman A. Enhanced coronary vasa vasorum neovascularization in experimental hypercholesterolemia. J Clin Invest. 1998;101(8):1551-1556.

12. Pasterkamp G, Galis ZS, de Kleijn DP. Expansive arterial remodeling: location, location, location. Arterioscler Thromb Vasc Biol. 2004;24(4):650-657.

13. Kim WY, Stuber M, Bornert P, Kissinger KV, Manning WJ, Botnar RM. Three-dimensional black-blood cardiac magnetic resonance coronary vessel wall imaging detects positive arterial remodeling in patients with nonsignificant coronary artery disease. Circulation. 2002;106(3):296-299.

14. Lutgens E, van Suylen RJ, Faber BC, Gijbels MJ, Eurlings PM, Bijnens AP, Cleutjens KB, Heeneman S, Daemen MJ. Atherosclerotic plaque rupture: local or systemic process? Arterioscler Thromb Vasc Biol. 2003;23(12):2123-2130.

15. Goldstein JA, Demetriou D, Grines CL, Pica M, Shoukfeh M, O’Neill WW. Multiple complex coronary plaques in patients with acute myocardial infarction. $N$ Engl J Med. 2000;343(13):915-922.

16. Rioufol G, Finet G, Ginon I, Andre-Fouet X, Rossi R, Vialle E, Desjoyaux E, Convert G, Huret $J F$, Tabib A. Multiple atherosclerotic plaque rupture in acute coronary syndrome: a threevessel intravascular ultrasound study. Circulation. 2002;106(7):804-808.

17. Toussaint JF, LaMuraglia GM, Southern JF, Fuster V, Kantor HL. Magnetic resonance images lipid, fibrous, calcified, hemorrhagic, and thrombotic components of human atherosclerosis in vivo. Circulation. 1996;94(5):932-938.

18. Moody AR. Magnetic resonance direct thrombus imaging. J Thromb Haemost. 2003;1(7):1403-1409.

19. Murphy RE, Moody AR, Morgan PS, Martel AL, Delay GS, Allder S, MacSweeney ST, Tennant WG, Gladman J, Lowe J, Hunt BJ. Prevalence of complicated carotid atheroma as detected by magnetic resonance direct thrombus imaging in patients with suspected carotid 
artery stenosis and previous acute cerebral ischemia. Circulation. 2003;107(24):30533058.

20. Cappendijk VC, Cleutjens KB, Heeneman S, Schurink GW, Welten RJ, Kessels AG, Van Suylen RJ, Daemen MJ, Van Engelshoven JM, Kooi ME. In vivo detection of hemorrhage in human atherosclerotic plaques with magnetic resonance imaging. J Magn Reson Imaging. 2004;20(1):105-110.

21. Bradley WG, Jr. MR appearance of hemorrhage in the brain. Radiology. 1993;189(1):1526.

22. Shinnar M, Fallon JT, Wehrli S, Levin M, Dalmacy D, Fayad ZA, Badimon JJ, Harrington M, Harrington E, Fuster V. The diagnostic accuracy of ex vivo MRI for human atherosclerotic plaque characterization. Arterioscler Thromb Vasc Biol. 1999;19(11):2756-2761.

23. Yuan C, Mitsumori LM, Ferguson MS, Polissar NL, Echelard D, Ortiz G, Small R, Davies JW, Kerwin WS, Hatsukami TS. In vivo accuracy of multispectral magnetic resonance imaging for identifying lipid-rich necrotic cores and intraplaque hemorrhage in advanced human carotid plaques. Circulation. 2001;104(17):2051-2056.

24. Serfaty JM, Chaabane L, Tabib A, Chevallier JM, Briguet A, Douek PC. Atherosclerotic plaques: classification and characterization with T2-weighted high-spatial-resolution MR imaging-- an in vitro study. Radiology. 2001;219(2):403-410.

25. Cai JM, Hatsukami TS, Ferguson MS, Small R, Polissar NL, Yuan C. Classification of human carotid atherosclerotic lesions with in vivo multicontrast magnetic resonance imaging. Circulation. 2002;106(11):1368-1373.

26. Yuan C, Tsuruda JS, Beach KN, Hayes CE, Ferguson MS, Alpers CE, Foo TK, Strandness DE. Techniques for high-resolution MR imaging of atherosclerotic plaque. J Magn Reson Imaging. 1994;4(1):43-49.

27. Yuan C, Petty C, O'Brien KD, Hatsukami TS, Eary JF, Brown BG. In vitro and in situ magnetic resonance imaging signal features of atherosclerotic plaque-associated lipids. Arterioscler Thromb Vasc Biol. 1997;17(8):1496-1503.

28. Fayad ZA, Connick TJ, Axel L. An improved quadrature or phased-array coil for MR cardiac imaging. Magn Reson Med. 1995;34(2):186-193.

29. Hayes CE, Mathis CM, Yuan C. Surface coil phased arrays for high-resolution imaging of the carotid arteries. J Magn Reson Imaging. 1996;6(1):109-112.

30. Ouhlous M, Lethimonnier F, Dippel DW, van Sambeek MR, van Heerebeek LC, Pattynama PM, van Der Lugt A. Evaluation of a dedicated dual phased-array surface coil using a black-blood FSE sequence for high resolution MRI of the carotid vessel wall. J Magn Reson Imaging. 2002;15(3):344-351.

31. Quick HH, Debatin JF, Ladd ME. MR imaging of the vessel wall. Eur Radiol. 2002;12(4):889900.

32. Schar M, Kim WY, Stuber M, Boesiger P, Manning WJ, Botnar RM. The impact of spatial resolution and respiratory motion on MR imaging of atherosclerotic plaque. J Magn Reson Imaging. 2003;17(5):538-544.

33. Pruessmann KP, Weiger M, Scheidegger MB, Boesiger P. SENSE: sensitivity encoding for fast MRI. Magn Reson Med. 1999;42(5):952-962.

34. Botnar RM, Bucker A, Kim WY, Viohl I, Gunther RW, Spuentrup E. Initial experiences with in vivo intravascular coronary vessel wall imaging. J Magn Reson Imaging. 2003;17(5):615-619.

35. Worthley SG, Helft G, Fuster V, Fayad ZA, Shinnar M, Minkoff LA, Schechter C, Fallon JT, Badimon JJ. A novel nonobstructive intravascular MRI coil: in vivo imaging of experimental atherosclerosis. Arterioscler Thromb Vasc Biol. 2003;23(2):346-350.

36. Hillenbrand CM, Wong B, Griswold MA, Zhang S, Rafie S, Lewin JS, Duerk JL. Intravascular Parallel Imaging: A Feasibility Study. Paper presented at: International Society for Magnetic Resonance in Medicine, 2004; Kyoto, Japan. 
37. Quick HH, Ladd ME, Nanz D, Mikolajczyk KP, Debatin JF. Vascular stents as RF antennas for intravascular MR guidance and imaging. Magn Reson Med. 1999;42(4):738-745.

38. Quick HH, Zenge MO, Kuehl H, Kaiser G, Aker S, Bosk S, Debatin JF, Ladd ME. Interventional MRA with no strings attached: wireless active catheter visualization. Paper presented at: Internal Society for Magnetic Resonance in Medicine, 2004; Kyoto, Japan.

39. Weiger M, Pruessmann KP, Kassner A, Roditi G, Lawton T, Reid A, Boesiger P. Contrastenhanced 3D MRA using SENSE. J Magn Reson Imaging. 2000;12(5):671-677.

40. Finn JP, Edelman RR. Black-blood and segmented k-space magnetic resonance angiography. Magn Reson Imaging Clin N Am. 1993;1(2):349-357.

41. Edelman RR, Chien D, Kim D. Fast selective black blood MR imaging. Radiology. 1991;181(3):655-660.

42. Fleckenstein JL, Archer BT, Barker BA, Vaughan JT, Parkey RW, Peshock RM. Fast short-tau inversion-recovery MR imaging. Radiology. 1991;179(2):499-504.

43. Fayad ZA, Fuster V. Atherothrombotic plaques and the need for imaging. Neuroimaging Clin N Am. 2002;12(3):351-364.

44. Song HK, Wright AC, Wolf RL, Wehrli FW. Multislice double inversion pulse sequence for efficient black-blood MRI. Magn Reson Med. 2002;47(3):616-620.

45. Parker DL, Goodrich KC, Masiker M, Tsuruda JS, Katzman GL. Improved efficiency in double-inversion fast spin-echo imaging. Magn Reson Med. 2002;47(5):1017-1021.

46. Yarnykh VL, Yuan C. Multislice double inversion-recovery black-blood imaging with simultaneous slice reinversion. J Magn Reson Imaging. 2003;17(4):478-483.

47. Itskovich VV, Mani V, Mizsei G, Aguinaldo JG, Samber DD, Macaluso F, Wisdom P, Fayad ZA. Parallel and nonparallel simultaneous multislice black-blood double inversion recovery techniques for vessel wall imaging. J Magn Reson Imaging. 2004;19(4):459-467.

48. Steinman DA, Rutt BK. On the nature and reduction of plaque-mimicking flow artifacts in black blood MRI of the carotid bifurcation. Magn Reson Med. 1998;39(4):635-641.

49. Hatsukami TS, Ross R, Polissar NL, Yuan C. Visualization of fibrous cap thickness and rupture in human atherosclerotic carotid plaque in vivo with high-resolution magnetic resonance imaging. Circulation. 2000;102(9):959-964.

50. Mitsumori LM, Hatsukami TS, Ferguson MS, Kerwin WS, Cai J, Yuan C. In vivo accuracy of multisequence MR imaging for identifying unstable fibrous caps in advanced human carotid plaques. J Magn Reson Imaging. 2003;17(4):410-420.

51. Yuan C, Kerwin WS, Ferguson MS, Polissar N, Zhang S, Cai J, Hatsukami TS. Contrastenhanced high resolution MRI for atherosclerotic carotid artery tissue characterization. $J$ Magn Reson Imaging. 2002;15(1):62-67.

52. Wasserman BA, Smith WI, Trout HH, 3rd, Cannon RO, 3rd, Balaban RS, Arai AE. Carotid artery atherosclerosis: in vivo morphologic characterization with gadolinium-enhanced double-oblique MR imaging initial results. Radiology. 2002;223(2):566-573.

53. Kerwin W, Hooker A, Spilker M, Vicini P, Ferguson M, Hatsukami T, Yuan C. Quantitative magnetic resonance imaging analysis of neovasculature volume in carotid atherosclerotic plaque. Circulation. 2003;107(6):851-856.

54. Kerwin WS, O'Brien KD, Ferguson M, Hatsukami T, Yuan C. Dynamic Contrast-Enhanced MRI Markers of Inflammation in Carotid Atherosclerosis. Proc Intl Soc Mag Reson Med. 2004;11:454.

55. Yarnykh VL, Yuan C. T1-insensitive flow suppression using quadruple inversion-recovery. Magn Reson Med. 2002;48(5):899-905.

56. Sirol M, Itskovich VV, Mani V, Aguinaldo JG, Fallon JT, Misselwitz B, Weinmann HJ, Fuster $\mathrm{V}$, Toussaint JF, Fayad ZA. Lipid-rich atherosclerotic plaques detected by gadofluorineenhanced in vivo magnetic resonance imaging. Circulation. 2004;109(23):2890-2896.

57. Pell GS, Lewis DP, Branch CA. Pulsed arterial spin labeling using TurboFLASH with suppression of intravascular signal. Magn Reson Med. 2003;49(2):341-350. 
58. Yuan C, Miller ZE, Cai J, Hatsukami T. Carotid atherosclerotic wall imaging by MRI. Neuroimaging Clin N Am. 2002;12(3):391-401, vi.

59. Fayad ZA, Nahar T, Fallon JT, Goldman M, Aguinaldo JG, Badimon JJ, Shinnar M, Chesebro $\mathrm{JH}$, Fuster $\mathrm{V}$. In vivo magnetic resonance evaluation of atherosclerotic plaques in the human thoracic aorta: a comparison with transesophageal echocardiography. Circulation. 2000;101(21):2503-2509.

60. Fayad ZA, Fuster V, Fallon JT, Jayasundera T, Worthley SG, Helft G, Aguinaldo JG, Badimon $\mathrm{JJ}$, Sharma SK. Noninvasive in vivo human coronary artery lumen and wall imaging using black-blood magnetic resonance imaging. Circulation. 2000;102(5):506-510.

61. Botnar RM, Stuber M, Kissinger KV, Kim WY, Spuentrup E, Manning WJ. Noninvasive coronary vessel wall and plaque imaging with magnetic resonance imaging. Circulation. 2000;102(21):2582-2587.

62. Toussaint JF, Southern JF, Fuster V, Kantor HL. T2-weighted contrast for NMR characterization of human atherosclerosis. Arterioscler Thromb Vasc Biol. 1995;15(10):1533-1542.

63. Yuan C, Hatsukami TS, Obrien KD. High-Resolution magnetic resonance imaging of normal and atherosclerotic human coronary arteries ex vivo: discrimination of plaque tissue components. J Investig Med. 2001;49(6):491-499.

64. Yuan C, Mitsumori LM, Beach KW, Maravilla KR. Carotid atherosclerotic plaque: noninvasive MR characterization and identification of vulnerable lesions. Radiology. 2001;221(2):285-299.

65. Yuan C, Zhang SX, Polissar NL, Echelard D, Ortiz G, Davis JW, Ellington E, Ferguson MS, Hatsukami TS. Identification of fibrous cap rupture with magnetic resonance imaging is highly associated with recent transient ischemic attack or stroke. Circulation. 2002;105(2):181-185.

66. Cappendijk VC, Kessels AG, Heeneman S, Cleutjens KB, Schurink GW, Welten RJ, Daemen MJ, van Engelshoven JM, Kooi ME. Logistic regression analysis of optimal MR weighting combinations for atherosclerotic plaque assessment. Proc Int/ Soc Mag Reson Med. 2004;11:1918.

67. Chan SK, Jaffer FA, Botnar RM, Kissinger KV, Goepfert L, Chuang ML, O'Donnell CJ, Levy D, Manning WJ. Scan reproducibility of magnetic resonance imaging assessment of aortic atherosclerosis burden. J Cardiovasc Magn Reson. 2001;3(4):331-338.

68. Jaffer FA, O'Donnell CJ, Larson MG, Chan SK, Kissinger KV, Kupka MJ, Salton C, Botnar RM, Levy D, Manning WJ. Age and sex distribution of subclinical aortic atherosclerosis: a magnetic resonance imaging examination of the Framingham Heart Study. Arterioscler Thromb Vasc Biol. 2002;22(5):849-854.

69. Corti R, Fuster V, Fayad ZA, Worthley SG, Helft G, Smith D, Weinberger J, Wentzel J, Mizsei $G$, Mercuri M, Badimon JJ. Lipid lowering by simvastatin induces regression of human atherosclerotic lesions: two years' follow-up by high-resolution noninvasive magnetic resonance imaging. Circulation. 2002;106(23):2884-2887.

70. Walker L, Ismail A, McMeekin W, Lambert D, Mendelow AD, Birchall D. Computed tomography angiography for the evaluation of carotid atherosclerotic plaque: correlation with histopathology of endarterectomy specimens. Stroke. 2002;33(4):977-981.

71. Schroeder S, Kopp AF, Baumbach A, Meisner C, Kuettner A, Georg C, Ohnesorge B, Herdeg $C$, Claussen CD, Karsch KR. Noninvasive detection and evaluation of atherosclerotic coronary plaques with multislice computed tomography. J Am Coll Cardiol. 2001;37(5):14301435.

72. Becker CR, Nikolaou K, Muders M, Babaryka G, Crispin A, Schoepf UJ, Loehrs U, Reiser MF. Ex vivo coronary atherosclerotic plaque characterization with multi-detector-row CT. Eur Radiol. 2003;13(9):2094-2098.

73. Nikolaou K, Sagmeister S, Knez A, Klotz E, Wintersperger BJ, Becker CR, Reiser MF. Multidetector-row computed tomography of the coronary arteries: predictive value and 
quantitative assessment of non-calcified vessel-wall changes. Eur Radiol. 2003;13(11):2505-2512.

74. Yuan C, Kerwin WS. MRI of atherosclerosis. J Magn Reson Imaging. 2004;19(6):710-719.

75. Botnar RM, Stuber M, Lamerichs R, Smink J, Fischer SE, Harvey P, Manning WJ. Initial experiences with in vivo right coronary artery human MR vessel wall imaging at 3 tesla. $J$ Cardiovasc Magn Reson. 2003;5(4):589-594.

76. Berg A, Sailer J, Rand T, Moser E. Diffusivity- and T2 imaging at 3 Tesla for the detection of degenerative changes in human-excised tissue with high resolution: atherosclerotic arteries. Invest Radiol. 2003;38(7):452-459.

77. Maki JH, Wilson GJ, Lauffer RB, Weiskoff RM, Yuan C. Apparent vessel wall inflammation detected using MS-325, blood pool contrast agent. Proc Intl Soc Mag Reson Med. 2001;9:639.

78. Kooi ME, Cappendijk VC, Cleutjens KB, Kessels AG, Kitslaar PJ, Borgers M, Frederik PM, Daemen MJ, van Engelshoven JM. Accumulation of ultrasmall superparamagnetic particles of iron oxide in human atherosclerotic plaques can be detected by in vivo magnetic resonance imaging. Circulation. 2003;107(19):2453-2458.

79. Yu X, Song SK, Chen J, Scott MJ, Fuhrhop RJ, Hall CS, Gaffney PJ, Wickline SA, Lanza GM. High-resolution MRI characterization of human thrombus using a novel fibrin-targeted paramagnetic nanoparticle contrast agent. Magn Reson Med. 2000;44(6):867-872.

80. Flacke S, Fischer S, Scott MJ, Fuhrhop RJ, Allen JS, McLean M, Winter P, Sicard GA, Gaffney PJ, Wickline SA, Lanza GM. Novel MRI contrast agent for molecular imaging of fibrin: implications for detecting vulnerable plaques. Circulation. 2001;104(11):1280-1285.

81. Botnar RM, Perez AS, Witte S, Wiethoff AJ, Laredo J, Hamilton J, Quist W, Parsons EC, Jr., Vaidya A, Kolodziej A, Barrett JA, Graham PB, Weisskoff RM, Manning WJ, Johnstone MT. In vivo molecular imaging of acute and subacute thrombosis using a fibrin-binding magnetic resonance imaging contrast agent. Circulation. 2004;109(16):2023-2029.

82. Zhao XQ, Yuan C, Hatsukami TS, Frechette EH, Kang XJ, Maravilla KR, Brown BG. Effects of prolonged intensive lipid-lowering therapy on the characteristics of carotid atherosclerotic plaques in vivo by MRI: a case-control study. Arterioscler Thromb Vasc Biol. 2001;21(10):1623-1629.

83. von Ingersleben G, SchmiedI UP, Hatsukami TS, Nelson JA, Subramaniam DS, Ferguson MS, Yuan C. Characterization of atherosclerotic plaques at the carotid bifurcation: correlation of high-resolution MR imaging with histologic analysis--preliminary study. Radiographics. 1997;17(6):1417-1423.

84. Botnar RM, Buecker A, Wiethoff AJ, Parsons EC, Jr, Katoh M, Katsimaglis G, Weisskoff RM, Lauffer RB, Graham PB, Gunther RW, Manning WJ, Spuentrup E. In Vivo Magnetic Resonance Imaging of Coronary Thrombosis Using a Fibrin-Binding Molecular Magnetic Resonance Contrast Agent. Circulation. 2004:01. CIR.0000134960.0000131304.0000134987. 



\section{Chapter 3}

\section{Magnetic resonance imaging of the coronary arteries}

S.C. Gerretsen, M.E. Kooi, S. Schalla, T. Delhaas, G. Snoep, J.M.A. Van Engelshoven, T. Leiner

Cardiovascular Journal of South Africa 2007; 18(4):248 


\begin{abstract}
Despite progress in prevention and early diagnosis, coronary artery disease (CAD) remains one of the leading causes of mortality in the world. For many years, invasive X-ray coronary angiography has been the method of choice for the diagnosis of significant CAD. However, up to $40 \%$ of patients referred for elective $\mathrm{X}$-ray coronary angiography have no clinically significant stenoses. These patients still remain subjected to the potential risks of X-ray angiography. As an alternative, magnetic resonance imaging (MRI) is currently one of the most promising techniques for non-invasive imaging of the coronary arteries. Over the past two decades, many technical developments have been implemented that have led to major improvements in coronary MRI. Nowadays, both anatomical and functional information can be obtained with high temporal and spatial resolution and good image quality. In this review we will discuss the technical foundations and current status of clinical coronary MRI, and some potential future applications.
\end{abstract}




\section{Introduction}

Despite progress in prevention and early diagnosis, coronary artery disease (CAD) remains the leading cause of mortality in the world, accounting for $13 \%$ of all deaths worldwide ${ }^{1,2}$. For many years, invasive X-ray coronary angiography has been the method of choice for the diagnosis of significant CAD (defined as more than $50 \%$ stenosis of the coronary artery lumen). Although several non-invasive tests are available to help discriminate between patients with and without significant angiographic disease, studies demonstrated that up to $40 \%$ of patients referred for elective X-ray coronary angiography have no clinically significant stenoses ${ }^{3,4}$. Despite the absence of significant narrowing, these patients remain subjected to the potential risks of X-ray angiography. Therefore, development of a clinically useful non-invasive technique is desirable.

Of the non-invasive techniques, multi-detector row computed tomography (MDCT) and magnetic resonance imaging (MRI) are currently the most promising for non-invasive imaging of the coronary arteries. MDCT is a rapidly evolving technique with the main advantage of isotropic high spatial resolution. MRI, however, is the established standard technique for studying cardiac anatomical structure and function and does not involve exposure to ionising radiation. Furthermore, MRI contrast agents are much safer than the iodinated contrast agents, as evidenced by the much lower rate of allergic reactions and the absence of clinically detectable nephrotoxicity ${ }^{5}$.

This review will focus on the technical foundations and the current status of clinical coronary MRI. Since the coronary arteries were first depicted with MRI in the mid $1980 s^{6,7}$, many technical developments have been implemented that have led to major improvements in image quality. Nowadays it is possible to routinely visualise the proximal and middle parts of the coronary arteries and their branches with high accuracy. In addition, development of vessel wall imaging techniques is promising for detection of wall abnormalities in the absence of significant CAD.

\section{Technical aspects of coronary magnetic resonance imaging}

A thorough understanding of the relative merits and shortcomings of coronary MRI demands a basic knowledge of equipment and technical principles, which 
will be discussed below. Currently, coronary MRI demands a compromise between spatial resolution, scan duration and vessel-to-background contrast.

\section{Equipment considerations}

State-of-the-art coronary MRI is performed on 1.5 Tesla (T) MR-systems using dedicated cardiac phased-array radio-frequency coils applied to the chest wall. Technological advances in MR system architecture now enable accelerated data acquisition by simultaneously using 16 - or 32-receiver channels ${ }^{8}$.

Appropriate cardiac receiver coils are required to meet the high in-plane spatial resolution requirements for coronary MRI while maintaining a sufficient signal-to-noise ratio (SNR) in comparison with use of the standard system built-in body coil. The use of these coils should be standard for all coronary MRI examinations ${ }^{9}$. Because the SNR decreases with the distance from the surface receiver coil, cardiac specific coils have been optimised for the size of the heart and the distance of the heart from the chest wall. The right, left main and left anterior descending (LAD) coronary arteries are located relatively close to the anterior chest wall and can therefore be visualised with good image quality. However, the more distal parts of the circumflex artery are more difficult to depict.

With phased-array coils, parallel imaging techniques such as sensitivity encoding (SENSE) ${ }^{10}$, simultaneous acquisition of spatial harmonics $(\mathrm{SMASH})^{11}$, and generalised autocalibrating partially parallel acquisitions (GRAPPA) ${ }^{12}$ can be used to accelerate image acquisition by using the locally differing sensitivities of the separate receiver-coil elements. The acceleration factor is dependent on the coil type, and is typically two- to three-fold. With the newest generation of 16- and 32-receiver channel systems, even higher factors can be reached $^{8,13}$. However, a trade-off must be made between image quality and scan duration since the use of high-acceleration factors will lead to decreased SNR and contrast-to-noise ratio $(\mathrm{CNR})^{10,14}$.

In recent years, 3.0 T high-field MRI systems have become more widely available and are starting to be used for coronary imaging. The potential doubling of the SNR at 3.0 T could lead to further progress in cardiac applications, including coronary MRI. However, increased susceptibility effects and specific absorption rate (SAR) limitations due to altered penetration of radiofrequency (RF) pulses are potentially disadvantageous ${ }^{15}$. Nevertheless, first results of cardiac and coronary MRI at $3 \mathrm{~T}$ are promising (figure 1 ) and show increased SNR and CNR compared to the results at 1.5 $\mathrm{T}^{16-18}$. However, the theoretically predicted two-fold gain in SNR has not yet been achieved and 
current techniques do not result in significantly improved image quality and diagnostic accuracy compared with the quality and accuracy at $1.5 \mathrm{~T}^{19}$. On the other hand, Huber et al. found the added SNR at $3 \mathrm{~T}$ to be sufficient to use parallel imaging with a reduction factor of two. This resulted in a $50 \%$ reduction in scan duration, with largely preserved image quality despite inevitable SNR loss relative to conventional full acquisition at $3 \mathrm{~T}^{20}$.
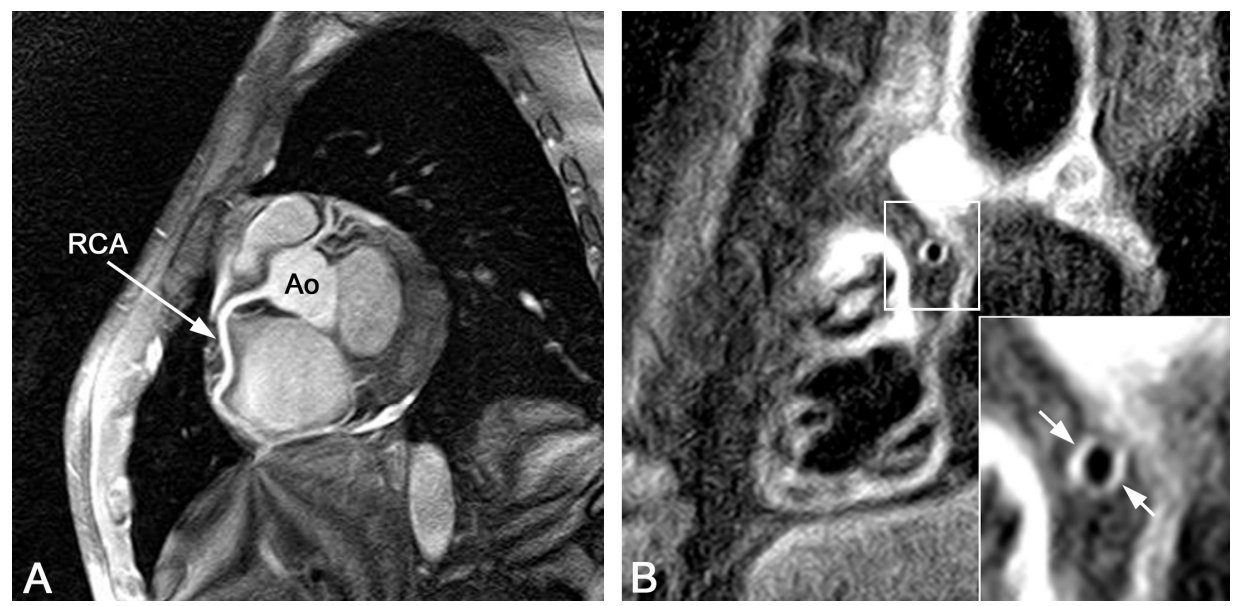

Figure 1. Three Tesla images of the right coronary artery (RCA). (A) Three-dimensional gradient echo sequence of the RCA using a T2 pre-pulse and fat saturation. (B) Dual inversion recovery (DIR) and fat-saturated gradient echo sequence of the RCA vessel wall. Both images show a high signal-to-noise ratio (SNR). The coronary vessel wall is clearly visible in B (arrows). Ao: aorta. (Courtesy M Stuber, Johns Hopkins University, Baltimore, MD, USA.)

\section{Spatial resolution requirements}

Coronary MRI data acquisition is technically challenging because of the tortuosity and small calibre (on average $1.5-5.5 \mathrm{~mm}^{21}$ ) of the coronary arteries. In this context, it is important to realise that accurate assessment of the degree of stenosis demands at least three pixels across the normal vascular lumen, as has been demonstrated by Hoogeveen et al. ${ }^{22}$ This constraint imposes a submillimetre in-plane resolution on coronary artery MRI protocols, especially in protocols used for stenosis detection.

The use of modern MR systems in combination with dedicated surface coils and optimised pulse sequences readily enables sub-millimetre in-plane resolution with current best pixel sizes of around $0.7 \times 0.7 \mathrm{~mm}$ and slice thickness in the order of $1 \mathrm{~mm}$. Despite satisfying the resolution requirement, the spatial resolution of coronary MRI is currently lower compared to the resolution of X-ray angiography (in the order of $0.2-0.3 \mathrm{~mm}$ ), and MDCT (pixel 
sizes of around $0.5 \mathrm{~mm}$ ). A drawback of coronary MRI is that higher-resolution images increase acquisition time and lead to lower SNR when all other parameters are kept constant.

\section{Motion compensation}

Because the MR data acquisition process is inherently motion sensitive, techniques must be applied to compensate for cardiac and respiratory motion. During the cardiac cycle, in-plane coronary artery displacement can be up to 5 $\mathrm{mm}^{23,24}$. The right coronary artery is more motion sensitive than the left coronary system. The data points needed to reconstruct an image of the heart and coronary arteries are generally obtained over multiple consecutive cardiac cycles. This strategy is also known as 'segmented' $k$-space sampling and demands accurate four-lead vector ECG registration ${ }^{25}$ and a regular cardiac rhythm.

Studies by Hofman et al. and Wang et al. have demonstrated that coronary artery motion is minimal during mid-diastolic diastasis, the cardiac rest period $^{24,26}$, and that best image quality is obtained when the acquisition window is optimised by using a subject-specific trigger delay ${ }^{27}$ after detection of the R-wave. The length of both the end-systolic and mid-diastolic rest periods depends on heart rate and can be individually determined from high temporal resolution ciné images. To obtain good image quality, an individually tailored acquisition window, preferably less than $120 \mathrm{~ms}$, is advised ${ }^{24,28,29}$.

An additional important source of motion artefacts is beat-to-beat variations in heart rate and premature heartbeats. Leiner et al. have demonstrated improved coronary MR image quality with the use of combined respiratory gating and arrhythmia rejection ${ }^{30}$. The possibility of exactly tailoring acquisition duration and correcting for variations in heart rate is a major strength of MR imaging. In contrast, MDCT acquisition times are generally not individually tailored and almost always exceed the length of mid-diastolic diastasis. This has led to preventative use of beta-blockers to lower heart rate during CT imaging, a strategy not routinely used in MR imaging.

In addition to taking into account cardiac contraction, respiratory motion has to be compensated for. At present, two techniques are used for respiratory motion compensation: holding the breath, and navigator gating. Holding the breath is highly dependent on patient cooperation. In addition, patients with pulmonary disease or heart failure are often not able to hold their breath long enough. Furthermore, slow cranial shifting of the diaphragm (drift) dur- 
ing breath hold can still cause motion of the heart and the coronary arteries during acquisition ${ }^{31}$.

The navigator gating technique, on the other hand, uses a twodimensional pencil beam that is placed on an interface that reflects respiratory motion, eg the lung-liver or lung-myocardium interface ${ }^{32}$. The navigator monitors the motion of this interface during free breathing. Data are accepted only when the selected interface falls within a user-defined window positioned around the end-expiratory level of the interface. With this technique, less patient cooperation is required. However, diaphragmatic drift can also occur during free breathing. Therefore, drift correction of the navigator window during the scan is essential to maintain sufficient efficiency and reasonable scan duration.

In terms of image quality and diagnostic accuracy, the free-breathing navigator technique is superior to breath-hold coronary $\mathrm{MRI}^{33,34}$. Because of longer scan duration (not limited by breath hold), better SNR or spatial resolution can be achieved.

\section{Pulse sequences and vessel-to-background contrast}

The optimal coronary MRI sequence has not yet been established. Essential elements are cardiac gating, respiratory motion suppression and pre-pulses to increase the signal of coronary arterial blood in relation to surrounding tissue (ie, increased CNR). Furthermore, SNR should be optimised while at the same time keeping scan duration within acceptable limits.

Both bright-blood and black-blood techniques have been evaluated in two-dimensional (2-D) and three-dimensional (3-D) pulse sequences. Brightblood sequences tend to overestimate atherosclerotic lesions because of artificial darkening caused by focal turbulent flow ${ }^{35}$. The vessel luminal diameter may therefore be underestimated in comparison with conventional X-ray angiography. On the other hand, the signal intensity of thrombus, vessel wall and various components of plaque may appear high on bright-blood coronary MR angiography (MRA), thereby obscuring focal stenoses.

Despite these drawbacks, the majority of sequences for coronary artery lumen imaging are bright-blood approaches with 2-D or 3-D gradient echo sequences with Cartesian segmented $k$-space sampling. Two-dimensional breath-hold coronary MRA has been shown to be a promising and valuable method for assessment of the native coronary arteries. With 3-D methods, scan duration is longer but these methods also have inherent advantages, including minimising bulk cardiac motion, superior SNR, the acquisition of thin 
contiguous sections and the ability to post-process and reformat the data set $^{36}$. Recently, bright-blood balanced steady-state free-precession (bSSFP) sequences have gained considerable interest. SSFP imaging is a very promising technique for coronary MRA MRI at $1.5 \mathrm{~T}$ with high SNR and CNR ${ }^{37}$. Nevertheless, this sequence is more sensitive to magnetic field inhomogeneities. The increased main field inhomogeneity and B1 field variations at $3 \mathrm{~T}$ can potentially be problematic for SSFP imaging ${ }^{16}$.

By contrast, black-blood coronary imaging is performed using spin echo sequences. With this technique, there is a potential for enhancing CNR in comparison with gradient echo approaches. In addition, black-blood sequences appear to be particularly advantageous for patients with implants such as vascular clips or sternal wires because spin echo techniques are less sensitive to the susceptibility artefacts from metallic implants ${ }^{38,39}$.

The coronary arteries can be imaged using either a double-oblique, targeted approach or a whole-heart scan. With the former technique, a 3-D slab is acquired in a user-defined orientation around the coronary arteries. The vessel of interest can be covered with high spatial resolution, and scan duration is shorter compared to whole-heart MRI. Although extensive parts of the coronary arteries can be depicted with this technique ${ }^{36}$, multiple scans are required since not all coronary arteries can be covered with one scan (figure $2 \mathrm{~A}, \mathrm{~B}$ ). The whole-heart technique, first described by Weber et $\mathrm{Il}^{40}{ }^{40}$, is a magnetisation prepared bSSFP sequence using an acquisition volume covering the whole heart. The major advantages of the technique are that positioning of the imaging volume is relatively simple, it facilitates high-quality coronary MRA of the complete coronary artery tree in a single measurement and it allows post-processing and display of data sets similar to MDCT (figure $2 \mathrm{C}$ ). A drawback at present is the relatively long acquisition duration, although this will change with more widespread use of parallel imaging techniques.

An important aspect of coronary imaging is the contrast between coronary arteries and surrounding epicardial fat and myocardium. In comparison with MDCT, exogenous contrast media are not necessary to achieve coronary artery enhancement. Several techniques have been developed to increase CNR between the blood and myocardium. Perivascular fat can be suppressed by applying fat saturation ${ }^{41}$ or spectral pre-saturation with inversion recovery (SPIR) pre-pulses. Suppression of the myocardium can be achieved by the use of a T2-preparatory pre-pulse, a technique in which a dedicated pre-pulse is used to achieve a decreased signal from the myocardium while maintaining 
the signal from the blood, leading to an improved CNR between blood and myocardium and better vessel definition ${ }^{28,42}$.
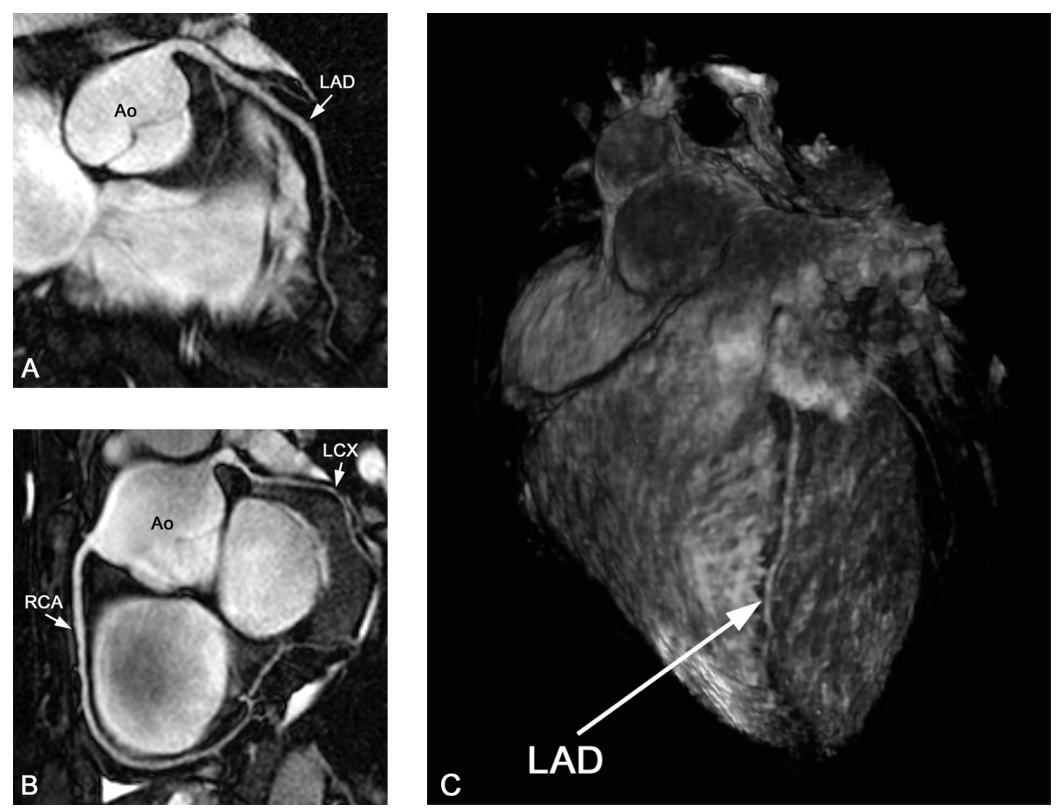

Figure 2. (A) Targeted images of the left anterior descending artery (LAD), (B) right coronary artery (RCA) and $(C)$ whole-heart scan in healthy volunteers. With the targeted approach, highresolution images of the coronary arteries and some branches can be obtained in a relatively short scan time. By using a whole-heart approach, all coronary arteries are imaged in one scan, and the data set allows for post-processing and display of anatomy similar to multi-detector computed tomography. LCX: left circumflex artery, Ao: aorta.

The role of exogenous contrast agents remains to be established, as the use of contrast medium can actually reduce vessel-to-background contrast. For instance, commonly used extracellular agents extravasate into the myocardium and perivascular fat, thereby decreasing the contrast between the coronaries and the myocardium. The use of intravascular contrast agents could be an alternative since these agents exhibit prolonged intravascular retention and have a longer plasma half-life and shorter $\mathrm{T} 1$, resulting in higher signal intensity. This allows imaging over a longer period of time so navigator techniques can be used to obtain images of high quality with high blood/muscle contrast and better vessel delineation ${ }^{43,44}$ In addition, contrast agents may become an important adjunct to coronary imaging at $3 \mathrm{~T}$ as these agents ameliorate some of the imaging artefacts encountered at higher field strengths ${ }^{45}$. 


\section{Clinical indications for coronary MRI}

\section{Detection of anomalous coronary arteries}

Although congenital coronary artery anomalies are relatively uncommon - the estimated incidence is about $1 \%$ in the general population - they can be the cause of severe myocardial ischaemia, infarction or sudden cardiac death ${ }^{46}$. These adverse events commonly occur during or immediately following intense exercise and are thought to be related to compression or proximal angulation, which obstructs blood flow within the anomalous vessels, leading to distal ischaemia, ventricular tachycardia and ventricular fibrillation ${ }^{47}$. Therefore, it is vital that the precise anatomical arrangement is identified to enable the appropriate management plan to be followed ${ }^{48}$.

Projection X-ray angiography used to be the imaging test of choice for the diagnosis and characterisation of these anomalies. However, detection of anomalies may be difficult and the exact anatomical course can be difficult to determine. One of the main advantages of using MRI instead of X-ray angiography is the visualisation of the coronary arteries in relation to other mediastinal structures such as the right ventricular outflow tract. Threedimensional coronary MRI is well suited for the depiction of anomalous coronary artery origins (figure 3). Several studies have demonstrated that MR angiography is highly accurate in detecting anomalous coronary arteries and delineating the proximal course ${ }^{48-50}$. Coronary MRI is now the method of choice in young patients in whom coronary artery anomaly is suspected or needs to be further clarified, or if the patient has another cardiac anomaly associated with coronary anomalies ${ }^{51}$.

A coronary artery fistula is the most important haemodynamically significant coronary artery anomaly. It is characterised by an abnormal communication between a coronary artery and a cardiac chamber, major vessel or other vascular structure. Surgical repair of the fistula is recommended for symptomatic patients and for asymptomatic patients at risk for future complications (steal, aneurysms, large shunts) ${ }^{52}$. As a non-invasive technique, MRI is very suitable for detection and follow-up of these fistulae (figure 4). 


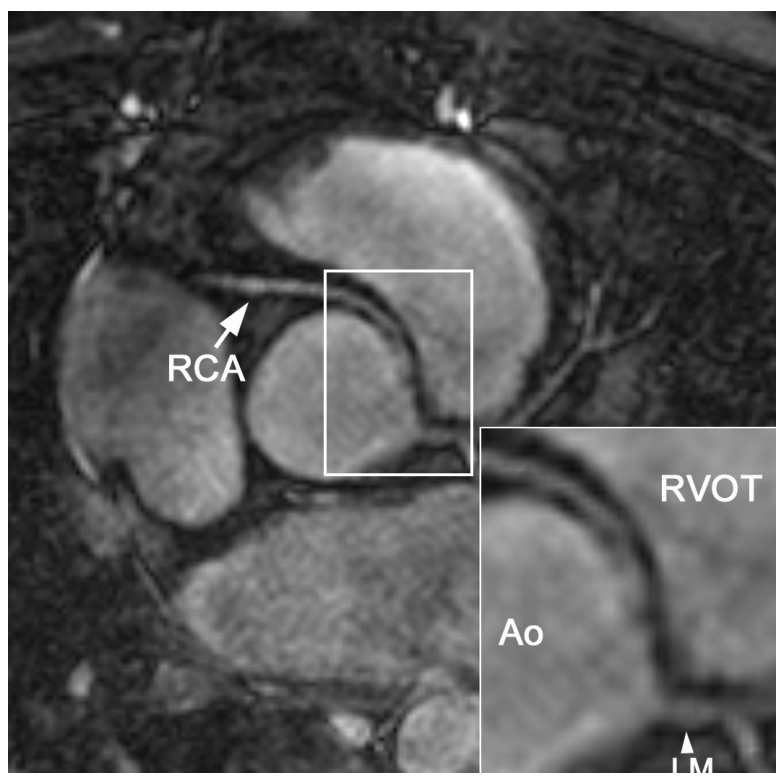

Figure 3. Three-dimensional balanced steady-state free precession (bSSFP) coronary MRI at 1.5 $\mathrm{T}$ in a 51-year-old female with aberrant right coronary artery (RCA). The RCA originates from the left coronary artery sinus and traverses between the aorta $(\mathrm{Ao})$ and the right ventricular outflow tract (RVOT). LM indicates the left main stem.
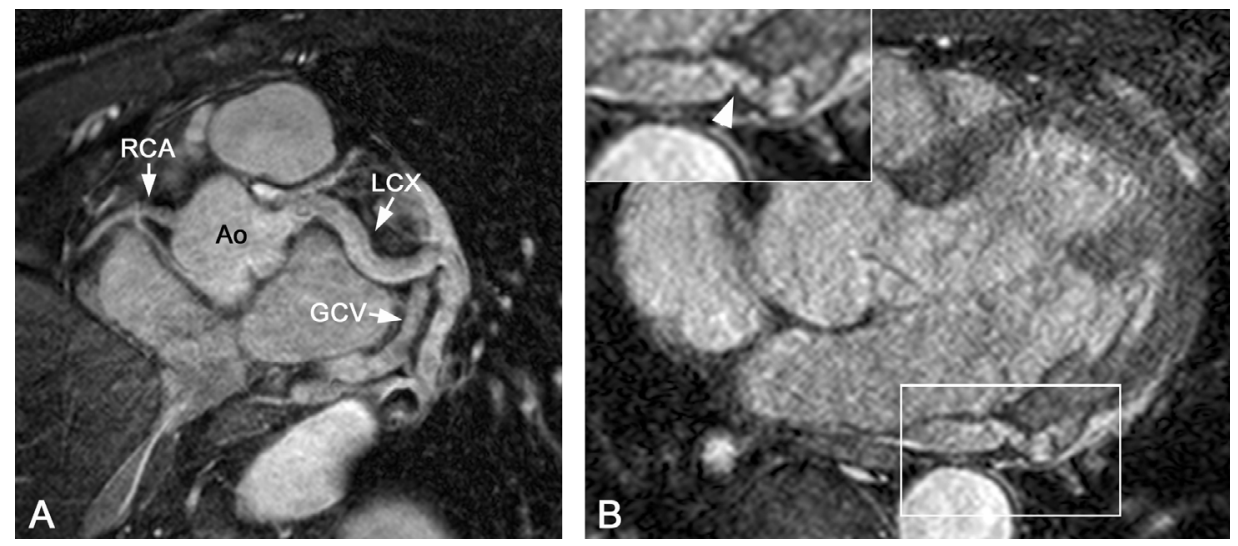

Figure 4. (A) Targeted Cartesian balanced steady-state free precession (bSSFP) and (B) wholeheart source image in a patient with a coronary arteriovenous fistula. Note the enlarged LCX compared to the left anterior descending artery (LAD) and right coronary artery (RCA). There is a connection (arrowhead) between the left circumflex artery (LCX) and the coronary sinus. GCV: great cardiac vein, Ao: aorta.

\section{Kawasaki disease and follow-up of coronary artery aneurysms}

Kawasaki disease, an acute vasculitis of unknown origin, is the leading cause of acquired coronary artery disease in children in developing countries and is 
now reported as a potential risk factor for adult ischaemic heart disease and sudden death in early adulthood ${ }^{53}$. There is a $25 \%$ chance of serious cardiovascular damage if treatment is not initiated early in the course of the disease $^{54}$. Coronary damage, including dilatation, aneurysms (defined as coronary diameter $>4 \mathrm{~mm}$ ) and giant aneurysms (coronary diameter $>8 \mathrm{~mm}$ ) develop in up to $5 \%$ of timeously treated patients. In addition to aneurysm development in infants and children, this syndrome may eventually lead to thrombotic occlusion, premature atherosclerosis and progression to ischaemic heart diseas $\mathrm{e}^{53}$. Serial evaluation of coronary aneurysms is important, and regression of these aneurysms has been reported in approximately $50 \%$ of the patients ${ }^{55}$. In young children, transthoracic echocardiography is usually adequate for detecting and following these aneurysms, but this technique often becomes inadequate as children grow. An alternative method for follow up is MRI, which is considered equivalent to coronary angiography ${ }^{56,57}$ (figure 5).

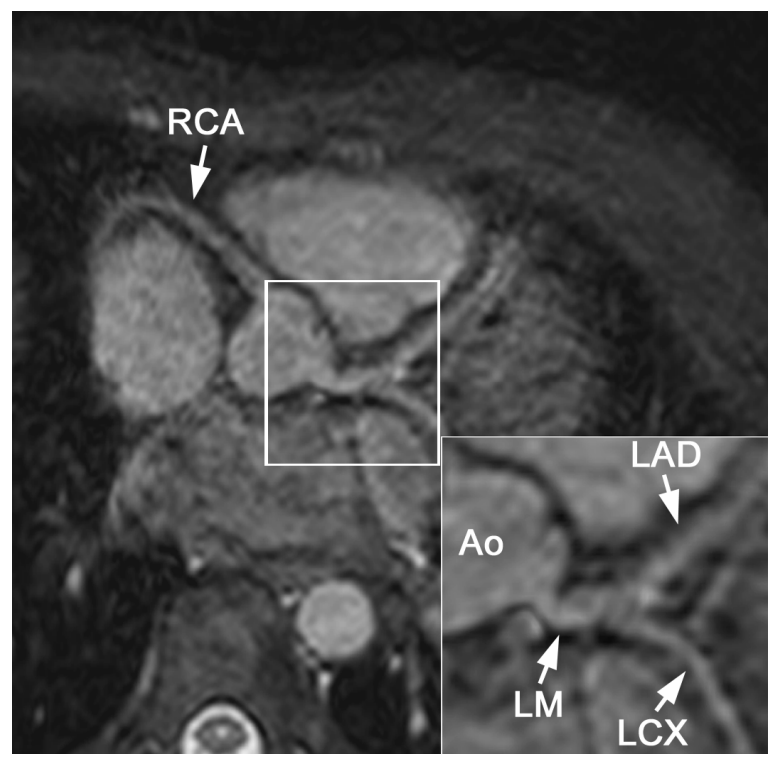

Figure 5. Post-processed wholeheart scan of a 12-year-old boy diagnosed with Kawasaki disease. Dilatation of the left and right coronary artery can be seen. Note the kinking and aneurysmatic distal part (diameter 4.4 $\mathrm{mm}$ ) of the left main stem (LM) in comparison with the diameter of the ostium (diameter $2.8 \mathrm{~mm}$ ). Ao: aorta, LAD: left anterior descending artery, LCX: left circumflex artery, RCA: right coronary artery.

\section{Detection of stenoses in native coronary arteries}

The most important potential clinical application of coronary MRI is detection of stenoses in native coronary arteries. For this purpose, bSSFP bright-blood techniques are mostly used where areas of focal stenosis produce signal voids of varying severity related to the angiographic degree of stenosis (figure 6). However, gradient echo coronary MRI may sometimes overestimate the degree of stenosis as blood flow alterations in stenotic segments can cause sig- 
nal loss in the segment distal to the lesion ${ }^{58}$. Similarly, the presence of heavy calcification in the coronary vessel wall may lead to signal voids that artificially suggest the presence of significant stenoses. On the other hand, adequate collateral blood flow is readily detected as it results in signal in the lumen distal to an occlusion.
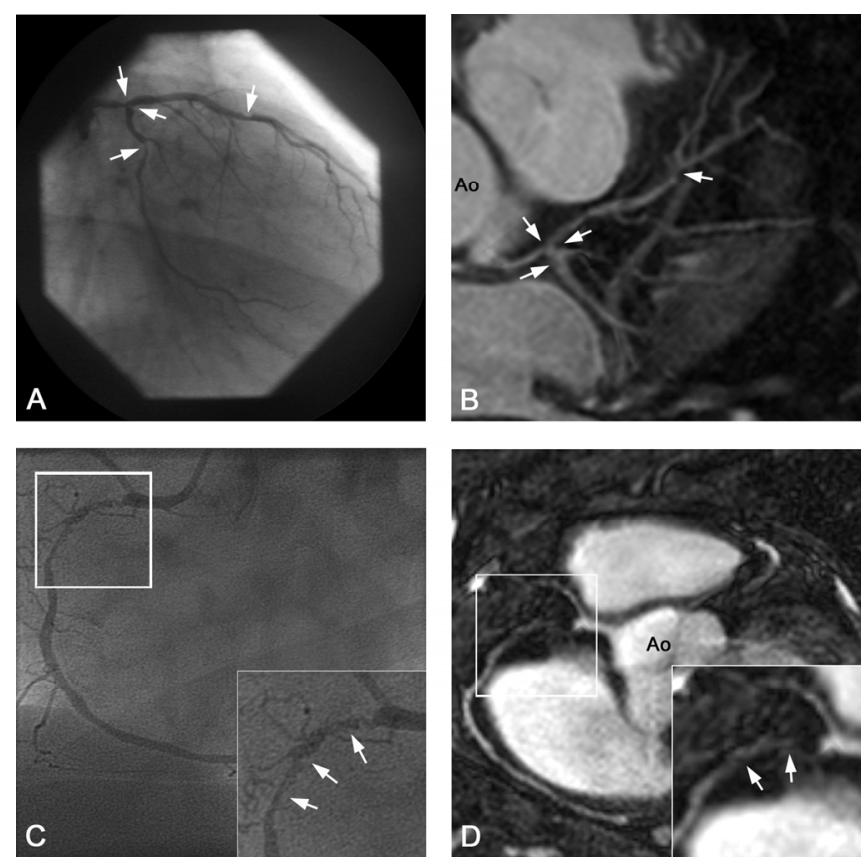

Figure 6. Correlation between coronary X-ray angiography and MRI. X-ray angiography (A) and a targeted Cartesian balanced steady-state free precession (bSSFP) MR sequence (B) in a 62year-old patient with left coronary artery disease. X-ray angiography (C) and radial bSSFP images (D) in a different 53-year-old patient with stable angina. A diffuse, long and severe stenosis of the proximal right coronary artery (RCA) can be seen with both techniques. In both cases, there is a good correlation between angiography and MRI (arrows).

A meta-analysis by Danias et al. summarising the diagnostic performance of 39 studies of coronary MRA found the technique to have moderately high sensitivity for detecting significant proximal stenoses and to be of value for exclusion of significant multi-vessel CAD in subjects with suspected CAD considered for diagnostic catheterisation (Table 1). The study found coronary MRA to have high diagnostic performance in all vessels except the left circumflex coronary artery, and it was particularly useful to rule out the presence of significant CAD to a probability below $5 \%$, especially in individuals with modest suspicion for CAD (pre-test probability for CAD below 20\%). However, this 
meta-analysis showed large heterogeneity of the results, indicating that the performance of coronary MRA is, at present, probably still centredependent ${ }^{59}$.

Table 1. Diagnostic Accuracy of Coronary MRA Compared to Conventional X-Ray Angiography

\begin{tabular}{lll}
\hline Analysis & $\begin{array}{l}\text { Weighted sensitivity } \\
\text { RE }(\%)(95 \% \mathrm{CI})\end{array}$ & $\begin{array}{l}\text { Weighted specificity } \\
\text { RE }(\%)(95 \% \mathrm{Cl})\end{array}$ \\
\hline Segment level $^{+}$ & $73(69-77)^{*}$ & $86(80-90)^{*}$ \\
Left main $^{+}$ & $69(56-79)$ & $91(84-95)^{*}$ \\
LAD & $79(73-84)^{*}$ & $81(71-88)^{*}$ \\
LCX & $61(52-69)$ & $85(78-90)^{*}$ \\
RCA & $71(64-78)^{*}$ & $84(77-88)^{*}$ \\
Subject level & $88(82-92)$ & $56(43-68)^{*}$ \\
Vessel level & $75(68-80)^{*}$ & $85(78-90)^{*}$ \\
\hline
\end{tabular}

*Statistically significant $(p<0.10)$ between-study heterogeneity.

${ }^{\dagger}$ Four studies evaluated the left main together with the proximal segment of the LAD. These data were included in the LAD analysis.

$\mathrm{Cl}=$ confidence interval; $\mathrm{LAD}=$ left anterior descending; $\mathrm{LCX}=$ left circumflex; $\mathrm{RCA}=$ right coronary artery; RE = random effects.

[modified from: Danias et al. J Am Coll Cardiol 44(9) 2004.]

Of note, the largest multi-centre coronary MRA study to date reported on 109 patients scheduled for elective X-ray angiography because of suspected CAD. This study found high sensitivity, modest specificity and high negative predictive value and overall accuracy of coronary MRA for the identification of coronary disease, especially in subjects with left main coronary artery disease or three-vessel disease ${ }^{3}$.

An infrequent cause of chest pain is myocardial bridging, a condition in which part of a coronary artery is situated in the myocardium and compressed during systole. Long tunnelled segments of coronary arteries, more severe systolic diameter narrowing of the tunnelled segment and tachycardia may result in myocardial ischaemia. ${ }^{52}$ MRI using systolic and diastolic acquisition windows can be used to non-invasively detect and follow patients with myocardial bridging ${ }^{60}$ (figure 7). 

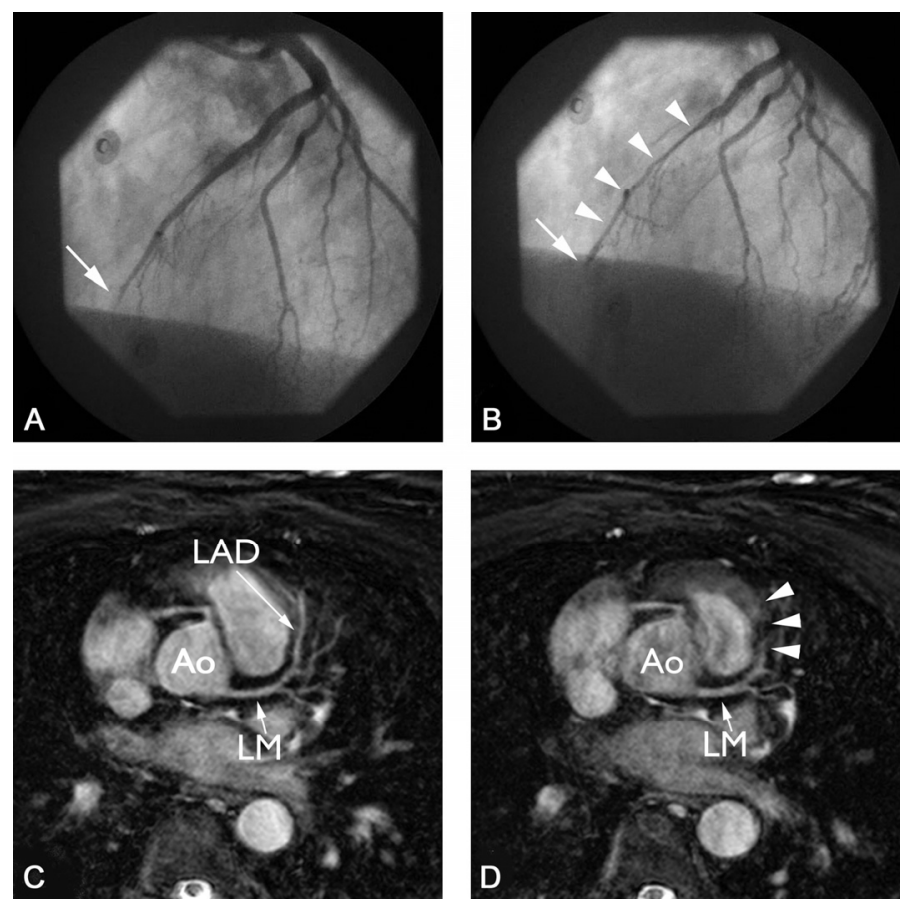

Figure 7. Coronary angiogram (A, B) and targeted Cartesian balanced steady-state free precession (bSSFP) MRI with mid-diastolic (C) and systolic imaging (D) in a 52-year-old man with acute anterior wall myocardial infarction. Coronary angiography revealed single-vessel disease of the left anterior descending artery (LAD). In A, distal occlusion of the LAD can be seen (arrow). B, systolic squeezing of the intramyocardial mid-LAD (arrowheads). $C$, the proximal and midsegment of the LAD can be seen during diastole, however, this segment disappears during systole ( $D$, arrowheads). Ao: aorta, LM: left main stem.

\section{Assessment of coronary artery bypass grafts (CABG)}

Occlusion or stenosis of grafts can occur after coronary artery bypass grafting and this incidence increases over time ${ }^{61}$. Because of their fixed position and large lumen size, bypass grafts are relatively easy to image despite possible artefacts due to the presence of sternal wires or metal clips. Langerak et al. have demonstrated that MRI can be used to determine graft patency and to assess the presence of vein graft disease with a fair diagnostic accuracy. Sensitivity and specificity for identifying graft occlusion and stenosis ranged from $65-83 \%$ and $80-100 \%$, respectively ${ }^{62}$.

\section{Intracoronary stents}

Nowadays, intracoronary stents are routinely used as adjunct to percutaneous coronary artery revascularisations for CAD. Early MRI can be safely performed 
as early as one to three days after stent implantation ${ }^{63-66}$. Depending on the material of the stent, local susceptibility effects lead to signal voids and artefacts. The size of the artefact is influenced by the type of MR sequence (larger with gradient echo sequences), imaging parameters and stent material (less with titanium, larger with stainless steel) ${ }^{67,68}$. At present, these artefacts prevent the direct visualisation of in-stent restenosis. Recently, a new MR-lucent stent was developed by Spuentrup et al. In an animal model, this stent allowed for completely artefact-free coronary MRA and vessel wall imaging ${ }^{68,69}$.

\section{Flow and perfusion measurements}

The functional significance of a stenosis cannot only be determined by assessment of the anatomical severity. In a substantial number of cases, functional information is therefore obtained by measuring coronary blood flow and flow reserve. The latter parameter is the ratio of maximal hyperaemic coronary flow to baseline coronary flow ${ }^{70}$. Assessment of the functional significance of a stenosis is particularly important in lesions with intermediate severity because the interpretation of such lesions significantly influences therapeutic decisions in patients with coronary artery disease ${ }^{71}$.

Fast phase-contrast ciné MRI is an application that can provide noninvasive assessment of blood flow and flow reserve in human coronary arteries. The technique has recently been used for detection of flow in native coronary arteries before and after interventions, and in bypass grafts for detection of graft stenosis ${ }^{70,72}$. Additionally, MRI of coronary anatomy and flow can be combined with wall motion and stress perfusion studies ${ }^{73-76}$.

\section{Future developments: vessel wall and plaque imaging}

Although luminography is the established method for detection of atherosclerotic lesions, it is well known to underestimate early atherosclerosis, since atherosclerotic plaques can be present without visible luminal narrowing. This phenomenon was first described by Glagov et al. and is also known as 'positive remodelling ${ }^{77,78}$. Falk et al. and Schoenhagen et al. found that patients with only mild-to-moderate luminal narrowing actually have a higher risk of a future acute coronary syndrome when compared to patients with more significant luminal narrowing ${ }^{79,80}$. This is especially the case when plaques have a large lipid-rich necrotic core and a thin fibrous cap. 
Since these publications, MR vessel wall imaging has become a topic of considerable interest. Because of the superior ability of MRI to differentiate different soft tissues, it is uniquely suited for non-invasive serial imaging of the arterial vessel wall, which might be useful for monitoring progression or regression of atherosclerotic plaque during treatment of atherosclerosis with statins $^{81}$, even in the absence of significant luminal narrowing ${ }^{82}$. Additionally, MRI can potentially be used for risk stratification, eg. identification of those plaques with increased risk of causing ischaemic complications. MR imaging of the vessel wall has been performed in the aorta ${ }^{83}$ and the carotid arteries ${ }^{84,85}$. In these vessels, detection and characterisation of plaque components is feasible. Fayad et al. ${ }^{86}$ and Botnar et al. ${ }^{29}$ were the first to succeed in using MRI to directly visualise coronary vessel wall disease. However, MRI of the coronary vessel wall is still considered to be an experimental technique.

The coronary vessel wall can be visualised with high spatial resolution in cross-sectional or longitudinal fashion. With MRI, increased coronary vessel wall thickness and wall area could be detected in patients with angiographically proven CAD compared to healthy volunteers ${ }^{29,86}$. In addition, Kim et al. found that positive remodelling in patients with non-significant coronary artery disease could be detected ${ }^{87}$. Furthermore, Desai et al. demonstrated that assessment of coronary vessel wall thickness from MR images is highly reproducible $^{88}$. In contrast to larger arteries such as the carotids, however, in vivo detection of plaque components in human coronaries is currently limited by scan duration, SNR and spatial resolution.

Coronary vessel wall thickness is only $0.5-0.75 \mathrm{~mm}$ in healthy young subjects. In the diseased vessel wall, thickness increases to over $1 \mathrm{~mm}$. With current pixel sizes of about $0.7 \times 0.7 \mathrm{~mm}$, only one or two pixels usually cover the vessel wall. For accurate plaque characterisation however, at least one pixel in each vessel wall layer should be present ${ }^{89}$. In addition, motion compensation strategies for coronary vessel wall imaging are more stringent than for coronary MRA ${ }^{27}$. The feasibility of coronary vessel wall imaging at $3 \mathrm{~T}$ has recently been demonstrated. With more experience with higher field systems, further improvements in scan duration, resolution and image quality can be expected $^{90,91}$. 

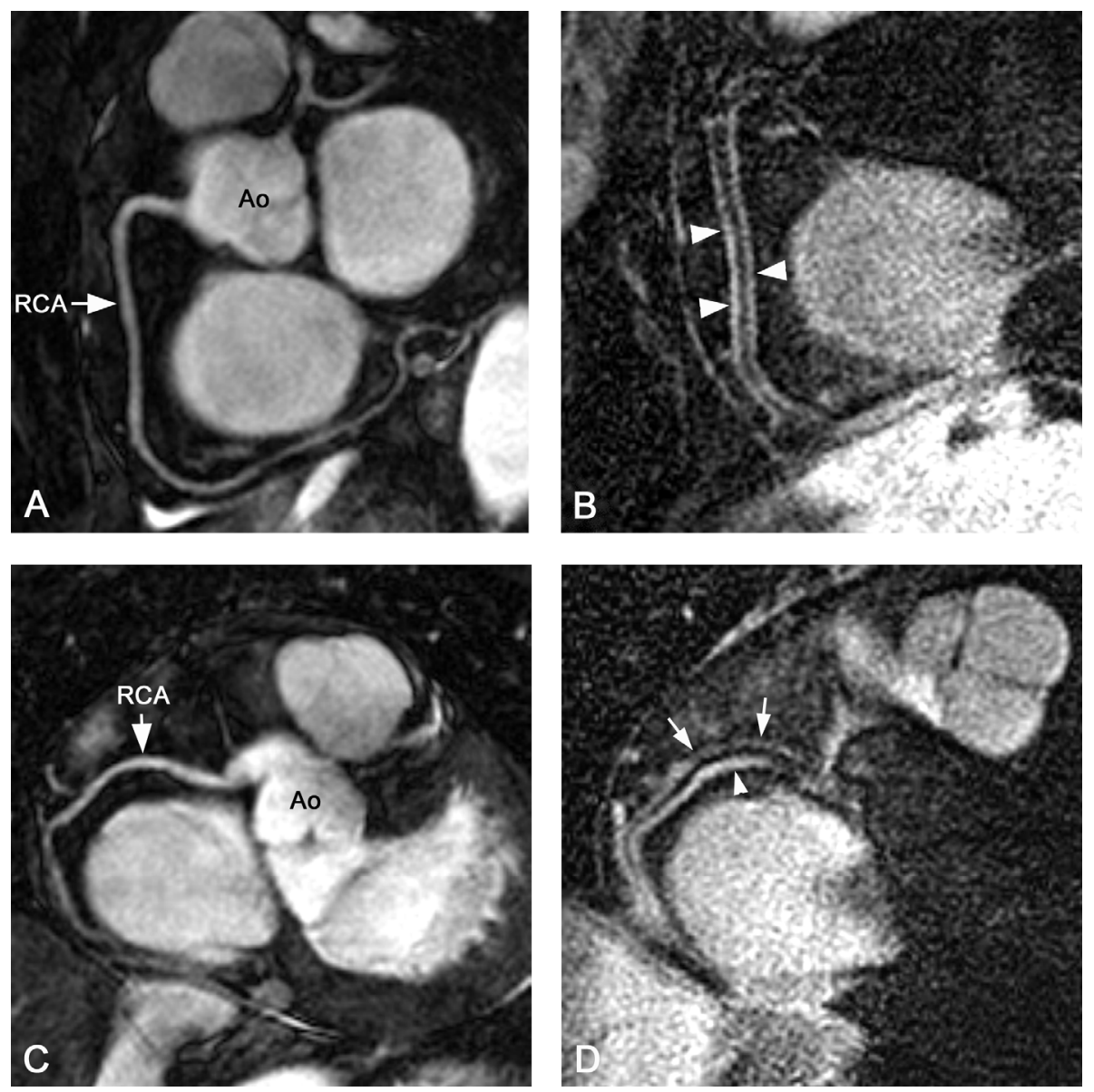

Figure 8. Radial balanced steady-state free precession (bSSFP) (A) and vessel wall scan (B) of the right coronary artery (RCA) in a 62-year-old healthy female. The proximal and middle part of the RCA were free of atherosclerotic disease. The vessel wall (arrowheads) is well delineated, thin and has a uniform signal intensity. BSSFP (C) and vessel wall scan (D) in a 59-year-old female without history of coronary artery disease. In D, note the thickening and bright signal intensity of the posterior wall of the RCA (arrowhead) compared to the anterior wall (arrows).

MR coronary vessel wall imaging can be performed with several techniques. To distinguish the vessel wall from the lumen, the use of dual inversion prepulses for suppression of blood signal is essential. Two-dimensional techniques perpendicular to the vessel axis have been used, but with these techniques there is limited coverage of the artery of interest. In vivo multisequence imaging, as was done previously in, for instance, the carotid arteries $^{92,93}$, is very time consuming in the coronary arteries ${ }^{94}$. By contrast, 3-D imaging offers the opportunity for more extensive longitudinal coverage of the coronaries, improved SNR and higher spatial resolution ${ }^{95}$ (figures 1,8 ). 
Another promising development in the field of (coronary) plaque imaging is the use of contrast agents targeted to thrombus or endothelial cell surface markers. For instance, a fibrin-binding MR contrast agent has successfully been used for the detection of fresh thrombus in a variety of animal models and humans ${ }^{96-99}$. When conventional extracellular agents are used, a delayed enhancement-like phenomenon, similar to that observed in stunned myocardium, can be observed within the coronary vessel wall ${ }^{100,101}$. The exact significance of this finding remains to be elucidated, however.

\section{Coronary $\mathrm{MRI}$ in relation to other techniques}

There are many techniques, both non-invasive as well as invasive, that can be used to obtain information about the coronary artery lumen and vessel wall. Invasive techniques include X-ray coronary angiography, coronary intravascular ultrasonography (IVUS) $)^{102-104}$, optical coherence tomography (OCT) $)^{105-108}$, angioscopy ${ }^{109,110}$, intravascular MRI ${ }^{111}$ and thermography ${ }^{112,113}$. Except for IVUS, these techniques are currently only used in pre-clinical studies, but they might become useful in detection of coronary (vulnerable) plaque.

The most promising non-invasive alternative to MRI is MDCT, which can be performed with reliable results in selected patient populations, especially with the latest generation of 64-detector row scanners which combine thinslice collimation with short gantry rotation times ${ }^{114}$. Currently, MDCT is used for the evaluation of patients with a low pre-test likelihood of a significant coronary stenosis, patients with recurrent angina, follow-up of patients with previous coronary artery bypass grafting or coronary stents when they are located in proximal branches, the evaluation of chronic total coronary occlusion before percutaneous recanalisation, detection of coronary artery anomalies, and for the quantification of coronary artery calcium ${ }^{115}$. A pre-clinical application of coronary $\mathrm{CT}$ is plaque imaging. It has been reported that coronary $\mathrm{CT}$ angiography has the potential to detect coronary plaques, quantify their volumes and eventually characterise their composition ${ }^{116,117}$. However, extensive calcification has a major influence on these results, preventing adequate assessment of plaque composition in combined calcified/non-calcified plaques.

It is clear from the previous discussions that there are still questions about the future roles of both $\mathrm{CT}$ and MRI for coronary artery imaging. The evaluation of CAD by MRI or CT uses various strategies: detection of coronary calcifi- 
cations (CT), direct imaging of coronary artery stenoses (MRI or CT) and detection of reduced coronary perfusion reserve (stress ciné MRI and stress perfusion MRI) ${ }^{118}$. Both CT and MRI can be used for direct imaging of atherosclerotic lesions, measurement of atherosclerotic burden and possibly characterisation of plaque components ${ }^{119}$. Appropriate selection of patients is important for the successful application of these emerging imaging modalities.

At present both MRI and MDCT have proven to be clinically useful in the assessment of individuals with low and intermediate pre-test probability of significant CAD. Patients with high pre-test probability are best served by $\mathrm{CAG}^{118}$. For emergency patients presenting with atypical chest pain, MDCT has major advantages because it is fast and the coronary arteries can be visualised with high isotropic spatial resolution while at the same time the presence of pulmonary embolism and aortic dissection can be assessed. However, screening for coronary artery disease or the follow-up of patients is not advised since the use of iodinated contrast agents is not without risks and radiation dose is high, varying from 1.5-16.3 mSv for MDCT (compared to 3-5 mSv for conventional $\mathrm{CAG})^{120,121}$.

MRI is more favourable for screening and follow-up because of its lack of ionising radiation and the use of safer contrast agents, but it currently lacks spatial resolution. However, intrinsic contrast-resolution is higher for MRI compared to CT. This is advantageous in tissue characterisation. Another major advantage of MRI is the integration of anatomical coronary imaging in a more comprehensive cardiac examination in which cardiac morphology, global cardiac function, regional wall motion and the extent of myocardial infarction can be assessed.

\section{Conclusions}

Coronary MRI is a reliable, non-invasive and patient-friendly technique that can be used in combination with perfusion and wall motion studies to assess the presence of coronary artery anomalies, for follow-up of patients with coronary artery aneurysms as a complication of Kawasaki disease, to rule out proximal coronary artery stenoses in patients with a low and intermediate pre-test likelihood of CAD, and to detect myocardial infarction. The development of MR coronary vessel wall imaging and contrast agents targeted to plaque components will allow for fundamental in vivo insight into plaque development. Additional benefits can be expected from the transition to higher 
field-strength systems and the implementation of parallel imaging techniques in combination with dedicated coils and blood-pool contrast agents.

The authors thank M Stuber from Johns Hopkins Hospital, Baltimore, MD, USA for providing $3 \mathrm{~T}$ coronary images. Dr Leiner is a recipient of a VENI grant from the Netherlands Organisation for Scientific Research (grant 916.46.034). 


\section{References}

1. Thom T, Haase N, Rosamond W, Howard VJ, Rumsfeld J, Manolio T, Zheng ZJ, Flegal K, O'Donnell C, Kittner S, Lloyd-Jones D, Goff DC, Jr., Hong Y, Adams R, Friday G, Furie K, Gorelick P, Kissela B, Marler J, Meigs J, Roger V, Sidney S, Sorlie P, Steinberger J, Wasserthiel-Smoller S, Wilson M, Wolf P. Heart disease and stroke statistics--2006 update: a report from the American Heart Association Statistics Committee and Stroke Statistics Subcommittee. Circulation. 2006;113(6):e85-151.

2. Mackay J, Mensah GA. The atlas of heart disease and stroke. 1st ed. Geneva: World Health Organization; 2004.

3. Kim WY, Danias PG, Stuber M, Flamm SD, Plein S, Nagel E, Langerak SE, Weber OM, Pedersen EM, Schmidt M, Botnar RM, Manning WJ. Coronary magnetic resonance angiography for the detection of coronary stenoses. N Engl J Med. 2001;345(26):1863-1869.

4. Budoff MJ, Georgiou D, Brody A, Agatston AS, Kennedy J, Wolfkiel C, Stanford W, Shields $\mathrm{P}$, Lewis RJ, Janowitz WR, Rich S, Brundage BH. Ultrafast computed tomography as a diagnostic modality in the detection of coronary artery disease: a multicenter study. Circulation. 1996;93(5):898-904.

5. Runge VM. Safety of approved MR contrast media for intravenous injection. J Magn Reson Imaging. 2000;12(2):205-213.

6. Lieberman JM, Alfidi RJ, Nelson AD, Botti RE, Moir TW, Haaga JR, Kopiwoda S, Miraldi FD, Cohen AM, Butler HE, et al. Gated magnetic resonance imaging of the normal and diseased heart. Radiology. 1984;152(2):465-470.

7. Paulin S, von Schulthess GK, Fossel E, Krayenbuehl HP. MR imaging of the aortic root and proximal coronary arteries. AJR Am J Roentgenol. 1987;148(4):665-670.

8. Niendorf T, Hardy CJ, Cline H, Giaquinto RO, Grant AK, Rofsky NM, Sodickson DK. Highly Accelerated Single Breath-Hold Coronary MRA with Whole Heart Coverage Using a Cardiac Optimized 32-Element Coil Array. Paper presented at: Proceedings of the ISMRM, 13th scientific Meeting and Exhibition, 2005; Miami Beach, FL, USA.

9. Weber OM, Stuber M. Coronary Magnetic Resonance Angiography: Technical Approaches. In: Higgins CB, de Roos A, eds. MRI and CT of the cardiovascular system. 2nd ed. Philadelphia, Pennsylvania: Lippincott Williams \& Wilkins; 2006:280-298.

10. Pruessmann KP, Weiger $M$, Scheidegger MB, Boesiger P. SENSE: sensitivity encoding for fast MRI. Magn Reson Med. 1999;42(5):952-962.

11. Sodickson DK, Manning WJ. Simultaneous acquisition of spatial harmonics (SMASH): fast imaging with radiofrequency coil arrays. Magn Reson Med. 1997;38(4):591-603.

12. Griswold MA, Jakob PM, Heidemann RM, Nittka M, Jellus V, Wang J, Kiefer B, Haase A. Generalized autocalibrating partially parallel acquisitions (GRAPPA). Magn Reson Med. 2002;47(6):1202-1210.

13. Hardy CJ, Cline HE, Giaquinto RO, Niendorf T, Grant AK, Sodickson DK. 32-element receiver-coil array for cardiac imaging. Magn Reson Med. 2006;55(5):1142-1149.

14. Wintersperger BJ, Reeder SB, Nikolaou K, Dietrich O, Huber A, Greiser A, Lanz T, Reiser MF, Schoenberg SO. Cardiac CINE MR imaging with a 32-channel cardiac coil and parallel imaging: impact of acceleration factors on image quality and volumetric accuracy. J Magn Reson Imaging. 2006;23(2):222-227.

15. Gutberlet $M$, Noeske R, Schwinge K, Freyhardt P, Felix R, Niendorf T. Comprehensive cardiac magnetic resonance imaging at 3.0 Tesla: feasibility and implications for clinical applications. Invest Radiol. 2006;41(2):154-167. 
16. Bi X, Li D. Coronary arteries at 3.0 T: Contrast-enhanced magnetization-prepared threedimensional breathhold MR angiography. J Magn Reson Imaging. 2005;21(2):133-139.

17. Nayak KS, Cunningham CH, Santos JM, Pauly JM. Real-time cardiac MRI at 3 tesla. Magn Reson Med. 2004;51(4):655-660.

18. Stuber M, Botnar RM, Fischer SE, Lamerichs R, Smink J, Harvey P, Manning WJ. Preliminary report on in vivo coronary MRA at 3 Tesla in humans. Magn Reson Med. 2002;48(3):425429.

19. Sommer T, Hackenbroch M, Hofer U, Schmiedel A, Willinek WA, Flacke S, Gieseke J, Traber F, Fimmers R, Litt $H$, Schild H. Coronary MR angiography at 3.0 T versus that at $1.5 \mathrm{~T}$ : initial results in patients suspected of having coronary artery disease. Radiology. 2005;234(3):718-725.

20. Huber ME, Kozerke S, Pruessmann KP, Smink J, Boesiger P. Sensitivity-encoded coronary MRA at 3T. Magn Reson Med. 2004;52(2):221-227.

21. Waller BF, Schlant RC. Anatomy of the Heart. In: Alexander RW, Schlant RC, Fuster V, eds. Hurst's The Heart. Vol 1. 9th ed. New York: McGraw-Hill Companies; 1998:19-79.

22. Hoogeveen RM, Bakker CJ, Viergever MA. Limits to the accuracy of vessel diameter measurement in MR angiography. J Magn Reson Imaging. 1998;8(6):1228-1235.

23. Foo TKF, Ho VB, Hood MN. Vessel Tracking: Prospective Adjustment of Section-selective MR Angiographic Locations for Improved Coronary Artery Visualization over the Cardiac Cycle1. Radiology. 2000;214(1):283-289.

24. Hofman MB, Wickline SA, Lorenz $\mathrm{CH}$. Quantification of in-plane motion of the coronary arteries during the cardiac cycle: implications for acquisition window duration for MR flow quantification. J Magn Reson Imaging. 1998;8(3):568-576.

25. Fischer SE, Wickline SA, Lorenz $\mathrm{CH}$. Novel real-time R-wave detection algorithm based on the vectorcardiogram for accurate gated magnetic resonance acquisitions. Magn Reson Med. 1999;42(2):361-370.

26. Wang Y, Vidan E, Bergman GW. Cardiac Motion of Coronary Arteries: Variability in the Rest Period and Implications for Coronary MR Angiography. Radiology. 1999;213(3):751758.

27. Kim WY, Stuber M, Kissinger KV, Andersen NT, Manning WJ, Botnar RM. Impact of bulk cardiac motion on right coronary MR angiography and vessel wall imaging. J Magn Reson Imaging. 2001;14(4):383-390.

28. Botnar RM, Stuber M, Danias PG, Kissinger KV, Manning WJ. Improved coronary artery definition with T2-weighted, free-breathing, three-dimensional coronary MRA. Circulation. 1999;99(24):3139-3148.

29. Botnar RM, Stuber M, Kissinger KV, Kim WY, Spuentrup E, Manning WJ. Noninvasive coronary vessel wall and plaque imaging with magnetic resonance imaging. Circulation. 2000;102(21):2582-2587.

30. Leiner T, Katsimaglis G, Yeh EN, Kissinger KV, van Yperen G, Eggers H, Manning WJ, Botnar RM. Correction for heart rate variability improves coronary magnetic resonance angiography. J Magn Reson Imaging. 2005;22(4):577-582.

31. Vasbinder GB, Maki JH, Nijenhuis RJ, Leiner T, Wilson GJ, Kessels AG, Lemaire EE, Kaandorp DW, Ho KY, van Engelshoven JM. Motion of the distal renal artery during threedimensional contrast-enhanced breath-hold MRA. J Magn Reson Imaging. 2002;16(6):685-696.

32. Stuber M, Botnar RM, Danias PG, Kissinger KV, Manning WJ. Submillimeter Threedimensional Coronary MR Angiography with Real-time Navigator Correction: Comparison of Navigator Locations. Radiology. 1999;212(2):579-587.

33. McConnell MV, Khasgiwala VC, Savord BJ, Chen MH, Chuang ML, Edelman RR, Manning WJ. Comparison of respiratory suppression methods and navigator locations for MR coronary angiography. AJR Am J Roentgenol. 1997;168(5):1369-1375. 
34. Jahnke C, Paetsch I, Schnackenburg B, Bornstedt A, Gebker R, Fleck E, Nagel E. Coronary MR angiography with steady-state free precession: individually adapted breath-hold technique versus free-breathing technique. Radiology. 2004;232(3):669-676.

35. Evans AJ, Blinder RA, Herfkens RJ, Spritzer CE, Kuethe DO, Fram EK, Hedlund LW. Effects of turbulence on signal intensity in gradient echo images. Invest Radiol. 1988;23(7):512-518.

36. Stuber M, Botnar RM, Danias PG, Sodickson DK, Kissinger KV, Van Cauteren M, De Becker J, Manning WJ. Double-oblique free-breathing high resolution three-dimensional coronary magnetic resonance angiography. J Am Coll Cardiol. 1999;34(2):524-531.

37. Deshpande VS, Shea SM, Laub G, Simonetti OP, Finn JP, Li D. 3D magnetization-prepared true-FISP: a new technique for imaging coronary arteries. Magn Reson Med. 2001;46(3):494-502.

38. Stuber M, Botnar RM, Kissinger KV, Manning WJ. Free-breathing black-blood coronary MR angiography: initial results. Radiology. 2001;219(1):278-283.

39. Hug J, Nagel E, Bornstedt A, Schnackenburg B, Oswald H, Fleck E. Coronary arterial stents: safety and artifacts during MR imaging. Radiology. 2000;216(3):781-787.

40. Weber OM, Martin AJ, Higgins CB. Whole-heart steady-state free precession coronary artery magnetic resonance angiography. Magn Reson Med. 2003;50(6):1223-1228.

41. Li D, Paschal C, Haacke E, Adler L. Coronary arteries: three-dimensional MR imaging with fat saturation and magnetization transfer contrast. Radiology. 1993;187(2):401-406.

42. Brittain JH, Hu BS, Wright GA, Meyer CH, Macovski A, Nishimura DG. Coronary angiography with magnetization-prepared T2 contrast. Magn Reson Med. 1995;33(5):689-696.

43. Stuber M, Botnar RM, Danias PG, McConnell MV, Kissinger KV, Yucel EK, Manning WJ. Contrast agent-enhanced, free-breathing, three-dimensional coronary magnetic resonance angiography. J Magn Reson Imaging. 1999;10(5):790-799.

44. Deshpande VS, Cavagna F, Maggioni F, Schirf BE, Omary RA, Li D. Comparison of gradientecho and steady-state free precession for coronary artery magnetic resonance angiography using a gadolinium-based intravascular contrast agent. Invest Radiol. 2006;41(3):292298.

45. Fonseca CG, Nael K, Weinmann H-J, Nyborg G, Laub G, Finn JP. Cardiac Cine MRI at 3.0T: Initial Experience with Gadomer-17 in a Swine Model. Paper presented at: Proceedings of the ISMRM, 14th Scientific Meeting and Exhibition, 2006; Seattle, WA, USA.

46. Chaitman BR, Lesperance J, Saltiel J, Bourassa MG. Clinical, angiographic, and hemodynamic findings in patients with anomalous origin of the coronary arteries. Circulation. 1976;53(1):122-131.

47. Varghese A, Keegan J, Pennell DJ. Cardiovascular magnetic resonance of anomalous coronary arteries. Coron Artery Dis. 2005;16(6):355-364.

48. Bunce NH, Lorenz CH, Keegan J, Lesser J, Reyes EM, Firmin DN, Pennell DJ. Coronary artery anomalies: assessment with free-breathing three-dimensional coronary MR angiography. Radiology. 2003;227(1):201-208.

49. Post JC, van Rossum AC, Bronzwaer JG, de Cock CC, Hofman MB, Valk J, Visser CA. Magnetic resonance angiography of anomalous coronary arteries. A new gold standard for delineating the proximal course? Circulation. 1995;92(11):3163-3171.

50. McConnell MV, Ganz P, Selwyn AP, Li W, Edelman RR, Manning WJ. Identification of anomalous coronary arteries and their anatomic course by magnetic resonance coronary angiography. Circulation. 1995;92(11):3158-3162.

51. Pennell DJ, Sechtem UP, Higgins CB, Manning WJ, Pohost GM, Rademakers FE, van Rossum AC, Shaw $\mathrm{L}$, Yucel EK. Clinical indications for cardiovascular magnetic resonance (CMR): Consensus Panel report. J Cardiovasc Magn Reson. 2004;6(4):727-765.

52. Waller BF. Nonatherosclerotic coronary heart disease. In: Alexander RW, Schlant RC, Fuster V, eds. Hurst's The Heart. Vol 1. 9th ed. New York: McGraw-Hill Companies; 1998:1197-1240. 
53. Falcini F. Kawasaki disease. Curr Opin Rheumatol. 2006;18(1):33-38.

54. Burns JC, Glode MP. Kawasaki syndrome. Lancet. 2004;364(9433):533-544.

55. Kato H, Sugimura T, Akagi T, Sato N, Hashino K, Maeno Y, Kazue T, Eto G, Yamakawa R. Long-term consequences of Kawasaki disease. A 10- to 21-year follow-up study of 594 patients. Circulation. 1996;94(6):1379-1385.

56. Greil GF, Stuber M, Botnar RM, Kissinger KV, Geva T, Newburger JW, Manning WJ, Powell AJ. Coronary magnetic resonance angiography in adolescents and young adults with kawasaki disease. Circulation. 2002;105(8):908-911.

57. Mavrogeni S, Papadopoulos G, Douskou M, Kaklis S, Seimenis I, Baras P, Nikolaidou P, Bakoula C, Karanasios E, Manginas A, Cokkinos DV. Magnetic resonance angiography is equivalent to $\mathrm{X}$-ray coronary angiography for the evaluation of coronary arteries in Kawasaki disease. J Am Coll Cardiol. 2004;43(4):649-652.

58. Pennell DJ, Bogren HG, Keegan J, Firmin DN, Underwood SR. Assessment of coronary artery stenosis by magnetic resonance imaging. Heart. 1996;75(2):127-133.

59. Danias PG, Roussakis A, loannidis JP. Diagnostic performance of coronary magnetic resonance angiography as compared against conventional $\mathrm{X}$-ray angiography: a meta-analysis. J Am Coll Cardiol. 2004;44(9):1867-1876.

60. Bekkers SC, Leiner T. Images in cardiovascular medicine. Myocardial bridging. Circulation. 2006;113(9):e390-391.

61. Fitzgibbon GM, Kafka HP, Leach AJ, Keon WJ, Hooper GD, Burton JR. Coronary bypass graft fate and patient outcome: angiographic follow-up of 5,065 grafts related to survival and reoperation in 1,388 patients during 25 years. J Am Coll Cardiol. 1996;28(3):616-626.

62. Langerak SE, Vliegen HW, de Roos A, Zwinderman AH, Jukema JW, Kunz P, Lamb HJ, van Der Wall EE. Detection of vein graft disease using high-resolution magnetic resonance angiography. Circulation. 2002;105(3):328-333.

63. Porto I, Selvanayagam J, Ashar V, Neubauer S, Banning AP. Safety of magnetic resonance imaging one to three days after bare metal and drug-eluting stent implantation. Am J Cardiol. 2005;96(3):366-368.

64. Schroeder AP, Houlind K, Pedersen EM, Thuesen L, Nielsen TT, Egeblad H. Magnetic resonance imaging seems safe in patients with intracoronary stents. J Cardiovasc Magn Reson. 2000;2(1):43-49.

65. Kramer CM, Rogers WJ, Jr., Pakstis DL. Absence of adverse outcomes after magnetic resonance imaging early after stent placement for acute myocardial infarction: a preliminary study. J Cardiovasc Magn Reson. 2000;2(4):257-261.

66. Gerber TC, Fasseas P, Lennon RJ, Valeti VU, Wood CP, Breen JF, Berger PB. Clinical safety of magnetic resonance imaging early after coronary artery stent placement. J Am Coll Cardiol. 2003;42(7):1295-1298.

67. Maintz $D$, Kugel $H$, Schellhammer F, Landwehr P. In vitro evaluation of intravascular stent artifacts in three-dimensional MR angiography. Invest Radiol. 2001;36(4):218-224.

68. Buecker A, Spuentrup E, Ruebben A, Mahnken A, Nguyen TH, Kinzel S, Gunther RW. New metallic MR stents for artifact-free coronary MR angiography: feasibility study in a swine model. Invest Radiol. 2004;39(5):250-253.

69. Spuentrup E, Ruebben A, Mahnken A, Stuber M, Kolker C, Nguyen TH, Gunther RW, Buecker A. Artifact-free coronary magnetic resonance angiography and coronary vessel wall imaging in the presence of a new, metallic, coronary magnetic resonance imaging stent. Circulation. 2005;111(8):1019-1026.

70. Hundley WG, Lange RA, Clarke GD, Meshack BM, Payne J, Landau C, McColl R, Sayad DE, Willett DL, Willard JE, Hillis LD, Peshock RM. Assessment of coronary arterial flow and flow reserve in humans with magnetic resonance imaging. Circulation. 1996;93(8):15021508. 
71. Sakuma H, Higgins CB. Coronary Blood Flow Measurements. In: Higgins CB, de Roos A, eds. MRI and CT of the cardiovascular system. 2nd ed. Philadelphia, Pennsylvania: Lippincott Williams \& Wilkins; 2006:316-324.

72. Langerak SE, Vliegen HW, Jukema JW, Kunz P, Zwinderman AH, Lamb HJ, van der Wall EE, de Roos $A$. Value of magnetic resonance imaging for the noninvasive detection of stenosis in coronary artery bypass grafts and recipient coronary arteries. Circulation. 2003;107(11):1502-1508.

73. Manning WJ, Atkinson DJ, Grossman W, Paulin S, Edelman RR. First-pass nuclear magnetic resonance imaging studies using gadolinium-DTPA in patients with coronary artery disease. J Am Coll Cardiol. 1991;18(4):959-965.

74. Al-Saadi N, Nagel E, Gross M, Bornstedt A, Schnackenburg B, Klein C, Klimek W, Oswald H, Fleck E. Noninvasive detection of myocardial ischemia from perfusion reserve based on cardiovascular magnetic resonance. Circulation. 2000;101(12):1379-1383.

75. Nagel E, Klein C, Paetsch I, Hettwer S, Schnackenburg B, Wegscheider K, Fleck E. Magnetic resonance perfusion measurements for the noninvasive detection of coronary artery disease. Circulation. 2003;108(4):432-437.

76. Klem I, Heitner JF, Shah DJ, Sketch MH, Jr., Behar V, Weinsaft J, Cawley P, Parker M, Elliott M, Judd RM, Kim RJ. Improved detection of coronary artery disease by stress perfusion cardiovascular magnetic resonance with the use of delayed enhancement infarction imaging. J Am Coll Cardiol. 2006;47(8):1630-1638.

77. Glagov S, Weisenberg E, Zarins CK, Stankunavicius R, Kolettis GJ. Compensatory enlargement of human atherosclerotic coronary arteries. N Engl J Med. 1987;316(22):1371-1375.

78. Schoenhagen P, Ziada KM, Vince DG, Nissen SE, Tuzcu EM. Arterial remodeling and coronary artery disease: the concept of "dilated" versus "obstructive" coronary atherosclerosis. J Am Coll Cardiol. 2001;38(2):297-306.

79. Falk E, Shah PK, Fuster V. Coronary plaque disruption. Circulation. 1995;92(3):657-671.

80. Schoenhagen P, Ziada KM, Kapadia SR, Crowe TD, Nissen SE, Tuzcu EM. Extent and direction of arterial remodeling in stable versus unstable coronary syndromes : an intravascular ultrasound study. Circulation. 2000;101(6):598-603.

81. Corti R, Fuster V, Fayad ZA, Worthley SG, Helft G, Smith D, Weinberger J, Wentzel J, Mizsei $G$, Mercuri $M$, Badimon JJ. Lipid lowering by simvastatin induces regression of human atherosclerotic lesions: two years' follow-up by high-resolution noninvasive magnetic resonance imaging. Circulation. 2002;106(23):2884-2887.

82. Fayad ZA. Noncoronary and coronary atherothrombotic plaque imaging and monitoring of therapy by MRI. Neuroimaging Clin N Am. 2002;12(3):461-471.

83. Fayad ZA, Nahar T, Fallon JT, Goldman M, Aguinaldo JG, Badimon JJ, Shinnar M, Chesebro $\mathrm{JH}$, Fuster $\mathrm{V}$. In vivo magnetic resonance evaluation of atherosclerotic plaques in the human thoracic aorta: a comparison with transesophageal echocardiography. Circulation. 2000;101(21):2503-2509.

84. Toussaint JF, LaMuraglia GM, Southern JF, Fuster V, Kantor HL. Magnetic resonance images lipid, fibrous, calcified, hemorrhagic, and thrombotic components of human atherosclerosis in vivo. Circulation. 1996;94(5):932-938.

85. Yuan C, Beach KW, Smith LH, Jr., Hatsukami TS. Measurement of atherosclerotic carotid plaque size in vivo using high resolution magnetic resonance imaging. Circulation. 1998;98(24):2666-2671.

86. Fayad ZA, Fuster V, Fallon JT, Jayasundera T, Worthley SG, Helft G, Aguinaldo JG, Badimon $\mathrm{JJ}$, Sharma SK. Noninvasive in vivo human coronary artery lumen and wall imaging using black-blood magnetic resonance imaging. Circulation. 2000;102(5):506-510.

87. Kim WY, Stuber M, Bornert P, Kissinger KV, Manning WJ, Botnar RM. Three-dimensional black-blood cardiac magnetic resonance coronary vessel wall imaging detects positive ar- 
terial remodeling in patients with nonsignificant coronary artery disease. Circulation. 2002;106(3):296-299.

88. Desai MY, Lai S, Barmet C, Weiss RG, Stuber M. Reproducibility of 3D free-breathing magnetic resonance coronary vessel wall imaging. Eur Heart J. 2005;26(21):2320-2324.

89. Schar M, Kim WY, Stuber M, Boesiger P, Manning WJ, Botnar RM. The impact of spatial resolution and respiratory motion on MR imaging of atherosclerotic plaque. J Magn Reson Imaging. 2003;17(5):538-544.

90. Koktzoglou I, Simonetti O, Li D. Coronary artery wall imaging: initial experience at 3 Tesla. J Magn Reson Imaging. 2005;21(2):128-132.

91. Botnar RM, Stuber M, Lamerichs R, Smink J, Fischer SE, Harvey P, Manning WJ. Initial experiences with in vivo right coronary artery human MR vessel wall imaging at 3 tesla. $J$ Cardiovasc Magn Reson. 2003;5(4):589-594.

92. Cappendijk VC, Cleutjens KB, Kessels AG, Heeneman S, Schurink GW, Welten RJ, Mess WH, Daemen MJ, van Engelshoven JM, Kooi ME. Assessment of human atherosclerotic carotid plaque components with multisequence MR imaging: initial experience. Radiology. 2005;234(2):487-492.

93. Cai JM, Hatsukami TS, Ferguson MS, Small R, Polissar NL, Yuan C. Classification of human carotid atherosclerotic lesions with in vivo multicontrast magnetic resonance imaging. Circulation. 2002;106(11):1368-1373.

94. Gerretsen SC, Kooi ME, Botnar RM, Engelshoven JMAv, Leiner T. Multi-Sequence Coronary Vessel Wall MRI at 1.5T: A Feasibility Study. Paper presented at: Proceedings of the ISMRM, 13th scientific meeting and exhibition, 2005; Miami Beach, Florida, USA.

95. Botnar RM, Kim WY, Bornert P, Stuber M, Spuentrup E, Manning WJ. 3D coronary vessel wall imaging utilizing a local inversion technique with spiral image acquisition. Magn Reson Med. 2001;46(5):848-854.

96. Spuentrup E, Buecker A, Katoh M, Wiethoff AJ, Parsons EC, Jr., Botnar RM, Weisskoff RM, Graham PB, Manning WJ, Gunther RW. Molecular magnetic resonance imaging of coronary thrombosis and pulmonary emboli with a novel fibrin-targeted contrast agent. Circulation. 2005;111(11):1377-1382.

97. Botnar RM, Perez AS, Witte S, Wiethoff AJ, Laredo J, Hamilton J, Quist W, Parsons EC, Jr., Vaidya A, Kolodziej A, Barrett JA, Graham PB, Weisskoff RM, Manning WJ, Johnstone MT. In vivo molecular imaging of acute and subacute thrombosis using a fibrin-binding magnetic resonance imaging contrast agent. Circulation. 2004;109(16):2023-2029.

98. Spuentrup E, Fausten B, Kinzel S, Wiethoff AJ, Botnar RM, Graham PB, Haller S, Katoh M, Parsons EC, Jr., Manning WJ, Busch T, Gunther RW, Buecker A. Molecular magnetic resonance imaging of atrial clots in a swine model. Circulation. 2005;112(3):396-399.

99. Sirol M, Fuster V, Badimon JJ, Fallon JT, Moreno PR, Toussaint JF, Fayad ZA. Chronic thrombus detection with in vivo magnetic resonance imaging and a fibrin-targeted contrast agent. Circulation. 2005;112(11):1594-1600.

100. Ibrahim T, Maintz D, Dirschinger J, Schachoff S, Schomig A, Manning WJ, Schwaiger M, Botnar RM. Delayed Enhancement MR Coronary Vessel Wall Imaging in Patients with Suspected Coronary Artery Disease. Paper presented at: Proceedings of the ISMRM, 14th Scientific Meeting and Exhibition, 2006; Seattle, WA, USA.

101. Maintz D, Ozgun M, Hoffmeier A, Fischbach R, Kim WY, Stuber M, Manning WJ, Heindel W, Botnar RM. Selective coronary artery plaque visualization and differentiation by contrast-enhanced inversion prepared MRI. Eur Heart J. 2006.

102. Ge J, Chirillo F, Schwedtmann J, Gorge G, Haude M, Baumgart D, Shah V, von Birgelen C, Sack S, Boudoulas H, Erbel R. Screening of ruptured plaques in patients with coronary artery disease by intravascular ultrasound. Heart. 1999;81(6):621-627.

103. von Birgelen C, Klinkhart W, Mintz GS, Papatheodorou A, Herrmann J, Baumgart D, Haude $\mathrm{M}$, Wieneke $\mathrm{H}$, Ge J, Erbel R. Plaque distribution and vascular remodeling of ruptured and 
nonruptured coronary plaques in the same vessel: an intravascular ultrasound study in vivo. J Am Coll Cardiol. 2001;37(7):1864-1870.

104. Gorge G, Ge J, Haude M, Shah V, Jeremias A, Simon H, Erbel R. Intravascular ultrasound for evaluation of coronary arteries. Herz. 1996;21(2):78-89.

105. Kume T, Akasaka T, Kawamoto T, Watanabe N, Toyota E, Neishi Y, Sukmawan R, Sadahira $\mathrm{Y}$, Yoshida K. Assessment of coronary arterial plaque by optical coherence tomography. Am J Cardiol. 2006;97(8):1172-1175.

106. Huang D, Swanson EA, Lin CP, Schuman JS, Stinson WG, Chang W, Hee MR, Flotte T, Gregory K, Puliafito CA, et al. Optical coherence tomography. Science. 1991;254(5035):11781181.

107. Jang IK, Tearney GJ, MacNeill B, Takano M, Moselewski F, Iftima N, Shishkov M, Houser S, Aretz HT, Halpern EF, Bouma BE. In vivo characterization of coronary atherosclerotic plaque by use of optical coherence tomography. Circulation. 2005;111(12):1551-1555.

108. Patel NA, Stamper DL, Brezinski ME. Review of the ability of optical coherence tomography to characterize plaque, including a comparison with intravascular ultrasound. Cardiovasc Intervent Radiol. 2005;28(1):1-9.

109. Ohtani T, Ueda Y, Mizote I, Oyabu J, Okada K, Hirayama A, Kodama K. Number of yellow plaques detected in a coronary artery is associated with future risk of acute coronary syndrome: detection of vulnerable patients by angioscopy. I Am Coll Cardiol. 2006;47(11):2194-2200.

110. Thieme T, Wernecke KD, Meyer R, Brandenstein E, Habedank D, Hinz A, Felix SB, Baumann $G$, Kleber FX. Angioscopic evaluation of atherosclerotic plaques: validation by histomorphologic analysis and association with stable and unstable coronary syndromes. J Am Coll Cardiol. 1996;28(1):1-6.

111. Botnar RM, Bucker A, Kim WY, Viohl I, Gunther RW, Spuentrup E. Initial experiences with in vivo intravascular coronary vessel wall imaging. J Magn Reson Imaging. 2003;17(5):615-619.

112. Casscells W, Hathorn B, David M, Krabach T, Vaughn WK, McAllister HA, Bearman G, Willerson JT. Thermal detection of cellular infiltrates in living atherosclerotic plaques: possible implications for plaque rupture and thrombosis. Lancet. 1996;347(9013):1447-1451.

113. Stefanadis C, Diamantopoulos L, Vlachopoulos C, Tsiamis E, Dernellis J, Toutouzas K, Stefanadi E, Toutouzas P. Thermal Heterogeneity Within Human Atherosclerotic Coronary Arteries Detected In Vivo : A New Method of Detection by Application of a Special Thermography Catheter. Circulation. 1999;99(15):1965-1971.

114. Ropers D, Rixe J, Anders K, Kuttner A, Baum U, Bautz W, Daniel WG, Achenbach S. Usefulness of multidetector row spiral computed tomography with $64-\mathrm{x}$ 0.6-mm collimation and $330-\mathrm{ms}$ rotation for the noninvasive detection of significant coronary artery stenoses. Am J Cardiol. 2006;97(3):343-348.

115. Cademartiri F, Mollet NR, Feyter PJd, Krestin GP. Coronary Computed Tomography Angiography. In: Higgins $C B$, de Roos $A$, eds. MRI and CT of the cardiovascular system. 2nd ed. Philadelphia, Pennsylvania: Lippincott Williams \& Wilkins; 2006:351-360.

116. Schroeder S, Kopp AF, Baumbach A, Meisner C, Kuettner A, Georg C, Ohnesorge B, Herdeg $C$, Claussen CD, Karsch KR. Noninvasive detection and evaluation of atherosclerotic coronary plaques with multislice computed tomography. J Am Coll Cardiol. 2001;37(5):14301435.

117. Kopp AF, Schroeder S, Baumbach A, Kuettner A, Georg C, Ohnesorge B, Heuschmid M, Kuzo R, Claussen CD. Non-invasive characterisation of coronary lesion morphology and composition by multislice $\mathrm{CT}$ : first results in comparison with intracoronary ultrasound. Eur Radiol. 2001;11(9):1607-1611. 
118. Nikolaou K, Poon M, Sirol M, Becker CR, Fayad ZA. Complementary results of computed tomography and magnetic resonance imaging of the heart and coronary arteries: a review and future outlook. Cardiol Clin. 2003;21(4):639-655.

119. Fayad ZA, Fuster V, Nikolaou K, Becker C. Computed tomography and magnetic resonance imaging for noninvasive coronary angiography and plaque imaging: current and potential future concepts. Circulation. 2002;106(15):2026-2034.

120. Kuettner A, Beck T, Drosch T, Kettering K, Heuschmid M, Burgstahler C, Claussen CD, Kopp $A F$, Schroeder S. Diagnostic accuracy of noninvasive coronary imaging using 16-detector slice spiral computed tomography with $188 \mathrm{~ms}$ temporal resolution. J Am Coll Cardiol. 2005;45(1):123-127.

121. Mollet NR, Cademartiri F, Krestin GP, McFadden EP, Arampatzis CA, Serruys PW, de Feyter PJ. Improved diagnostic accuracy with 16-row multi-slice computed tomography coronary angiography. J Am Coll Cardiol. 2005;45(1):128-132. 



\title{
Chapter 4
}

\author{
Detection of coronary plaques \\ using MR coronary vessel wall \\ imaging: validation of findings with \\ intravascular ultrasound
}

S.C. Gerretsen, A.G. Kessels, P.J. Nelemans, J. Dijkstra, J.H.C. Reiber, R.J. van der Geest, M. Katoh, J. Waltenberger, J.M.A. van Engelshoven, R.M. Botnar, M.E. Kooi, T. Leiner 


\section{Abstract}

Introduction: The current standard of reference for coronary imaging, X-ray coronary angiography (CAG), is limited to visualization of the coronary lumen. Imaging of the vessel wall with MR-CVW may provide more detailed information about true plaque burden and coronary remodeling in individual subjects. The purpose of this study was to compare MR imaging of the coronary vessel wall (MR-CVW) to intravascular ultrasound (IVUS), the standard of reference for coronary vessel wall imaging, with regard to plaque detection and wall thickness measurements.

Methods: In this prospective study 17 patients (15M, 2F, mean age 60.1 yrs) with chest pain referred for CAG were included. All patients underwent both IVUS and MR-CVW imaging of the right coronary artery (RCA). Subsequently the proximal and middle parts of the RCA coronary vessel wall were analyzed for the presence and location of coronary plaques.

Results: In total, 52 matching RCA regions of interest were available for comparison. There was good visual agreement between IVUS and MR-CVW for qualitative assessment of presence of disease, with sensitivity of $94 \%$ and specificity of $76 \%$. Absolute wall thickness measurements demonstrated a significant difference between measured mean wall thickness on IVUS and MR-CVW ( 0.48 vs $1.24 \mathrm{~mm}, p<0.001$ ), but a large heterogeneity between wall thickness measurements resulting in a low correlation between IVUS and MRCVW.

Conclusion: MR-CVW is able to accurately detect coronary vessel wall thickening in the RCA when compared to IVUS although there is a low correlation between both modalities in terms of absolute wall thickness measurements. 


\section{Introduction}

Detection of atherosclerotic plaque can be helpful in individual risk assessment, prevention and treatment of complications of atherosclerosis. For imaging of coronary artery disease (CAD), the current standard of reference is invasive $\mathrm{X}$-ray coronary angiography (CAG). This technique is able to image the coronary arteries with high spatial resolution but is limited to assessment of the coronary lumen. The vessel wall is not visualized with CAG and plaque burden is often underestimated since positive or outward remodeling precedes the development of angiographically detectable stenosis ${ }^{1,2}$. Positive remodeling refers to a focal compensatory increase in vessel size, due to expansion of the internal elastic lamina, without narrowing of the lumen in response to increasing plaque burden ${ }^{1,3,4}$. A study by Schoenhagen et al. found that positive remodeling and larger plaque areas are associated with unstable clinical presentation ${ }^{3}$, showing that complications of atherosclerotic plaques can arise in vessels without a hemodynamically significant stenosis. These findings suggest a potential role for imaging of the coronary vessel wall as a novel tool to improve risk stratification by non-invasive identification of coronary plaques.

The current standard of reference for in-vivo visualization of coronary vessel wall abnormalities is intravascular ultrasonography (IVUS). At present, IVUS is the most accurate and widely used imaging modality for assessment of coronary vessel wall geometry in patients, but it is an invasive and costly technique that is not suitable for screening asymptomatic subjects.

Because of its non-invasiveness and the ability to visualize and distinguish soft tissues, magnetic resonance imaging (MRI) has emerged as a potential alternative to IVUS for imaging of the arterial vessel wall ${ }^{5,6}$. Due to its lack of ionizing radiation, MRI is well-suited for serial imaging, offering the possibility to monitor the effect of pharmacologic intervention on plaques ${ }^{7,8}$. Previous studies have demonstrated the capability of MRI to visualize the coronary vessel wall with high spatial resolution as well as vessel wall thickening and positive remodeling in patients ${ }^{9,10}$. Despite these encouraging results it remains unclear if and to what extent changes found with MR coronary vessel wall imaging (MR-CVW) accurately reflect true underlying coronary wall thickening. 
The aim of this study was to investigate the ability of MR-CVW to accurately detect right coronary artery (RCA) wall thickening and positive remodeling in comparison to the established standard of reference, IVUS.

\section{Methods}

\section{Subjects}

Consecutive patients with symptoms of chest pain who were referred for CAG were included in this study if they were older than 18 years and after giving informed consent. Exclusion criteria were hemodynamic instability, severe arrhythmia and contra-indications for MRI. Approval of the institutional review board was obtained prior to the start of this study.

\section{MR Imaging protocol}

All scans were performed on a clinical 1.5 T system (Intera, Release 11.1 Philips Medical Systems, Best, The Netherlands) using a dedicated 5-element phased-array cardiac coil. Subjects were examined in the supine position. First, localizing scans were obtained and the subject specific trigger delay and acquisition window were determined. These scans were followed by coronary MR angiography (CMRA) of the RCA. The imaging plane through the RCA was determined by a 3-point plan scan tool, resulting in targeted, longitudinal visualization of the entire RCA in a double oblique plane. For CMRA we used a bright blood balanced steady state free precession (bSSFP) sequence (TR/TE/FA: $6.2 / 3.1 / 120^{\circ}$, in-plane spatial resolution: $0.98 \times 0.98$ and slice thickness $3 \mathrm{~mm}$ ). In the same orientation, a coronary vessel wall scan was acquired with a proton density weighted 3D fast gradient echo sequence employing radial k-space sampling. A localized double inversion recovery (DIR) prepulse, as previously published ${ }^{10,11}$, was used to visualize the coronary wall. In brief, imaging parameters for the vessel wall scan were: Data acquisition: every other heartbeat, TR: $8.0 \mathrm{~ms}$, TE: $2.0 \mathrm{~ms}$, flip angle: $30^{\circ}$, field of view: $300 \times 300 \mathrm{~mm}$, matrix: $384 \times 384$. The resulting acquired in-plane spatial resolution was $0.78 \times 0.78 \mathrm{~mm}$ with a slice thickness of $3 \mathrm{~mm}$. Subsequently, slices were interpolated to $1.5 \mathrm{~mm}$. SPIR was used for fat suppression. For reduction of cardiac motion artefacts, cardiac triggering was used and images were acquired in mid-diastole. To prevent respiratory motion artifacts during this free-breathing acquisition, navigator gating was used to select end-expiratory 
data. Scan duration was approximately 8.9 minutes excluding navigator efficiency at a heart rate of 65 beats per second.

\section{IVUS imaging protocol}

After performing CAG of the RCA, IVUS imaging was performed in the same vessel after administration of $0.2 \mathrm{mg}$ intracoronary nitroglycerin. A commercially available IVUS imaging console (Galaxy 2, Boston Scientific, California, USA) and a $40 \mathrm{MHz}$ catheter (Atlantis SR Pro, Boston scientific) were used. Images were acquired during continuous pullback at a speed of $0.5 \mathrm{~mm} / \mathrm{s}$ with 30 frames per second.

\section{Image analysis}

For analysis purposes the RCA was divided into three segments according to the American Heart Association classification ${ }^{12}$. Only the proximal and middle segments of the RCA (segments 1 and 2) were analyzed. In these two segments four regions of interest (ROIs) were defined in consensus by 2 observers who were blinded to IVUS results. In both the anterior and posterior vessel wall one ROI per segment was identified (figure 1). Due to tortuousity of the coronary arteries and performing measurements on source images instead of multiplanar reformats to prevent reconstruction errors, multiple short ROIs were delineated. Thickened as well as non-thickened parts of the vessel wall were included to ensure a mix of diseased and non-diseased ROIs. After selection of ROls in the MR-CVW datasets, one observer independently matched the MR images with the IVUS datasets using dedicated viewing and analysis software for the IVUS (QCU-CMS, (Leiden University Medical Center, Department of Radiology, Division of Image Processing, Leiden, The Netherlands, in cooperation with MEDIS $^{13}$ ) and MR datasets (VesselMASS, Leiden University Medical Center, Department of Radiology, Division of Image Processing, Leiden, The Netherlands ${ }^{14}$ ), which allow for rotational display of stretches vessel wall views of both the IVUS and MR-CVW images of the RCA. Due to the anisotropic resolution of MR-CVW, reconstructed axial MR-CVW images are not suited for analysis and therefore a stretched view of the IVUS data was reconstructed and compared to the longitudinal MR-CVW data for matching purposes. Matching was performed by visual comparison of regions with and without wall thickening followed by measuring the distance of the ROI to landmarks like the ostium of the RCA and the nearest bifurcation points (side 
branches) on both MRI and IVUS to be sure that the same area of the vessel was included (figure 2).
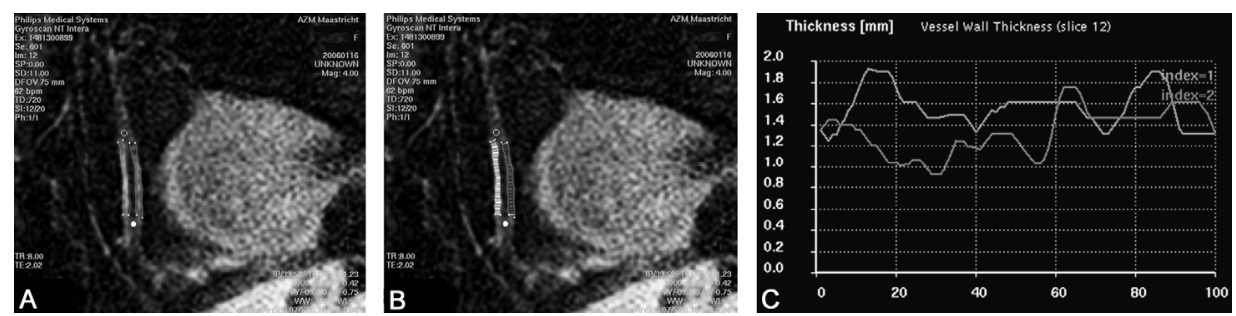

Figure 1. Measurement of vessel wall thickness on source images. The anterior and posterior vessel walls are delineated as separate ROIs in segment 2 of the right coronary artery $(A)$. In each ROI 100 measurements are made of the anterior (yellow) and posterior (red) wall thickness (B). The custom made software program calculates wall thickness over the entire length of the measured ROls for the anterior (index 1) and posterior (index 2) vessel wall (C).
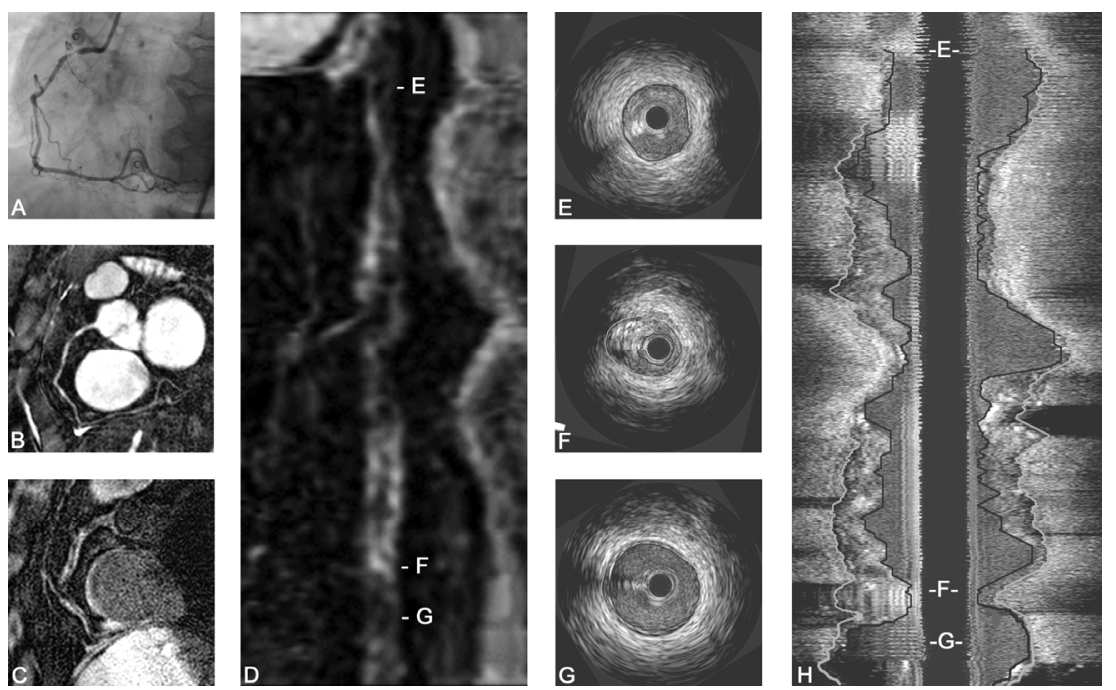

Figure 2. 61 y/o female with stable angina. X-ray angiography (A) and coronary MRA (B) demonstrate high grade stenosis in the proximal RCA. C) corresponding MR vessel wall scan demonstrate several area's with vessel wall thickening and high signal intensity. E (distal RCA), F (diseased area) and G (proximal RCA) are cross-sectional IVUS images and refer to the corresponding area's as shown on stretched MPR of the vessel wall scan (D) and the longitudinal IVUSreformat $(\mathrm{H})$. $\mathrm{F}$ is the area of maximum stenosis.

Each ROI in the MR images was analyzed by 2 observers in consensus regarding the presence of disease. Because of anticipated differences between absolute vessel wall thickness and measured wall thickness due to limitations in spatial resolution of MR-CVW, regions of interest were visually compared to 
the rest of the vessel wall. A ROI was considered 'diseased' if there was focal vessel wall thickening or clearly increased signal intensity as well as corresponding luminal narrowing compared to adjacent, regularly delineated segments. If there was no luminal narrowing but the vessel wall was thickened compared to the adjacent vessel wall, the ROI was classified as "positive remodeling" and therefore also classified as a diseased segment. ROIs with normal lumen diameter compared to the rest of the vessel and with a vessel wall that had no areas of focal wall thickening or focal high signal intensity, were classified as "not diseased". The probability of disease in the MR-CVW images was scored using the following 5-point scale: $5=$ certainly diseased, 4 = probably diseased, 3 = uncertain, 2 = probably not diseased, 1 = certainly not diseased. On IVUS images, the high spatial resolution allows for more accurate quantification of vessel wall thickness. A ROI was classified as normal if there was no intimal thickening or intimal thickening less than $0.3 \mathrm{~mm}$. A segment was classified as "diseased" on IVUS if there was visible plaque or wall thickening more than $0.3 \mathrm{~mm}^{15}$.

Quantitative evaluation of the MR images of the RCA vessel wall was performed with the custom made software package VesselMASS. In the predefined ROIs, the inner and outer borders of the vessel wall were manually delineated. To avoid errors in thickness measurement due to reconstruction errors, only source images were used for measurements. For each ROI, minimal, maximal and mean vessel wall thickness of the right coronary vessel wall were measured.

Quantitative analysis of IVUS images was performed in QCU-CMS and consisted of offline measurement of minimal, mean and maximal vessel wall thickness in each ROI on axial source images after choosing the correct radial through the vessel.

\section{Statistical analysis}

Statistical analysis was performed with SPSS 15 for Windows (SPSS Inc, Chicago, IL, USA). Sensitivity, specificity, negative predictive value (NPV) and positive predictive value (PPV) were calculated based on the final diagnosis on MRI using IVUS as the standard of reference. Sensitivity and specificity for different degrees of certainty for diagnosing the presence of disease on MRCVW were compared to the final diagnosis on IVUS, and visualized using receiver operating characteristic (ROC) curve analysis and the corresponding area under the curve (AUC). In addition, mean wall thickness as measured in matched ROIs at MR-CVW and IVUS was compared using the paired samples t- 
test. The relationship between measurements with both techniques were evaluated with linear regression analysis and visualized with Bland Altman and scatterplots. Significance was established at a $p$ value of less than 0.05 .

\section{Results}

Of the 23 patients enrolled in this study, evaluable IVUS and MR images were obtained in 17 patients. Six out of 23 patients were excluded from analysis because of unexpected claustrophobia and therefore inability to undergo MRI $(n=2)$, withdrawal from the study after MRI but before IVUS $(n=2)$, difficulties to perform IVUS $(n=1)$ or inability to delineate the coronary vessel wall with certainty on MR-CVW due to higher signal intensity of the surrounding tissue, probably due to insufficient fat suppression $(n=1)$. Demographic data and known risk factors of the remaining 17 patients are summarized in table 1. No data about coronary calcium score was available for our subjects. MRI and IVUS were performed in random order, with a mean interval of $12 \pm 10$ days (range: 1-30 days).

CAG revealed significant stenoses $(\geq 50 \%)$ in the proximal and mid RCA of six subjects, one subject had a significant stenosis in the distal RCA, 7 subjects had non-significant $(<50 \%)$ stenoses in the RCA and 3 subjects had no angiographically visible stenoses in the RCA. Five out of these 7 subjects with non-significant stenoses in the RCA underwent percutaneous intervention of lesions in the left anterior descending or circumflex artery.

Table 1. Patient characteristics.

\begin{tabular}{ll}
\hline & $\begin{array}{l}\text { Evaluable patients } \\
(\mathrm{N}=17)\end{array}$ \\
\hline characteristics & $15(88)$ \\
Male sex, $\mathrm{n}(\%)$ & $60.12(9.06)$ \\
Age, $\mathrm{y}( \pm \mathrm{SD})$ & $6(35)$ \\
$\geq 50 \%$ stenosis in proximal and mid RCA, $\mathrm{n}(\%)$ & $83.47(12.89)$ \\
Weight, kg ( $\pm \mathrm{SD})$ & $134(11.03)$ \\
Systolic blood pressure, mm Hg ( $\pm \mathrm{SD})$ & $77(9.94)$ \\
Diastolic blood pressure, mm Hg ( $\pm \mathrm{SD})$ & $1(5.9)$ \\
Diabetes, $\mathrm{n}(\%)$ & $4(24)$ \\
Current smoker, $\mathrm{n}(\%)$ & $9(59)$ \\
Hypertension, $\mathrm{n}(\%)$ & $16(94)$ \\
Cholesterol lowering medication, $\mathrm{n}(\%)$ &
\end{tabular}

Patient characteristics of the 17 patients with evaluable images. 
In the included patients, the proximal, middle and often the distal part of the RCA were visualized on the MR-CVW scan. As explained above, multiple short vessel wall segments in the proximal and middle RCA were used for analysis since only short ROIs could be delineated per slice. Not all of the $68(17 \times 4)$ potential ROIs could be analyzed because there was a discrepancy between IVUS and MR-CVW in the number of available ROIs. In 8 patients, less than 4 ROIs were available on MR-CVW due to the inability to distinguish the vessel wall from the lumen ( $n=6$, all distally located in the middle RCA segments) or surrounding tissue $(n=2)$. In addition, IVUS pullback distance was sometimes shorter than the visualized vessel wall on MR-CVW due to inability to insert the IVUS catheter deep enough in the RCA beyond a severe stenosis or tortuousity of the RCA ( $n=3)$, and in some patients the origin of the RCA was not well visualized on IVUS due to the need to insert the guiding catheter into the origin ( $n=3)$. In the 17 subjects in whom both MR-CVW and IVUS were available a comparison between IVUS and MR-CVW was eventually performed in 52 matched ROls located in the proximal and middle RCA, consisting of both diseased and non-diseased segments. The mean length per ROI was $10.6 \pm 2.6$ $\mathrm{mm}$ (range $6.2-18.5 \mathrm{~mm}$ ). In figure 2 results are shown of a patient with stenosis of the proximal RCA.

ROC Curve

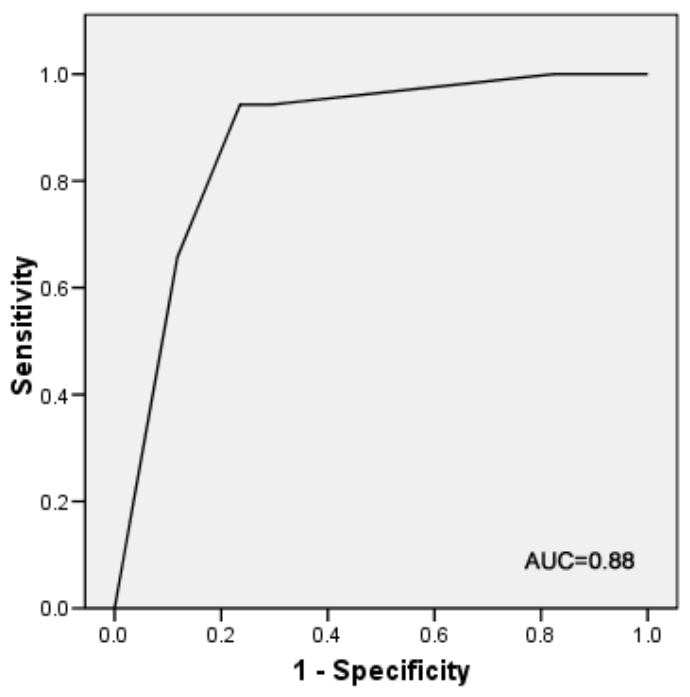

Figure 3. Receiver operating characteristic (ROC) curve. ROC curve for different degrees of certainty for diagnosing the presence of disease. The area under the curve (AUC) is 0.88 . 
Based on MRI, 15/52 (29\%) segments were classified as normal and 37/52 (71\%) as diseased. On IVUS, 17/52 ROIs (33\%) were classified as normal, and $35 / 52$ ROIs (67\%) were classified as diseased. Based on IVUS, there was only one patient completely free of vessel wall thickening in all visualized segments. There was good agreement between MR-CVW and IVUS with regard to the assessment of disease. Based on qualitative assessment of presence of disease, sensitivity was $94 \%$, specificity was $77 \%$, NPV was $87 \%$ and PPV was $89 \%$. The ROC-curve demonstrated an AUC of 0.88 (95\% $\mathrm{Cl} 0.76-0.99$; figure $3)$. In all subjects with significant stenoses in the proximal and middle RCA as demonstrated by CAG, the lesion was also visualized with both IVUS and MRI.

There was disagreement between IVUS and MR-CVW with regard to the presence of disease in 6/52 vessel wall segments (12\%). MR-CVW was false negative in 2 ROIs, and false positive in 4 ROIs. Comparison of IVUS and MRCVW images demonstrated heavy calcification of the coronary vessel wall in the 2 false negative ROIs (in the same patient), with preservation of normal lumen diameter. The four false positive ROls that were seen (3 patients) had mild intima hyperplasia at IVUS with a thickness of less than $0.3 \mathrm{~mm}$ in 2 ROIs and normal vessel wall thickness in the other 2 ROIs.

Results of vessel wall thickness measurements are listed in table 2 . With IVUS a significantly lower vessel wall thickness was found when compared to MR-CVW (0.48 vs $1.24 \mathrm{~mm}, \mathrm{p}<0.001)$. There was large heterogeneity between the different measurements resulting in a low $R^{2}$ value of 0.17 (figure 4). Bland Altman analysis demonstrated that the heterogeneity of measurements was independent of average vessel wall thickness (figure 4). However, there was a significant difference in vessel wall thickness between segments classified as normal versus segments classified as diseased on both MR-CVW (1.07 vs $1.32 \mathrm{~mm}, \mathrm{p}=0.004$ ) and IVUS (0.27 vs $0.59 \mathrm{~mm}, \mathrm{p}<0.001)$.

Table 2. Wall thickness measurements.

\begin{tabular}{lllll}
\hline & $\begin{array}{l}\text { Overall } \\
(\mathrm{N}=52)\end{array}$ & $\begin{array}{l}\text { diseased ROI's } \\
(\mathrm{N}=35)\end{array}$ & $\begin{array}{l}\text { normal ROI's } \\
(\mathrm{N}=17)\end{array}$ & $\begin{array}{l}\mathrm{P} \text { (normal vs } \\
\text { diseased) }\end{array}$ \\
\hline MR-CVW (mm ( $\pm \mathrm{SD}))$ & $1.24( \pm 0.30)$ & $1.32( \pm 0.30)$ & $1.07( \pm 0.22)$ & 0.004 \\
IVUS (mm ( $\pm \mathrm{SD}))$ & $0.48( \pm 0.25)$ & $0.59( \pm 0.22)$ & $0.27( \pm 0.14)$ & $<0.001$ \\
Ratio (MR / IVUS) & $3.3( \pm 1.89)$ & $2.6( \pm 1.25)$ & $4.9( \pm 2.1)$ & $<0.001$ \\
$\mathrm{p}$ & $<0.001$ & $<0.001$ & $<0.001$ & \\
\hline
\end{tabular}

Mean vessel wall thickness ( $\mathrm{mm}( \pm \mathrm{SD})$ ) in 52 matched regions of interest (ROI's) as measured on coronary vessel wall MRI (MR-CVW) and intravascular ultrasound (IVUS) and divided in diseased and normal ROI's. 

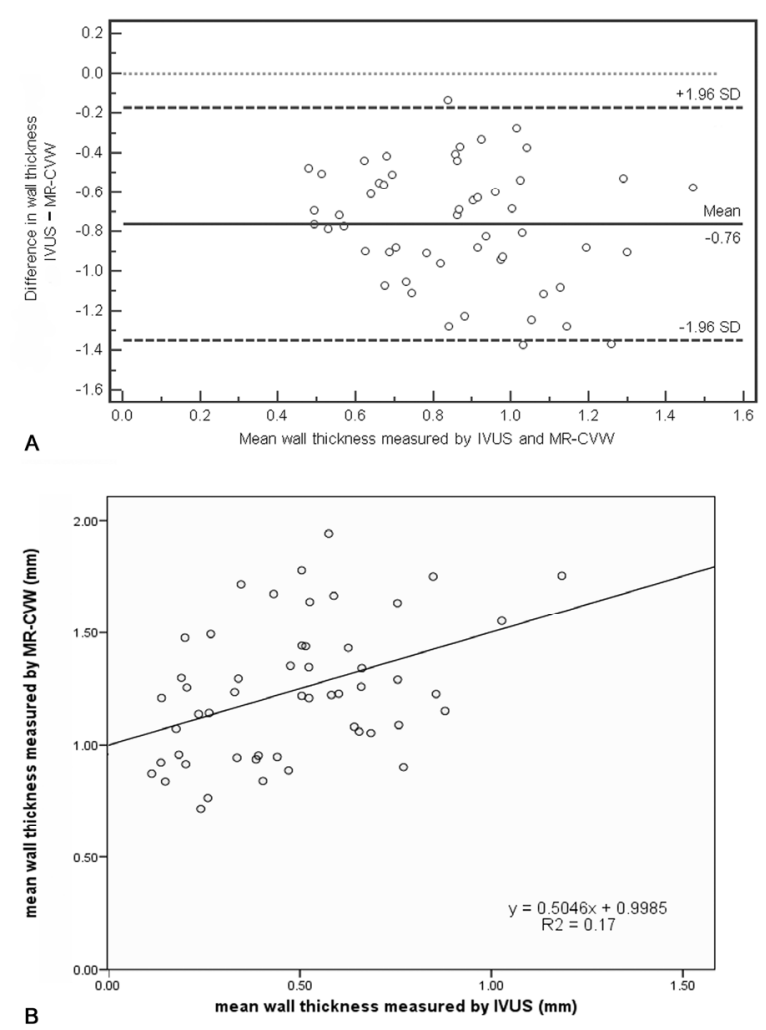

Figure 4. Correlation of coronary vessel wall thickness measurements. Bland Altman plot (A) and scatterplot (B) for coronary vessel wall thickness as measured on intravascular Ultrasound (IVUS) and the MR coronary vessel wall scan (MR-CVW). There is a large heterogeneity of wall thickness measurements when IVUS is compared to MR-CVW, resulting in a low correlation coefficient $\left(R^{2}=0.17\right)$.

\section{Discussion}

In the current study we found that MR-CVW imaging is able to detect focal coronary artery vessel wall thickening with high accuracy compared to the established standard of reference IVUS. Both positive remodeling as well as wall thickening associated with coronary stenosis could reliably be detected with MR-CVW, although the accuracy of absolute quantification of wall thickness is limited by the lower spatial resolution of MRI.

Vessel wall imaging is an area of research that has attracted intense interest over the past few years. MRI was first used to visualize the carotid and aortic vessel wall ${ }^{5,6,16}$. With improvements in MR hardware and sequences, 
imaging of the coronary vessel wall became feasible ${ }^{9,10}$. Coronary artery disease is the leading cause of mortality and morbidity in the western world ${ }^{17}$, and prevention of its complications is of great importance. The ultimate aim of imaging the vessel wall is detection and subsequent preventive treatment of relevant lesions prior to the development of symptoms due to atherothrombosis. Risk assessment scores like PROCAM ${ }^{18}$ or Framingham ${ }^{19}$ give an indication of risk for complications due to atherosclerosis, but these risks are based on population level rather than on an individual basis.

To our knowledge, this is the first study to demonstrate that atherosclerotic changes in the vessel wall as seen with MR-CVW accurately mirror the findings as obtained with the established standard of reference, IVUS. Although 17 subjects is a limited amount of subjects, we analyzed multiple segments per subject and we believe that the segment-by-segment analysis from this pilot study gives a good impression about the possibilities and limitations of MR-CVW compared to IVUS. Due to time constraints we limited imaging to the RCA. However, MR-CVW can also be performed in the $L A D^{11}$. Furthermore, MR-CVW is not only capable of detecting advanced atherosclerosis, but also early stages of the disease process such as positive remodeling.

Despite the capability to accurately identify segments of the coronary wall that harbored disease, we found a low correlation between absolute measurements of vessel wall thickness. Presumably due to limitations in spatial resolution of MRI we found a systematic overestimation of wall thickness by MR-CVW compared to IVUS. A thickness of the intima-media complex smaller than $0.3 \mathrm{~mm}$ is suggested as an empirical arbitrary cut-off to distinguish between atherosclerotic plaque and mild physiological intimal thickening ${ }^{15}$. This value of $0.3 \mathrm{~mm}$ at IVUS was used as the cutoff value to distinguish diseased from non-diseased coronary artery segments. The in-plane spatial resolution of the MR vessel wall sequence as used in our study was $0.78 \mathrm{~mm}$. According to physics, the minimal distance between two points which can be visually distinguished at full width at half maximum (FWHM) is 2 times the pixel distance, in our study this would be $1.6 \mathrm{~mm}$. Therefore, with currently used spatial resolution, small changes in wall thickness as found by IVUS cannot accurately be distinguished by measuring wall thickness on MR-CVW but are probably distinguished by changes in pixel intensity due to partial volume effects. Due to the non-isotropic voxel size and the chosen imaging plane, these partial volume effects are mostly encountered in the slice-direction. In figure 4, it can be seen that the mean overestimation of MR-CVW versus IVUS is approximately $0.8 \mathrm{~mm}$, i.e. one pixel width. It is likely that studies using opti- 
mized protocols, axial imaging planes or high field MR-systems would demonstrate better results. However, in our study we chose for large coverage of the RCA and we validated the most commonly used technique for coronary vessel wall imaging. Despite the limited spatial resolution of this technique, MR-CVW was still capable of detecting thickened coronary vessel wall by using qualitative evaluation of vessel wall characteristics such as identification of areas with a focal increase in signal intensity, or focal wall thickening, as demonstrated by the good agreement in detection of wall thickening between MRCVW and IVUS.

Apart from the lower spatial resolution there are other potential reasons that could have caused the discrepancies that were found between MR-CVW imaging and IVUS. In this study, there was a difference in the layers of the vessel wall that were included in the measurement. On IVUS, only intimathickness was measured. With the current spatial resolution of MR-CVW, different vessel wall layers cannot be distinguished. Measurement of wall thickness on MRI therefore includes intima, media and adventitia. Secondly, matching of images was challenging, mainly because of difficulties in identifying the best matching longitudinal cross-section on IVUS for the ROIs drawn on MR-CVW and also due to some distortions of the RCA on IVUS, which was caused by the presence of an intravascular catheter and rotation of the IVUS catheter in the vessel due to vessel curvature. To minimize errors, we correlated the position of the ROIs to the origin of the RCA and the position of side branches. In our study, only vessel wall thickness was measured on both IVUS and MRI. For future studies, plaque area or volume as measured on axial MR images instead of wall thickness measurements on longitudinal images might be a more accurate representation of plaque burden. Furthermore the use of axial MR-CVW imaging decreases the chance for matching-errors due to partial volume effects in the slice encoding direction. However, this implies that the currently used, relatively fast longitudinal MR-CVW should be changed to a more time consuming axial vessel wall scan, which limits the area of the coronary artery that can be covered in the same imaging time. For instance, axial imaging was performed in a large cohort in the Multi-Ethnic Study of Atherosclerosis (MESA) ${ }^{20}$ although in that study only the proximal portions of the main coronary arteries were analyzed due to time constraints, and only a maximum of 7 slices were acquired per patient.

Thirdly, we used a double inversion recovery technique to suppress blood in the RCA. This technique is flow dependent, and in the present study, only the blood in the proximal and middle parts could reliably be suppressed on 
MR-CVW. Inadequate suppression of (slow-flowing) blood at the lumen-vessel wall interface might be the cause of overestimation of wall thickness in the four false positive vessel segments. As expected this phenomenon occurred mostly in the non-proximal parts of the RCA (3/4 cases). Finally, calcification of the vessel wall can lead to underestimation of wall thickness or even the inability to visualize the vessel wall in heavily calcified vessel walls, since calcification has a very low signal intensity on MR-sequences ${ }^{16,21}$. In our study we encountered 2 false negative ROIs on MR-CVW, corresponding IVUS images demonstrated calcification of the vessel wall with preservation of the lumen. However, in other calcified ROIs as seen with IVUS, there was agreement between IVUS and MR-CVW. Thus, a pitfall for MR-CVW would be the presence of calcified plaque, especially in an area with positive remodeling. However, the presence of (heavily) calcified plaques in the coronary vessel wall also causes artefacts in IVUS and in Computed Tomography (CT), thereby decreasing the ability for analysis of plaques and, especially in $\mathrm{CT}$, the degree of stenosis ${ }^{22,23}$.

Although the main goal of our study was to validate the MR-CVW technique by comparing it to the standard of reference IVUS, it must be mentioned that $\mathrm{CT}$ is more widely available for patient care and in recent studies good results were reported for detection of coronary artery disease ${ }^{24,25}$. One of the main advantages of $\mathrm{CT}$ is that scan time is very short, which allows for fast assessment of the whole coronary artery tree instead of only the RCA. CT correlates better to IVUS than MR-CVW, which is probably related to differences in spatial resolution $\left(0.4 \times 0.4 \times 0.4 \mathrm{~mm}\right.$ in $\mathrm{CT}^{26}$ versus $0.8 \times 0.8 \times 3 \mathrm{~mm}$ in MR-CVW in the current study). However, there was still some disagreement between measurements on CT and IVUS with both overestimation and underestimation of plaque volumes, lumen and vessel diameters on CT depending on plaque composition (calcified versus non-calcified plaques) and scan parameters ${ }^{27-29}$. In addition, although reported radiation doses in the literature vary greatly depending on the technique that was used, from $1 \mathrm{mSv}$ to even more than $20 \mathrm{mSv}^{30,31}$, radiation dose has decreased with newer CT techniques $^{32}$ But even with low radiation dose, CT still exposes patients to ionizing radiation and iodinated contrast agents, both of which make $\mathrm{CT}$ less attractive for serial imaging, in young or asymptomatic patients and patients with allergies for iodinated contrast agents. MRI can safely be used in these cases. Since cardiac MRI already is the standard of reference for measurements of cardiac function or detection of scar tissue after myocardial infarction, incorporation of coronary lumen and vessel wall sequences in current cardiac protocols 
could lead to a comprehensive cardiac and coronary evaluation in one examination.

\section{Conclusion}

This study demonstrated the ability of MR-CVW to accurately detect coronary vessel wall thickening in the RCA when compared to IVUS, the standard of reference for coronary vessel wall imaging. However, MR-CVW systematically overestimates absolute coronary vessel wall thickness.

\section{Acknowledgements}

The authors would like to thank Boston scientific Nederland B.V. for their training in and assistance with acquiring the IVUS-images. Furthermore we would like to thank all interventional cardiologists working in the Maastricht University Medical Center, for their assistance with IVUS procedures. 


\section{References}

1. Glagov S, Weisenberg E, Zarins CK, Stankunavicius R, Kolettis GJ. Compensatory enlargement of human atherosclerotic coronary arteries. N Engl J Med. 1987;316(22):1371-1375.

2. Libby P. Inflammation in atherosclerosis. Nature. 2002;420(6917):868-874.

3. Schoenhagen P, Ziada KM, Kapadia SR, Crowe TD, Nissen SE, Tuzcu EM. Extent and direction of arterial remodeling in stable versus unstable coronary syndromes : an intravascular ultrasound study. Circulation. 2000;101(6):598-603.

4. Losordo DW, Rosenfield K, Kaufman J, Pieczek A, Isner JM. Focal compensatory enlargement of human arteries in response to progressive atherosclerosis. In vivo documentation using intravascular ultrasound. Circulation. 1994;89(6):2570-2577.

5. Fayad ZA, Nahar T, Fallon JT, Goldman M, Aguinaldo JG, Badimon JJ, Shinnar M, Chesebro $\mathrm{JH}$, Fuster $\mathrm{V}$. In vivo magnetic resonance evaluation of atherosclerotic plaques in the human thoracic aorta: a comparison with transesophageal echocardiography. Circulation. 2000;101(21):2503-2509.

6. Yuan C, Beach KW, Smith LH, Jr., Hatsukami TS. Measurement of atherosclerotic carotid plaque size in vivo using high resolution magnetic resonance imaging. Circulation. 1998;98(24):2666-2671.

7. Corti R, Fuster V, Fayad ZA, Worthley SG, Helft G, Smith D, Weinberger J, Wentzel J, Mizsei $G$, Mercuri M, Badimon JJ. Lipid lowering by simvastatin induces regression of human atherosclerotic lesions: two years' follow-up by high-resolution noninvasive magnetic resonance imaging. Circulation. 2002;106(23):2884-2887.

8. Adams GJ, Greene J, Vick GW, 3rd, Harrist R, Kimball KT, Karmonik C, Ballantyne CM, Insull $\mathrm{W}$, Jr., Morrisett JD. Tracking regression and progression of atherosclerosis in human carotid arteries using high-resolution magnetic resonance imaging. Magn Reson Imaging. 2004;22(9):1249-1258.

9. Botnar RM, Stuber M, Kissinger KV, Kim WY, Spuentrup E, Manning WJ. Noninvasive coronary vessel wall and plaque imaging with magnetic resonance imaging. Circulation. 2000;102(21):2582-2587.

10. Kim WY, Stuber M, Bornert P, Kissinger KV, Manning WJ, Botnar RM. Three-dimensional black-blood cardiac magnetic resonance coronary vessel wall imaging detects positive arterial remodeling in patients with nonsignificant coronary artery disease. Circulation. 2002;106(3):296-299.

11. Botnar RM, Kim WY, Bornert P, Stuber M, Spuentrup E, Manning WJ. 3D coronary vessel wall imaging utilizing a local inversion technique with spiral image acquisition. Magn Reson Med. 2001;46(5):848-854.

12. Austen WG, Edwards JE, Frye RL, Gensini GG, Gott VL, Griffith LS, McGoon DC, Murphy $\mathrm{ML}$, Roe BB. A reporting system on patients evaluated for coronary artery disease. Report of the Ad Hoc Committee for Grading of Coronary Artery Disease, Council on Cardiovascular Surgery, American Heart Association. Circulation. 1975;51(4 Suppl):5-40.

13. Dijkstra J, Koning G, Reiber JH. Quantitative measurements in IVUS images. Int J Card Imaging. 1999;15(6):513-522.

14. Adame IM, van der Geest RJ, Wasserman BA, Mohamed MA, Reiber JH, Lelieveldt BP. Automatic segmentation and plaque characterization in atherosclerotic carotid artery MR images. Magma. 2004;16(5):227-234.

15. Di Mario C, Gorge G, Peters R, Kearney P, Pinto F, Hausmann D, von Birgelen C, Colombo A, Mudra $\mathrm{H}$, Roelandt J, Erbel R. Clinical application and image interpretation in intracoronary ultrasound. Study Group on Intracoronary Imaging of the Working Group of 
Coronary Circulation and of the Subgroup on Intravascular Ultrasound of the Working Group of Echocardiography of the European Society of Cardiology. Eur Heart J. 1998;19(2):207-229.

16. Toussaint JF, LaMuraglia GM, Southern JF, Fuster V, Kantor HL. Magnetic resonance images lipid, fibrous, calcified, hemorrhagic, and thrombotic components of human atherosclerosis in vivo. Circulation. 1996;94(5):932-938.

17. Rosamond W, Flegal K, Furie K, Go A, Greenlund K, Haase N, Hailpern SM, Ho M, Howard V, Kissela B, Kittner S, Lloyd-Jones D, McDermott M, Meigs J, Moy C, Nichol G, O'Donnell C, Roger V, Sorlie P, Steinberger J, Thom T, Wilson M, Hong Y. Heart disease and stroke statistics--2008 update: a report from the American Heart Association Statistics Committee and Stroke Statistics Subcommittee. Circulation. 2008;117(4):e25-146.

18. Assmann G, Cullen P, Schulte H. Simple scoring scheme for calculating the risk of acute coronary events based on the 10-year follow-up of the prospective cardiovascular Munster (PROCAM) study. Circulation. 2002;105(3):310-315.

19. Grundy SM, Balady GJ, Criqui MH, Fletcher G, Greenland P, Hiratzka LF, Houston-Miller N, Kris-Etherton P, Krumholz HM, LaRosa J, Ockene IS, Pearson TA, Reed J, Washington R, Smith SC, Jr. Primary prevention of coronary heart disease: guidance from Framingham: a statement for healthcare professionals from the AHA Task Force on Risk Reduction. American Heart Association. Circulation. 1998;97(18):1876-1887.

20. Miao C, Chen S, Macedo R, Lai S, Liu K, Li D, Wasserman BA, Vogel-Claussen J, Lima JA, Bluemke DA. Positive remodeling of the coronary arteries detected by magnetic resonance imaging in an asymptomatic population: MESA (Multi-Ethnic Study of Atherosclerosis). J Am Coll Cardiol. 2009;53(18):1708-1715.

21. Leiner T, Gerretsen S, Botnar R, Lutgens E, Cappendijk V, Kooi E, van Engelshoven J. Magnetic resonance imaging of atherosclerosis. Eur Radiol. 2005;15(6):1087-1099.

22. Stolzmann P, Scheffel H, Leschka S, Plass A, Baumuller S, Marincek B, Alkadhi H. Influence of calcifications on diagnostic accuracy of coronary $C T$ angiography using prospective ECG triggering. AJR Am J Roentgenol. 2008;191(6):1684-1689.

23. Ong TK, Chin SP, Liew CK, Chan WL, Seyfarth MT, Liew HB, Rapaee A, Fong YY, Ang CK, Sim $\mathrm{KH}$. Accuracy of 64-row multidetector computed tomography in detecting coronary artery disease in 134 symptomatic patients: influence of calcification. Am Heart J. 2006;151(6):1323 e1321-1326.

24. Mowatt G, Cook JA, Hillis GS, Walker S, Fraser C, Jia X, Waugh N. 64-Slice computed tomography angiography in the diagnosis and assessment of coronary artery disease: systematic review and meta-analysis. Heart. 2008;94(11):1386-1393.

25. Hamon M, Morello R, Riddell JW. Coronary arteries: diagnostic performance of 16- versus 64-section spiral CT compared with invasive coronary angiography--meta-analysis. Radiology. 2007;245(3):720-731.

26. Nikolaou K, Rist C, Wintersperger BJ, Jakobs TF, van Gessel R, Kirchin MA, Knez A, von Ziegler F, Reiser MF, Becker CR. Clinical value of MDCT in the diagnosis of coronary artery disease in patients with a low pretest likelihood of significant disease. AJR Am J Roentgenol. 2006;186(6):1659-1668.

27. Otsuka M, Bruining N, Van Pelt NC, Mollet NR, Ligthart JM, Vourvouri E, Hamers R, De Jaegere P, Wijns W, Van Domburg RT, Stone GW, Veldhof S, Verheye S, Dudek D, Serruys PW, Krestin GP, De Feyter PJ. Quantification of coronary plaque by 64-slice computed tomography: a comparison with quantitative intracoronary ultrasound. Invest Radiol. 2008;43(5):314-321.

28. Schroeder S, Kopp AF, Ohnesorge B, Flohr T, Baumbach A, Kuettner A, Herdeg C, Karsch $\mathrm{KR}$, Claussen CD. Accuracy and reliability of quantitative measurements in coronary arteries by multi-slice computed tomography: experimental and initial clinical results. Clin Radiol. 2001;56(6):466-474. 
29. Achenbach S, Moselewski F, Ropers D, Ferencik M, Hoffmann U, MacNeill B, Pohle K, Baum U, Anders K, Jang IK, Daniel WG, Brady TJ. Detection of calcified and noncalcified coronary atherosclerotic plaque by contrast-enhanced, submillimeter multidetector spiral computed tomography: a segment-based comparison with intravascular ultrasound. Circulation. 2004;109(1):14-17.

30. Einstein AJ, Henzlova MJ, Rajagopalan S. Estimating risk of cancer associated with radiation exposure from 64-slice computed tomography coronary angiography. Jama. 2007;298(3):317-323.

31. Stolzmann P, Leschka S, Betschart T, Desbiolles L, Flohr TG, Marincek B, Alkadhi H. Radiation dose values for various coronary calcium scoring protocols in dual-source CT. Int J Cardiovasc Imaging. 2009;25(4):443-451.

32. Alkadhi H, Stolzmann P, Scheffel H, Desbiolles L, Baumuller S, Plass A, Genoni M, Marincek B, Leschka S. Radiation dose of cardiac dual-source CT: the effect of tailoring the protocol to patient-specific parameters. Eur J Radiol. 2008;68(3):385-391. 


\section{Chapter 5}

\section{Visualization of coronary wall atherosclerosis in asymptomatic subjects and patients with coronary artery disease using magnetic resonance imaging}

S.C. Gerretsen, M.E. Kooi, A.G. Kessels, S. Schalla, M. Katoh, R.J. van der Geest W.J. Manning, J. Waltenberger, J.M.A. van Engelshoven, R.M. Botnar, T. Leiner

PLoS 2010;5(9):e12998 


\section{Abstract}

Introduction: Magnetic resonance imaging (MRI) is sensitive to early atherosclerotic changes such as positive remodeling in patients with coronary artery disease (CAD). We assessed prevalence, quality and extent of coronary atherosclerosis in a group of healthy subjects compared to patients with confirmed CAD.

Methods: Twenty -two patients with confirmed CAD (15M, 7F, mean age $60.4 \pm$ 10.4 years) and 26 healthy subjects without history of CAD (11M, 15F, mean age $56.1 \pm 4.4$ years) underwent MRI of the right coronary artery (RCA) and vessel wall (MR-CVW) on a clinical 1.5T MR-scanner. Wall thickness measurements of both groups were compared.

Results: Stenoses of the RCA (both < and $\geq 50 \%$ on CAG) were present in all patients. In 21/22 patients, stenoses detected at MRI corresponded to stenoses detected with conventional angiography. In 19/26 asymptomatic subjects, there was visible luminal narrowing in the MR luminography images. Fourteen of these subjects demonstrated corresponding increase in vessel wall thickness. In 4/26 asymptomatic subjects vessel wall thickening without luminal narrowing was present. Maximum and mean wall thickness in patients were significantly higher ( 2.16 vs $1.92 \mathrm{~mm}$, and 1.38 vs $1.22 \mathrm{~mm}$, both $p<0.05$ ).

Conclusion: In this cohort of middle-aged individuals, both patients with stable angina and angiographically proven coronary artery disease as well as agematched asymptomatic subjects exhibited coronary vessel wall thickening detectable with MR coronary vessel wall imaging. Maximum and mean wall thickness were significantly higher in patients. The vast majority of asymptomatic subjects had either positive remodeling without luminal narrowing, or nonsignificant stenosis. 


\section{Introduction}

Coronary artery disease (CAD) remains the leading cause of mortality and morbidity in the Western World and developing countries despite continued improvements in prevention and early diagnosis ${ }^{1,2}$. The most frequent cause underlying an acute coronary event is disruption of an atherosclerotic plaque ${ }^{3,4}$. Rupture-prone plaques are referred to as thin-cap fibroatheroma and characterized pathologically as having a large necrotic core, high macrophage content and a thin, fibrous $\mathrm{cap}^{3,4}$.

In asymptomatic individuals acute myocardial infarction and sudden death may be the first clinical manifestation of coronary atherosclerosis ${ }^{5}$. About 50$64 \%$ of all sudden cardiac deaths occur without prior recognition of coronary heart disease ${ }^{1}$. Well-established risk factors for coronary atherosclerosis are hypercholesterolaemia, hypertension, cigarette smoking, diabetes mellitus, and systemic inflammation ${ }^{6,7}$. However, despite their usefulness for global risk assessment, these parameters lack specificity for prediction of individual coronary plaque burden.

Detection of subclinical coronary atherosclerosis in high-risk patients might become an important strategy to prevent clinical coronary heart disease. Compared to other imaging modalities magnetic resonance imaging (MRI) has superior ability to differentiate soft tissues and has shown to facilitate characterization of atherosclerotic plaque components in the aorta and carotid artery by using multisequence $\mathrm{MRI}^{8-10}$. These properties make it uniquely suited for serial non-invasive imaging of the vessel wall, and for monitoring effects of pharmaceuticals on plaque progression or regression. Prior work has demonstrated the capability of MRI to visualize the coronary vessel wall (CVW) with high spatial resolution, as well as vessel wall thickening and positive Glagov-type remodeling in patients ${ }^{11-13}$.

In this study we sought to evaluate the prevalence and extent of coronary atherosclerosis in a cohort of middle-aged subjects without clinical CAD. MR coronary vessel wall (MR-CVW) characteristics were compared to a positive control group of patients with angiographically confirmed CAD. 


\section{Materials and Methods}

\section{Subjects}

Between October 2005 and February 2007, 26 middle-aged subjects without previous history or clinical symptoms of CAD and 25 patients with symptoms of stable angina and angiographically confirmed CAD were enrolled. Healthy subjects were recruited via newspaper advertisement. Patients were recruited from the cardiology outpatient clinic of our hospital after having x-ray coronary angiography (CAG). Patients with confirmed CAD underwent MRI prior to percutaneous coronary intervention. Hemodynamically unstable patients or patients with previous interventions in the right coronary artery (RCA) as well as patients with severe arrhythmia or contra-indications for MRI were excluded. Approval of the Maastricht University Medical Center review board and written informed consent of all participants were obtained prior to inclusion.

In addition to registration of demographic data and risk factors, the estimated glomerular filtration rate (eGFR) and PROCAM-score ${ }^{14}$ were calculated whenever data were available.

\section{MR Imaging protocol}

All MR studies were performed on a clinical 1.5T system (Intera, Release 11.1 Philips Medical Systems, Best, The Netherlands) using a dedicated 5-element phased-array cardiac radiofrequency (RF) coil. Subjects were examined in the supine position. First, localizer scans were obtained and the subject specific middiastolic trigger delay and acquisition window were determined. These scans were followed by a double oblique oriented three-dimensional (3D) bright blood balanced steady state free precession (bSSFP) coronary MR angiography (CMRA) of the RCA (TR/TE/FA: $6.2 / 3.1 / 120^{\circ}$, resolution: $0.98 \times 0.98 \times 3 \mathrm{~mm}$ ). In the same orientation, a vessel wall scan was acquired (3D FFE, radial k-space sampling, modified double inversion recovery (DIR) prepulse) as previously described $^{13,15,16}$. Imaging parameters for the vessel wall scan were: TR: $8 \mathrm{~ms}$, repeated every other heartbeat for good blood suppression, TE: $2.0 \mathrm{~ms}$, Flip Angle: $30^{\circ}$, Field of view: $300 \times 300 \mathrm{~mm}$ and matrix: $384 \times 384$. Twenty interpolated slices of $1 \mathrm{~mm}$ were obtained. The resulting (acquired) spatial resolution was $0.78 \times 0.78 \times 2 \mathrm{~mm}$. Cardiac gating and a 2D navigator beam were used for compensation of cardiac and respiratory motion. This protocol has previously been shown to result in highly reproducible images of the coronary vessel wall in healthy volunteers ${ }^{16}$. No contrast agents or sublingual nitroglycerin were used. 


\section{Evaluation of coronary artery stenosis and plaque burden}

Image quality (IQ) of the vessel wall datasets was scored by two experienced, independent blinded observers on a 4 point scale: $1=$ =well-defined vessel wall borders and high vessel wall-to-background contrast; $2=$ some blurring of the vessel wall borders, average to good vessel-wall to background contrast; $3=$ major artifacts or severe blurring of the vessel wall borders, low to average vessel wall-to-background contrast, and $4=v e s s e l$ wall cannot be identified, very low vessel wall-to-background contrast (modified from Zhang et al. ${ }^{17}$ and Spuentrup et al. $^{18}$ ). An experienced cardiologist blinded to the results of the vessel wall scans assessed the location and degree of a stenosis on the CMRA images. Coronary artery luminograms were classified as negative when there was no visible sign of disease or mild to moderate luminal narrowing (stenosis $<50 \%$ ). Significant disease (stenosis $\geq 50 \%$ ) was considered to be present in cases of obvious narrowing of the vessel or marked attenuation of coronary lumen signal $^{19}$. X-ray coronary angiography (CAG) - available in all CAD patients - was visually interpreted by different cardiologists prior to MRI.

Subsequently, an observer blinded to clinical data quantitatively analyzed coronary artery wall images. Minimum, mean and maximum wall thickness were measured on the 3D vessel wall sequence. Lumen diameter was measured on both bSSFP and MR-CVW images. For measurements, a custom made software package was used (VesseIMASS, Leiden University Medical Center, department of Radiology, division Image Processing, Leiden, the Netherlands) ${ }^{20}$, adapted for viewing and analysis of longitudinal coronary vessel wall images. For analysis purposes the RCA vessel wall was divided into three segments according to the American Heart Association classification ${ }^{21}$.

To prevent errors in wall thickness and lumen diameter measurements due to reconstruction errors, only source images were used for measurements. In source images where the vessel wall was visible, the inner and outer borders of the anterior and posterior vessel wall were manually delineated (figure 1). Each resulting region of interest (ROI) was automatically divided in 100 subsegments for quantitative analysis of wall thickness. Because measurements in adjacent subsegments are not independent due to partial volume effects we corrected for the length of the measured segment and spatial resolution by only using subsegments from separate voxels and discarding measurements in between. The number of included segments equals the number of voxels in the ROI, which was calculated by dividing the length of the ROI by the in-plane spatial resolution. Coronary plaque burden was quantified as the mean and maximum RCA vessel wall thickness along the proximal two vessel segments ${ }^{19}$. In addition 
to measuring wall thickness, a normalized wall index was calculated (100* (diameter lumen divided by the sum of anterior and posterior wall thickness)) to get a better quantitative impression about the degree of positive remodeling.
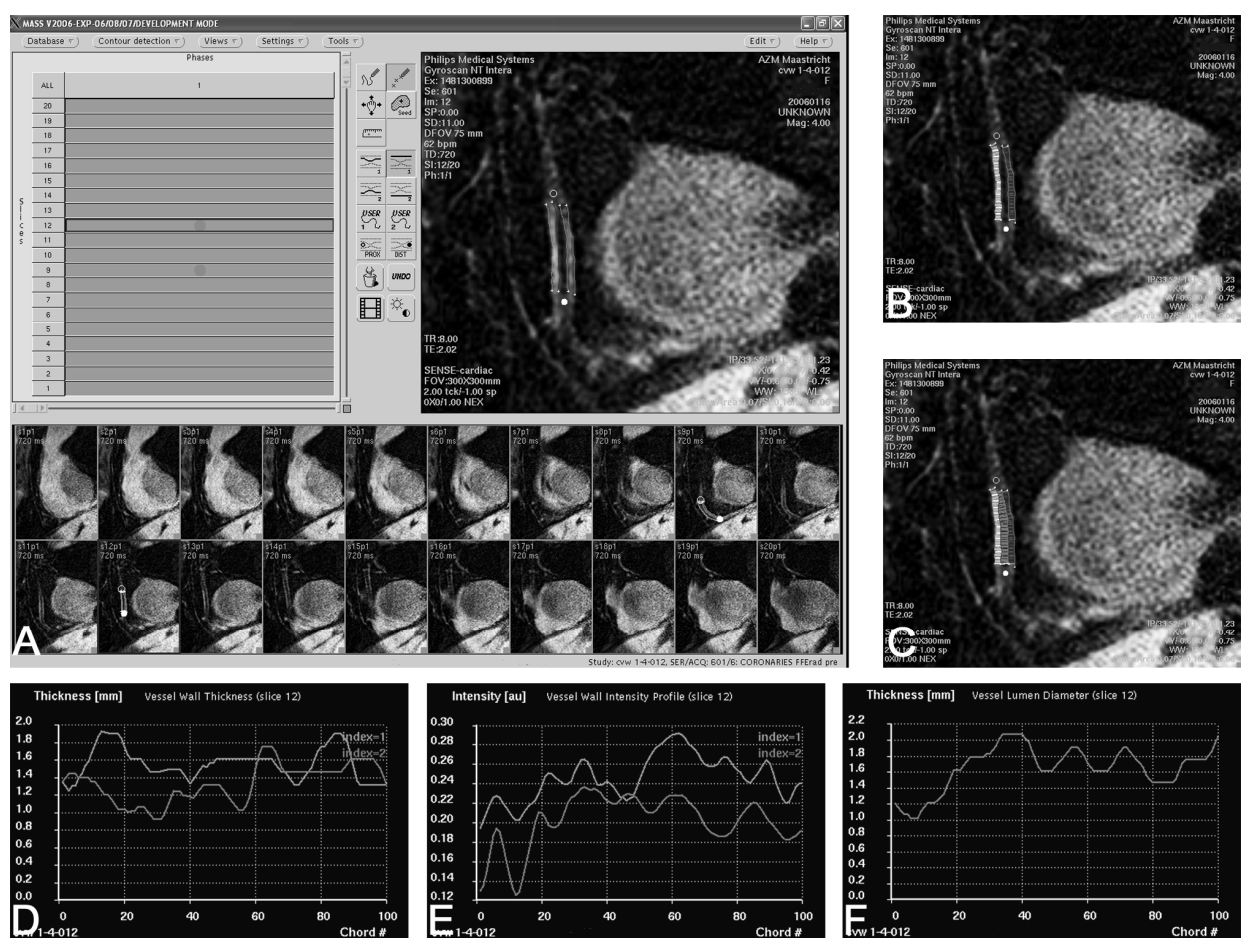

Figure 1. Measurement of vessel wall thickness and signal intensity on source images. The anterior and posterior vessel walls are delineated (A). In each segment 100 measurements are made of the thickness and signal intensity of the proximal and distal RCA vessel wall and the diameter of the lumen $(B, C)$. The custom made software program calculates wall thickness, signal intensity, and lumen diameter (D-F) over the entire length of the measured segment.

Based on both CMRA and MR-CVW, areas could be classified as diseased or notdiseased according to the following criteria: ROls with vessel wall thickening were classified as diseased. This could either be in areas of stenosis (combination of luminal narrowing with vessel wall thickening) or in areas with positive remodeling (wall thickening without luminal narrowing. ROls with normal lumen diameter compared to the rest of the vessel and with a vessel wall that had no areas of focal wall thickening or focal high signal intensity, were classified as "not diseased". Since calcified plaques demonstrate low signal intensity on all MR sequences and can therefore be difficult to visualize, ROIs with obvious luminal narrowing but without visible vessel wall thickening were interpreted as 
diseased with (heavily) calcified plaque if overall image quality of the vessel wall scan was good and if the vessel wall and lumen could be distinguished in other segments of the vessel.

\section{Statistical analysis}

Statistical analysis was performed using SPSS 11.5 (SPSS Inc., Chicago, IL, USA). Differences in IQ between the patient and control group were compared using a Wilcoxon rank-sum test. Minimum, maximum and mean wall thickness and the normalized wall index in both groups were compared using an unpaired student t-test. Differences between men and women in both groups were analyzed using a Wilcoxon rank-sum test. In addition, we pooled the results by testing the global hypothesis that all results of the measurements (minimum, maximum and mean values) of vessel wall thickness were equal using the ordinary least square test ${ }^{22,23}$. Significance was assumed at two-tailed $p$ values of less than 0.05 .

\section{Results}

\section{Subject characteristics}

All 51 subjects underwent coronary MRI without complications. In three patients, the coronary vessel wall sequence could not be performed due to severe back pain ( 1 patient) and software problems ( 2 patients). This resulted in evaluable vessel wall scans in 26 asymptomatic subjects ( $11 \mathrm{M}$, mean age $56 \pm 4$ yrs) and 22 patients ( $15 \mathrm{M}$, mean age $60 \pm 10 \mathrm{yrs}$ ).

Clinical characteristics of this study cohort are listed in table 1 . There was a significant difference in subjects' weight and the presence of hypercholesterolemia and hypertension between both groups. In the patient group, there was a trend towards higher prevalence of males and higher age, higher incidence of diabetes, and higher PROCAM score. In patients $(n=12)$ in whom a PROCAM score could be calculated, a 10-year risk for acute coronary events of $12.0 \%$ ( \pm 8.1 , range: $1.3-25.1 \%$ ) was present, versus $4.8 \%$ ( \pm 2.4 , range: $1.9-8 \%$ ) in control subjects $(n=6)$. Linear regression showed a weak correlation between eGFR and mean wall thickness (R: $0.54, p<0.01$ ). In subjects with low eGFR decreased vessel wall thickness was found. 
Table 1. Subject characteristics.

\begin{tabular}{|c|c|c|c|}
\hline & $\begin{array}{l}\text { Patients } \\
(\mathrm{N}=22)\end{array}$ & $\begin{array}{l}\text { Asymptomatic subjects } \\
(\mathrm{N}=26)\end{array}$ & $P$ \\
\hline \multicolumn{4}{|l|}{ characteristics } \\
\hline Gender, male $\mathrm{n}(\%)$ & $15(68)$ & $11(42)$ & 0.08 \\
\hline Age, y $( \pm S D)$ & $60.41(10.35)$ & $56.08(4.43)$ & 0.08 \\
\hline Weight, $\mathrm{kg}( \pm \mathrm{SD})$ & 81.27 (15.59) & $71.35(13.73)$ & 0.02 \\
\hline Systolic blood pressure, $\mathrm{mm} \mathrm{Hg}( \pm \mathrm{SD})$ & $137(14.16)$ & $133(16.38)$ & 0.39 \\
\hline Diastolic blood pressure, $\mathrm{mm} \mathrm{Hg}( \pm \mathrm{SD})$ & $80(9.28)$ & $79(11.46)$ & 0.87 \\
\hline Diabetes, $\mathrm{n}(\%)$ & $3(13.6)$ & $0(0)$ & 0.08 \\
\hline Current smoker, n (\%) & $3(13.6)$ & $5(19.2)$ & 0.61 \\
\hline Hypertension, n (\%) & $13(59.1)$ & $1(3.8)$ & $<0.01$ \\
\hline Hypercholesterolemia, n (\%) & $11(50)$ & $2(7.7)$ & 0.01 \\
\hline eGFR $( \pm S D) \mathrm{mL}^{*} \min ^{-2} * 1.73 \mathrm{~m}^{-2}$ & $88.61(27.5)(n=22)$ & $76.01(24.2)(n=9)$ & 0.24 \\
\hline PROCAM-score $( \pm S D)^{+}$ & $44.6(9.7)(n=12)$ & $36.0(6.0)(n=6)$ & 0.07 \\
\hline
\end{tabular}

* eGFR: estimated Glomerular Filtration Rate.

+ PROCAM-score: based on the PROspective CArdiovascular Muenster study-scoring scheme.

\section{Coronary artery atherosclerosis}

The prevalence of coronary stenoses as identified by CMRA in the 48 subjects with complete scans is listed in Table 2. Significant coronary artery stenoses $(\geq 50 \%)$ were found in 17 patients on CMRA, but only in 16 patients on CAG. In $19 / 26$ asymptomatic subjects (73\%), there was evidence of at least some luminal narrowing on CMRA. Nine of these 19 asymptomatic subjects had a significant stenosis $(\geq 50 \%)$. In the patient group, the degree of stenosis as estimated on CMRA ( $<$ or $\geq$ than 50\%) was compared to the results of CAG. In 21 out of 22 patients (95\%), location of stenoses detected on CMRA corresponded to stenoses detected with CAG, although in some segments there was overestimation of the degree of stenosis on CMRA. Agreement between CAG and CMRA for detection of lesions is demonstrated in table 3 . Sensitivity and specificity were $100 \%$ and $83 \%$, respectively.

Table 2. Stenoses on coronary MRA.

\begin{tabular}{lll}
\hline & $\begin{array}{l}\text { Patients } \\
(\mathrm{N}=22)\end{array}$ & $\begin{array}{l}\text { Asymptomatic } \\
\text { Subjects }(\mathrm{N}=26)\end{array}$ \\
\hline No stenoses & $0(0)$ & $7(27)$ \\
$<50 \%$ stenoses & $5(23)$ & $10(38)$ \\
$\geq 50 \%$ stenoses & $17(77)$ & $9(35)$ \\
\hline
\end{tabular}

Prevalence of stenoses (number (\%)) in the right coronary artery as seen with coronary MRA. 
Table 3. Comparison between CMRA and CAG on segment level.

\begin{tabular}{lllll}
\hline & & CAG & & Non-evaluable \\
\cline { 2 - 5 } & & $0-50 \%$ & $\geq 50 \%$ & segments \\
\hline CMRA proximal & $<50 \%$ & 10 & 0 & 0 \\
& $\geq 50 \%$ & 2 & 10 & 1 (CAG) \\
CMRA mid $\left({ }^{*}\right)$ & $<50 \%$ & 10 & 0 & \\
& $\geq 50 \%$ & 3 & 8 & 4 (CMRA) \\
CMRA distal & $<50 \%$ & 10 & 0 & 1 (CAG) \\
& $\geq 50 \%$ & 5 & 2 & (CAG) \\
\hline
\end{tabular}

Agreement between coronary MRA (CMRA) and X-ray coronary angiography (CAG) on degree of stenoses in the right coronary artery in patients with coronary artery disease $(\mathrm{N}=22)$ in the proximal, mid and distal RCA. Values represent number of segments.

Lumen diameter as measured on MR-CVW, was slightly smaller compared to diameters measured on CMRA. In patients, lumen diameter on CMRA was $1.86 \pm 0.46 \mathrm{~mm}$, versus $1.66 \pm 0.53 \mathrm{~mm}$ on MR-CVW ( $p=0.02$ ). In asymptomatic subjects, lumen diameter was $2.01 \pm 0.55 \mathrm{~mm}$ on CMRA and $1.64 \pm 0.63 \mathrm{~mm}$ on MR-CVW $(p<0.01)$. The slight difference in in-plane spatial resolution between both techniques ( $0.99 \mathrm{~mm}$ on CMRA, $0.78 \mathrm{~mm}$ on MR-CVW), can theoretically lead to overestimation of the lumen diameter on CMRA, but also overestimation of coronary stenoses, or underestimation of lumen diameter on MR-CVW. However, on MR-CVW partial volume may play a more important role since the lumen is surrounded by vessel wall. It is more probable that lumen measurements are more accurate on CMRA, although a slight influence of the signal of the vessel wall on diameter measurements on CMRA cannot be ruled out completely. In theory however, we expect that this effect is minimal due to the technique used for suppression of myocardial signal (T2prep). Since the vessel wall is mainly composed of smooth muscle cells, collagen and elastin, the T2 is expected to be similar to the $\mathrm{T} 2$ of myocardium. Because of signal suppression due to T2prep, only little signal contribution of the vessel wall can be expected.

There was a trend towards smaller minimum lumen diameter as measured on the luminography sequence in the patient group $(1.06 \pm 0.58 \mathrm{~mm}$ in patients vs $1.35 \pm 0.53 \mathrm{~mm}$ in asymptomatic subjects, $p=0.08$ ). However, no significant differences could be demonstrated between mean $(1.86 \pm 0.46 \mathrm{~mm}$ in patients, $2.0 \pm 0.55 \mathrm{~mm}$ in asymptomatic subjects, $\mathrm{p}=0.35)$ and maximum $(2.91 \pm 0.57 \mathrm{~mm}$ in patients, $2.73 \pm 0.70 \mathrm{~mm}$ in subjects, $p=0.35$ ) luminal diameters of the two groups (Table 4).

IQ of the vessel wall scans was good in the majority of cases with a mean score of $1.42 \pm 0.58$ for all subjects. There was no significant difference in IQ be- 
tween patients and asymptomatic subjects $(1.32 \pm 0.57$ vs $1.5 \pm 0.58$ for observer $1, p=0.21,1.42 \pm 0.58$ vs $1.41 \pm 0.59$ for observer $2, p=0.9)$.

Table 4. Vessel wall thickness and lumen diameter measurements.

\begin{tabular}{llll}
\hline & $\begin{array}{l}\text { Patients } \\
(\mathrm{N}=22)\end{array}$ & $\begin{array}{l}\text { Asymptomatic } \\
\text { subjects }(\mathrm{N}=26)\end{array}$ & $\mathrm{p}$ \\
\hline Vessel wall: & & & \\
Minimal vessel wall thickness $(\mathrm{mm})( \pm \mathrm{SD})$ & $0.71(0.19)$ & $0.65(0.16)$ & 0.269 \\
Maximal vessel wall thickness $(\mathrm{mm})( \pm \mathrm{SD})$ & $2.16(0.37)$ & $1.92(0.44)$ & 0.048 \\
Mean vessel wall thickness $(\mathrm{mm})( \pm \mathrm{SD})$ & $1.38(0.18)$ & $1.22(0.22)$ & 0.011 \\
Overall (standardized) wall thickness $( \pm \mathrm{SD})$ & $0.87(2.25)$ & $-0.74(2.57)$ & 0.026 \\
Lumen CMRA & & & \\
Minimal lumen diameter $(\mathrm{mm})( \pm \mathrm{SD})$ & $1.06(0.58)$ & $1.35(0.53)$ & 0.080 \\
Maximal lumen diameter $(\mathrm{mm})( \pm \mathrm{SD})$ & $2.91(0.57)$ & $2.73(0.70)$ & 0.354 \\
Mean lumen diameter $(\mathrm{mm})( \pm \mathrm{SD})$ & $1.86(0.46)$ & $2.01(0.55)$ & 0.346 \\
Lumen MR-CVW & & & \\
Minimal lumen diameter $(\mathrm{mm})( \pm \mathrm{SD})$ & $0.91(0.58)$ & $1.02(0.53)$ & 0.475 \\
Maximal lumen diameter $(\mathrm{mm})( \pm \mathrm{SD})$ & $2.57(0.66)$ & $2.39(0.81)$ & 0.396 \\
Mean lumen diameter $(\mathrm{mm})( \pm \mathrm{SD})$ & $1.66(0.53)$ & $1.64(0.63)$ & 0.930 \\
Normalized wall index $(\%),( \pm S D)$ & $68.2(17.0)$ & $82.8(20.7)$ & 0.012 \\
\hline Vessel wall &
\end{tabular}

Vessel wall thickness and lumen diameter measurements $( \pm S D)$ measured on both CMRA and MRCVW in patients and healthy volunteers. Normalized wall index was calculated as a value to represent positive remodeling according to the following formula: 100*(lumen diameter / sum of anterior and posterior wall thickness).

Various degrees of non-uniform vessel wall thickening were seen on the MRCVW scans in patients and asymptomatic subjects (figures 2 and 3). Quantitative results are summarized in Table 4. Maximum and mean wall thicknesses were significantly larger in the patient group. The normalized wall index was higher in asymptomatic subjects when compared to patients ( $82.8 \pm 20.7$ versus $68.2 \pm 17.0, p=0.012)$, representing an increased wall thickness in all patients and asymptomatic subjects but a relatively thicker vessel wall compared to lumen diameter in patients. Pooled results of wall thickness also demonstrated a significant difference between the groups $(p=0.03)$. 

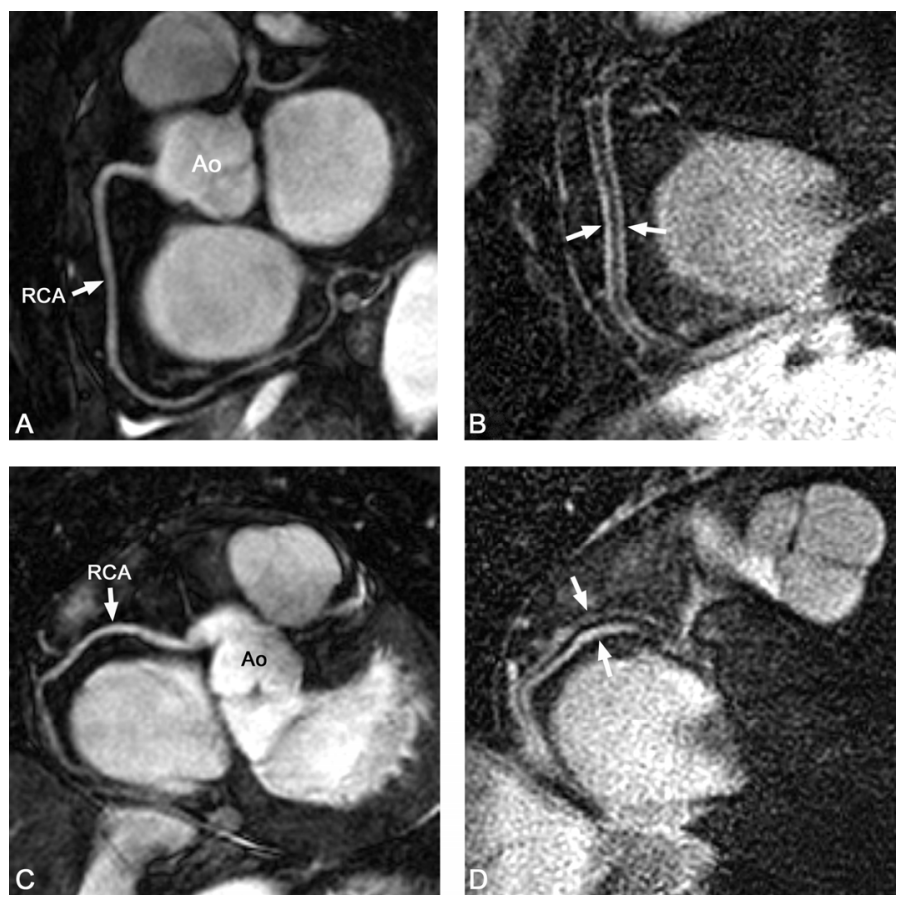

Figure 2. MRA and MR-CVW in asymptomatic subjects. Balanced steady state free precession (bSSFP) coronary MRA $(A, C)$ and corresponding vessel wall scans $(B, D)$ of the right coronary artery (RCA) in asymptomatic subjects. $A$ and $B$ represent the RCA of a $62 \mathrm{y} / \mathrm{o}$ female $(A, B)$. There is a thin vessel wall with uniform signal intensity (arrows in B). In C and D, the RCA of a 54 y/o female is shown. In this subject, the posterior proximal vessel wall is thicker and has higher signal intensity compared to the anterior vessel wall (arrows in D), indicating the presence of positive remodeling. Ao indicates aorta.

Overall, there was good agreement between luminal narrowing at CMRA and increased wall thickness at MR-CVW in all patients. Agreement between CMRA and MR-CVW in asymptomatic subjects is demonstrated in Table 5. There were 5 asymptomatic subjects with stenoses without wall thickening: in three of these subjects, the area of stenosis was not well visualized on the vessel wall scan, in one subject vessel wall and lumen could hardly be distinguished and in one subject the location of the vessel wall thickening did not correspond to the area of stenosis on CMRA. 

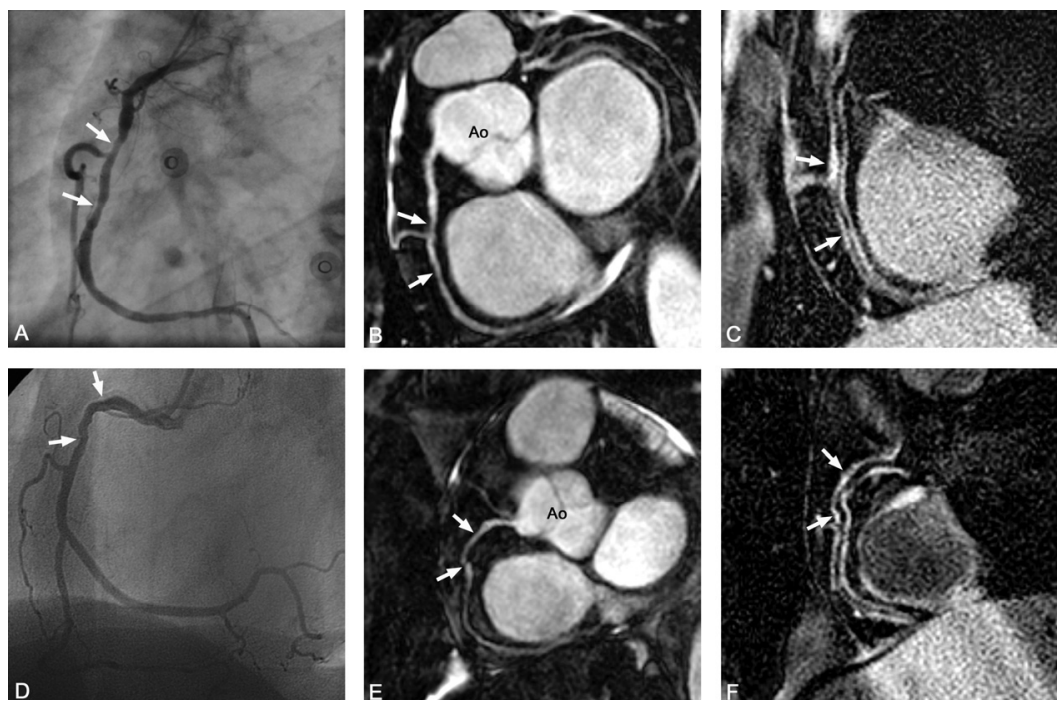

Figure 3. $M R A$ and $M R-C V W$ in patients with stable angina. X-ray coronary angiography $(A, D)$, balanced steady state free precession (bSSFP) coronary MRA (B,E) and corresponding vessel wall scans $(C, F)$ of the right coronary artery (RCA) in two patients with stable angina. In a 40 y/o male $(A-C)$, vessel wall thickness and signal intensity are increased in areas of stenosis and wall irregularities (arrows). In a $67 \mathrm{y} / \mathrm{o}$ female (D-F) the culprit lesion was located in the left anterior descending artery (not imaged). However, the proximal RCA demonstrated wall focal luminal irregularities (arrows in $\mathrm{D}, \mathrm{E}$ ). In $\mathrm{F}$, corresponding focal heterogeneity in wall thickness and signal intensity of the entire vessel wall are clearly visible. Ao indicates aorta.

Table 5. MR-CVW versus CMRA

\begin{tabular}{llll}
\hline & & CMRA & \\
& & No stenoses & Stenoses \\
\hline MR-CVW & No Wall thickening & 3 & 5 \\
& Wall thickening & 4 & 14 \\
\hline
\end{tabular}

Agreement between MR coronary vessel wall imaging (MR-CVW) and coronary magnetic resonance imaging (CMRA) for detection of stenoses and vessel wall thickening in asymptomatic volunteers. Values represent number of subjects

The groups were age-matched, but not matched for gender. There was a trend towards a higher prevalence of women in the group of healthy volunteers (Table 1). In patients, there were no significant differences between men and women. However, in the group of healthy volunteers, there was a significant difference in mean vessel wall thickness, mean luminal diameter on CMRA, mean luminal diameter on MR-CVW and a trend towards difference in normalized wall index (Table 6). 
Table 6. Gender related differences

\begin{tabular}{llll}
\hline & Men & Women & $\mathrm{p}$ \\
\hline Patients $(15 M, 7 F)$ & & & \\
Mean vessel wall thickness $(\mathrm{mm})( \pm \mathrm{SD})$ & $1.41(0.18)$ & $1.32(0.18)$ & 0.341 \\
Lumen diameter on CMRA $(\mathrm{mm})( \pm \mathrm{SD})$ & $1.90(0.38)$ & $1.79(0.61)$ & 0.307 \\
Lumen diameter on MR-CVW $(\mathrm{mm})( \pm \mathrm{SD})$ & $1.66(0.49)$ & $1.65(0.63)$ & 0.805 \\
Normalized wall index $(\%),( \pm \mathrm{SD})$ & $67.8(13.0)$ & $69.1(24.9)$ & 0.916 \\
Healthy subjects $(11 \mathrm{M}, 15 F)$ & & & \\
Mean vessel wall thickness $(\mathrm{mm})( \pm \mathrm{SD})$ & $1.34(0.24)$ & $1.14(0.18)$ & 0.046 \\
Lumen diameter on CMRA (mm) $( \pm S \mathrm{SD})$ & $2.43(0.57)$ & $1.69(0.26)$ & 0.001 \\
Lumen diameter on MR-CVW $(\mathrm{mm})( \pm \mathrm{SD})$ & $2.04(0.75)$ & $1.36(0.31)$ & 0.005 \\
Normalized wall index $(\%),( \pm S D)$ & $94.0(26.6)$ & $74.6(9.3)$ & 0.092 \\
\hline
\end{tabular}

Gender related differences in the group of patients $(n=22)$ and the group of healthy volunteers $(n=26)$.

\section{Discussion}

This is one of the few studies to use non-invasive MRI to assess coronary artery plaque burden in an asymptomatic population-based cohort of adults using magnetic resonance CVW imaging. The most significant finding of this study is the high prevalence of coronary wall plaque in asymptomatic adults free of known CAD. Four out of 26 healthy subjects exhibited evidence of positive remodeling without luminal narrowing and the majority of subjects $(19 / 26)$ exhibited evidence of luminal narrowing at CMRA, in some cases even exceeding $50 \%$. As expected, the burden of coronary atherosclerosis was higher in the positive control group, which consisted of patients with angiographically confirmed CAD. Despite the lack of a gold standard for visualization of the coronary vessel wall (i.e. intravascular ultrasound), these data suggest that MRI may help to non-invasively identify not only late stages of atherosclerosis but also the early manifestations of atherosclerotic disease in the coronary vessel wall.

Our results corroborate the findings of Kim et al., who investigated subjects with longstanding diabetes type 1 but without cardiovascular symptoms ${ }^{19}$. In these asymptomatic patients, only $10 \%$ of patients with nephropathy and $0 \%$ of patients with normoalbuminuria had evidence of coronary stenoses although the prevalence of visually identifiable coronary plaque in the RCA was higher ( $76 \%$ in patients with nephropathy versus $15 \%$ in patients with normoalbuminuria). The prevalence of vessel wall thickening in the RCA is in the same range as in our study group, however, we found more cases of luminal narrowing, probably reflecting differences in study populations. Although diabetic subjects tend to have more atherosclerosis, our asymptomatic subjects were older than the 
subjects with diabetic nephropathy from the study by Kim et al. (mean age of 56 vs 48 years). Additionally, MRI is known to overestimate stenosis and possible slight differences in spatial resolution between the used techniques can contribute to differences in assessment of stenosis. Tuzcu et al. ${ }^{24}$ studied a population of 262 subjects and found vessel wall thickening of more than $0.5 \mathrm{~mm}$ on intravascular ultrasonography (IVUS) in $>70 \%$ of asymptomatic subjects by the age of 40 , while only $8 \%$ of X-ray coronary angiograms of the entire cohort demonstrated mild luminal irregularities. While the study by Tuzcu once again underscores that early vessel wall abnormalities go undetected at coronary angiography, there was a large difference in prevalence of luminal irregularities compared to our study. The fact that our study demonstrated luminal irregularities on CMRA in $>70 \%$ of subjects compared to $8 \%$ in the study by Tuzcu et al. can be explained by the better spatial resolution of X-ray coronary angiography compared to CMRA, the fact that flow disturbances on CMRA can lead to overestimation of the degree of stenoses, and the difference in age and case-mix between the populations.

A recent publication from the Multi-Ethnic Study of Atherosclerosis (MESA) also found positive remodeling in a large cohort of 179 subjects without known coronary artery disease $\mathrm{e}^{25}$. In contrast to our study, the MESA study did not find any significant stenoses $(\geq 50 \%)$, despite the use of similar spatial resolution as well as an identical technique for suppressing blood flow ${ }^{25}$. Axial images of all three coronary arteries (LM, RCA and LAD) were acquired, but due to time constrains this was limited to the proximal parts of the vessels of interest, with only one slice in the LM and 3 slices in the RCA and LAD. Axial imaging of the coronary vessel wall is very time consuming, and the longitudinal technique that we used offers an overview of the vessel wall in a much larger part of the coronary artery of interest. The difference in acquisition approach, especially the chosen imaging plane and resulting differences in partial volume artefacts, between our study and the MESA study is one of the likely explanations for the discordant results.

Clinical CAD has a long asymptomatic period during which biological risk factors interact with genetic and environmental influences to initiate and promote the development of coronary atherosclerotic plaque ${ }^{26,27}$. Once established, atherosclerosis can exist in a subclinical state characterized by the presence of plaque but an absence of clinical signs and symptoms. Acute clinical manifestations of coronary atherosclerosis such as unstable angina and myocardial infarction are usually the consequence of acute rupture of the atherosclerotic plaque, leading to exposure of thrombogenic components to the bloodstream, with 
superimposed thrombus formation ${ }^{28}$. Although traditional risk factors and risk scores such as the Framingham ${ }^{7,29}$ and PROCAM $^{14}$ scores are accurate at predicting risk to experience a cardiovascular event in the near future for groups of patients, they often lack discriminative power to characterize individual subjects risk. Approximately $40 \%$ of the adult population in the U.S. and Western Europe are at intermediate $(0.5-2.0 \%)$ and $10 \%$ at high risk ( $>15 \%)$ for developing an acute coronary event over the next decade ${ }^{30}$. Therefore, further risk stratification of individual patients with CAD using novel biochemical markers as well as noninvasive imaging techniques may be important. Our study was motivated by the paucity of data on the prevalence and characteristics of early CAD and coronary atherosclerotic plaque burden at MRI in an unselected cohort of asymptomatic middle aged adults free of known CAD at baseline. However, it is known that the measured degree of coronary stenosis that was taken as significant in this study (i.e. $\geq 50 \%$ ) often is not associated with significant impairment in coronary blood flow. This might be the reason why none of the control subjects with stenoses $\geq 50 \%$ at MRI were symptomatic. An alternative explanation could be that with MRI luminal irregularities are erroneously overestimated ${ }^{31-33}$, which is one of the shortcomings of MRI in comparison to conventional $\mathrm{X}$ ray angiography.

Whether MR-CVW confers additional information over more established non-invasive imaging techniques such as calcium scoring ${ }^{34,35}$ and multislice computed tomography (MSCT) $)^{36,37}$ is unknown. Spatial resolution of CT is better. However, in comparison to epicardial coronary artery calcium scoring, MRI can detect earlier changes such as outward remodeling. Outward remodeling has been shown to be associated with plaques that have a higher relative content of fibrofatty components as opposed to calcification ${ }^{38}$, as well as with plaques that ultimately exhibit an unstable clinical presentation ${ }^{39}$. The excellent soft-tissue resolution of MRI enables better characterization of plaque components than CT. Furthermore, no contrast agents are needed to visualize the coronary vessel wall with $\mathrm{MRI}$, which is beneficial in patients with renal failure or allergies. An additional advantage of MRI is that it does not require radiation exposure, an issue that takes on considerable importance when weighing risks and benefits in asymptomatic subjects, and when follow-up studies are desired $^{40}$.

Limitations of this study should be considered. Due to ethical considerations, no comparison to a standard of reference was obtained in asymptomatic volunteers and therefore, there is no certainty about actual prevalence of abnormalities in this group. Furthermore, the groups were matched for age but 
not for gender. It is known that there are gender related differences in coronary artery disease. In general, women have a less typical clinical presentation and often have fewer angiographic high-risk features ${ }^{41,42}$. In our group of asymptomatic volunteers, there were several significant differences between men and women. Women had thinner vessel walls and smaller lumen diameter, however, the lower normalized wall index in women indicates a relatively thick vessel wall compared to lumen diameter, which could be related to more positive remodeling. In patients, these differences between men and women were not found. Our results are supported by the study by Miao et al. who also found gender related differences in lumen size, vessel wall area and mean vessel wall thickness in a large cohort of asymptomatic men and women who underwent MRI of the coronary vessel wall ${ }^{25}$. However, in both men and women, they found a similar, significant, relationship between vessel wall thickness and outer lumen area or lumen area, both measures for the degree of positive remodeling. In the study by Miao et al., there was no comparison between patients with CAD and healthy subjects. Due to the difference in the amount of women between both groups in our study, future studies should not only match for age but also for gender to further study possible gender-related differences.

Currently, there are still some limitations in scan technique for coronary vessel wall imaging. With currently used in-plane spatial resolution of $0.78 \mathrm{~mm}$, detection of small variations in wall thickness due to partial volume effects are not yet possible. Additionally, due to the current spatial resolution, it can be expected that partial volume effects account for overestimation of coronary vessel wall thickness. Other factors that lead to overestimation of wall thickness are curvature of the vessel and out of plane orientation of the vessel. However, these factors play a more important role with multiplanar reformatting, and to minimize errors due to these factors, measurements were performed on source images.

Furthermore, because the obvious long-term goal of MR-CVW imaging is not only measurement of plaque size but also composition, increased spatial resolution is needed to characterize plaque components. This is important, as it is known that a large lipid-rich necrotic core and a thin fibrous cap portend a poor prognosis. First attempts at characterization of coronary plaques using contrastenhanced MR-CVW imaging have been made by Maintz et al. ${ }^{43}$ and Yeon et al. ${ }^{44}$, who demonstrated that use of contrast-enhanced MR CVW imaging allowed identification of areas of delayed enhancement that correlated with severity of atherosclerosis by MSCT and quantitative X-ray angiography. Also, whether therapeutic intervention guided by imaging modalities will influence clinical 
event rates remains an important focus of research. Imaging cannot be regarded as an isolated tool to determine prognosis. However, it is highly likely that imaging will only confer additional information in selected subgroups of subjects in combination with traditional risk factors and (novel) serological markers. This concept is also known as the 'vulnerable patient ${ }^{\prime 45}$. Further limitations include the relatively low sample size and, because of an attempt to limit total scantime in our subjects, analysis of coronary plaque burden was restricted to the RCA.

In conclusion, although there was low prevalence of significant coronary stenoses, we found coronary atherosclerotic plaque in a large proportion of asymptomatic middle-aged subjects at MR CVW imaging. As expected, there were less stenoses and asymptomatic subjects exhibited lower mean coronary vessel wall thickness compared to a control group of patients with angiographically proven coronary artery disease. Because the time-course from subclinical disease to clinical events is highly variable, it is important that future studies focus on the association between MR CVW evidence of disease and clinically manifest incident CAD. 


\section{References}

1. Rosamond W, Flegal K, Furie K, Go A, Greenlund K, Haase N, Hailpern SM, Ho M, Howard V, Kissela B, Kittner S, Lloyd-Jones D, McDermott M, Meigs J, Moy C, Nichol G, O'Donnell C, Roger V, Sorlie P, Steinberger J, Thom T, Wilson M, Hong Y. Heart disease and stroke statistics--2008 update: a report from the American Heart Association Statistics Committee and Stroke Statistics Subcommittee. Circulation. 2008;117(4):e25-146.

2. Mackay J, Mensah GA. The atlas of heart disease and stroke. 1st ed. Geneva: World Health Organization; 2004.

3. Burke AP, Farb A, Malcom GT, Liang YH, Smialek J, Virmani R. Coronary risk factors and plaque morphology in men with coronary disease who died suddenly. $N$ Engl J Med. 1997;336(18):1276-1282.

4. Davies MJ. The composition of coronary-artery plaques. N Engl J Med. 1997;336(18):13121314.

5. Virmani R, Burke AP, Farb A, Kolodgie FD. Pathology of the vulnerable plaque. J Am Coll Cardiol. 2006;47(8 Suppl):C13-18.

6. Ridker PM, Buring JE, Cook NR, Rifai N. C-reactive protein, the metabolic syndrome, and risk of incident cardiovascular events: an 8-year follow-up of 14,719 initially healthy American women. Circulation. 2003;107(3):391-397.

7. Wilson PW, D'Agostino RB, Levy D, Belanger AM, Silbershatz $\mathrm{H}$, Kannel WB. Prediction of coronary heart disease using risk factor categories. Circulation. 1998;97(18):1837-1847.

8. Fayad ZA, Nahar T, Fallon JT, Goldman M, Aguinaldo JG, Badimon JJ, Shinnar M, Chesebro JH, Fuster $\mathrm{V}$. In vivo magnetic resonance evaluation of atherosclerotic plaques in the human thoracic aorta: a comparison with transesophageal echocardiography. Circulation. 2000;101(21):2503-2509.

9. Cappendijk VC, Cleutjens KB, Kessels AG, Heeneman S, Schurink GW, Welten RJ, Mess WH, Daemen MJ, van Engelshoven JM, Kooi ME. Assessment of human atherosclerotic carotid plaque components with multisequence MR imaging: initial experience. Radiology. 2005;234(2):487-492.

10. Cai JM, Hatsukami TS, Ferguson MS, Small R, Polissar NL, Yuan C. Classification of human carotid atherosclerotic lesions with in vivo multicontrast magnetic resonance imaging. Circulation. 2002;106(11):1368-1373.

11. Fayad ZA, Fuster V, Fallon JT, Jayasundera T, Worthley SG, Helft G, Aguinaldo JG, Badimon JJ, Sharma SK. Noninvasive in vivo human coronary artery lumen and wall imaging using blackblood magnetic resonance imaging. Circulation. 2000;102(5):506-510.

12. Botnar RM, Stuber M, Kissinger KV, Kim WY, Spuentrup E, Manning WJ. Noninvasive coronary vessel wall and plaque imaging with magnetic resonance imaging. Circulation. 2000;102(21):2582-2587.

13. Kim WY, Stuber M, Bornert P, Kissinger KV, Manning WJ, Botnar RM. Three-dimensional black-blood cardiac magnetic resonance coronary vessel wall imaging detects positive arterial remodeling in patients with nonsignificant coronary artery disease. Circulation. 2002;106(3):296-299.

14. Assmann G, Cullen P, Schulte $\mathrm{H}$. Simple scoring scheme for calculating the risk of acute coronary events based on the 10-year follow-up of the prospective cardiovascular Munster (PROCAM) study. Circulation. 2002;105(3):310-315.

15. Botnar RM, Kim WY, Bornert P, Stuber M, Spuentrup E, Manning WJ. 3D coronary vessel wall imaging utilizing a local inversion technique with spiral image acquisition. Magn Reson Med. 2001;46(5):848-854. 
16. Desai MY, Lai S, Barmet C, Weiss RG, Stuber M. Reproducibility of 3D free-breathing magnetic resonance coronary vessel wall imaging. Eur Heart J. 2005;26(21):2320-2324.

17. Zhang S, Hatsukami TS, Polissar NL, Han C, Yuan C. Comparison of carotid vessel wall area measurements using three different contrast-weighted black blood MR imaging techniques. Magn Reson Imaging. 2001;19(6):795-802.

18. Spuentrup E, Katoh M, Buecker A, Manning WJ, Schaeffter T, Nguyen T-H, Kuhl HP, Stuber M, Botnar RM, Gunther RW. Free-breathing 3D Steady-State Free Precession Coronary MR Angiography with Radial k-Space Sampling: Comparison with Cartesian k-Space Sampling and Cartesian Gradient-Echo Coronary MR Angiography--Pilot Study. Radiology. 2004;231(2):581-586.

19. Kim WY, Astrup AS, Stuber M, Tarnow L, Falk E, Botnar RM, Simonsen C, Pietraszek L, Hansen PR, Manning WJ, Andersen NT, Parving HH. Subclinical coronary and aortic atherosclerosis detected by magnetic resonance imaging in type 1 diabetes with and without diabetic nephropathy. Circulation. 2007;115(2):228-235.

20. Adame IM, van der Geest RJ, Wasserman BA, Mohamed MA, Reiber JH, Lelieveldt BP. Automatic segmentation and plaque characterization in atherosclerotic carotid artery MR images. Magma. 2004;16(5):227-234.

21. Austen WG, Edwards JE, Frye RL, Gensini GG, Gott VL, Griffith LS, McGoon DC, Murphy ML, Roe BB. A reporting system on patients evaluated for coronary artery disease. Report of the Ad Hoc Committee for Grading of Coronary Artery Disease, Council on Cardiovascular Surgery, American Heart Association. Circulation. 1975;51(4 Suppl):5-40.

22. O'Brien PC. Procedures for comparing samples with multiple endpoints. Biometrics. 1984;40(4):1079-1087.

23. Läuter J. Exact $\mathrm{T}$ and $\mathrm{F}$ tests for analyzing studies with multiple endpoints. Biometrics. 1996;52(3):964-970.

24. Tuzcu EM, Kapadia SR, Tutar E, Ziada KM, Hobbs RE, McCarthy PM, Young JB, Nissen SE. High prevalence of coronary atherosclerosis in asymptomatic teenagers and young adults: evidence from intravascular ultrasound. Circulation. 2001;103(22):2705-2710.

25. Miao C, Chen S, Macedo R, Lai S, Liu K, Li D, Wasserman BA, Vogel-Claussen J, Lima JA, Bluemke DA. Positive remodeling of the coronary arteries detected by magnetic resonance imaging in an asymptomatic population: MESA (Multi-Ethnic Study of Atherosclerosis). J Am Coll Cardiol. 2009;53(18):1708-1715.

26. Fuster V. Lewis A. Conner Memorial Lecture. Mechanisms leading to myocardial infarction: insights from studies of vascular biology. Circulation. 1994;90(4):2126-2146.

27. Strong JP, Mc GH, Jr. The natural history of coronary atherosclerosis. Am J Pathol. 1962;40:37-49.

28. Lee RT, Libby P. The unstable atheroma. Arterioscler Thromb Vasc Biol. 1997;17(10):18591867.

29. Grundy SM, Balady GJ, Criqui MH, Fletcher G, Greenland P, Hiratzka LF, Houston-Miller N, Kris-Etherton P, Krumholz HM, LaRosa J, Ockene IS, Pearson TA, Reed J, Washington R, Smith SC, Jr. Primary prevention of coronary heart disease: guidance from Framingham: a statement for healthcare professionals from the AHA Task Force on Risk Reduction. American Heart Association. Circulation. 1998;97(18):1876-1887.

30. Wood D, De Backer G, Faergeman O, Graham I, Mancia G, Pyorala K. Prevention of coronary heart disease in clinical practice. Recommendations of the Second Joint Task Force of European and other Societies on coronary prevention. Eur Heart J. 1998;19(10):1434-1503.

31. Clevert DA, Johnson T, Michaely H, Jung EM, Flach PM, Strautz TI, Reiser M, Schoenberg SO. High-grade stenoses of the internal carotid artery: comparison of high-resolution contrast enhanced 3D MRA, duplex sonography and power Doppler imaging. Eur J Radiol. 2006;60(3):379-386. 
32. Leiner T. Magnetic resonance angiography of abdominal and lower extremity vasculature. Top Magn Reson Imaging. 2005;16(1):21-66.

33. Patel ST, Mills JL, Sr., Tynan-Cuisinier G, Goshima KR, Westerband A, Hughes JD. The limitations of magnetic resonance angiography in the diagnosis of renal artery stenosis: comparative analysis with conventional arteriography. J Vasc Surg. 2005;41(3):462-468.

34. Rumberger JA, Simons DB, Fitzpatrick LA, Sheedy PF, Schwartz RS. Coronary artery calcium area by electron-beam computed tomography and coronary atherosclerotic plaque area. A histopathologic correlative study. Circulation. 1995;92(8):2157-2162.

35. Greenland P, LaBree L, Azen SP, Doherty TM, Detrano RC. Coronary artery calcium score combined with Framingham score for risk prediction in asymptomatic individuals. Jama. 2004;291(2):210-215.

36. de Roos A, Kroft LJ, Bax JJ, Geleijns J. Applications of multislice computed tomography in coronary artery disease. J Magn Reson Imaging. 2007;26(1):14-22.

37. Leber AW, Becker A, Knez A, von Ziegler F, Sirol M, Nikolaou K, Ohnesorge B, Fayad ZA, Becker CR, Reiser M, Steinbeck G, Boekstegers P. Accuracy of 64-slice computed tomography to classify and quantify plaque volumes in the proximal coronary system: a comparative study using intravascular ultrasound. J Am Coll Cardiol. 2006;47(3):672-677.

38. Fujii K, Carlier SG, Mintz GS, Wijns W, Colombo A, Bose D, Erbel R, de Ribamar Costa J, Jr., Kimura M, Sano K, Costa RA, Lui J, Stone GW, Moses JW, Leon MB. Association of plaque characterization by intravascular ultrasound virtual histology and arterial remodeling. $\mathrm{Am} J$ Cardiol. 2005;96(11):1476-1483.

39. Schoenhagen P, Ziada KM, Kapadia SR, Crowe TD, Nissen SE, Tuzcu EM. Extent and direction of arterial remodeling in stable versus unstable coronary syndromes : an intravascular ultrasound study. Circulation. 2000;101(6):598-603.

40. Brenner DJ, Hall EJ. Computed tomography--an increasing source of radiation exposure. $N$ Engl J Med. 2007;357(22):2277-2284.

41. Akhter N, Milford-Beland S, Roe MT, Piana RN, Kao J, Shroff A. Gender differences among patients with acute coronary syndromes undergoing percutaneous coronary intervention in the American College of Cardiology-National Cardiovascular Data Registry (ACC-NCDR). Am Heart J. 2009;157(1):141-148.

42. Lokhandwala JO, Skelding KA. Sex differences in percutaneous coronary interventions. J Cardiovasc Transl Res. 2009;2(3):300-305.

43. Maintz D, Ozgun M, Hoffmeier A, Fischbach R, Kim WY, Stuber M, Manning WJ, Heindel W, Botnar RM. Selective coronary artery plaque visualization and differentiation by contrastenhanced inversion prepared MRI. Eur Heart J. 2006;27(14):1732-1736.

44. Yeon SB, Sabir A, Clouse M, Martinezclark PO, Peters DC, Hauser TH, Gibson CM, Nezafat R, Maintz D, Manning WJ, Botnar RM. Delayed-enhancement cardiovascular magnetic resonance coronary artery wall imaging: comparison with multislice computed tomography and quantitative coronary angiography. J Am Coll Cardiol. 2007;50(5):441-447.

45. Naghavi M, Libby P, Falk E, Casscells SW, Litovsky S, Rumberger J, Badimon JJ, Stefanadis C, Moreno P, Pasterkamp G, Fayad Z, Stone PH, Waxman S, Raggi P, Madjid M, Zarrabi A, Burke A, Yuan C, Fitzgerald PJ, Siscovick DS, de Korte CL, Aikawa M, Juhani Airaksinen KE, Assmann G, Becker CR, Chesebro JH, Farb A, Galis ZS, Jackson C, Jang IK, Koenig W, Lodder RA, March K, Demirovic J, Navab M, Priori SG, Rekhter MD, Bahr R, Grundy SM, Mehran R, Colombo A, Boerwinkle E, Ballantyne C, Insull W, Jr., Schwartz RS, Vogel R, Serruys PW, Hansson GK, Faxon DP, Kaul S, Drexler H, Greenland P, Muller JE, Virmani R, Ridker PM, Zipes DP, Shah PK, Willerson JT. From vulnerable plaque to vulnerable patient: a call for new definitions and risk assessment strategies: Part I. Circulation. 2003;108(14):1664-1672. 


\section{Chapter 6}

\section{Time-efficient black blood coronary vessel wall imaging at $3 T$ using}

Improved Motion Sensitized Driven Equilibrium (iMSDE): Feasibility
and reproducibility

J. Wang, S.C. Gerretsen, J.H. Maki, C. Jaarsma, M.E. Kooi, D. Herzka, B. Chu, V.L.Yarnykh, C. Yuan, T. Leiner 


\begin{abstract}
Introduction: Coronary artery disease remains the number one cause of death in the western world. Accurate detection of subclinical atherosclerotic lesions of the coronary artery using non-invasive imaging approaches has intense clinical interest. The aim of this study is to explore the feasibility and reproducibility of a time-efficient coronary vessel wall measurement approach using an improved motion-sensitized driven equilibrium (iMSDE) pulse sequence.
\end{abstract}

Methods: In this study, the iMSDE pulse sequence was first optimized for in vivo coronary wall imaging to achieve sufficient blood suppression. It was then applied on a group of healthy volunteers $(\mathrm{N}=8)$ to evaluate its feasibility of vessel wall visualization. The same technique was also applied on a separate group of volunteers $(\mathrm{N}=19)$ for reproducibility study by scanning the same subject in two separate scanning sessions.

Results: The iMSDE sequence was found to provide good coronary vessel wall delineation on healthy volunteers. It was also found to provide reproducible coronary vessel wall diameter and thickness measurements in both proximal and middle segments of the right coronary artery. The study also found a significantly increased vessel wall thickness in a subgroup of old volunteers, when compared to their young counterparts.

Conclusion: As a summary, the feasibility of iMSDE based coronary vessel wall imaging was proved and its reproducibility was demonstrated in the first time. This technique can potentially be utilized for fast and accurate coronary artery disease detection in a clinical environment. 


\section{Introduction}

Coronary artery disease (CAD) remains the number one cause of death in the Western world ${ }^{1}$ and over half of all patients with sudden cardiac death do not experience typical chest pain symptoms prior to this event ${ }^{2,3}$. In order to identify patients with relevant but unrecognized CAD, clinical algorithms such as the Framingham Risk Index ${ }^{4}$ and Prospective Cardiovascular Münster Heart Study (PROCAM) ${ }^{5}$ risk scores have been developed. Although the use of these and other risk scores is a major advance over clinical risk prediction based on relative risk estimates, they still remain imperfect for predicting cardiovascular events in individual patients ${ }^{6}$.

To overcome this limitation, a lot of efforts have been directed to detect the presence of subclinical atherosclerotic lesions using non-invasive imaging approaches, such as computed tomography angiography ${ }^{7}$ and intravascular ultrasonography ${ }^{8}$. Magnetic resonance imaging (MRI) is also an attractive technique for this purpose as it is totally non-invasive, does not require the injection of contrast medium, and is well suited for repetitive imaging in cases when follow-up is desired. Furthermore, with the inherent soft tissue contrast, $\mathrm{MRI}$ is capable of detecting not only luminal narrowing ${ }^{9}$, but also positive remodeling ${ }^{10}$ of the coronary vessel wall $(\mathrm{CVW})^{11}$. This latter phenomenon has been traditionally regarded as a pivotal sign of clinically relevant future coronary artery disease ${ }^{\mathbf{1 2}}$, and might influence individual treatment decisions.

MRI black-blood techniques, which can suppress the usually hyperintense blood signal for better visualization of the vessel wall, are important for coronary artery vessel wall measurements. The currently used method for MR CVW imaging is based on a double inversion recovery (DIR) prepulse ${ }^{11}$. This technique, however, is limited in a few aspects when applied for CVW imaging. First, it requires a relatively long inversion time ( $\mathrm{TI}$ ), usually $400-500 \mathrm{~ms}$, to achieve sufficient blood nulling. As a result, imaging of a single coronary artery may take up to 10-15 minutes with this method since a repetition time (TR) of two heartbeats is required to achieve sufficient blood suppression. Second, DIR based techniques can achieve only suboptimal blood suppression if the imaging plane is not perpendicular to the flow direction. As a result, when an artery with tortuous segments is imaged, flow artifacts can be observed. Furthermore, as has been shown in carotid artery imaging, the DIR technique is known to suffer from high signal-intensity slow flow artifacts at the boundary be- 
tween the vessel wall and lumen as it requires complete blood replenishing to achieve luminal blood suppression ${ }^{13}$.

An improved motion-sensitized driven equilibrium (iMSDE) technique that was originally developed for carotid artery imaging ${ }^{13,14}$, has been recently shown to achieve more time efficient acquisition and more accurate depiction of the luminal boundaries. We hypothesize that robust and reproducible in vivo $M R$ imaging of the human $C V W$ can be achieved in a more time-efficient manner by using the iMSDE technique. The objective of the current study was to investigate whether the iMSDE preparation ${ }^{14}$ could also be applied for CVW imaging and whether the measurements are reproducible.

\section{Materials and Methods}

\section{Study design}

In the first part of the study, the iMSDE sequence was tested for feasibility and optimized to acquire CVW in a time efficient manner. After the imaging parameters were determined, the reproducibility of the new method was investigated in the second part of the study. All scans were performed on a clinical 3.0T system (Philips Achieva, Release 2.5, Best, The Netherlands), using a commercially available 6-element phased-array cardiac coil. Subjects were examined in the supine position. This study has been approved by the local institutional review board and signed informed consent was obtained from all participants.

\section{MR Pulse Sequence}

The pulse sequence diagram of the iMSDE sequence is shown in figure 1 a. Compared to the traditional $\mathrm{MSDE}^{13}$, the iMSDE technique was selected for this study because it provides better immunity to local magnetic field inhomogeneities as well as image degradation caused by eddy currents ${ }^{14}$. This is a particularly important merit for high-field cardiac applications where significant field inhomogeneities are more likely to present.

The imaging diagram for iMSDE based CVW imaging is shown in figure $1 \mathrm{~b}$. Benefiting from the short duration of the iMSDE sequence ( $20 \mathrm{~ms})$, only $1 \mathrm{R}-\mathrm{R}$ interval was required for CVW imaging. The turbo field echo (TFE) acquisition window had a total duration of less than $120 \mathrm{~ms}$. The trigger delay time ranged from 550-750 ms (figure 1b), based on subject heart rate. Other scanning parameters for the optimized iMSDE-prepared black-blood coronary vessel wall 
imaging protocol include: 3D TFE sequence, TR/TE 10/2.3 ms, flip angle 20, TFE factor 19 , FOV $300 \times 264 \times 30 \mathrm{~mm}$, pixel size $0.9 \times 0.9 \times 1.5 \mathrm{~mm}$, in-plane reconstruction matrix $512 \times 512$, fat saturation, and two averages. The total scan time was $4 \mathrm{~min} 6 \mathrm{sec}$ with $100 \%$ navigator efficiency (Calculated for heart rate of 60 beats/min).

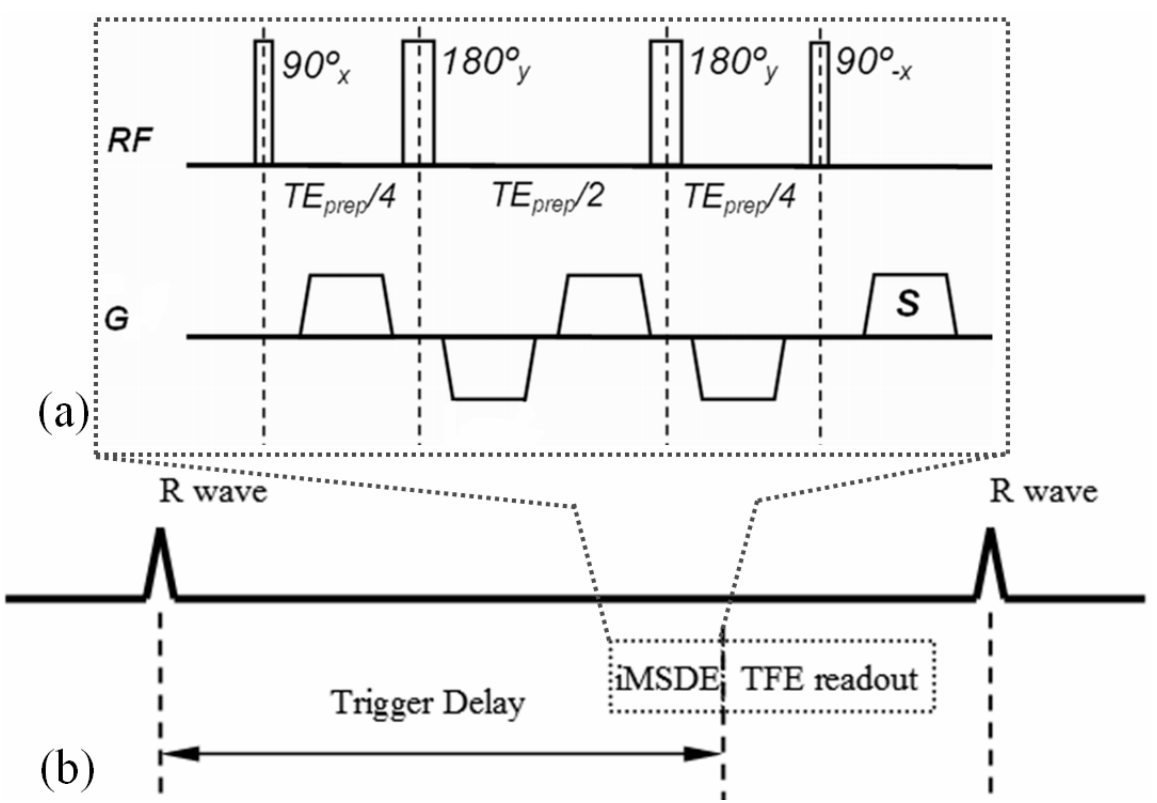

Figure 1. Imaging diagram of the pulse sequence used for this study: (a) the improved MSDE (iMSDE) pulse sequence used to suppress blood signal; and (b) the timing of iMSDE prepulse and TFE acquisition sequence in a CVW imaging process.

\section{Feasibility Testing and Sequence Optimization}

The feasibility of iMSDE CVW MR imaging was tested in eight healthy volunteers ( 5 males, age range: 28-63 years) without known cardiovascular disease.

Localizing scans were obtained and the subject specific trigger delay and acquisition window were determined as previously described ${ }^{15}$. These scans were followed by coronary MRA (CMRA) using a bright blood threedimensional (3D) turbo field echo (TFE) sequence in combination with spectrally selective fat saturation to image the RCA lumen. Imaging parameters were: TR/TE $6.2 / 3.1 \mathrm{~ms}, 120^{\circ}$ flip angle, 10 slices; acquired resolution: $0.98 \times 0.98 \times 3 \mathrm{~mm}$. The imaging slab was oriented to cover the entire RCA up to the origin of the posterior descending branch. In the same orientation, the CVW scans of the RCA were acquired. 
After the feasibility was established, the first gradient moment of the iMSDE sequence was optimized to balance the blood suppression capability and overall image quality. For this purpose a series of images with $1.5 \mathrm{~ms}$ dephasing gradient duration were acquired at the same location of one volunteer (male, 33 years) while changing the gradient strength, and correspondingly, the first gradient moment. The $\mathrm{m} 1$ varied from $0-300 \mathrm{mTms} 2 / \mathrm{m}$, in steps of approximately $75 \mathrm{mTms} 2 / \mathrm{m}$. Cardiac synchronization was used to trigger the signal acquisition and respiratory navigator was used to compensate for involuntary motions caused by breathing. The total scanning time was 2 min $30 \mathrm{sec}$ without considering navigator efficiency.

The signal-to-noise ratio (SNR) was defined as the ratio between the signal of the region of interest (ROI) and the standard deviation of an ROI from cardiac muscle ${ }^{16}$. Contrast-to-noise (CNR) between two tissues was defined as the difference of the SNR between two tissues.

Due to the limited size of the coronary wall itself, cardiac wall was selected for contrast-to-noise ratio optimization. The CNR between the left ventricle chamber wall and ventricle lumen, as well as lumen and muscle SNR were used for optimization.

\section{Reproducibility study}

The feasibility of robust CVW MR imaging using the iMSDE sequence was tested in a reproducibility study in 19 healthy volunteers without any known symptoms of coronary atherosclerosis. In order to image a range of CVW thicknesses, 10 younger volunteers ( 8 males; mean age $25 \pm 4.7$ years (mean \pm standard deviation), as well as 9 older volunteers ( 7 males; mean age $59 \pm 9.2$ years) were recruited.

A stack of images, parallel to each other, were planned based on the scout right coronary artery angiogram scan by using the three-point planning. The slice package contained 20 slices so that the whole target artery was covered, even when the arteries are tortuous.

To assess the reproducibility of the CVW MR imaging protocol, all subjects were imaged twice. After the first scanning session was complete, patients were completely taken out of the magnet and off the scanner table. Subsequently, a second session was initiated within 15 minutes after completion of the first. In the second scanning session, the entire exam was repeated including patient and tabletop re-positioning, acquisition of scout views as well as a fresh determination of subject specific trigger delays followed by acquisition of the coronary artery luminogram and vessel wall images. 


\section{Image processing and analysis}

For viewing purposes, all coronary artery lumen and vessel wall images were processed with a curved multiplanar reformation algorithm by using the Soapbubble research tool (Soapbubble, Philips Healthcare). The curved multiplanar reformation process allowed for the simultaneous display of multiple coronary segments in one two-dimensional (2D) representation, to facilitate further image analysis. Two experienced MR reviewers with 7-10 years of cardiovascular image review experience then evaluated the reformatted images. The MR reviewers first evaluated the image quality according to the readability of the coronary arteriograms and vessel wall images on a three-point scale. A grade of 1 was given when images were uninterpretable due to motion artifacts and/or suboptimal suppression of luminal signal; a grade of 2 denoted acceptable image quality with only minor artifacts; and a grade of 3 was given in case of good artifact-free image quality. For images graded with score 2 or 3 , the black blood images were then evaluated for quantitative measurements.

For quantitative analyses, the RCA was divided into proximal and middle parts in accordance with the AHA classification ${ }^{17}$. Lumen diameter and mean wall thickness of the vessel wall were measured on source images using custom-written software (VesselMASS, Laboratory for Image Processing (LKEB), Leiden, The Netherlands). First, the mean lumen diameter was measured in both proximal and middle segments, from both the bright and black blood images. Subsequently, visible parts of the vessel wall were outlined and mean anterior and posterior wall thickness was measured. In segments where there was no visible vessel wall, CVW thickness was set an arbitrary value of $0.1 \mathrm{~mm}$.

\section{Statistical Analysis}

Mean image quality was compared using a paired Student's t-test. The reproducibility of iMSDE CVW imaging was evaluated using the Bland-Altman plots to investigate the segment-by-segment agreement between the two measurements. The agreement between two measurements with regard to mean lumen diameter and vessel wall thickness between different scanning sessions was compared using Wilcoxon signed rank test. A $\boldsymbol{P}$ value below 0.05 was taken to indicate statistical significance. 


\section{Results}

\section{Sequence optimization}

iMSDE coronary vessel wall imaging was found to provide good image quality (figures 2 and 3). Lumen SNR demonstrated monotonic decrease with an increase of the dephasing gradient strengths (figure 2). At the same time, the CNR between blood and cardiac muscle was maximized when the first gradient moment was $153.5 \mathrm{mTms} 2 / \mathrm{m}$ as seen in figure 4 . With a further increase of the gradient strength, the loss of the cardiac muscle signal becomes apparent, while no significant improvement in blood suppression is achieved. As a result, the optimal value of the first gradient moment based on CNR consideration $(153.5 \mathrm{mTms} 2 / \mathrm{m})$ was used in the following experiments.

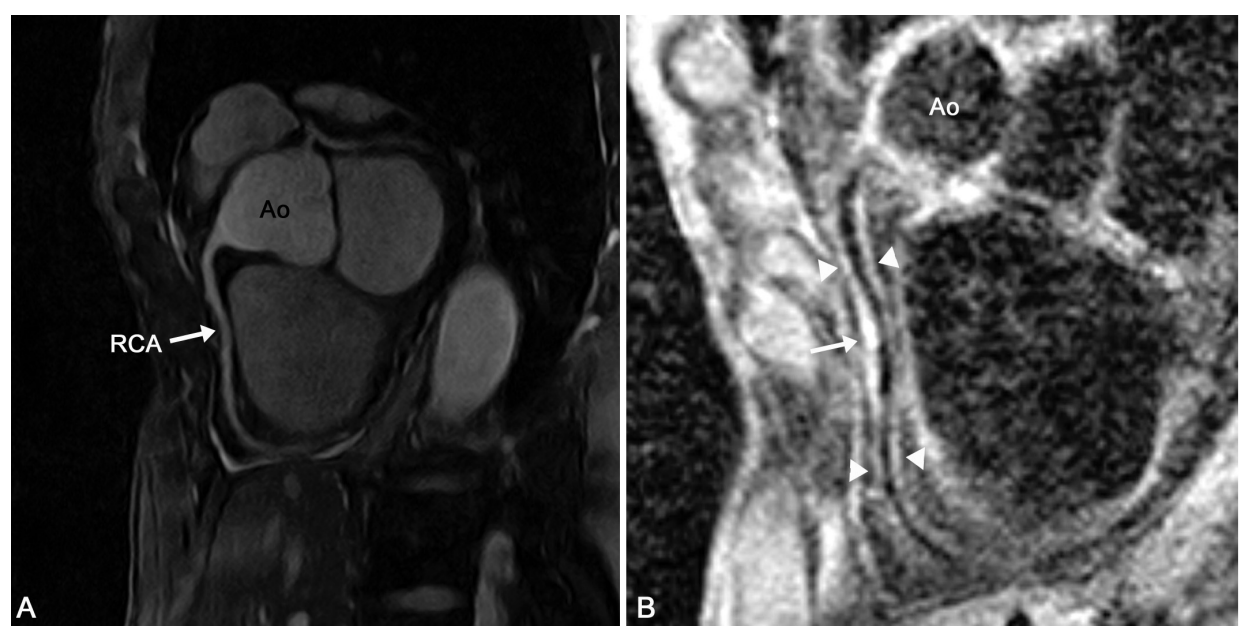

Figure 2. Results after sequence optimization in a 78 y/o male volunteer. A) Bright blood coronary MRA of the right coronary artery (RCA). The RCA can be visualized with excellent image quality. B) Good delineation of the vessel wall (arrowheads) with excellent suppression of luminal blood was obtained. Note the focal area of wall thickening (arrow). 

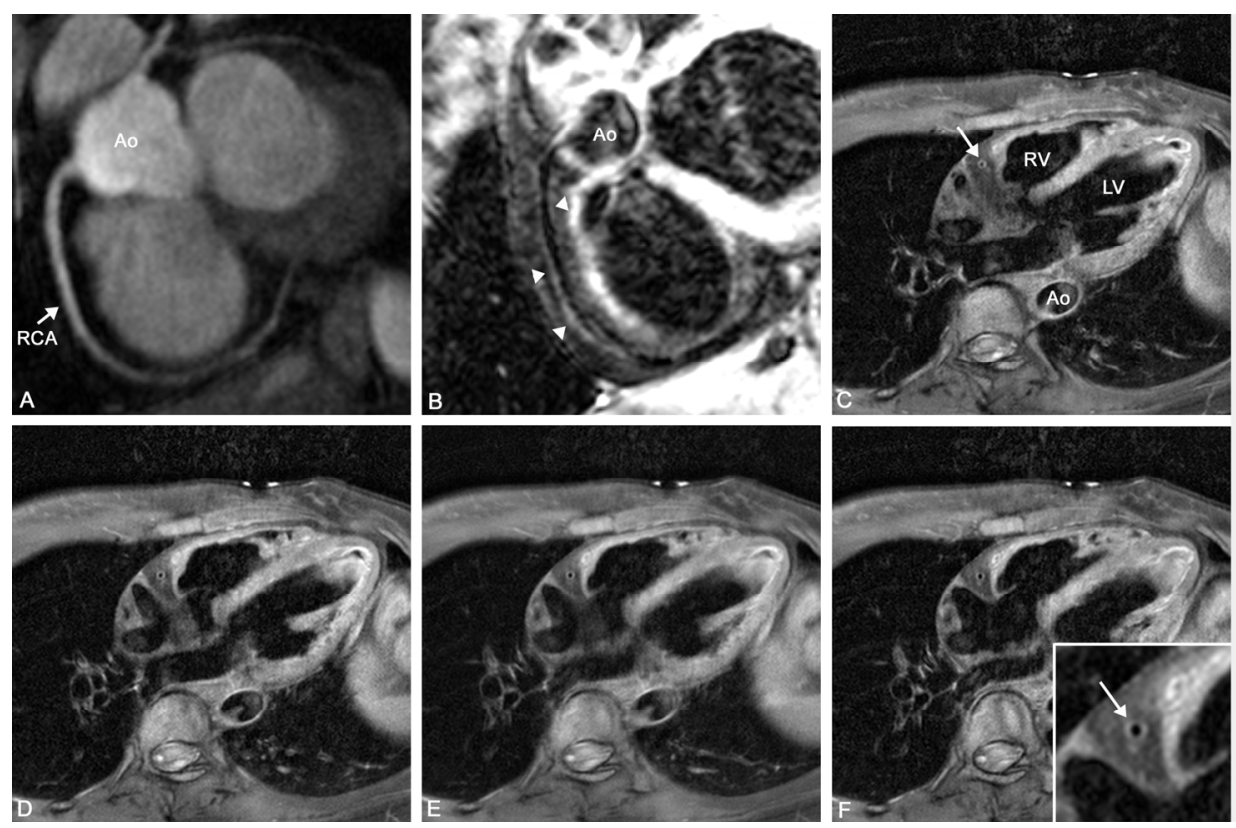

Figure 3. Results after sequence optimization in a $33 \mathrm{y} / 0$ female volunteer. A) Again, the right coronary artery (RCA) can be visualized with good image quality on bright blood coronary MRA. Ao indicates aorta. B) Good delineation of the vessel wall (arrowheads) with good suppression of luminal blood was obtained. C-F) demonstrate 4 cross-sectional iMSDE images in different areas of the RCA with good delineation of the vessel wall (arrow). RV indicates right ventricle, LV indicates left ventricle.

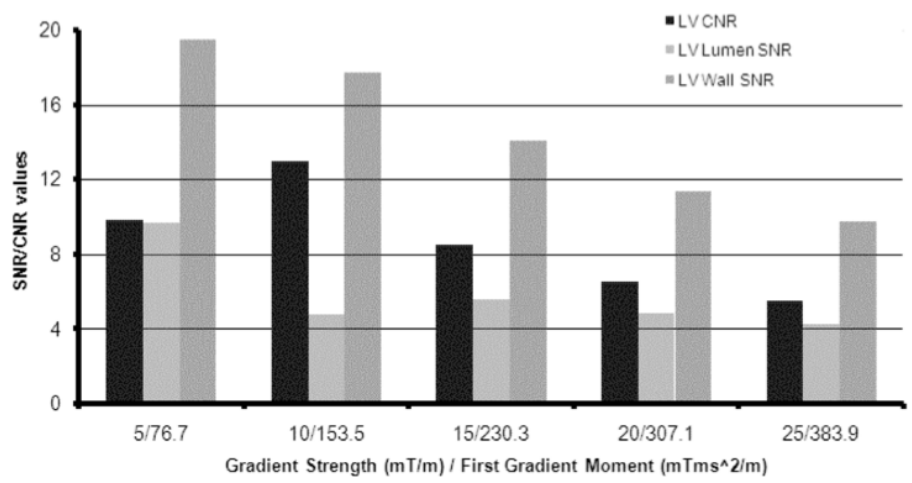

Figure 4. iMSDE sequence parameter optimization for fast human heart imaging. The CNR of LV chamber (black bar) maximizes when the first gradient moment is $153.5 \mathrm{mTms} / \mathrm{m}$. 


\section{Reproducibility study}

In 17 of 19 subjects two measurements of the coronary lumen were acquired successfully. Coronary lumen images of the other 2 subjects were excluded because of persistent problems with erratic vectorcardiograms. Of the 136 potential vessel wall measurements (17 subjects $\times 4$ measurements at 2 time points), 12 measurements in 3 subjects could not be obtained due to VCG problems $(n=4)$, susceptibility artifacts $(n=4)$ or motion artifacts $(n=4)$ in 1 of the 2 acquisitions. In 84 segments the vessel wall was identified and measured, and 68 segments ( 34 pairs) were matched for the Bland-Altman analysis. Among all segments, 40 vessel segments exhibited no discernable vessel wall.

Image quality of the images was generally rated as 'good and artifact free' (grade 3 as defined above). Mean image quality of the proximal and middle segments of the RCA with both bright and black blood acquisitions is listed in table 1.

Table 1 Image quality score

\begin{tabular}{lllll}
\hline Sequence & Location* & $\begin{array}{l}\text { Scan 1 } \\
(\text { mean } \pm \text { SD) }\end{array}$ & $\begin{array}{l}\text { Scan 2 } \\
(\text { mean } \pm \text { SD) }\end{array}$ & P-value \\
\hline Bright Blood & Proximal $(n=17)$ & $2.88 \pm 0.33$ & $2.82 \pm 0.39$ & 0.32 \\
& Middle $(n=17)$ & $2.94 \pm 0.24$ & $2.94 \pm 0.24$ & 1.00 \\
Black Blood & Proximal $(n=15)$ & $2.63 \pm 0.50$ & $2.44 \pm 0.51$ & 0.08 \\
(iMSDE) & Middle $(n=15)$ & $2.69 \pm 0.48$ & $2.69 \pm 0.60$ & 1.00 \\
\hline
\end{tabular}

Image quality of the visualized proximal and middle segments in both the bright blood scan and iMSDE vessel wall sequence for both scanning sessions; Values represent number of paired measurements, standard deviations (SD) represent variation between subjects.

Reproducibility of both the lumen and vessel wall measurements was good, as evidenced by similar mean luminal diameter and wall thickness at the two different time points (tables 2 and 3), as well as low bias in the Bland-Altman analyses (figures 5 and 6). Of note, there was a substantial difference in luminal diameter between bright and black blood imaging (table 2), most likely due to partial volume effects and the difference in spatial resolution between the two sequences. Comparing the vessel wall thickness between old and young subjects, a significantly thickened vessel wall was observed on in the old population (Young: $1.09 \pm 0.34 \mathrm{~mm}$, Old: $1.69 \pm 0.37 \mathrm{~mm}, \mathrm{p}<0.01$ ). Examples of $\mathrm{CVW}$ images at different time points in the younger and older age groups are shown in figures 7 and 8. 
Table 2. Reproducibility of lumen diameter measurements

\begin{tabular}{lllll}
\hline Sequence & Location* & Scan 1 $(\mathrm{mm} \pm \mathrm{SD})$ & Scan 2 $(\mathrm{mm} \pm \mathrm{SD})$ & P-value \\
\hline Bright Blood & Proximal $(\mathrm{n}=17)$ & $3.57 \pm 0.80$ & $3.65 \pm 0.87$ & 0.74 \\
Black Blood & Middle $(\mathrm{n}=17)$ & $3.47 \pm 1.02$ & $3.44 \pm 1.00$ & 0.14 \\
(iMSDE) & Proximal $(\mathrm{n}=16)$ & $2.49 \pm 0.75$ & $2.40 \pm 0.73$ & 0.23 \\
\hline
\end{tabular}

Measurements of lumen diameter (in $\mathrm{mm} \pm \mathrm{SD}$ ) were performed on both bright blood coronary MRA and the black blood vessel wall scans of the first and second scanning session. There are no significant differences in absolute lumen diameter measurements; Values represent number of paired measurements, standard deviations (SD) represent variation between subjects.

Table 3. Reproducibility of Vessel Wall Imaging using the iMSDE prepulse

\begin{tabular}{llll}
\hline Location* & Scan $1(\mathrm{~mm} \pm \mathrm{SD})$ & Scan $2(\mathrm{~mm} \pm$ SD) & P-value \\
\hline Anterior Proximal $(\mathrm{n}=8)$ & $1.15 \pm 0.37$ & $1.16 \pm 0.43$ & 0.92 \\
Posterior Proximal $(\mathrm{n}=8)$ & $1.23 \pm 0.50$ & $1.43 \pm 0.37$ & 0.27 \\
Anterior Middle $(\mathrm{n}=9)$ & $1.12 \pm 0.30$ & $1.28 \pm 0.31$ & 0.23 \\
Posterior Middle $(\mathrm{n}=9)$ & $1.47 \pm 0.30$ & $1.31 \pm 0.13$ & 0.64 \\
\hline
\end{tabular}

Measurements of vessel wall thickness (in $\mathrm{mm} \pm \mathrm{SD}$ ) were performed in both the anterior and posterior vessel wall in proximal and middle right coronary artery segments. There are no significant differences in measured vessel wall thickness between the first and second scanning session; * Values represent number of paired measurements. Only segments with discernable vessel wall were taken into account.

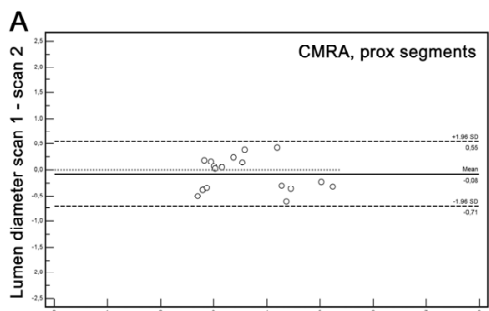

mean lumen diameter scan 1 and scan 2

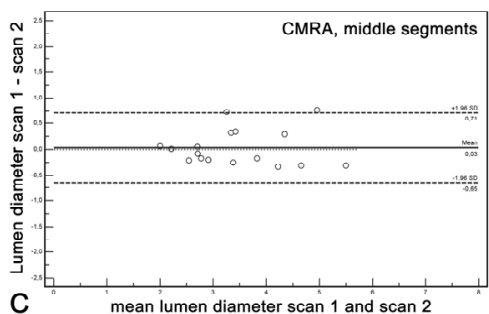

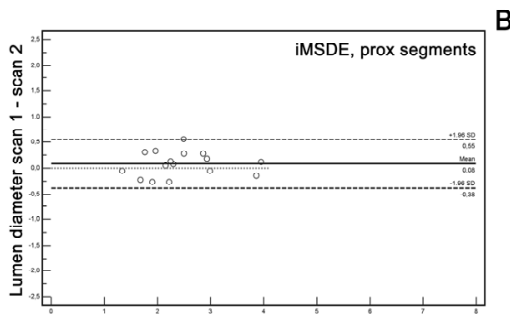

mean lumen diameter scan 1 and scan 2

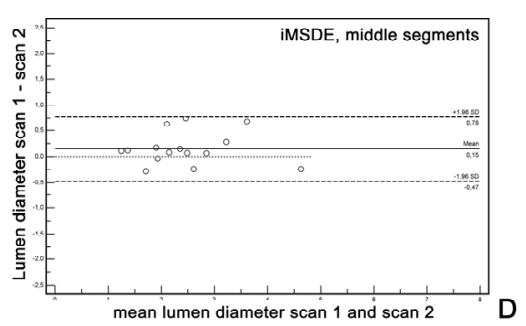

Figure 5. Agreement of lumen diameter measurements. Bland Altman plots for right coronary artery (RCA) lumen diameter as measured on the bright blood coronary MRA $(A, C)$ and on iMSDE vessel wall scans $(B, D)$ demonstrate low bias between results of the first and second scanning session. Measurements were performed in proximal $(A, B)$ and middle $(C, D)$ RCA segments. 

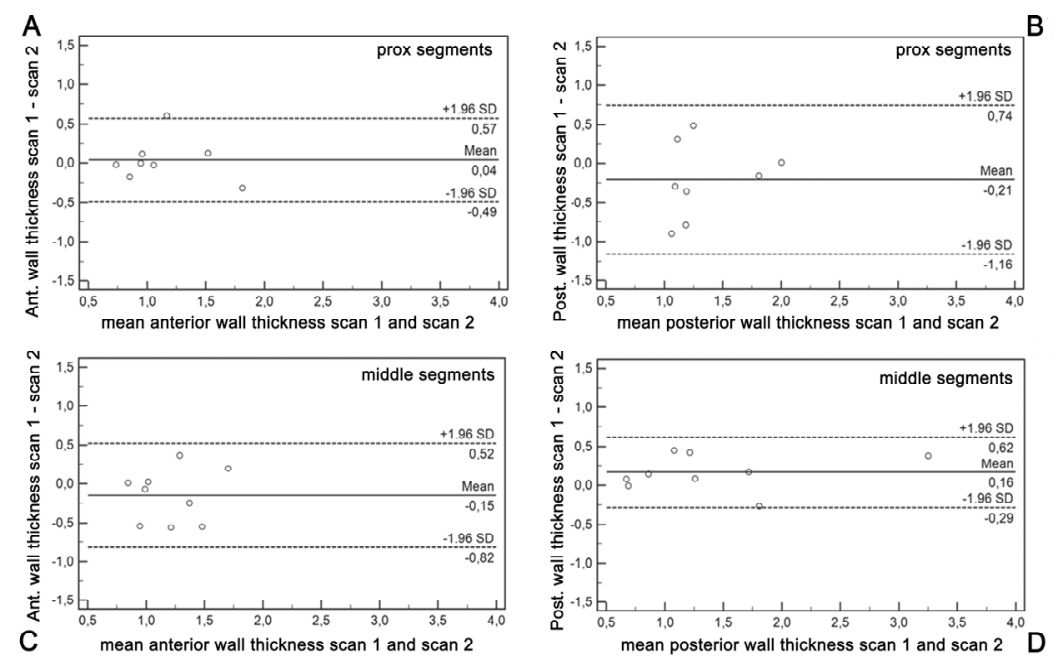

Figure 6. Agreement of vessel wall thickness measurements. Bland Altman plots for right coronary artery (RCA) vessel wall thickness measured on iMSDE images in both the anterior $(A, C)$ and posterior vessel wall $(B, D)$ demonstrate good agreement between results of the first and second scanning session. Measurements were performed in proximal $(A, B)$ and middle $(C, D)$ RCA segments.
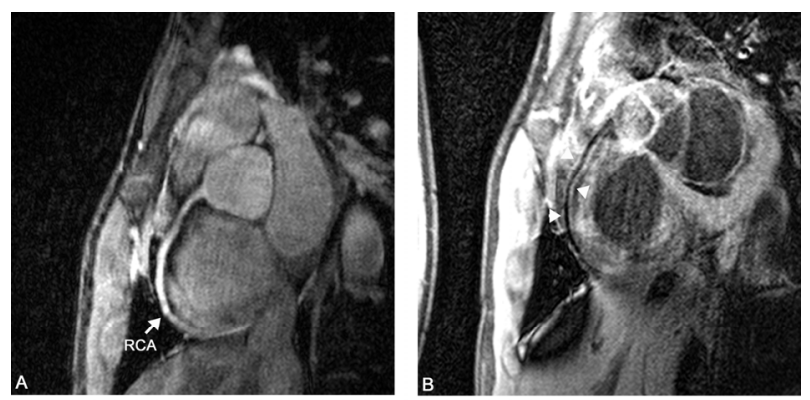

Figure 7. Bright blood coronary $\operatorname{MRA}(A, C)$ and $\mathrm{MMSDE}$ vessel wall scan $(B, D)$ in a 23 y/o male. $A$ and $B$ represents the first scanning session, $C$ and $\mathrm{D}$ represent the second session. The right coronary artery (RCA) was visualized in both sessions, and on the
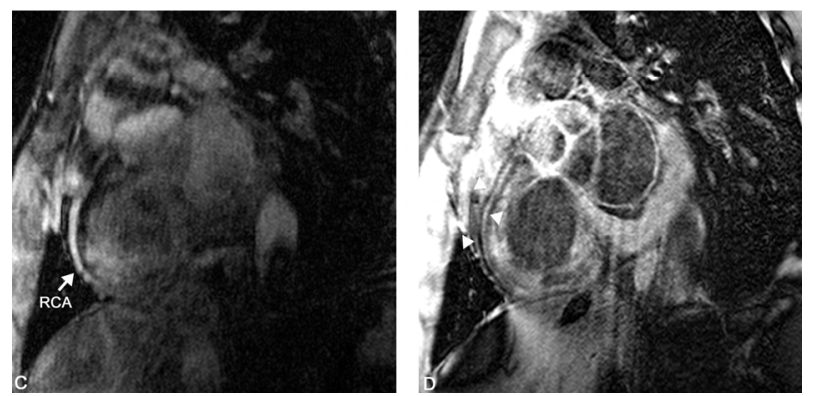
iMSDE scan there is good delineation of the vessel wall (arrowheads). Note excellent suppression of blood signal. 

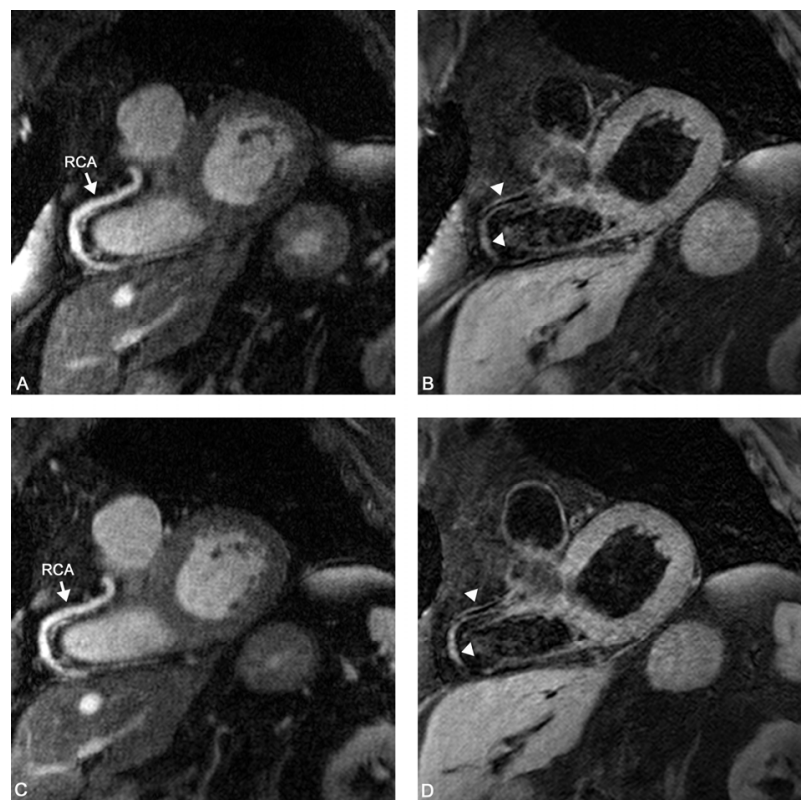

Figure 8. Bright blood coronary $\operatorname{MRA}(A, C)$ and $\mathrm{MSDE}$ vessel wall scan $(B, D)$ in a 76 y/o male. $A$ and $B$ represents the first scanning session, $C$ and $D$ represent the second session. Excellent visualization of the right coronary artery (RCA) $(A, C)$ and vessel wall (arrowheads) (B, D) was achieved in both sessions. Note excellent suppression of blood signal.

\section{Discussion}

In this work we have demonstrated the feasibility and reproducibility of a novel and more time-efficient method of coronary vessel wall (CVW) imaging using the improved motion-sensitized driven equilibrium (iMSDE) technique.

Compared to the traditional DIR technique ${ }^{18}$, iMSDE technique is advantageous in a few aspects. First, it has improved time efficiency due to the much shorter preparation time (iMSDE $\sim 20 \mathrm{~ms}$ vs. DIR $400-500 \mathrm{~ms}^{13}$ ). Since the iMSDE sequence does not rely on the long TI for blood suppression, it is more proper for the coronary artery imaging application. As demonstrated in this study, the iMSDE prepulse fits within a single heart beat, which allowed imaging with doubled time efficiency (i.e. half the acquisition time) when compared to the DIR-based sequences. Second, iMSDE can suppress blood flow in virtually any direction and thus promises improved flow suppression efficiency, especially for tortuous arteries. The longitudinal images obtained in this study can delineate an extended coverage of the coronary artery clearly in a stack of thin slices, which will be very helpful for the early and fast diagnosis of any possible atherosclerotic plaque.

The reproducibility of the new technique has been proved to be good, as evidenced by the small bias and variation in the Bland Altman analyses. Furthermore, to our best knowledge, this is the first report that has investigated 
the reproducibility of CVW imaging at 3.0T. Good reproducibility is a key feature of any technique that is to be applied to follow changes in coronary wall geometry over time. Although good reproducibility was found in both age groups, as the reproducibility in the elder group was found to be higher. We believe fewer partial volume effects in the vessel wall measurements cause this difference, since elderly people presented thicker vessel walls compared to the younger counterparts.

The current study has several limitations. In the reproducibility part of the study, only the RCA from a relatively small group of subjects were imaged due to the scanning time limitation. This fact, however, does not negatively affect the conclusion of this study since the primary goal of this study was to test the feasibility and reproducibility of the new iMSDE based CVW imaging technique. No technical obstacles are anticipated for transferring this technique to a larger population or for visualizing other coronary arteries. Another limitation of this study is that the study population has been limited to volunteers with no known coronary diseases. However, we would anticipate seeing this technique more robustly applied to patients with diagnosed diseases since the thickened coronary artery vessel wall generally allows for better visualization, particularly for a resolution and signal-to-noise limited application like this.

Also, the spatial resolution used in this study is relatively low, which prevented finer segments to be quantified using MRI CVW imaging. However, the primary goal of this study was to explore the feasibility and reproducibility of CVW imaging at $3 \mathrm{~T}$ rather than optimizing the technique for all segments. The low resolution makes it sometimes hard to visualize normal coronary artery wall because of the partial volume effect. A higher SNR generally allows higher spatial resolution images to be used and vessel wall more robustly imaged, as has been demonstrated by Gerretsen et al. who have described acquired voxel sizes of $0.78 \times 0.78 \times 2.0 \mathrm{~mm}^{3}{ }^{19}$. Advances in hardware such as a 32-channel cardiac coil and the recently proposed parallel transmission technique ${ }^{20}$ have both been demonstrated for higher SNR imaging. We anticipate that these technical advancements will further improve the current coronary artery imaging technique by increasing the current spatial resolution used.

Finally, this study lacks a direct comparison between iMSDE and DIR based CVW imaging. The shorter magnetization recovery period (a single R-R) used by iMSDE allows for much improved acquisition efficiency compared to the multiple R-R intervals used by the DIR technique. This approach, however, will also lead to reduced magnetization recovery during each heartbeat, thus limiting the overall SNR achievable. Theoretically, by averaging two acquisitions of 
iMSDE acquired with shorter TR, the overall SNR should still be higher than the single acquisition of DIR with longer TR. Besides, the improved flow suppres$\operatorname{sion}^{13}$ and no T1 dependency can also justify the usage of this technique.

Other than MR, multidetector row computed tomography (MDCT) based coronary imaging has also been applied to evaluate the coronary artery wall. CT relies primarily on the calcium score, which quantifies the amount of calcium around the coronary artery for risk evaluation. Although elevated calcium scores have been linked with increased cardiac symptoms ${ }^{21}$, the role of calcified lesions in atherosclerosis lesions is still controversial. Some recent studies indicate that calcified lesions have been found to, instead of promoting plaque rupture, stabilize the atherosclerotic plaque. As a result, the applicability of using calcium scores for plaque rupture risk assessment is still undetermined. However, the newest generation of MDCT equipment is now also capable of imaging the coronary vessel wall, with even better spatial and temporal resolution than MR CVW imaging ${ }^{22-24}$. Nevertheless, radiation and contrast burdens remain non-negligible concerns, especially for repeated imaging ${ }^{25}$. Furthermore, coronary MRA and MR CVW imaging would make helpful complements to more established cardiac MR imaging techniques such as black blood imaging to delineate cardiac anatomy ${ }^{26}$, steady state free precession cine imaging ${ }^{27}$ and myocardial perfusion imaging ${ }^{28}$.

In conclusion, we have demonstrated the feasibility and reproducibility of a new method to improve the time-efficiency of coronary artery vessel wall imaging. The reproducibility of the study has also been well established in a group of volunteers in two age groups. This technique can potentially be utilized for fast and accurate coronary artery disease detection. 


\section{References}

1. Lloyd-Jones D, Adams RJ, Brown TM, Carnethon M, Dai S, De Simone G, Ferguson TB, Ford E, Furie K, Gillespie C, Go A, Greenlund K, Haase N, Hailpern S, Ho PM, Howard V, Kissela B, Kittner S, Lackland D, Lisabeth L, Marelli A, McDermott MM, Meigs J, Mozaffarian D, Mussolino M, Nichol G, Roger VL, Rosamond W, Sacco R, Sorlie P, Thom T, Wasserthiel-Smoller S, Wong ND, Wylie-Rosett J. Heart disease and stroke statistics--2010 update: a report from the American Heart Association. Circulation. 2010;121(7):e46-e215.

2. de Vreede-Swagemakers JJ, Gorgels AP, Dubois-Arbouw WI, van Ree JW, Daemen MJ, Houben LG, Wellens HJ. Out-of-hospital cardiac arrest in the 1990's: a population-based study in the Maastricht area on incidence, characteristics and survival. J Am Coll Cardiol. 1997;30(6):1500-1505.

3. Kannel WB, Thomas HE, Jr. Sudden coronary death: the Framingham Study. Ann N Y Acad Sci. 1982;382:3-21.

4. Wilson PW, D'Agostino RB, Levy D, Belanger AM, Silbershatz $H$, Kannel WB. Prediction of coronary heart disease using risk factor categories. Circulation. 1998;97(18):1837-1847.

5. Assmann G, Cullen P, Schulte H. Simple scoring scheme for calculating the risk of acute coronary events based on the 10-year follow-up of the prospective cardiovascular Munster (PROCAM) study. Circulation. 2002;105(3):310-315.

6. Lloyd-Jones DM, Tian L. Predicting cardiovascular risk: so what do we do now? Arch Intern Med. 2006;166(13):1342-1344.

7. Vogl TJ, Abolmaali ND, Diebold T, Engelmann K, Ay M, Dogan S, Wimmer-Greinecker G, Moritz A, Herzog C. Techniques for the detection of coronary atherosclerosis: multidetector row CT coronary angiography. Radiology. 2002;223(1):212-220.

8. Tuzcu EM, Kapadia SR, Tutar E, Ziada KM, Hobbs RE, McCarthy PM, Young JB, Nissen SE. High prevalence of coronary atherosclerosis in asymptomatic teenagers and young adults: evidence from intravascular ultrasound. Circulation. 2001;103(22):2705-2710.

9. Kim WY, Danias PG, Stuber M, Flamm SD, Plein S, Nagel E, Langerak SE, Weber OM, Pedersen EM, Schmidt M, Botnar RM, Manning WJ. Coronary magnetic resonance angiography for the detection of coronary stenoses. N Engl J Med. 2001;345(26):1863-1869.

10. Glagov S, Weisenberg E, Zarins CK, Stankunavicius R, Kolettis GJ. Compensatory enlargement of human atherosclerotic coronary arteries. N Engl J Med. 1987;316(22):1371-1375.

11. Kim WY, Stuber M, Bornert P, Kissinger KV, Manning WJ, Botnar RM. Three-dimensional black-blood cardiac magnetic resonance coronary vessel wall imaging detects positive arterial remodeling in patients with nonsignificant coronary artery disease. Circulation. 2002;106(3):296-299.

12. Narula J, Garg P, Achenbach S, Motoyama S, Virmani R, Strauss HW. Arithmetic of vulnerable plaques for noninvasive imaging. Nat Clin Pract Cardiovasc Med. 2008;5 Suppl 2:S210.

13. Wang J, Yarnykh VL, Hatsukami T, Chu B, Balu N, Yuan C. Improved suppression of plaquemimicking artifacts in black-blood carotid atherosclerosis imaging using a multislice motion-sensitized driven-equilibrium (MSDE) turbo spin-echo (TSE) sequence. Magn Reson Med. 2007;58(5):973-981.

14. Wang J, Yarnykh VL, Yuan C. Enhanced image quality in black-blood MRI using the improved motion-sensitized driven-equilibrium (iMSDE) sequence. J Magn Reson Imaging. 2010;31(5):1256-1263. 
15. Leiner T, Katsimaglis G, Yeh EN, Kissinger KV, van Yperen G, Eggers H, Manning WJ, Botnar RM. Correction for heart rate variability improves coronary magnetic resonance angiography. J Magn Reson Imaging. 2005;22(4):577-582.

16. Fan Z, Zhang Z, Chung YC, Weale P, Zuehlsdorff S, Carr J, Li D. Carotid arterial wall MRI at 3T using 3D variable-flip-angle turbo spin-echo (TSE) with flow-sensitive dephasing (FSD). J Magn Reson Imaging. 2010;31(3):645-654.

17. Austen WG, Edwards JE, Frye RL, Gensini GG, Gott VL, Griffith LS, McGoon DC, Murphy ML, Roe BB. A reporting system on patients evaluated for coronary artery disease. Report of the Ad Hoc Committee for Grading of Coronary Artery Disease, Council on Cardiovascular Surgery, American Heart Association. Circulation. 1975;51(4 Suppl):5-40.

18. Edelman RR, Chien D, Kim D. Fast selective black blood MR imaging. Radiology. 1991;181(3):655-660.

19. Gerretsen SC, Kooi ME, Kessels AG, Schalla S, Katoh M, Van der Geest RJ, Manning WJ, Waltenberger J, Van Engelshoven JMA, Botnar RM, Leiner T. Visualization of coronary wall atherosclerosis in asymptomatic subjects and patients with coronary artery disease using magnetic resonance imaging. PLOS ONE. 2010 (Accepted).

20. Katscher U, Bornert P. Parallel RF transmission in MRI. NMR Biomed. 2006;19(3):393-400.

21. Greenland P, LaBree L, Azen SP, Doherty TM, Detrano RC. Coronary artery calcium score combined with Framingham score for risk prediction in asymptomatic individuals. Jama. 2004;291(2):210-215.

22. Achenbach S, Raggi P. Imaging of coronary atherosclerosis by computed tomography. Eur Heart J. 2010; Epub ahead of print.

23. Leber AW, Becker A, Knez A, von Ziegler F, Sirol M, Nikolaou K, Ohnesorge B, Fayad ZA, Becker CR, Reiser M, Steinbeck G, Boekstegers P. Accuracy of 64-slice computed tomography to classify and quantify plaque volumes in the proximal coronary system: a comparative study using intravascular ultrasound. J Am Coll Cardiol. 2006;47(3):672-677.

24. Korosoglou G, Mueller D, Lehrke S, Steen H, Hosch W, Heye T, Kauczor HU, Giannitsis E, Katus HA. Quantitative assessment of stenosis severity and atherosclerotic plaque composition using 256-slice computed tomography. Eur Radiol.20(8):1841-1850.

25. Einstein AJ, Henzlova MJ, Rajagopalan S. Estimating risk of cancer associated with radiation exposure from 64-slice computed tomography coronary angiography. Jama. 2007;298(3):317-323.

26. Simonetti OP, Finn JP, White RD, Laub G, Henry DA. "Black blood" T2-weighted inversionrecovery MR imaging of the heart. Radiology. 1996;199(1):49-57.

27. Bloomer TN, Plein S, Radjenovic A, Higgins DM, Jones TR, Ridgway JP, Sivananthan MU. Cine MRI using steady state free precession in the radial long axis orientation is a fast accurate method for obtaining volumetric data of the left ventricle. J Magn Reson Imaging. 2001;14(6):685-692.

28. Wilke N, Simm C, Zhang J, Ellermann J, Ya X, Merkle H, Path G, Ludemann H, Bache RJ, Ugurbil K. Contrast-enhanced first pass myocardial perfusion imaging: correlation between myocardial blood flow in dogs at rest and during hyperemia. Magn Reson Med. 1993;29(4):485-497. 



\section{Chapter 7}

Cardiac cine MRI: Comparison of 1.5 T, non-enhanced $3.0 \mathrm{~T}$ and blood pool enhanced 3.0 T imaging

S.C. Gerretsen, B. Vers/uis, S.C.A.M. Bekkers, T. Leiner

European journal of Radiology 2008;65(1):80 


\section{Abstract}

Introduction: Cardiac cine imaging using balanced steady state free precession sequences (bSSFP) suffers from artefacts at 3.0 T. We compared bSSFP cardiac cine imaging at $1.5 \mathrm{~T}$ with gradient echo imaging at $3.0 \mathrm{~T}$ with and without a blood pool contrast agent.

Methods: Eleven patients referred for cardiac cine imaging underwent imaging at $1.5 \mathrm{~T}$ and 3.0 T. At 3.0 $\mathrm{T}$ images were acquired before and after administration of $0.03 \mathrm{mmol} / \mathrm{kg}$ gadofosveset. Blood pool signal-to-noise ratio (SNR), temporal variations in SNR, ejection fraction and myocardial mass were compared. Subjective image quality was scored on a four-point scale.

Results: Blood pool SNR increased with more than $75 \%$ at 3.0 T compared to $1.5 \mathrm{~T}(p<0.001)$; after contrast administration at $3.0 \mathrm{~T}$ SNR increased with $139 \%(p<0.001)$. However, variations in blood pool SNR at $3.0 \mathrm{~T}$ were nearly three times as high versus those at $1.5 \mathrm{~T}$ in the absence of contrast medium ( $p$ $<0.001$ ); after contrast administration this was reduced to approximately a factor $1.4(p=0.21)$. Saturation artefacts led to significant overestimation of ejection fraction in the absence of contrast administration (1.5 T: $44.7 \pm 3.1$ vs. $3.0 \mathrm{~T}: 50.7 \pm 4.2[p=0.04]$ vs. $3.0 \mathrm{~T}$ post contrast: $43.4 \pm 2.9[p=0.55])$. Subjective image quality was highest for $1.5 \mathrm{~T}(2.8 \pm 0.3)$, and lowest for non-enhanced $3.0 \mathrm{~T}(1.7 \pm 0.6 ; p=0.006)$.

Conclusion: GRE cardiac cine imaging at 3.0 T after injection of the blood pool agent gadofosveset leads to improved objective and subjective cardiac cine image quality at 3.0 $\mathrm{T}$ and to the same conclusions regarding cardiac ejection fraction compared to bSSFP imaging at $1.5 \mathrm{~T}$. 


\section{Introduction}

Despite the relatively widespread availability of 3.0 T MR scanners their exact role in cardiac imaging remains to be defined. Problems with $B 0$ - and B1inhomogenity at $3.0 \mathrm{~T}$ lead to problems with off-resonance artefacts, potentially compromising the reliability of the current standard, balanced steady state free precession (bSSFP) cardiac cine imaging. Because of these reasons it might be useful to revert to regular gradient echo (GRE) cardiac cine imaging given that saturation artifacts, which prompted the switch to bSSFP in the first place ${ }^{1}$, can be over-come. Fonseca et al. have already demonstrated in a swine model that the addition of the blood pool agent Gadomer-17 (BayerSchering Pharma, Berlin, Germany) greatly improved GREcardiac cine imaging at 3.0 $\mathrm{T}^{2}$. Gadomer-17, however, is still in clinical trials and not yet clinically available.

Recently the first blood pool agent, gadofosveset trisodium (Vasovist, BayerSchering Pharma, Berlin, Germany) has been approved for clinical use in the European Union. Gadofosveset exhibits reversible binding to albumin, which results in prolonged intravascular retention of at least $85 \%$ of the injected dose $^{3}$. Because of the prolonged intravascular retention and resultant prolonged reduction in blood T1 this agent might also be useful for GRE cardiac cine imaging.

The purpose of the current study was to investigate the clinical feasibility of non-enhanced and blood pool-enhanced GRE cardiac cine MRI at 3.0 T in patients referred for cardiac cine imaging and to compare image quality and functional parameters with non-enhanced bSSFP cardiac cine MRI obtained at $1.5 \mathrm{~T}$.

\section{Materials and methods}

\section{Patients}

Eleven male patients referred for cardiac cine MRI at $1.5 \mathrm{~T}$ were also imaged at 3.0 T before and after administration of gadofosveset trisodium. The mean age of the patients was 56.5 years (range: 33-83 years). Indications for imaging were determination of left ventricular function after recent myocardial infarction ( $n=6)$, suspected cardiomyopathy $(n=2)$, suspected valve leakage $(n=1)$, suspected arrhythmogenic right ventricular dysplasia $(n=1)$ and suspected 
intracardiac shunt $(n=1)$. The study was approved by the local medical ethics committee and all patients were required to give informed consent before they were included in the study.

\section{MR imaging}

MR Imaging was performed on both $1.5 \mathrm{~T}$ and $3.0 \mathrm{~T}$ commercially available systems. The 1.5T MR imager was a Philips Intera (Software version 11.1; Philips Medical Systems, Best, The Netherlands) equipped with a gradient strength of $30 \mathrm{mT} / \mathrm{m}$ and a maximum slew rate of $150 \mathrm{mT} /(\mathrm{m} \mathrm{ms})$. For all examinations on $1.5 \mathrm{~T}$ the commercially available 5-element cardiac coil was used. The studies at 3.0 T were acquired on a Philips Achieva 3.0 T magnet (Software version 1.1; Philips Medical Systems) equipped with a gradient strength of $80 \mathrm{mT} / \mathrm{m}$ and a maximum slew rate of $200 \mathrm{mT} /(\mathrm{m} \mathrm{ms})$. At $3.0 \mathrm{~T}$ a 6 -element cardiac coil was used. The temporal resolution of the scans was $25 \mathrm{~ms}$. The number of phases acquired depended on the heart rate.

After patient positioning, interactive scout views were obtained of the chest and heart followed by either bSSFP cardiac cine imaging at 1.5 T, or GRE cardiac cine imaging at 3.0 T. Images were obtained in the short axis, and the horizontal and vertical left ventricular long axes as well as the left ventricular outflow tract. As good as possible it was attempted to obtain the same imaging planes in each orientation. At 3.0 T the exact same cine sequences were obtained before and after contrast administration. Imaging parameters used at both field strengths are listed in table 1.

Table 1. MR imaging parameters

\begin{tabular}{lll}
\hline & Field strength \\
\cline { 2 - 3 } & $1.5 \mathrm{~T}$ & $3.0 \mathrm{~T}$ \\
\hline Pulse sequence & bSSFP & $\mathrm{GRE}$ \\
TR $(\mathrm{ms})$ & 3.8 & 5.4 \\
TE $(\mathrm{ms})$ & 1.9 & 3.2 \\
Flip angle $(\circ)$ & 50 & 15 \\
Field-of-view $(\mathrm{mm})$ & $350 \times 300$ & $350 \times 300$ \\
Matrix & $246 \times 192$ & $192 \times 152$ \\
Slice thickness $(\mathrm{mm})$ & 6.0 & 8.0 \\
Acquired voxel size $\left(\mathrm{mm}^{3}\right)$ & $1.4 \times 1.6 \times 6.0$ & $1.8 \times 2.0 \times 8.0$ \\
\hline
\end{tabular}

bSSFP: balanced steady state free precession; GRE: gradient recalled echo. 


\section{Contrast medium}

At $3.0 \mathrm{~T}$ each patient received $0.03 \mathrm{mmol} / \mathrm{kg}$ of the blood pool agent gadofosveset trisodium after cine images were obtained in the aforementioned orientations. A few minutes after injection, cine images were obtained for a second time. Contrast was injected by means of an MR compatible power remote contolled power injector (Spectris, Medrad, Maastricht, The Netherlands) at a rate of $1.0 \mathrm{~mL} / \mathrm{s}$ through 18-gauge intravenous canulla placed in an antecubital vein.

\section{Quantitative image evaluation}

For quantitative evaluation, the signal-to-noise (SNR) and blood pool-tomyocardium $(\mathrm{B} / \mathrm{M})$ ratios were calculated over the cardiac cycle in both the short and vertical long axis orientations at the different field strengths. In addition, functional parameters were calculated.

SNR was measured on the middle slice of the acquisitions and determined by dividing the signal obtained in a region of interest (ROI) placed in the blood pool by the standard deviation of noise measured in a ROI outside the body. Noise was corrected by the Rayleigh factor ${ }^{4}$. Care was taken not to include overt artefacts due to ghosting in the phase-encoding direction. The $\mathrm{B} / \mathrm{M}$ ratio was determined by dividing the signal from the blood pool ROI by the signal in a region of interest placed in the septal part of the myocardium.

Functional parameters were calculated using the CAAS MRV software package (Version 3.0, Pie Medical, Maastricht, The Netherlands). Endocardial end-diastolic volume (EDV), end-systolic volume (ESV), myocardial mass and ejection fraction (EF) were determined by manual placement of contours. The boundary of the left ventricle, the mitral valve plane and apex were marked manually on the two- and four-chamber long axis images. Subsequently epicardial and endocardial contours were drawn on the short axis images. Papillary muscles and trabeculations were considered part of the blood pool and excluded from the myocardium. After determination of EDV and ESV ejection fraction was calculated by subtracting ESV from EDV and dividing by EDV.

\section{Qualitative image evaluation}

Subjective image quality was scored for both the short axis and vertical long axis images on a three-point scale by a single observer with 7 years of experience in evaluation of cardiac MRI studies. Images were scored on a four point 
scale with $0=$ non-diagnostic images, $1=$ marginally diagnostic with marked artefacts hindering interpretation, 2 = diagnostic image quality with only minor artefacts present and $3=$ excellent image quality without noticable artefacts.

\section{Statistical analysis}

Mean SNR and B/M ratios over the cardiac cycle as well as the maximum difference in these values over the cardiac cycle were compared with using analysis of variance. Ejection fraction and myocardial mass were compared using a paired samples ttest. Subjective image quality was compared with Wilcoxon's signed rank test. Significance was assumed when $p$-values were below 0.05 .

\section{Results}

All examinations were technically successfully and there were no adverse reactions after injection of the contrast medium. Although the $\mathrm{B} / \mathrm{M}$ ratio was highest for 1.5 T, the SNR of the bloodpool was significantly higher at $3.0 \mathrm{~T}$ and increased even further after contrast administration (table 2). As expected, the administration of contrast also led to a substantial decrease in B/M ratio because of increased signal intensity of the myocardium. In contrast to $1.5 \mathrm{~T}$ there were large and significant variations in the SNR of the non-enhanced blood pool over the cardiac cycle at 3.0 T. Adminstration of contrast medium largely mitigated these variations, especially in the long axis orientation (figure 1).

Table 2. SNR and SNR variations over the cardiac cycle for the different field strengths and imaging orientations and $\mathrm{B} / \mathrm{M}$ ratio.

\begin{tabular}{|c|c|c|c|c|c|c|}
\hline & \multicolumn{6}{|c|}{ Field strength and orientation } \\
\hline & \multicolumn{2}{|l|}{$1.5 \mathrm{~T}$} & \multicolumn{2}{|l|}{$3.0 \mathrm{~T}$} & \multicolumn{2}{|c|}{ 3.0 T contrast-enhanced } \\
\hline & ShAx & $\mathrm{L} 2 \mathrm{CH}$ & ShAx & $\mathrm{L} 2 \mathrm{CH}$ & ShAx & $\mathrm{L} 2 \mathrm{CH}$ \\
\hline$\overline{S N R}$ & $98.7 \pm 12.1$ & $103.1 \pm 16.5$ & $175.5 \pm 27.8$ & $168.7 \pm 22.9$ & $239.2 \pm 24.3$ & $258.4 \pm 17.6$ \\
\hline $\mathrm{p}$-Valuea & NA & NA & $<0.001$ & $<0.001$ & $<0.001$ & $<0.001$ \\
\hline $\begin{array}{l}\text { Maximum SNR } \\
\text { variation (\%) }\end{array}$ & $10.9 \pm 4.2$ & $15.3 \pm 3.9$ & $27.9 \pm 8.5$ & $38.6 \pm 10.7$ & $14.3 \pm 2.4$ & $20.7 \pm 5.8$ \\
\hline p-Valuea & NA & NA & $<0.001$ & $<0.001$ & 0.21 & 0.12 \\
\hline $\mathrm{B} / \mathrm{M}$ ratio & $2.97 \pm 0.29$ & $3.16 \pm 0.40$ & $2.69 \pm 0.45$ & $2.55 \pm 0.55$ & $1.98 \pm 0.17$ & $2.21 \pm 0.34$ \\
\hline$p$-Value ${ }^{a}$ & NA & NA & 0.12 & 0.08 & 0.02 & 0.04 \\
\hline
\end{tabular}

ShAx: short axis; $\mathrm{L} 2 \mathrm{CH}$ : left ventricular vertical long axis; SNR: signal-to-noise ratio. B/M ratio: blood pool to myocardium ratio; a $p$-Value versus imaging at $1.5 \mathrm{~T}$; NA: not applicable. 
(a)

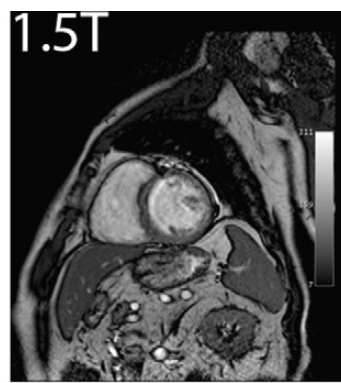

(b)

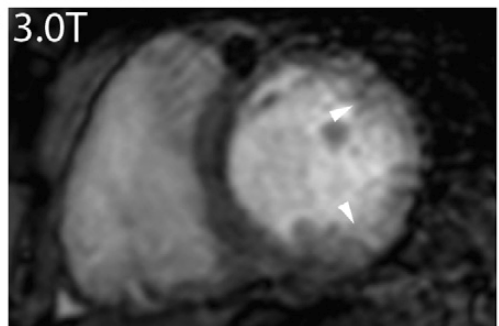

3.01
3.0T CE
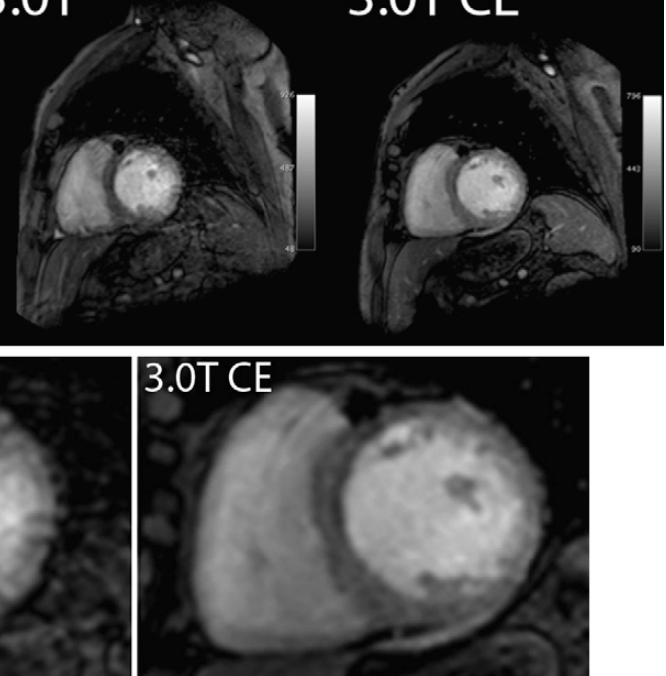

Figure 1. Fifty-five year old male patient imaged post myocardial infarction to determine left ventricular function. Short-axis images (a) obtained at 1.5 T (left panel); 3.0 T (middle panel) and 3.0 $\mathrm{T}$ post contrast administration (right panel). Note the more homogenous appearance of the left ventricular blood pool at 3.0 T after contrast administration and the better delineation of the myocardium from the blood pool (arrowheads in b).

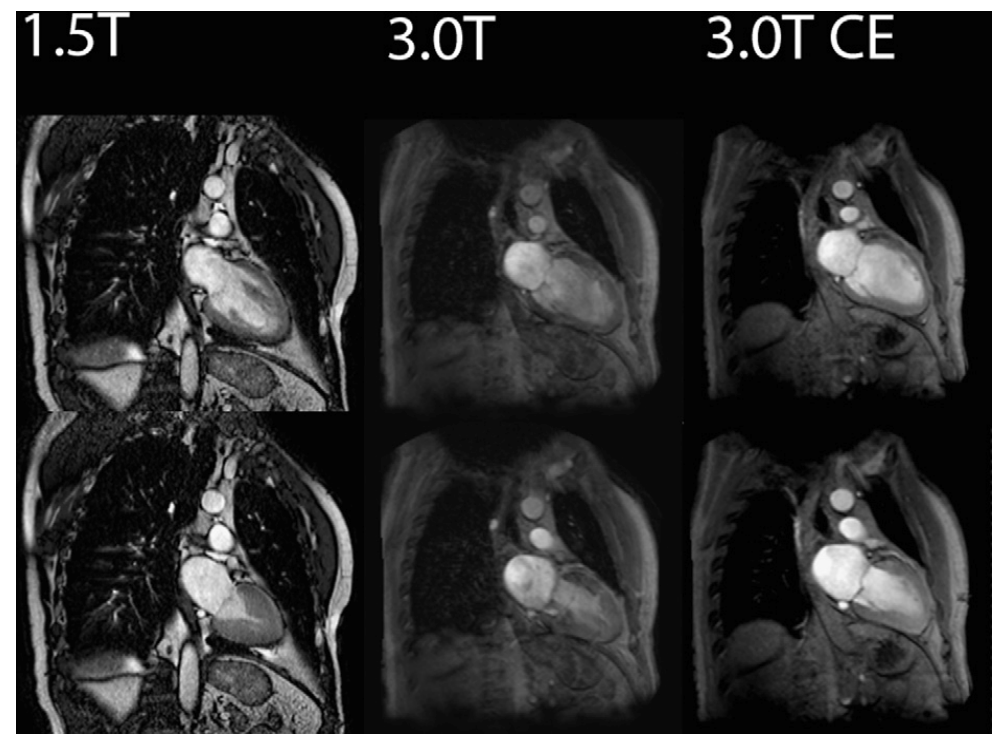

Figure 2. Seventy-two year old male patient imaged post myocardial infarction to determine left ventricular function. Vertical long axis images obtained at $1.5 \mathrm{~T}$ (left column); $3.0 \mathrm{~T}$ (middle column) and 3.0 T post contrast administration (right column). Images in the upper row were acquired at end-diastole; images in the lower row at end-systole. Without contrast administration the left ventricular blood pool is strongly inhomogeneous. 
Table 3. Ejection fractions and myocardial mass at the different field strengths

\begin{tabular}{llll}
\hline & \multicolumn{2}{l}{ Field strength } \\
\cline { 2 - 4 } & $1.5 \mathrm{~T}$ & $3.0 \mathrm{~T}$ & $3.0 \mathrm{~T}$ contrast-enhanced \\
\hline Ejection fraction (\%) $_{\text {p-Value }}^{\mathrm{a}}$ & $44.7 \pm 3.1$ & $50.7 \pm 4.2$ & $43.4 \pm 2.9$ \\
Myocardial mass (g) $_{\text {p-Value }}^{\mathrm{a}}$ & $\mathrm{NA}$ & 0.04 & 0.55 \\
p & $103 \pm 29.1$ & $126 \pm 32.5$ & $111 \pm 29.4$ \\
\hline
\end{tabular}

a $p$-Value versus imaging at $1.5 \mathrm{~T}$; NA: not applicable.

Table 4. Mean subjective image quality by field strength and orientation

\begin{tabular}{llll}
\hline & Field strength & \\
\cline { 2 - 4 } & $1.5 \mathrm{~T}$ & $3.0 \mathrm{~T}$ & $3.0 \mathrm{~T}$ contrast-enhanced \\
\hline Short axis & $2.8 \pm 0.3$ & $1.7 \pm 0.6$ & $2.5 \pm 0.4$ \\
p-Value $^{\mathrm{a}}$ & $\mathrm{NA}$ & 0.006 & 0.12 \\
Vertical long axis $^{\mathrm{p}}$ & $2.7 \pm 0.4$ & $1.4 \pm 0.5$ & $2.3 \pm 0.3$ \\
p-Value $^{\mathrm{a}}$ & $\mathrm{NA}$ & $<0.001$ & 0.08 \\
\hline
\end{tabular}

${ }^{a} p$-Value versus imaging at $1.5 \mathrm{~T}$; NA: not applicable.
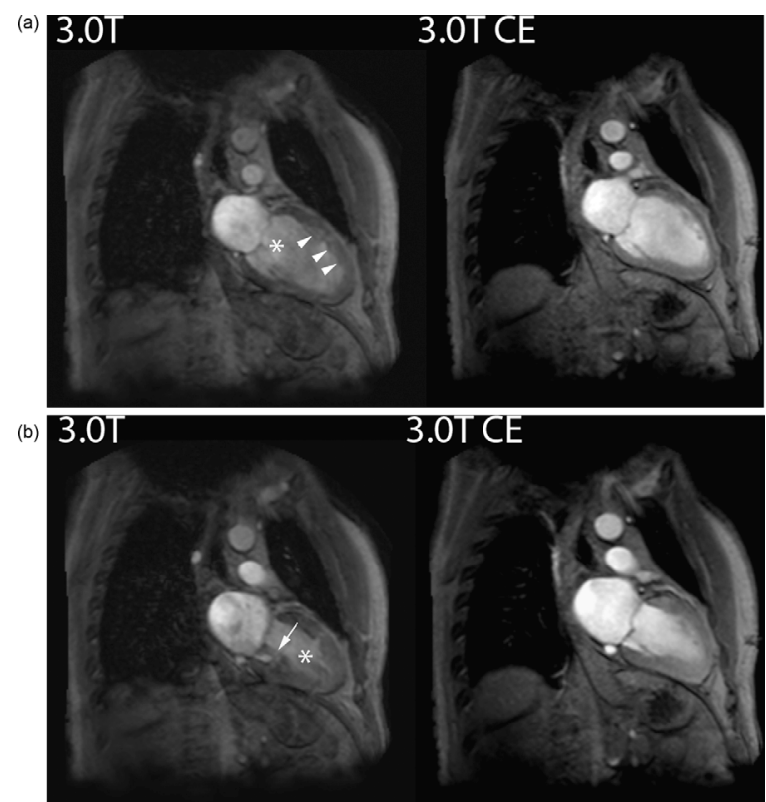

Figure 3. Zoomed images of same patient as in figure 2. Slow flowing blood at the interface between the endocardium and the left ventricular blood pool ( $a$, asterisk) give rise to saturation artefacts leading to overestimation of myocardial thickness ( $a$, arrowheads in left panel). After administration of contrast, blood pool, myocardium and trabeculae can be clearly differentiated. Images were obtained at end-diastole. A similar effect is seen in the end systolic quiescent period (b) where the presence of slow flowing blood at the interface between endocardium and the left ventricular blood pool (b, asterisk) also lead to saturation artefacts (b, arrow in left panel). After administration of contrast, blood pool, myocardium and trabeculae can be clearly differentiated. 
The mean ejection fractions determined from the images obtained at $1.5 \mathrm{~T}$ and the contrast-enhanced $3.0 \mathrm{~T}$ images were nearly identical. The variations in signal of the non-enhanced blood pool at 3.0 T, however, led to overestimation of myocardial mass and ejection fraction when compared to contrastenhanced 3.0 T imaging (table 3).

Subjective image quality was rated highest at $1.5 \mathrm{~T}$, followed by the $3.0 \mathrm{~T}$ post contrast images (table 4). Images obtained at 3.0 T without adminstration of contrast medium were deemed to be of significantly lower subjective image quality. Because of the temporal variations in signal intensity of the blood pool there were significant artefacts hindering interpretation in many nonenhanced 3.0 T studies, especially in the long axis orientations (figures 2 and 3 ).

\section{Discussion}

Recently, whole body 3.0 T MR imaging systems have become available and these systems have demonstrated advantages over imaging at $1.5 \mathrm{~T}$ for a broad range of applications. Since the SNR scales approximately linearly with the magnetic field strength $B 0$, the improved SNR at 3.0 T has led to noticable improvements in musculoskeletal $\left.\right|^{5}$ and neuroimaging applications ${ }^{6,7}$ as well as neurovascular ${ }^{8}$, peripheral vascular imaging ${ }^{9}$, prostate perfusion imaging ${ }^{10}$ and renal perfusion imaging ${ }^{11}$ compared to imaging at $1.5 \mathrm{~T}$.

With regard to imaging of the heart, migration to $3.0 \mathrm{~T}$ in favour of $1.5 \mathrm{~T}$ seems especially advantageous for myocardial perfusion imaging as evidenced by a better T1-weighted perfusion effect ${ }^{12}$ and a lack of subendocardial banding artefacts ${ }^{13}$ at $3.0 \mathrm{~T}$ compared to $1.5 \mathrm{~T}$. However, problems with radiofrequency uniformity can be a problem at $3.0 \mathrm{~T}$ relative to imaging at $1.5 \mathrm{~T}$. In addition, the fourfold increase in radiofrequency power deposition limits the allowable flip angles and minimum achievable TR. Also, the increased magnetic susceptibility effects at 3.0 T heighten the sensitivity to off-resonance artifacts. In an attempt to overcome the issues associated with bSSFP cine cardiac imaging at 3.0 T, Fonseca et al. proposed to use the experimental blood pool agent gadomer-17 (Bayer-Schering Pharma, Berlin, Germany) in combination with a GRE pulse sequence ${ }^{2}$. In their study in 12 pigs they reported a significant increase in SNR of the left ventricular blood pool and a significant decrease in temporal fluctuations of blood pool SNR over the cardiac cycle ${ }^{2}$.

Motivated by these promising results, we asked ourselves the question whether the commercially available blood pool agent gadofosveset would yield 
the same results in terms of SNR improvement and fluctuation over the cardiac cycle, but also in terms of the directly clinically relevant parameter ejection fraction. Although this contrast medium has been developed primarily for high-resolution MRA during the equilibrium phase, cardiac imaging seems an interesting application. The reversible binding of gadofosveset trisodium to plasma albumin, an effect that takes place immediately after injection, increases the T1-relaxation enhancement effect of the gadolinium complex. Moreover, the protein binding results in a much longer intravascular half life compared to extracellular MR contrast media, which has the potential to prolong the imaging window for cardiovascular imaging and improve spatial resolution and contrast.

Cine imaging of the beating heart remains the most important part of functional cardiac imaging. Until the widespread introduction of bSSFP sequences cine imaging involved the use of spoiled GRE pulse sequences to generate gated cine and gated velocity imaging. The difference between the various types of GRE sequences is a different gradient switching pattern applied between consecutive excitation pulses. Different gradient time courses produce different (spatially dependent) dephasings $\vartheta$ within the TR, which finally results in different types of steady states, and more importantly, in different image contrasts. Balanced SSFP is a special type of SSFP sequence where the gradient-induced dephasing within TR is exactly zero. In other words, within TR each applied gradient pulse is compensated by a gradient pulse with opposite polarity $^{1}$. In clinical terms, bSSFP offers a much higher contrast between myocardium and blood compared to conventional GRE imaging. The high contrast of bSSFP is produced both by the different ratio of T2 and T1 of blood and myocardium and by inflow effects. A second advantage of bSSFP is its high SNR even for very short TR. A conventional non-balanced GRE sequence with comparable TR and optimized Ernst flip angle exhibits a much lower SNR and CNR ${ }^{1}$.

Since spoiled GRE is largely a T1-weighted sequence it is dependent on through-plane flow enhancement to generate contrast between the blood and the myocardium, analogous to time-of-flight angiography ${ }^{14,15}$. Analogous to time-of-flight imaging, if the TR is too short or the flow too slow, the blood becomes satured, especially in cases where very short TR values are used. This saturation phenomenon is the basis of the observed fluctuations in SNR of the left ventricular blood pool, and not only leads to degradation in objective and subjective image quality but also to overestimation of myocardial mass and subsequently, ejection fraction. The improved differentiation of the blood pool from ventricular myocardium may also facilitate (semi-)automated left ven- 
tricular analysis by dedicated software packages, although this was not investigated in the current study. The current study has limitations. In the present study the comparison between $1.5 \mathrm{~T}$ and $3.0 \mathrm{~T}$ only focused on differences in quantitative measures of image quality, a single morphological parameter myocardial mass - and ejection fraction. We did not investigate possible differences in late enhancement patterns between both field strengths. In addition, the sample size was rather limited. Despite these limitations, however, we found clinically significant differences in image quality, and more important, in ejection fraction if no exogenous contrast medium was used to ameliorate the fluctuations in blood pool SNR over the cardiac cycle.

In conclusion, prolonged T1 reduction by means of injection of the intravascular blood pool agent gadofosveset leads to improved objective and subjective cardiac cine image quality at $3.0 \mathrm{~T}$ and to the same conclusions regarding cardiac ejection fraction. Combined with improved perfusion imaging at 3.0 $\mathrm{T}$ this might enable migration of comprehensive cardiac imaging to 3.0 $\mathrm{T}$. It remains to be determined how well blood pool imaging is suited for delineating areas of myocardial scar tissue and assessment of myocardial viability. 


\section{References}

1. Scheffler K, Lehnhardt S. Principles and applications of balanced SSFP techniques. Eur Radiol. 2003;13(11):2409-2418.

2. Fonseca CG, Nael K, Weinmann H-J, Nyborg G, Laub G, Finn JP. Cardiac Cine MRI at 3.0T: Initial Experience with Gadomer-17 in a Swine Model. Paper presented at: Proceedings of the ISMRM, 14th Scientific Meeting and Exhibition, 2006; Seattle, WA, USA.

3. Caravan P, Cloutier NJ, Greenfield MT, McDermid SA, Dunham SU, Bulte JW, Amedio JC, Jr., Looby RJ, Supkowski RM, Horrocks WD, Jr., McMurry TJ, Lauffer RB. The interaction of MS325 with human serum albumin and its effect on proton relaxation rates. J Am Chem Soc. 2002;124(12):3152-3162.

4. Parker DL, Haacke EM. Signal-to-noise, contrast-to-noise, and resolution. In: Potchen EJ, Haacke EM, Siebert JE, Gotschalk A, eds. Magnetic resonance angiography: concepts and applications. St. Louis: Mosby; 1993:56-79.

5. Bolog N, Nanz D, Weishaupt D. Muskuloskeletal MR imaging at 3.0 T: current status and future perspectives. Eur Radiol. 2006;16(6):1298-1307.

6. Frayne R, Goodyear BG, Dickhoff P, Lauzon ML, Sevick RJ. Magnetic resonance imaging at 3.0 Tesla: challenges and advantages in clinical neurological imaging. Invest Radiol. 2003;38(7):385-402.

7. Kosior RK, Wright CJ, Kosior JC, Kenney C, Scott JN, Frayne R, Hill MD. 3-Tesla versus 1.5Tesla magnetic resonance diffusion and perfusion imaging in hyperacute ischemic stroke. Cerebrovasc Dis. 2007;24(4):361-368.

8. DeLano MC, DeMarco JK. 3.0 T versus 1.5 T MR angiography of the head and neck. Neuroimaging Clin N Am. 2006;16(2):321-341, xi.

9. Leiner T, de Vries M, Hoogeveen R, Vasbinder GB, Lemaire E, van Engelshoven JM. Contrast-enhanced peripheral MR angiography at 3.0 Tesla: initial experience with a wholebody scanner in healthy volunteers. J Magn Reson Imaging. 2003;17(5):609-614.

10. Rouviere $\mathrm{O}$, Hartman RP, Lyonnet D. Prostate MR imaging at high-field strength: evolution or revolution? Eur Radiol. 2006;16(2):276-284.

11. Michaely HJ, Kramer H, Oesingmann N, Lodemann KP, Miserock K, Reiser MF, Schoenberg SO. Intraindividual comparison of MR-renal perfusion imaging at $1.5 \mathrm{~T}$ and $3.0 \mathrm{~T}$. Invest Radiol. 2007;42(6):406-411.

12. Araoz PA, Glockner JF, McGee KP, Potter DD, Jr., Valeti VU, Stanley DW, Christian TF. 3 Tesla MR imaging provides improved contrast in first-pass myocardial perfusion imaging over a range of gadolinium doses. J Cardiovasc Magn Reson. 2005;7(3):559-564.

13. Strach K, Meyer C, Thomas D, Naehle CP, Schmitz C, Litt H, Bernstein A, Cheng B, Schild H, Sommer T. High-resolution myocardial perfusion imaging at $3 \mathrm{~T}$ : comparison to $1.5 \mathrm{~T}$ in healthy volunteers. Eur Radiol. 2007;17(7):1829-1835.

14. Laub GA. Time-of-flight method of MR angiography. Magn Reson Imaging Clin N Am. 1995;3(3):391-398.

15. Finn JP, Nael K, Deshpande V, Ratib O, Laub G. Cardiac MR imaging: state of the technology. Radiology. 2006;241(2):338-354. 


\section{Chapter 8}

General discussion 
Despite advances in treatment and prevention, clinical manifestations of advanced atherosclerosis such as myocardial infarction and stroke remain the primary cause of death in the Western world and one of the primary sources of health care expenditure. Because of the high prevalence and the high mortality and morbidity due to cardiovascular diseases and the increasing financial burden on society, public health authorities are effecting a paradigm shift by increasingly focusing on prevention and early detection of cardiovascular disease, as opposed to treating complications with evermore sophisticated and expensive equipment and medications. As Braunwald noted in a recent editorial: 'the ultimate goal [in prevention of cardiovascular disease] will be to identify such [coronary] plaques by noninvasive imaging. Such an achievement, which still seems far off, could be the real solution to this critical medical problem ${ }^{1}$.

This thesis addresses non-invasive imaging of the coronary arteries and the coronary vessel wall using MRI. The overall aims of this thesis were 1) to study the capability of cardiovascular MR imaging of the human coronary vessel wall for detection and characterization of coronary artery disease (CAD) and 2) to investigate possibilities for advancement of cardiovascular MR imaging using the latest generation of 3.0T imaging equipment.

In order to achieve these aims we performed several studies. We compared the ability of MRI of the coronary vessel wall to accurately detect coronary vessel wall thickening to the current standard of reference for coronary vessel wall imaging: intravascular ultrasound (IVUS). This first-time validation study demonstrates and validates the potential of MRI as a non-invasive technique for the detection of atherosclerosis. We also compared MRI of the coronary vessel wall in patients with CAD and in healthy subjects. This study not only demonstrated a significant larger vessel wall thickness and higher signal intensity in subjects with CAD, but also revealed a high prevalence of subclinical atherosclerosis in middle-aged healthy subjects. In addition, we demonstrate a possibility to optimize coronary vessel wall imaging by using a newly developed technique (improved motion sensitized driven equilibrium, iMSDE) for flow suppression in the coronary arteries. Furthermore, we describe a method to improve contrast enhanced cine MR imaging of the heart at 3T. Both techniques open new opportunities to improve image quality and can potentially result in transfer of coronary and cardiac imaging from 1.5T to 3.0T. In this discussion, the results of the aforementioned studies will be placed in a broader context by discussing MRI in relation to other noninvasive imaging 
modalities such as coronary $\mathrm{CT}$, and by discussing the potential role of coronary vessel wall imaging in clinical practice.

\section{Part I - Results of this thesis}

Validation of MR coronary vessel wall imaging with intravascular ultrasound

In chapter 4 we found that with MRI of the coronary vessel wall (MR-CVW), accurate detection of atherosclerotic plaque is possible. Good sensitivity and specificity for the visual assessment of the presence and location of disease, defined as more than $300 \mu \mathrm{m}$ wall thickening on IVUS, were achieved (94 and $76 \%$, respectively), which confirmed that coronary vessel wall MRI is a promising noninvasive technique for detecting coronary artery disease. Although the presence and location of atherosclerosis could accurately be detected, there was a large difference and spread in absolute measurements of coronary vessel wall thickness between MR-CVW and IVUS. MRI consistently overestimated coronary wall thickness compared to IVUS. There are several possible explanations for this as discussed in chapter 4 , and most of them can be related to differences in spatial and temporal resolution between both techniques.

Despite the differences between MRI and IVUS, MRI was still capable of detecting coronary artery disease with high sensitivity and specificity. Furthermore, the value of absolute wall thickness might be less important than localized relative differences in vessel wall thickness and signal intensity which, as the present thesis demonstrated, also reliably signify the presence of CAD. In order to further investigate the ability of coronary vessel wall MRI to identify vulnerable plaque, prospective studies with the occurrence of acute coronary events as endpoint are needed.

To our knowledge, the study in chapter 4 is the first to compare in vivo MRI of the coronary arteries with IVUS as the standard of reference. For obvious reasons histological analysis of the coronary arteries is usually not possible, in contrast to studies on carotid arteries in which carotid endarterectomy is often performed that allows for histological correlation. Many studies have been performed in which MR imaging of the carotid vessel wall was performed in humans, and plaque characterization was possible by using a combination of different MR sequences. However, carotid arteries are larger, more superficially located, and are not subjected to as much motion as the coronary arteries. Multi-sequence coronary vessel wall imaging with the aim of subsequent plaque characterization is possible, although scan duration is very long and 
requirements for high-resolution imaging of the coronary vessel walls and plaque components make it much more challenging than in the carotid arteries $^{2}$. Depending on future developments in coronary artery and vessel wall MRI including MR hardware, other techniques also have to be considered for characterization of coronary plaque vulnerability or plaque components. The use of specific MR contrast agents, e.g. targeted to thrombi or extracellular matrix components in the vessel wall like elastin, is probably a very promising way for detection of coronary plaques within acceptable scan duration, and perhaps even to distinguish between the vulnerable and non-vulnerable plaque ${ }^{3-6}$.

\section{$M R I$ of the coronary vessel wall in patients and asymptomatic subjects}

In chapter 5, MRI of the coronary vessel wall in patients with CAD was compared to MR- CVW in age-matched healthy volunteers. Although coronary plaque burden as measured with MR was higher in patients with confirmed CAD, MR-CVW also demonstrated extensive, but asymptomatic atherosclerotic changes in the right coronary vessel wall in the majority of subjects without previously known CAD. This finding supports the widely held belief that the group of patients with symptomatic CAD is only the proverbial 'tip of the iceberg' of all subjects with CAD. However, because of the small sample size in this study, the cross-sectional study design, and the low absolute event rate, it remains unclear if and which of the subjects are at increased risk for future acute events.

The frequency of atherosclerotic changes in asymptomatic subjects was high, although this was not completely unexpected since the development of atherosclerosis starts at young age and remains clinically silent for decades. It is not until severe stenosis or plaque rupture occurs that coronary atherosclerosis manifests itself by the occurrence of chest pain or myocardial infarction. Furthermore, current understandings in the field of atherogenesis attributes an important role to plaques with a large lipid-rich and necrotic core and a thin fibrous cap which underscores the need for characterization of plaque components in addition to simply detecting their presence. Although our study confirms the ability of MRI to detect coronary plaque, prospective studies are needed to evaluate the ability of MRI to further characterize these high-risk plaques to be able to predict the occurrence of acute coronary syndromes. Once this is possible, individualized treatment strategies can then be used with the aim to prevent acute coronary syndromes. 
A novel MR technique for coronary vessel wall imaging

In chapter 6, a novel technique for coronary vessel wall imaging is described. This technique is based on an improved version of the motion sensitized driven equilibrium ( $\mathrm{MMSDE}$ ) prepulse and enables selective visualization of the coronary vessel wall by improved suppression of the signal of blood present in the coronary arteries. With iMSDE, 3 nonselective RF pulses with flip angles of $90^{\circ}$ $-180^{\circ}-90^{\circ}$ and symmetric gradients around the $180^{\circ}$ pulse result in phase dispersion among moving spins but not in stationary spins, thereby suppressing blood flow. In contrast to DIR, motion in all directions is suppressed and excellent black blood conditions are achieved regardless of the magnitude and direction of blood flow, as demonstrated in the aorta and carotid arteries 7,8 . The coronary arteries are still mainly imaged using double inversion recovery (DIR) techniques. Our study is the first to apply the iMSDE prepulse for coronary vessel wall imaging at $3 \mathrm{~T}$ and demonstrates that the coronary vessel wall can be visualized in half the scan duration compared to DIR methods. In addition to demonstrating the feasibility of the new method, we also found iMSDE to be a consistent technique as evidenced by the good reproducibility of measurements of lumen diameter and vessel wall thickness.

The DIR technique as described by Kim et al. ${ }^{9}$ and in chapters 4 and 5 of this thesis is primarily suited for use on $1.5 T$ scanners. The DIR technique requires high-fidelity targeted inversion slabs that can be difficult to achieve at 3.0T given the well-known $B_{0}$ and $B_{1}$ magnetic field inhomogeneities. Adjustments using adiabatic prepulses which are insensitive to RF inhomogeneities improve the performance of DIR at $3 \mathrm{~T}^{10,11}$, although RF penetration with current clinical systems is not optimal yet.

An important disadvantage of DIR is that the technique is flow dependent and harbors the potential for high signal-intensity slow flow artefacts at the lumen-vessel wall interface, which may lead to overestimation of coronary vessel wall thickness. Furthermore, long inversion times of approximately 520$850 \mathrm{~ms}$ and an effective repetition time (TR) of 2 heart beats are needed to suppress the signal of blood in more than the first few centimeters of the coronary arteries by replacing sufficient non-suppressed blood. However, even with a TR of 2 heartbeats, the inversion times are usually too short to cause sufficient outflow of non-suppressed blood in the more distal parts of the coronary arteries.

In contrast to the currently used DIR technique, the iMSDE technique is capable of better suppression of slow flowing blood ${ }^{8}$, which reduces the occur- 
rence of flow artefacts at the lumen-vessel wall interface and improves suppression of blood signal in distal parts of the vessel, leading to improved delineation of the vessel wall. Moreover, the technique can easily be used on 3.0T MR scanners. Most importantly, the scan time is reduced by half since the TR can be reduced from 2 to 1 heart beats.

A shift from $1.5 \mathrm{~T}$ to $3 \mathrm{~T}$ scanners is potentially advantageous as it offers shorter scan duration and/or higher signal to noise ratio, which can be exchanged for higher spatial resolution. Future research will be directed at comparisons of $\mathrm{MMSDE}$ and DIR considering flow suppression, especially in the more distal parts of the coronary arteries, and overall image quality, to compare wall thickness measurements with iMSDE with IVUS and to evaluate the potential of these refined coronary vessel wall imaging sequences in prospective studies with the aim to predict acute clinical events.

Cardiac cine imaging at 3T: improvements by using an intravascular contrastagent.

In chapter 7, another important limitation of cardiac imaging at $3 \mathrm{~T}$ is addressed. Cardiac MRI at 1.5T is the current standard for evaluation of cardiac motion, perfusion defects and myocardial viability. There are potential benefits of using higher field strengths, like higher spatial or temporal resolution or a better signal-to-noise ratio. However, there are some technical challenges as well. Current protocols cannot be directly translated to $3 \mathrm{~T}$ and need adjustment and with increasing field strength, magnetic field inhomogeneities also increase. These inhomogeneities cause artefacts that potentially degrade image quality unless better $B_{0}$ (main static magnetic field) and $B_{1}$ (RF excitation) shimming is performed. Balanced SSFP (bSSFP) sequences are especially susceptible to magnetic field distortions and therefore, gradient echo (GRE) sequences might be more suitable for 3T cardiac imaging.

Previous studies in swine demonstrated the ability of Gadomer ${ }^{12}$, an intravascular MR contrast agent, to improve cardiac cine GRE MR imaging at 3T by reducing artefacts that were caused by long $T_{1}$ relaxation time of the blood pool. However, Gadomer is not clinically available. In contrast to Gadomer, the intravascular albumin-binding contrast agent gadofosveset trisodium is approved for clinical use in humans in the European Union, the United States and several other countries.

We describe the use of gadofosveset trisodium to improve cardiac MRI at 3T. Our study demonstrated that this agent improves objective and subjective image quality of cine MRI at 3T. However, cardiac MRI at $1.5 \mathrm{~T}$ still has better 
image quality and does not require administration of contrast agents for cine imaging due to robust "balanced Steady State Free Precession" (bSSFP) imaging. Therefore further improvements in pulse sequences and/or hardware are needed to make cardiac imaging at $3 \mathrm{~T}$ more robust in clinical practice. To determine if migration to comprehensive cardiac imaging at $3 \mathrm{~T}$ is possible, also perfusion imaging is of importance in addition to cine imaging. Several groups demonstrated improved perfusion imaging at 3T compared to $1.5 \mathrm{~T}$ due to better $T_{1}$ perfusion effects and a lack of subendocardial banding artefacts, although there are also limitations in specific absorption rate (SAR), limitations in several scan parameters (like TR and flip angle (FA)) and off resonance artefacts ${ }^{13,14}$. An important advance that will mitigate many of these concerns is the introduction of multi-transmit technology ${ }^{15,16}$.

\section{Part II - Future developments of coronary vessel wall MRI}

Future development of coronary vessel wall MRI should focus on detection of the vulnerable plaque. To reach this goal, several important aspects should be considered. First, there is a need for technical improvements leading to faster acquisition techniques and higher spatial resolution. Once these building blocks are in place, visualization of the coronary vessel wall can be improved, and perhaps plaque components can be distinguished. Second, the use of (targeted) contrast agents might enable the detection of the true vulnerable plaque.

Improvements in MR hardware and software.

Technical improvements can be expected from hardware and sequence design. In hardware, the shift towards 3T and even 7T imaging and multi-element radiofrequency coils is important. As previously described, imaging at higher fields offers potential advantages like higher SNR which can be traded for faster acquisitions or higher spatial resolution. Both faster acquisitions and higher spatial resolution are desired for coronary imaging, since current protocols are time-consuming (8-10 minutes for coronary vessel wall scanning, navigator efficiency excluded). Improvement of spatial resolution results in more reliable measurements of vessel wall thickness or, in coronary angiography, more adequate classification of coronary stenoses.

Improvements in coil design will not only offer a better signal-to-noise ratio (SNR) or image quality, but can also offer the opportunity for faster acquisition 
due to parallel imaging ${ }^{17,18}$. With parallel imaging, the spatial variation in RF detector coil sensitivities is used to encode simultaneous spatial information. Undersampled data are acquired using a multi-element RF coil array, with a reduced number of phase encoding steps. The missing information is reconstructed instead of being acquired, thereby reducing scan duration. This decreases signal to noise ratio, although part of this can be compensated for by optimizing coil arrays and shifting from 1.5 to 3.0T. Compared to the currently mostly used 6-channel coil, a 32-channel coil array can reduce scanning time for coronary artery imaging with maintained image quality at $3 \mathrm{~T}^{19}$. Additional advantages of parallel imaging at $3 \mathrm{~T}$ is a reduction in specific absorption rate by reducing scan time and therefore a reduction in the total energy deposited $^{20}$. Additional technical improvements that will certainly improve image quality are the use of adiabatic RF excitation pulses ${ }^{10}$ as well as multitransmit coil arrays. Nowadays, there are further developments in MR data acquisition techniques, like radial $\mathrm{EPI}^{21}$, or advancement in reconstruction techniques that retrospectively correct for (respiratory) motion ${ }^{22}$. These techniques lead to significant reduction of scan time and a decrease in motion artifacts due to respiratory and cardiac motion.

\section{Contrast enhanced plaque imaging.}

In the whole spectrum of available MR contrast agents, there are the conventional extracellular contrast agents (i.e. Gd-DTPA), but also the newer class of intravascular agents, the prototype of which is Gadofosveset trisodium. Gadofosveset trisodium is a blood pool agent that reversibly binds to serum albumin after intravenous administration. This leads to increased $\mathrm{r} 1$ relaxivity, resulting in high signal intensity on T1 weighted MR sequences, and increased elimination half-life.

Several studies demonstrated uptake of the extravascular contrast agent Gd-DTPA in atherosclerotic plaque in the coronary arteries. The exact underlying mechanism is still unclear, although it might be associated with endothelial dysfunction, neovascularization, inflammation and/or fibrosis ${ }^{3,4}$. Lobbes et al. demonstrated a significantly larger signal enhancement after the administration of the blood pool agent gadofosveset trisodium in carotid atherosclerotic plaques of patients with symptomatic carotid stenosis (Transient Ischemic Attack (TIA) or stroke) compared to subjects with asymptomatic carotid steno$\mathrm{sis}^{5}$. This difference was associated with differences in intra-plaque albumin content. Albumin is thought to enter the plaque through adventitial and intraplaque microvessels. Lobbes et al. found no significant correlation with intra- 
plaque microvessel density, although nothing could be said about adventitial microvessel density since the adventitia is not surgically removed in endarterectomy.

Targeted contrast agents like EP-2104R (Lantheus Medical Imaging) or a alpha2-antiplasmin-based contrast agent have demonstrated their use in detection of thrombi in vitro, in vivo in animal studies (alpha2-antiplasmin-based agent and EP-2104R) and in humans (EP-2104R) ${ }^{23-26}$. These agents could therefore be used for detection of ruptured or erosive plaques, but further studies and optimization of imaging protocols and contrast agents are needed to guarantee sufficient visualization of coronary atherosclerotic plaques with clinical imaging systems. Although the use of targeted contrast agents seems very promising in theory, only results of preliminary studies in humans have been published yet. Further studies are needed to examine the value for clinical practice.

To make coronary vessel wall imaging with MR clinically applicable in this stage, the most important factor is probably to achieve faster image acquisition instead of higher spatial resolution. Considering the high sensitivity and specificity of MR-CVW for the detection of diseased vessel wall that was reported in this thesis, MR-CVW is already able to detect disease with the spatial resolution that can presently be achieved. The fact that a lot of asymptomatic subjects demonstrate wall thickening, indicates that absolute wall thickness is not directly related to the occurrence of symptoms. As we know, other factors than vessel wall thickening play a role in the occurrence of symptoms of coronary artery disease. The detection of the vulnerable plaque in the coronary arteries might not be achieved by visualization of plaque components using multisequence MRI but by other ways like using contrast agents.

\section{Part III - MR imaging in relation to coronary CT and other noninvasive imaging techniques}

There are many techniques, both non-invasive as well as invasive, that can be used to obtain information about the coronary artery lumen and vessel wall. Invasive techniques used in clinical practice include X-ray coronary angiography and coronary intravascular ultrasonography (IVUS) ${ }^{27,28}$. Other invasive techniques like optical coherence tomography $(\mathrm{OCT})^{29,30}$, angioscopy ${ }^{31,32}$, intravascular $\mathrm{MRI}^{33}$ and thermography $\mathrm{y}^{34,35}$ are currently only used in preclinical 
studies, although OCT is especially promising because of its unrivalled spatial resolution.

For non-invasive coronary imaging, both MRI and CT are promising techniques. Over the past decade, huge advances have been made in CT technology and accordingly the use of coronary CT has entered daily clinical practice, making it currently the most used technique as alternative to diagnostic conventional X-ray coronary angiography. However, the increased use of CT results in a major increase of radiation exposure of the population, and radiation dose can be high in $\mathrm{CT}$, up to $>20 \mathrm{mSv}$ and varies greatly between different acquisition techniques and different institutions ${ }^{36-38}$. Newer generations of CT scanners expose patients to much lower doses ${ }^{37,} 39$. However, increasing amounts of radiation due to an increase in the number of CT examinations in general, result in an increasing risk of imaging-induced cancer. This risk is small, but actual risk depends greatly on age and sex of the subjects ${ }^{36}$. This has implications for detecting disease in asymptomatic individuals. The use of CT in young or asymptomatic subjects should therefore be minimized, especially if alternative imaging modalities like MRI are available. However, the risk for developing cancer should always be weighed against the risk for developing coronary events.

Evaluation of CAD by MRI or CT is done with various strategies depending on the risk in the individual patient: detection of coronary calcifications (CT), direct imaging of coronary artery stenoses (MRI or $\mathrm{CT}$ ), visualization of coronary lesions (MRI or $\mathrm{CT}$ ) and detection of reduced coronary perfusion reserve (stress cine MRI and stress perfusion MRI) ${ }^{40}$. Both $\mathrm{CT}$ and MRI can be used for measurement of atherosclerotic burden and possibly characterization of plaque components ${ }^{41}$, although MRI is superior to CT for discrimination of different types of soft tissue and can visualize the coronary vessel wall without the use of contrast agents. Appropriate selection of patients is important for the successful application of these emerging imaging modalities. At present both MRI and MDCT have proven to be clinically useful in the assessment of individuals with low and intermediate pre-test probability of significant CAD. Patients with high pre-test probability are currently best served by $\mathrm{CAG}^{40}$.

MDCT can be performed with reliable results in selected patient populations, i.e. patients with a low or intermediate pre-test likelihood of a significant coronary stenosis or patients with recurrent angina, especially with the latest generation multidetector row scanners which combine thin slice collimation with short gantry rotation times ${ }^{42}$. These scanners can obtain information about the heart and coronary arteries with high spatial resolution. With newer 
scanners, especially dual source CT scanners, temporal resolution also improves, down to approximately $80 \mathrm{msec}$, which is still much slower compared to the temporal resolution of MRI, but allows for imaging of the heart within 10 seconds $^{43}$. This further increases diagnostic accuracy for detection of coronary artery stenosis especially at higher or irregular heart rates. Dual source CT can also be used for dual energy acquisition, which has the potential for better analysis of calcified coronary arteries or visualization of the coronary artery lumen within stents by reducing blooming artefacts ${ }^{43}$.

For the detection of coronary artery disease, CT has high sensitivity and specificity and good accuracy and is cost effective in the low- to intermediate risk category of patients ${ }^{44}$. Sensitivity ranges between $86-100 \%$, specificity ranges between $92-98 \%$ (for 64-detector scanners or dual source CT) ${ }^{43}$. In comparison, sensitivity and specificity of coronary MRA for detection of any coronary artery disease are $93 \%$ and $42 \%$ respectively. These numbers increase to a sensitivity of $100 \%$ and specificity of $85 \%$ for detection of stenoses of the left main coronary artery or detection of 3-vessel disease ${ }^{45-47}$. With latest generation CT scanners, the numbers of inevaluable segments in the coronary arteries decreases mainly due to improved temporal resolution and decrease in the number of non-evaluable coronary artery segments due to motion artefacts. However, heavy calcification still remains a problem for adequate analysis of the degree of stenosis. ${ }^{48}$. In MR imaging, there are no blooming artefacts from calcification, although calcification has low signal intensity on all weightings which can cause underestimation of true vessel wall thickness.

A preclinical application of coronary $C T$ is plaque imaging. It has been reported that coronary CT Angiography has the potential to detect coronary plaques, to quantify their volumes and to characterize their composition ${ }^{49,50}$. However, extensive calcification has a major influence on these results, preventing adequate assessment of plaque composition in combined calcified/non calcified plaques. Also, contrast agents influence the density - expressed in Hounsfield units - of plaque components which, in turn, influences reliability of characterization of plaque components ${ }^{51}$. Compared to MRI, CT lacks the excellent soft-tissue discrimination, which is needed for reliable detection of plaque components. Other advantages of MRI for vessel wall and plaque imaging compared to $\mathrm{CT}$ are the opportunity to use black blood techniques to visualize the vessel wall itself, the fact that contrast agents are not necessarily needed and the lack of ionizing radiation which makes serial imaging and imaging in asymptomatic or young subjects possible and safe. 
Another development in the detection of coronary plaques with $\mathrm{CT}$ is the recent use of PET-CT, to investigate the uptake of FDG in plaques in the coronary arteries. A study by Wykrzykowska et al. demonstrated coronary plaque FDG uptake in about half of the patients in a trend to significance when correlated with angiographic disease, although there was only a small difference in tracer uptake between the target (coronary plaque) and the background (myocardium $)^{52}$. To study uptake of FDG in the coronary arteries, a low-carbohydrate, high fat meal the night before as well as a vegetable oil on the morning of the PET-CT was needed to suppress high FDG uptake by the myocardium. This requires good patient cooperation, something that was not achieved in about one third of patients. Another recent study by Rominger et al. used a somatostatin receptor binding PET ligand ( ${ }^{68} \mathrm{Ga}$-DOTATATE) as an alternative to look at macrophages in the coronary arteries and found significant differences in uptake between a series of oncologic patients with and without calcified coronary plaques and prior cardiovascular events ${ }^{53}$. Although the idea of detection of (vulnerable) plaques with FDG uptake is interesting, it still is challenging.

\section{Part IV - Atherosclerosis and the (potential) role of coronary vessel wall imaging in clinical practice}

The development of atherosclerosis is a continuous process that starts at young age and slowly progresses over decades to a subclinical, and eventually, clinical state. In the development of atherosclerosis, luminal narrowing can occur. However, in early stages vessel wall thickening causes outward expansion of the vessel wall instead of luminal narrowing ${ }^{54}$. Therefore, atherosclerotic plaques can be missed on X-ray coronary angiography. The extent of outward remodeling is affected by plaque composition ${ }^{55,56}$, e.g. large lipid-rich plaques show more outward remodeling than fibrotic or calcified plaques. There are several processes that can lead to clinical symptoms. Most common is plaque rupture, in which the fibrous cap ruptures and plaque contents come into contact with the blood pool, which leads to thrombus formation and subsequent vessel occlusion. Another process is erosion of the surface of the cap. This can also cause thrombus formation. Third, intraplaque hemorrhage can cause sudden increase in plaque size and therefore narrowing of vessel diameter. And finally, emboli from anywhere in the body can migrate and cause occlusion of arteries elsewhere. 
Atherosclerosis is considered to be a systemic disease instead of a localized disorder. Patient outcome of atherosclerosis is not only determined by the presence of vulnerable, rupture-prone plaques, but also by vulnerable blood (prone to thrombosis) and vulnerable myocardium (prone to fatal arrhythmia). This insight led Naghavi and coworkers to coin the term "vulnerable patient" in an attempt to place the concept of the "vulnerable plaque" ${ }^{\text {"57 }}$ into the broader context of the individual patient.

Current insights into plaque biology and the phenomenon of plaque rupture seem to point to a more important role for plaque composition than just the degree of stenosis, since also mild to moderate stenoses can often cause erosion or rupture of plaque ${ }^{58}$ and thereby acute ischemic syndromes involving the coronary arteries, central nervous system or the peripheral arterial bed. However, current clinical decision-making is largely based on location and degree of stenosis, as determined with intra-arterial digital subtraction angiography (IA-DSA). Numerous studies have shown that MRI not only has the ability to detect and quantify stenoses but can also differentiate plaque components in the carotid arteries and the aorta ${ }^{59-64}$. Different soft tissues have different signal intensities depending on the sequence that is used for imaging. Focal differences of signal intensity can represent differences in plaque composition, which is related to plaque vulnerability as demonstrated previously in the carotid arteries and the aorta. However, due to previously described challenges, this is not feasible in the coronary arteries yet.

Except for imaging of the coronary arteries, MRI also is the standard of reference for evaluation and characterization of the myocardium, especially wall motion and perfusion. Myocardial abnormalities can be the result of coronary atherosclerosis and ischemia, and if present, they have prognostic implications. Furthermore, on an entirely different level, MRI can be used for spectroscopy of plasma ${ }^{65,66}$, thereby giving information about specific markers for inflammation or more specific for coronary atherosclerosis. Combination of several MR techniques might give a comprehensive overview of an individual's healthstatus.

The ultimate goal of coronary imaging is to detect the 'vulnerable' plaque, or even the vulnerable patient, to improve patient stratification for interventions to prevent potentially life-threatening complications of coronary atherosclerosis. Identification of patients at risk is currently done by assessing risk factors like hypercholesterolemia, hypertension, smoking and diabetes mellitus. These risk factors, together with age and gender, constitute the basis of the Framingham risk score ${ }^{67,68}$. With this score, patients can be classified into 
low- $(<0.5 \%$ per year), intermediate- $(0.5 \%-2 \%$ per year) and high-risk $(>2 \%$ per year) categories for the likelihood of development of acute coronary events. In the high-risk population it is believed that a small group of very-high-risk subjects can be identified with a risk of more than $15 \%$ per year. Braunwald proposed an algorithm for further evaluation of intermediate and high-risk subjects ${ }^{1}$. Further risk stratification of the intermediate risk subjects can be done by additional tests such as the amount of high-sensitivity C-reactive protein in the blood or the ankle-brachial index, to reclassify patients into the low- or high-risk group.

It is likely that imaging studies can also give additional (prognostic) information. Ultrasonographic measurement of carotid artery intimal-medial wall thickness, coronary calcium score with $\mathrm{CT}$, or MRI of (the walls of) the aorta and carotid arteries are all promising techniques in this regard. Imaging of the coronary arteries and vessel wall can also potentially be of great value since it directly visualizes the vessels of interest. The high-risk group needs intense global risk factor reduction. Further stratification is needed to identify and treat the very high-risk subjects ( $>15 \%$ per year) to prevent acute coronary events.

The accuracy and cost-effectiveness of the non-invasive imaging tests have to be further established. Currently, there is a lack of prospective studies. In the US, there currently is a large prospective study, the Biolmage study ${ }^{69}$. This study is a part of the "high risk plaque initiative", a research program focused on the understanding, recognition and management of atherosclerotic plaques (http://www.hrpinitiative.com). It aims at follow-up of a large asymptomatic population with several techniques which include MRI and $\mathrm{CT}$, but unfortunately, at this time no data are published. Another prospective study was performed by Motoyama et al. in a large population of patients with suspected coronary artery disease who underwent coronary CT angiography ${ }^{70}$. In this study, positive remodeling and the presence of low attenuation plaques were associated with a higher risk for acute coronary syndrome. The feasibility of imaging studies has already been demonstrated, but larger prospective studies are needed to evaluate the real potential of non-invasive imaging techniques in the detection of the vulnerable atherosclerotic plaque or the vulnerable patient.

The strength of MRI is that is has the capability to visualize the whole ischemic cascade, from early vessel wall thickening to late consequences of myocardial infarction, without the use of ionizing radiation. This makes MRI a safe technique, which can be easily used for serial evaluation, also in young 
and/or asymptomatic subjects. Cardiac MRI has already established itself for the detection of motion abnormalities, perfusion defects and assessment of myocardial viability ${ }^{71-73}$. Optimization of current coronary lumen and vessel wall sequences and implementation of these sequences in current cardiac protocols offers a comprehensive one-stop shop.

\section{Conclusions}

In conclusion, the studies performed for this thesis demonstrate that MRI of the coronary vessel wall is able to accurately detect areas of focal wall thickening with or without stenoses when compared to the current standard of reference for coronary vessel wall imaging. Furthermore, MR-CVW was able to detect significant differences in vessel wall thickness and signal intensity of the coronary vessel wall of patients with CAD compared to age-matched healthy volunteers. This thesis also describes several possibilities to further optimize coronary vessel wall imaging and cardiac cine imaging. With the promising results of this thesis and other previous studies, there is ground for further development and optimization towards a clinically comprehensive cardiac and coronary exam. Eventually, this may result in early and individualized risk assessment for complications of coronary atherosclerosis and for the follow up of treatment. 


\section{References}

1. Braunwald E. Epilogue: what do clinicians expect from imagers? J Am Coll Cardiol. 2006;47(8 Suppl):C101-103.

2. Gerretsen SC, Kooi ME, Botnar RM, Engelshoven JMAv, Leiner T. Multi-Sequence Coronary Vessel Wall MRI at 1.5T: A Feasibility Study. Paper presented at: Proceedings of the ISMRM, 13th scientific meeting and exhibition, 2005; Miami Beach, Florida, USA.

3. Maintz D, Ozgun M, Hoffmeier A, Fischbach R, Kim WY, Stuber M, Manning WJ, Heindel W, Botnar RM. Selective coronary artery plaque visualization and differentiation by contrastenhanced inversion prepared MRI. Eur Heart J. 2006;27(14):1732-1736.

4. Yeon SB, Sabir A, Clouse M, Martinezclark PO, Peters DC, Hauser TH, Gibson CM, Nezafat R, Maintz D, Manning WJ, Botnar RM. Delayed-enhancement cardiovascular magnetic resonance coronary artery wall imaging: comparison with multislice computed tomography and quantitative coronary angiography. J Am Coll Cardiol. 2007;50(5):441-447.

5. Lobbes MB, Heeneman S, Passos VL, Welten R, Kwee RM, van der Geest RJ, Wiethoff AJ, Caravan P, Misselwitz B, Daemen MJ, van Engelshoven JM, Leiner T, Kooi ME. Gadofosveset-Enhanced Magnetic Resonance Imaging of Human Carotid Atherosclerotic Plaques: A Proof-of-Concept Study. Invest Radiol. 2010;45(5):275-281.

6. Makowski MR, Blume U, Wiethoff AJ, Jansen C, Lazewatsky J, Robinson S, Botnar RM. In vivo Molecular MRI of atherosclerotic plaque progression in mice using a novel elastinbinding contrast agent. Paper presented at: Proceedings of the ISMRM, 17th scientific meeting and exhibition, 2009; Honolulu, Hawaii, USA.

7. Koktzoglou I, Li D. Diffusion-prepared segmented steady-state free precession: Application to 3D black-blood cardiovascular magnetic resonance of the thoracic aorta and carotid artery walls. J Cardiovasc Magn Reson. 2007;9(1):33-42.

8. Wang J, Yarnykh VL, Hatsukami T, Chu B, Balu N, Yuan C. Improved suppression of plaquemimicking artifacts in black-blood carotid atherosclerosis imaging using a multislice motion-sensitized driven-equilibrium (MSDE) turbo spin-echo (TSE) sequence. Magn Reson Med. 2007;58(5):973-981.

9. Kim WY, Stuber M, Bornert P, Kissinger KV, Manning WJ, Botnar RM. Three-dimensional black-blood cardiac magnetic resonance coronary vessel wall imaging detects positive arterial remodeling in patients with nonsignificant coronary artery disease. Circulation. 2002;106(3):296-299.

10. Priest AN, Bansmann PM, Kaul MG, Stork A, Adam G. Magnetic resonance imaging of the coronary vessel wall at $3 \mathrm{~T}$ using an obliquely oriented reinversion slab with adiabatic pulses. Magn Reson Med. 2005;54(5):1115-1122.

11. Bansmann PM, Priest AN, Muellerleile K, Stork A, Lund GK, Kaul MG, Adam G. MRI of the coronary vessel wall at $3 \mathrm{~T}$ : comparison of radial and cartesian k-space sampling. AJR Am J Roentgenol. 2007;188(1):70-74.

12. Fonseca CG, Nael K, Weinmann H-J, Nyborg G, Laub G, Finn JP. Cardiac Cine MRI at 3.0T: Initial Experience with Gadomer-17 in a Swine Model. Paper presented at: Proceedings of the ISMRM, 14th Scientific Meeting and Exhibition, 2006; Seattle, WA, USA.

13. Strach K, Meyer C, Thomas D, Naehle CP, Schmitz C, Litt H, Bernstein A, Cheng B, Schild H, Sommer T. High-resolution myocardial perfusion imaging at $3 \mathrm{~T}$ : comparison to $1.5 \mathrm{~T}$ in healthy volunteers. Eur Radiol. 2007;17(7):1829-1835.

14. Araoz PA, Glockner JF, McGee KP, Potter DD, Jr., Valeti VU, Stanley DW, Christian TF. 3 Tesla MR imaging provides improved contrast in first-pass myocardial perfusion imaging over a range of gadolinium doses. J Cardiovasc Magn Reson. 2005;7(3):559-564. 
15. Willinek WA, Gieseke J, kukuk G, Nelles M, König R, Andersson M, Thomas D, MorakkabatiSpitz N, Hoogeveen R, Kuhl CK, Schild HH. Parallel RF transmission in body MRI for reduced dielectric shading, improved B1 homogeneity and accelerated imaging at 3.0T: initial clinical experience in 40 patients using MultiTransmit. Paper presented at: Proceedings of the ISMRM, 17th scientific meeting and exhibition, 2009; Honolulu, Hawaii, USA.

16. Harvey PR, Zhai Z, Morich M, Mens G, van Yperen G, DeMeester G, Graesslin I, Hoogeveen R. SAR behaviour during whole -body MultiTransmit RF shimming at 3.0T. Paper presented at: Proceedings of the ISMRM, 17th scientific meeting and exhibition, 2009; Honolulu, Hawaii, USA.

17. Niendorf T, Hardy CJ, Giaquinto RO, Gross P, Cline HE, Zhu Y, Kenwood G, Cohen S, Grant AK, Joshi S, Rofsky NM, Sodickson DK. Toward single breath-hold whole-heart coverage coronary MRA using highly accelerated parallel imaging with a 32-channel MR system. Magn Reson Med. 2006.

18. Niendorf T, Sodickson DK. Parallel imaging in cardiovascular MRI: methods and applications. NMR Biomed. 2006;19(3):325-341.

19. Wiethoff AJ, Totman JJ, Uribe Arancibia SA, Schaeffter T, Botnar RM. Coronary artery imaging at 3T: A 32- versus 6-channel cardiac coil comparison. Paper presented at: Proceedings of the ISMRM, 17th scientific meeting and exhibition, 2009; Honolulu, Hawaii, USA.

20. McGee KP, Debbins JP, Boskamp EB, Blawat L, Angelos L, King KF. Cardiac magnetic resonance parallel imaging at 3.0 Tesla: technical feasibility and advantages. J Magn Reson Imaging. 2004;19(3):291-297.

21. Bhat $H$, Yang $Q$, Zuehlsdorff S, Li D. Contrast-enhanced whole-heart coronary MRA in 5 minutes using radial EPI. Paper presented at: Proceedings of the ISMRM-ESMRMB joint annual meeting, 2010; Stockholm, Sweden.

22. Bhat $H, G e ~ L$, Nielles-Vallespin S, Zuehlsdorff $S$, Li D. 3D projection reconstruction based respiratory motion correction technique for free-breathing coronary MRA. Paper presented at: Proceedings of the ISMRM-ESMRMB joint annual meeting, 2010; Stockholm, Sweden.

23. Spuentrup E, Botnar RM, Wiethoff AJ, Ibrahim T, Kelle $S$, Katoh $M$, Ozgun $M$, Nagel E, Vymazal J, Graham PB, Gunther RW, Maintz D. MR imaging of thrombi using EP-2104R, a fibrin-specific contrast agent: initial results in patients. Eur Radiol. 2008;18(9):1995-2005.

24. Vymazal J, Spuentrup E, Cardenas-Molina G, Wiethoff AJ, Hartmann MG, Caravan P, Parsons EC, Jr. Thrombus imaging with fibrin-specific gadolinium-based MR contrast agent EP2104R: results of a phase II clinical study of feasibility. Invest Radiol. 2009;44(11):697-704.

25. Botnar RM, Buecker A, Wiethoff AJ, Parsons EC, Jr., Katoh M, Katsimaglis G, Weisskoff RM, Lauffer RB, Graham PB, Gunther RW, Manning WJ, Spuentrup E. In vivo magnetic resonance imaging of coronary thrombosis using a fibrin-binding molecular magnetic resonance contrast agent. Circulation. 2004;110(11):1463-1466.

26. Miserus RJ, Herias MV, Prinzen L, Lobbes MB, Van Suylen RJ, Dirksen A, Hackeng TM, Heemskerk JW, van Engelshoven JM, Daemen MJ, van Zandvoort MA, Heeneman S, Kooi ME. Molecular MRI of early thrombus formation using a bimodal alpha2-antiplasmin-based contrast agent. JACC Cardiovasc Imaging. 2009;2(8):987-996.

27. Ge J, Chirillo F, Schwedtmann J, Gorge G, Haude M, Baumgart D, Shah V, von Birgelen C, Sack S, Boudoulas $\mathrm{H}$, Erbel R. Screening of ruptured plaques in patients with coronary artery disease by intravascular ultrasound. Heart. 1999;81(6):621-627.

28. von Birgelen C, Klinkhart W, Mintz GS, Papatheodorou A, Herrmann J, Baumgart D, Haude $\mathrm{M}$, Wieneke $\mathrm{H}$, Ge J, Erbel R. Plaque distribution and vascular remodeling of ruptured and nonruptured coronary plaques in the same vessel: an intravascular ultrasound study in vivo. J Am Coll Cardiol. 2001;37(7):1864-1870. 
29. Huang D, Swanson EA, Lin CP, Schuman JS, Stinson WG, Chang W, Hee MR, Flotte T, Gregory K, Puliafito CA, et al. Optical coherence tomography. Science. 1991;254(5035):11781181.

30. Patel NA, Stamper DL, Brezinski ME. Review of the ability of optical coherence tomography to characterize plaque, including a comparison with intravascular ultrasound. Cardiovasc Intervent Radiol. 2005;28(1):1-9.

31. Ohtani T, Ueda Y, Mizote I, Oyabu J, Okada K, Hirayama A, Kodama K. Number of yellow plaques detected in a coronary artery is associated with future risk of acute coronary syndrome: detection of vulnerable patients by angioscopy. I Am Coll Cardiol. 2006;47(11):2194-2200.

32. Thieme T, Wernecke KD, Meyer R, Brandenstein E, Habedank D, Hinz A, Felix SB, Baumann $G$, Kleber FX. Angioscopic evaluation of atherosclerotic plaques: validation by histomorphologic analysis and association with stable and unstable coronary syndromes. J Am Coll Cardiol. 1996;28(1):1-6.

33. Botnar RM, Bucker A, Kim WY, Viohl I, Gunther RW, Spuentrup E. Initial experiences with in vivo intravascular coronary vessel wall imaging. J Magn Reson Imaging. 2003;17(5):615619.

34. Casscells W, Hathorn B, David M, Krabach T, Vaughn WK, McAllister HA, Bearman G, Willerson JT. Thermal detection of cellular infiltrates in living atherosclerotic plaques: possible implications for plaque rupture and thrombosis. Lancet. 1996;347(9013):1447-1451.

35. Stefanadis C, Diamantopoulos L, Vlachopoulos C, Tsiamis E, Dernellis J, Toutouzas K, Stefanadi E, Toutouzas $P$. Thermal Heterogeneity Within Human Atherosclerotic Coronary Arteries Detected In Vivo : A New Method of Detection by Application of a Special Thermography Catheter. Circulation. 1999;99(15):1965-1971.

36. Einstein AJ, Henzlova MJ, Rajagopalan S. Estimating risk of cancer associated with radiation exposure from 64-slice computed tomography coronary angiography. Jama. 2007;298(3):317-323.

37. Alkadhi H, Stolzmann P, Scheffel H, Desbiolles L, Baumuller S, Plass A, Genoni M, Marincek $\mathrm{B}$, Leschka S. Radiation dose of cardiac dual-source CT: the effect of tailoring the protocol to patient-specific parameters. Eur J Radiol. 2008;68(3):385-391.

38. Stolzmann P, Leschka S, Betschart T, Desbiolles L, Flohr TG, Marincek B, Alkadhi H. Radiation dose values for various coronary calcium scoring protocols in dual-source CT. Int J Cardiovasc Imaging. 2009;25(4):443-451.

39. Shuman WP, Branch KR, May JM, Mitsumori LM, Strote JN, Warren BH, Dubinsky TJ, Lockhart DW, Caldwell JH. Whole-chest 64-MDCT of emergency department patients with nonspecific chest pain: Radiation dose and coronary artery image quality with prospective ECG triggering versus retrospective ECG gating. AJR Am J Roentgenol. 2009;192(6):1662-1667.

40. Nikolaou K, Poon M, Sirol M, Becker CR, Fayad ZA. Complementary results of computed tomography and magnetic resonance imaging of the heart and coronary arteries: a review and future outlook. Cardiol Clin. 2003;21(4):639-655.

41. Fayad ZA, Fuster V, Nikolaou K, Becker C. Computed tomography and magnetic resonance imaging for noninvasive coronary angiography and plaque imaging: current and potential future concepts. Circulation. 2002;106(15):2026-2034.

42. Ropers D, Rixe J, Anders K, Kuttner A, Baum U, Bautz W, Daniel WG, Achenbach S. Usefulness of multidetector row spiral computed tomography with $64-\times 0.6-\mathrm{mm}$ collimation and 330-ms rotation for the noninvasive detection of significant coronary artery stenoses. Am J Cardiol. 2006;97(3):343-348.

43. Bastarrika G, Lee YS, Huda W, Ruzsics B, Costello P, Schoepf UJ. CT of coronary artery disease. Radiology. 2009;253(2):317-338. 
44. Dewey M, Hamm B. Cost effectiveness of coronary angiography and calcium scoring using CT and stress MRI for diagnosis of coronary artery disease. Eur Radiol. 2007;17(5):13011309.

45. Dewey M, Teige F, Schnapauff D, Laule M, Borges AC, Wernecke KD, Schink T, Baumann G, Rutsch W, Rogalla P, Taupitz M, Hamm B. Noninvasive detection of coronary artery stenoses with multislice computed tomography or magnetic resonance imaging. Ann Intern Med. 2006;145(6):407-415.

46. Kim WY, Danias PG, Stuber M, Flamm SD, Plein S, Nagel E, Langerak SE, Weber OM, Pedersen EM, Schmidt M, Botnar RM, Manning WJ. Coronary magnetic resonance angiography for the detection of coronary stenoses. N Engl J Med. 2001;345(26):1863-1869.

47. Schuetz GM, Zacharopoulou NM, Schlattmann P, Dewey M. Meta-analysis: noninvasive coronary angiography using computed tomography versus magnetic resonance imaging. Ann Intern Med.152(3):167-177.

48. Stolzmann P, Scheffel H, Leschka S, Plass A, Baumuller S, Marincek B, Alkadhi H. Influence of calcifications on diagnostic accuracy of coronary $C T$ angiography using prospective ECG triggering. AJR Am J Roentgenol. 2008;191(6):1684-1689.

49. Schroeder S, Kopp AF, Baumbach A, Meisner C, Kuettner A, Georg C, Ohnesorge B, Herdeg $C$, Claussen CD, Karsch KR. Noninvasive detection and evaluation of atherosclerotic coronary plaques with multislice computed tomography. J Am Coll Cardiol. 2001;37(5):14301435.

50. Kopp AF, Schroeder S, Baumbach A, Kuettner A, Georg C, Ohnesorge B, Heuschmid M, Kuzo $R$, Claussen $C D$. Non-invasive characterisation of coronary lesion morphology and composition by multislice CT: first results in comparison with intracoronary ultrasound. Eur Radiol. 2001;11(9):1607-1611.

51. Cademartiri F, Mollet NR, Runza G, Bruining N, Hamers R, Somers P, Knaapen M, Verheye S, Midiri M, Krestin GP, de Feyter PJ. Influence of intracoronary attenuation on coronary plaque measurements using multislice computed tomography: observations in an ex vivo model of coronary computed tomography angiography. Eur Radiol. 2005;15(7):1426-1431.

52. Wykrzykowska J, Lehman S, Williams G, Parker JA, Palmer MR, Varkey S, Kolodny G, Laham R. Imaging of inflamed and vulnerable plaque in coronary arteries with $18 \mathrm{~F}-\mathrm{FDG}$ PET/CT in patients with suppression of myocardial uptake using a low-carbohydrate, high-fat preparation. J Nucl Med. 2009;50(4):563-568.

53. Rominger A, Saam T, Vogl E, Ubleis C, la Fougere C, Forster $S$, Haug A, Cumming P, Reiser MF, Nikolaou K, Bartenstein $P$, Hacker M. In vivo imaging of macrophage activity in the coronary arteries using 68Ga-DOTATATE PET/CT: correlation with coronary calcium burden and risk factors. J Nucl Med. 2010;51(2):193-197.

54. Glagov S, Weisenberg E, Zarins CK, Stankunavicius R, Kolettis GJ. Compensatory enlargement of human atherosclerotic coronary arteries. N Engl J Med. 1987;316(22):1371-1375.

55. Fujii K, Carlier SG, Mintz GS, Wijns W, Colombo A, Bose D, Erbel R, de Ribamar Costa J, Jr., Kimura M, Sano K, Costa RA, Lui J, Stone GW, Moses JW, Leon MB. Association of plaque characterization by intravascular ultrasound virtual histology and arterial remodeling. Am J Cardiol. 2005;96(11):1476-1483.

56. Rodriguez-Granillo GA, Serruys PW, Garcia-Garcia HM, Aoki J, Valgimigli M, van Mieghem CA, McFadden E, de Jaegere PP, de Feyter P. Coronary artery remodelling is related to plaque composition. Heart. 2006;92(3):388-391.

57. Naghavi M, Libby P, Falk E, Casscells SW, Litovsky S, Rumberger J, Badimon JJ, Stefanadis C, Moreno P, Pasterkamp G, Fayad Z, Stone PH, Waxman S, Raggi P, Madjid M, Zarrabi A, Burke A, Yuan C, Fitzgerald PJ, Siscovick DS, de Korte CL, Aikawa M, Juhani Airaksinen KE, Assmann G, Becker CR, Chesebro JH, Farb A, Galis ZS, Jackson C, Jang IK, Koenig W, Lodder RA, March K, Demirovic J, Navab M, Priori SG, Rekhter MD, Bahr R, Grundy SM, Mehran R, Colombo A, Boerwinkle E, Ballantyne C, Insull W, Jr., Schwartz RS, Vogel R, Serruys PW, 
Hansson GK, Faxon DP, Kaul S, Drexler H, Greenland P, Muller JE, Virmani R, Ridker PM, Zipes DP, Shah PK, Willerson JT. From vulnerable plaque to vulnerable patient: a call for new definitions and risk assessment strategies: Part I. Circulation. 2003;108(14):1664-1672.

58. Falk E, Shah PK, Fuster V. Coronary plaque disruption. Circulation. 1995;92(3):657-671.

59. Toussaint JF, LaMuraglia GM, Southern JF, Fuster V, Kantor HL. Magnetic resonance images lipid, fibrous, calcified, hemorrhagic, and thrombotic components of human atherosclerosis in vivo. Circulation. 1996;94(5):932-938.

60. Cai JM, Hatsukami TS, Ferguson MS, Small R, Polissar NL, Yuan C. Classification of human carotid atherosclerotic lesions with in vivo multicontrast magnetic resonance imaging. Circulation. 2002;106(11):1368-1373.

61. Fayad ZA, Fuster V. Characterization of atherosclerotic plaques by magnetic resonance imaging. Ann N Y Acad Sci. 2000;902:173-186.

62. Yuan C, Mitsumori LM, Ferguson MS, Polissar NL, Echelard D, Ortiz G, Small R, Davies JW, Kerwin WS, Hatsukami TS. In vivo accuracy of multispectral magnetic resonance imaging for identifying lipid-rich necrotic cores and intraplaque hemorrhage in advanced human carotid plaques. Circulation. 2001;104(17):2051-2056.

63. Cappendijk VC, Cleutjens KB, Kessels AG, Heeneman S, Schurink GW, Welten RJ, Mess WH, Daemen MJ, van Engelshoven JM, Kooi ME. Assessment of human atherosclerotic carotid plaque components with multisequence MR imaging: initial experience. Radiology. 2005;234(2):487-492.

64. Fayad ZA, Nahar T, Fallon JT, Goldman M, Aguinaldo JG, Badimon JJ, Shinnar M, Chesebro $\mathrm{JH}$, Fuster $\mathrm{V}$. In vivo magnetic resonance evaluation of atherosclerotic plaques in the human thoracic aorta: a comparison with transesophageal echocardiography. Circulation. 2000;101(21):2503-2509.

65. Brindle JT, Antti H, Holmes E, Tranter G, Nicholson JK, Bethell HW, Clarke S, Schofield PM, McKilligin E, Mosedale DE, Grainger DJ. Rapid and noninvasive diagnosis of the presence and severity of coronary heart disease using $1 \mathrm{H}-\mathrm{NMR}$-based metabonomics. Nat Med. 2002;8(12):1439-1444.

66. Kirschenlohr HL, Griffin JL, Clarke SC, Rhydwen R, Grace AA, Schofield PM, Brindle KM, Metcalfe JC. Proton NMR analysis of plasma is a weak predictor of coronary artery disease. Nat Med. 2006;12(6):705-710.

67. Wilson PW, D'Agostino RB, Levy D, Belanger AM, Silbershatz $\mathrm{H}$, Kannel WB. Prediction of coronary heart disease using risk factor categories. Circulation. 1998;97(18):1837-1847.

68. Grundy SM, Balady GJ, Criqui MH, Fletcher G, Greenland P, Hiratzka LF, Houston-Miller N, Kris-Etherton P, Krumholz HM, LaRosa J, Ockene IS, Pearson TA, Reed J, Washington R, Smith SC, Jr. Primary prevention of coronary heart disease: guidance from Framingham: a statement for healthcare professionals from the AHA Task Force on Risk Reduction. American Heart Association. Circulation. 1998;97(18):1876-1887.

69. Muntendam P, McCall C, Sanz J, Falk E, Fuster V. The Biolmage Study: novel approaches to risk assessment in the primary prevention of atherosclerotic cardiovascular disease--study design and objectives. Am Heart J.160(1):49-57 e41.

70. Motoyama S, Sarai M, Harigaya H, Anno H, Inoue K, Hara T, Naruse H, Ishii J, Hishida H, Wong ND, Virmani R, Kondo T, Ozaki Y, Narula J. Computed tomographic angiography characteristics of atherosclerotic plaques subsequently resulting in acute coronary syndrome. J Am Coll Cardiol. 2009;54(1):49-57.

71. Pennell DJ, Sechtem UP, Higgins CB, Manning WJ, Pohost GM, Rademakers FE, van Rossum $A C$, Shaw $L$, Yucel EK. Clinical indications for cardiovascular magnetic resonance (CMR): Consensus Panel report. J Cardiovasc Magn Reson. 2004;6(4):727-765.

72. Constantine G, Shan K, Flamm SD, Sivananthan MU. Role of MRI in clinical cardiology. Lancet. 2004;363(9427):2162-2171. 
73. Finn JP, Nael K, Deshpande V, Ratib O, Laub G. Cardiac MR imaging: state of the technology. Radiology. 2006;241(2):338-354. 
Summary 
Atherosclerosis is a chronic inflammatory disease of the vessel wall of large and medium sized arteries and, despite advancement in diagnosis and treatment, remains one of the most important causes of morbidity and mortality worldwide. Complications of atherosclerosis can occur when there is obstruction of the vascular lumen due to plaque rupture or erosion with subsequent thrombus formation, or after embolization of a preexisting thrombus. In the coronary arteries, this can lead to myocardial ischemia, infarction or even sudden cardiac death.

Until recently, X-ray coronary angiography was the preferred method for visualization of the coronary arteries. However, advances in our understanding of the development of atherosclerosis in concert with the introduction of advanced $M R$ and $C T$ imaging systems have led to a shift towards non-invasive imaging. One of the potential advantages of MR and $\mathrm{CT}$ is their capability to visualize the coronary vessel wall, although clinically, the accepted standard of reference for imaging of the coronary vessel wall remains intravascular ultrasonography (IVUS).

The primary objective of this thesis was to evaluate the potential of MRI for detection of coronary artery disease by visualization of the coronary vessel wall in patients with coronary artery disease (CAD). To place findings in patients in perspective, a cohort of asymptomatic subjects was also imaged. A secondary objective of this thesis was to develop techniques for optimization of MR imaging of the heart and coronary vessel wall at 3T. In order to achieve these objectives several studies were performed.

Chapter 2 presents an overview of the literature about the status and future role of MRI for the detection of atherosclerosis and characterization of atherosclerotic plaques.

Chapter 3 reviews the literature about MRI of the coronary arteries. The technical aspects, clinical indications and potential future applications of MRI of the coronary arteries are discussed.

In chapter 4, MR imaging of the coronary vessel wall was compared to intravascular ultrasound, the current standard of reference for coronary vessel wall imaging. This study demonstrated that MRI of the coronary vessel wall is able to accurately detect positive remodeling and coronary vessel wall thickening. However, mainly due to differences in spatial resolution and possible flow- 
related artefacts on MRI, there is a low correlation between both modalities in terms of absolute wall thickness measurements.

The study presented in chapter 5 investigated the prevalence and extent of coronary atherosclerosis in middle-aged asymptomatic volunteers and patients with angiographically proven coronary artery disease. As expected, the burden of coronary atherosclerosis, as determined by measured vessel wall thickness, was higher in patients. However, the majority of asymptomatic subjects also demonstrated various degrees of coronary atherosclerosis, which is consistent with current theories about plaque development.

Chapter 6 presents a new MR technique for black blood coronary vessel wall imaging. Motion sensitized driven equilibrium (MSDE) techniques have previously been used in the carotid arteries and the aorta. The aim of the study presented in this thesis was to explore the feasibility and reproducibility of a time-efficient coronary vessel wall measurement approach using an improved motion-sensitized driven equilibrium (iMSDE) pulse sequence. In this study, the feasibility of iMSDE based coronary vessel wall imaging was proved and its good reproducibility was demonstrated. In addition, scan duration of the iMSDE vessel wall scan was $50 \%$ shorter than with the currently used double inversion recovery technique, which makes iMSDE potentially interesting for fast and accurate coronary artery disease detection in a clinical environment.

Complications of coronary atherosclerosis include myocardial ischemia and infarction. MRI is the standard of reference for evaluation and characterization of the myocardium, especially for studying wall motion and perfusion. Clinically, cardiac MRI is currently mainly performed on $1.5 \mathrm{~T}$ clinical scanners. Although migration from $1.5 \mathrm{~T}$ to $3 \mathrm{~T}$ is still challenging due to the presence of artefacts and limitations in several scan parameters, imaging at 3T potentially offers benefits considering improved spatial resolution, signal to noise ratio and scan duration. In Chapter 7 we describe a solution for one of the problems associated with cardiac cine MRI at 3T. We investigated the effect of the administration of the blood pool agent gadofosveset on image quality. Although objective and subjective image quality was best at $1.5 \mathrm{~T}$, administration of gadofosveset clearly improved image quality at $3 \mathrm{~T}$ compared to non-enhanced imaging at $3 \mathrm{~T}$. Since perfusion imaging at $3 \mathrm{~T}$ is known to be superior to perfusion imaging at $1.5 \mathrm{~T}$, the results of this study are promising for future migration of comprehensive cardiac imaging at 3T. 
In Chapter 8, the findings of our studies are placed in perspective and discussed in relation to the published literature. Furthermore, the role of MRI is compared to other non-invasive imaging modalities and finally, the potential role of coronary (vessel wall) imaging in clinical practice is discussed.

From the studies in this thesis we conclude that:

1. MRI of the coronary vessel wall is able to accurately detect coronary vessel wall thickening in the RCA when compared to IVUS, although there is a low correlation between both modalities in terms of absolute wall thickness measurements.

2. Both middle-aged patients with stable angina and angiographically proven coronary artery disease as well as age-matched asymptomatic subjects exhibit coronary vessel wall thickening detectable with MR coronary vessel wall imaging. Maximum and mean wall thickness were significantly higher in patients. The vast majority of asymptomatic subjects had either positive remodeling without luminal narrowing, or non-significant stenoses.

3. Motion-sensitized black blood coronary vessel wall imaging is feasible, reproducible and more time efficient compared to the currently used double inversion recovery sequences.

4. Injection of the blood pool agent gadofosveset leads to improved objective and subjective cardiac cine image quality at $3 \mathrm{~T}$ and to the same conclusions regarding cardiac ejection fraction compared to bSSFP imaging at $1.5 \mathrm{~T}$. 

Samenvatting 
Atherosclerose, in de volksmond aderverkalking genoemd, is een chronische aandoening van de vaatwand van de grote en middelgrote arteriën. De afwijkingen beginnen al op jonge leeftijd en vormen de basis van ernstige ziekten zoals hartinfarct, beroerte en perifeer vaatlijden. Ondanks vooruitgang in diagnose en behandeling blijft atherosclerose een van de belangrijkste doodsoorzaken in de Westerse wereld.

Complicaties van atherosclerose ontstaan door afsluiting van een slagader waarna de bloedtoevoer naar het achterliggende orgaan stopt. Voorheen werd verondersteld dat vooral de mate van vernauwing (stenose) van een bloedvat hiervoor bepalend was. Recent is echter duidelijk geworden dat ook nietstenoserend atherosclerotisch vaatlijden geassocieerd is met acute vaatafsluitingen. Afsluiting van een kransslagader, ofwel coronairarterie, kan leiden tot zuurstofgebrek van de hartspier, het myocard, en uiteindelijk tot een hartinfarct of plotselinge hartdood. Het veronderstelde mechanisme dat ten grondslag ligt aan dit fenomeen is ruptuur van een 'instabiele' plaque. Instabiele plaques worden gekenmerkt door een hoge concentratie aan onstekingscellen met een dunne fibreuze overkapping. Daarbij hoeft er geen sprake te zijn van een ernstige vaatvernauwing.

Tot voor kort werden de coronairarteriën door middel van catheterisatie en röntgen angiografie in beeld gebracht. Met deze techniek kan alleen het lumen van een vat en niet de vaatwand en de daarin aanwezige atherosclerotische plaques afgebeeld worden. Afbeelden van de vaatwand kan wel met intravasculaire echografie (IVUS). Deze techniek wordt daartoe momenteel in de kliniek ook gebruikt maar de methode is invasief vanwege de vereiste hartcatheterisatie. Een alternatief is dus wenselijk. Geavanceerde scantechnieken (MRI en CT) bieden de mogelijkheid om op niet-invasieve wijze de coronaire vaatwand en de daarin aanwezige plaques af te beelden.

Het primaire doel van dit proefschrift was het evalueren van de mogelijkheden van MRI voor het detecteren van coronair vaatlijden. Een tweede doel was de technieken van MRI van het hart en de coronaire vaatwand te optimaliseren.

Hoofdstuk 2 geeft een overzicht van de literatuur over de status en toekomstige rol van MRI voor het detecteren van atherosclerose en voor de karakterisatie van atherosclerotische plaques. 
Hoofdstuk 3 beschrijft de literatuur met betrekking tot MRI van de coronairarteriën. De technische aspecten, klinische indicaties en de potentiële toekomstige toepassingen van MRI van de coronairarteriën worden besproken.

Om een indruk te krijgen van de nauwkeurigheid van MRI werden in hoofdstuk 4 de resultaten van MRI van de coronaire vaatwand vergeleken met de resultaten van IVUS als gouden standaard. Deze studie toonde aan dat MRI positieve remodelering en wandverdikkingen van de coronair arteriën nauwkeurig kan detecteren. Er is echter een slechte correlatie tussen IVUS en MRI met betrekking tot de absolute vaatwanddikte. Dit kan verklaard worden door het verschil in spatiële resolutie van beide technieken en mogelijk ook door bloedstroomgerelateerde artefacten op MRI.

In de studie in hoofdstuk 5 is onderzocht of ook bij gezonde asymptomatische personen van middelbare leeftijd met MRI coronaire vaatwandveranderingen aangetoond kunnen worden en in hoeverre deze veranderingen verschillen in vergelijking met patiënten van dezelfde leeftijd. Met andere woorden: ziet de vaatwand er bij gezonden anders uit dan bij personen met klachten? Zoals verwacht hadden patiënten in ernstigere mate coronairlijden (dikkere vaatwand) dan gezonde leeftijdsgenoten. Echter ook bij een meerderheid van de asymptomatische personen werden verschillende stadia van atherosclerose van de coronairarteriën gezien. Meestal betrof dit positieve remodellering of niet-significante stenosen. Deze bevinding is in overeenstemming met de huidige kennis over de ontwikkeling van atherosclerose.

In Hoofdstuk 6 wordt een nieuwe zwart-bloed MRI techniek beschreven voor het afbeelden van de coronaire vaatwand. De zogenaamde "motion sensitized driven equilibrium" (MSDE) pulssequentie is eerder gebruikt voor het afbeelden van de vaatwand van de arteria carotis en de aorta. Het doel van de studie zoals beschreven in dit proefschrift was het beoordelen van de toepasbaarheid en reproduceerbaarheid van deze tijdsefficiënte methode voor coronaire vaatwandimaging. Hiervoor werd gebruik gemaakt van een verbeterde MSDE (iMSDE) pulssequentie. In deze studie zijn de toepasbaarheid en de reproduceerbaarheid van iMSDE aangetoond. Daarnaast werd aangetoond dat de acquisitieduur met de iMSDE sequentie 50\% korter was dan de huidig gebruikte "double inversion recovery" techniek. Dit maakt iMSDE potentieel een aantrekkelijke techniek voor snelle en accurate detectie van coronair vaatlijden in een klinische setting. 
Complicaties van coronair vaatlijden zijn onder andere myocardischemie en infarcering. MRI is de gouden standaard voor evaluatie en karakterisatie van het myocard, en dan met name voor beoordeling van de wandbeweging en hartspierdoorbloeding (perfusie). In de dagelijkse patiëntenzorg wordt cardiale MRI nog veelal op 1.5T MRI scanners verricht. Hoewel de overstap naar 3T de nodige uitdagingen oplevert door de aanwezigheid van artefacten en beperking in een aantal scanparameters, levert beeldvorming op 3T ook potentiële voordelen op zoals verbeterde spatiële resolutie, signaal-ruis-verhouding en/of kortere scanduur. In Hoofdstuk 7 wordt een oplossing beschreven voor een van de problemen die geassocieerd zijn met cardiale cine MRI op 3T. In dit hoofdstuk werd het effect op de beeldkwaliteit van de toediening van het intravasculaire contrastmiddel gadofosveset onderzocht. Gadofosveset is een middel dat door zijn eigenschappen langer in de bloedbaan verblijft dan de in de dagelijkse routine gebruikte contrastmiddelen. Hoewel de objectieve en subjectieve beeldkwaliteit van cardiale cine MRI beter was op $1.5 \mathrm{~T}$, waren de beelden op $3 \mathrm{~T}$ duidelijk beter na toediening van contrast in vergelijking met niet-contrastversterkte opnamen. Aangezien het afbeelden van de perfusie van het myocard op 3T in eerdere onderzoeken beter is gebleken dan op 1.5T, zijn de resultaten van de in dit proefschrift beschreven studie behulpzaam in het toewerken naar cardiale beeldvorming op 3T.

In hoofdstuk 8 worden de bevindingen uit dit proefschrift besproken en vergeleken met de eerder gepubliceerde literatuur. Daarnaast wordt de rol van MRI vergeleken met andere niet-invasieve beeldvormende technieken en wordt de potentiële rol van MRI van de coronairarteriën en van de coronaire vaatwand in de klinische praktijk besproken.

Uit de onderzoeken zoals beschreven in dit proefschrift concluderen we dat:

1. MRI van de coronaire vaatwand accuraat afwijkingen in deze wand kan detecteren en lokaliseren in vergelijking met IVUS als gouden standaard.

2. In zowel patiënten met angiografisch aangetoond coronair vaatlijden als bij asymptomatische personen afwijkingen van de coronaire vaatwand met MRI gedetecteerd kunnen worden. De maximale en gemiddelde wanddikte was duidelijk groter in patiënten. De meeste asymp- 
tomatische personen hadden milde tot matige vernauwingen van de coronairarteriën of een positieve remodelering.

3. De nieuwe pulssequentie iMSDE een toepasbare, reproduceerbare en tijdsefficiënte methode is voor het afbeelden van de coronaire vaatwand op $3 \mathrm{~T}$ in vergelijking met de huidig gebruikte "double inversion recovery" scantechniek.

4. Cardiale cine MRI op $3 T$ na toediening van het contrastmiddel gadofosveset resulteert in verbeterde objectieve en subjectieve beeldkwaliteit en verbeterde bepaling van de cardiale ejectiefractie in vergelijking met niet-contrastversterkte beelden. 
Dankwoord 
Na stapels papier voor de MEC, bergen uitgeprinte artikelen om door te lezen, vele gescande collega's, patiënten en gezonde proefpersonen, ik weet niet hoeveel statistiek-files, vele versies van abstracts en manuscripten, leuke, interessante congressen en vele leuke ontmoetingen met allerlei mensen uit de radiologie- en MRI-wereld, ligt hier eindelijk mijn boekje. Tja... na al die jaren is het nu dus echt af.

Uiteraard wil ik alle proefpersonen bedanken, alle medeauteurs van de artikelen en natuurlijk ook de MRI laboranten die me hebben geholpen met het leren scannen en bij wie ik altijd terecht kon met vragen. Maar een aantal mensen wil ik in het bijzonder noemen.

Geachte professor van Engelshoven, beste Jos, ik ben er trots op dat u nog mijn promotor bent. Ik waardeer uw rust, inzichten, adviezen en betrokkenheid van de afgelopen jaren enorm. Bedankt voor alles!

Beste Tim, ik blijf het ongelooflijk vinden hoe jij in alle drukte je werk als radioloog, je onderzoek en je gezin weet te combineren. Jij weet daarnaast ook prima wat er nodig is om iemand te motiveren als alles allemaal niet helemaal ging zoals gepland. Ik wil je ontzettend bedanken voor alles wat je me de laatste jaren hebt bijgebracht, voor alle mogelijkheden die je me hebt gegeven en voor je gastvrijheid.

Beste Eline, je was altijd bereikbaar voor vragen en je nauwkeurigheid in de beoordeling van de opzet van een onderzoek of bij het doorlezen van de manuscripten hielp me om alles nog net wat breder te bekijken en op te schrijven. Bedankt voor je inzet!

Geachte professor Wildberger, ondanks dat mijn onderzoek al vergevorderd was op het moment dat $u$ in Maastricht begon, toonde $u$ vanaf het begin veel interesse en was $u$ goed op de hoogte van wat er speelt. Uw betrokkenheid, en uw inzet als voorzitter van de beoordelingscommissie, waardeer ik erg. Bedankt daarvoor.

Geachte professor Daemen, professor Mochtar en dr. Ir. Backes, bedankt voor jullie bijdrage voor de beoordelingscommissie.

Dear professor Stuber, dear Matthias, thank you for your efforts for the evaluation of my thesis. I'm very pleased that you will be in Maastricht for the defense as a member of the corona.

Dear professor Botnar, dear Rene, I'm very pleased that you will be in Maastricht for the defense as a member of the corona as well. Thank you for all your efforts and contributions in the last couple of years. 
Dear Jinnan, Jeff, Baocheng and professor Yuan, thank you for the opportunity to spend a great week in your lab in Seattle. It was really motivating to work with you all!

Beste Fons en Patty, jullie hulp met de statistiek en de discussies over de studies hebben enorm geholpen in het krijgen van inzichten in de resultaten. Bedankt voor jullie inbreng!

Susanne, Ine en Emilia, ontzettend bedankt voor jullie bijdrage aan het ontwerp van dit boekje en de uitnodigingen!

Natuurlijk wil ik daarnaast al mijn directe collega's bedanken. Om te beginnen de mensen "uit de kelder bij MRI 3" met wie ik al de tijd mijn kamer en de gang heb gedeeld en met wie ik hele leuke tijden heb beleefd, zowel in het AzM als daarbuiten, en bij wie ik steeds terecht kon als dat nodig was.

Ook al mijn collega-assistenten "boven op niveau 3" en alle stafleden wil ik bedanken. Een goede werksfeer bepaalt zo ontzettend veel, en de sfeer zoals die op onze afdeling heerst waardeer ik enorm. Ik ben blij dat ik bij de radiologie beland ben, en dat ik aan deze tijd niet alleen leuke collega's over hou maar ook een aantal hele goede vrienden!

Lieve Elleke, jij bent een van die collega's waar ik altijd op kan terugvallen als dat nodig zou zijn, en ook jij bent inmiddels meer geworden dan een gewone collega! Bedankt dat je er bij bent, en dat je vandaag als paranimf naast me staat. Ik wens je heel veel geluk met Bas en Mai, en daarnaast wens ik je ook veel succes in je eigen carrière.

Lieve Joyce, vanaf het moment dat ik je vroeg of je een van mijn paranimfen wilde zijn was je al bezig met wat je allemaal voor me kon doen. No worries, het valt allemaal wel mee. Het is zo leuk hoe die dingen lopen... Vanaf ons eerste levensjaar komen we al bij elkaar over de vloer, en ondanks dat er veel veranderd is in ons leven blijft die goede vriendschap nog steeds bestaan. Ook jij bedankt dat je vandaag naast me staat, en veel geluk met Jordy en Milla!

Door de jaren heen leer je mensen kennen, je leert vooral je echte vrienden kennen en steeds meer te waarderen. Om een lang verhaal kort en vooral leesbaar te houden ga ik niet iedereen bij naam noemen en bedanken, maar de mensen om wie het hier gaat weten dat wel... Lieve vrienden, ontzettend bedankt voor jullie begrip, interesse, alle leuke avondjes, etentjes, uitstapjes en vakanties en bedankt voor al die keren dat ik op jullie terug kon vallen als dat nodig was! 
En last but not least: mijn familie, en dan vooral pap, mam, Heleen en Nick: ook jullie bedankt voor de steun en jullie geduld, voor alle goedbedoelde adviezen (waar ik misschien niet altijd naar luisterde...) en voor de mogelijkheid om te praten en te discussiëren als dat nodig was. Door jullie vertrouwen sta ik daar waar ik nu sta. Lieve Lonneke, sinds kort hoor jij er ook bij: welkom in de familie en veel geluk gewenst! 

Curriculum vitae 
$-180-$ 


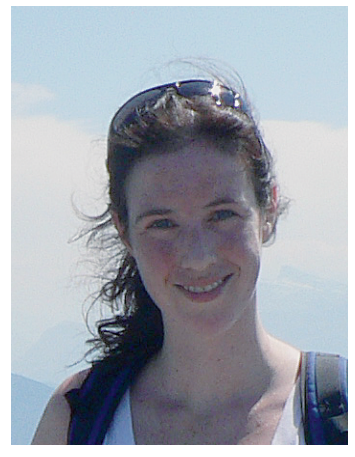

Suzanne Carina Gerretsen was born on February 22, 1978 in The Hague, the Netherlands. She moved to Maastricht where she obtained her high school diploma at the Jeanne d'Arc College (currently Porta Mosana) in 1996. After one year of nursing school she started her medical training in 1997 at Maastricht University in Maastricht, the Netherlands. In December 2003 she graduated from Medical School (cum laude), and in March 2004 she started as a PhD student at the department of Radiology of the Maastricht University Medical Center under supervision of Prof. dr. Jos van Engelshoven, dr. Tim Leiner and dr. Eline Kooi. In October 2009, her abstract about her research was one of the six nominees for the "Pelerin prijs" from the Maastricht University Medical Center. The results of her research are presented in this thesis.

In December 2007 Suzanne officially started her residency in Radiology in Maastricht University Medical Center under supervision of dr. M. de Haan. 

List of publications 
S.C. Gerretsen, M.E. Kooi, A.G. Kessels, S. Schalla, M. Katoh, R.J. van der Geest, W.J. Manning, J. Waltenberger, J.M.A. van Engelshoven, R.M. Botnar, T. Leiner. Visualization of coronary wall atherosclerosis in asymptomatic subjects and patients with coronary artery disease using magnetic resonance imaging. PLoS ONE 20105 e12998

S.C. Gerretsen, T.F. le Maire, S. Miller, S.A. Thurnher, C.U. Herborn, H.J. Michaely, H. Kramer, A. Vanzulli, J. Vyzamal, M.N. Wasser, C.E.M. Ballarati, M.A. Kirchin, G. Pirovano, T. Leiner. Multicenter, Double-blind, randomized, intraindividual crossover comparison of Gadobenate Dimeglumine and Gadopentetate Dimeglumine for MR Angiography of Peripheral Arteries. Radiology 2010255 988

S.C. Gerretsen, B. Versluis, S.C. Bekkers, T. Leiner. Cardiac Cine MRI: comparison of 1.5T, non-enhanced 3.0T and blood pool enhanced 3.0T imaging. EJR 20086580

S.C. Gerretsen, M.E. Kooi, S. Schalla, T. Delhaas, G. Snoep, J.M.A. van Engelshoven, $\mathrm{T}$. Leiner. Magnetic Resonance Imaging of the coronary arteries. CVJSA 200718248

T. Leiner, S.C. Gerretsen, R.M. Botnar, E. Lutgens, V.C. Cappendijk, M.E. Kooi, J.M.A. van Engelshoven. Magnetic Resonance Imaging of Atherosclerosis. Eur radiol 2005151087

R.J. Nijenhuis, S.C. Gerretsen, T. Leiner, M.J. Jacobs, J.M.A. van Engelshoven, and W.H. Backes. Comparison of 0.5-M Gd-DTPA With 1.0-M Gadobutrol for Magnetic Resonance Angiography of the Supplying Arteries of the Spinal Cord in Thoracoabdominal Aortic Aneurysm Patients. JMRI 200522136 

Color figures 


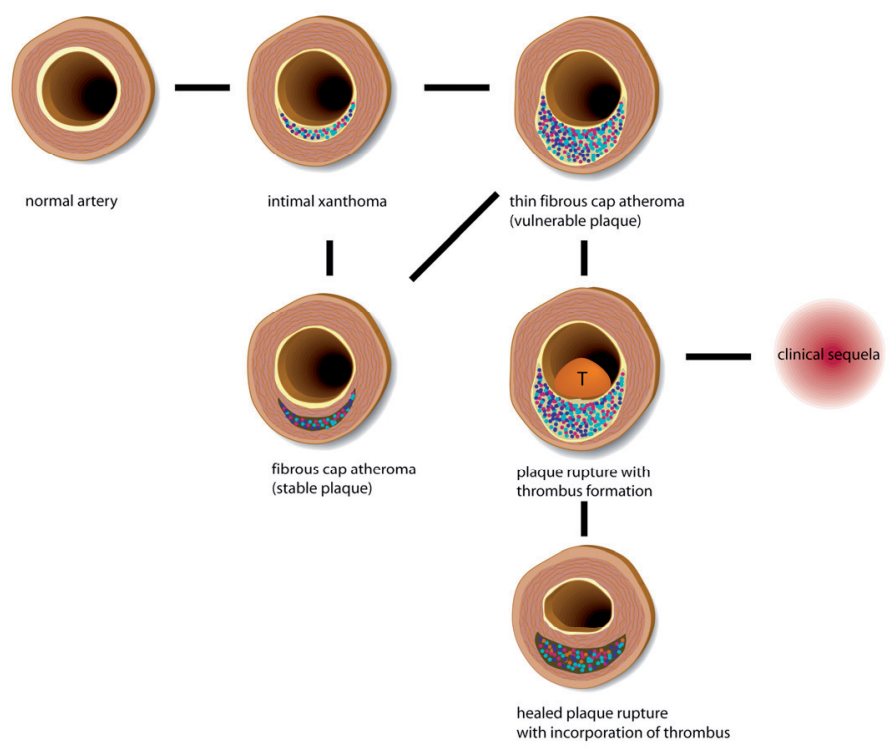

Chapter 2 - Figure 1. Different stages of plaque development (see text for description). Black lines denote transitions between different stages. T signifies thrombus.
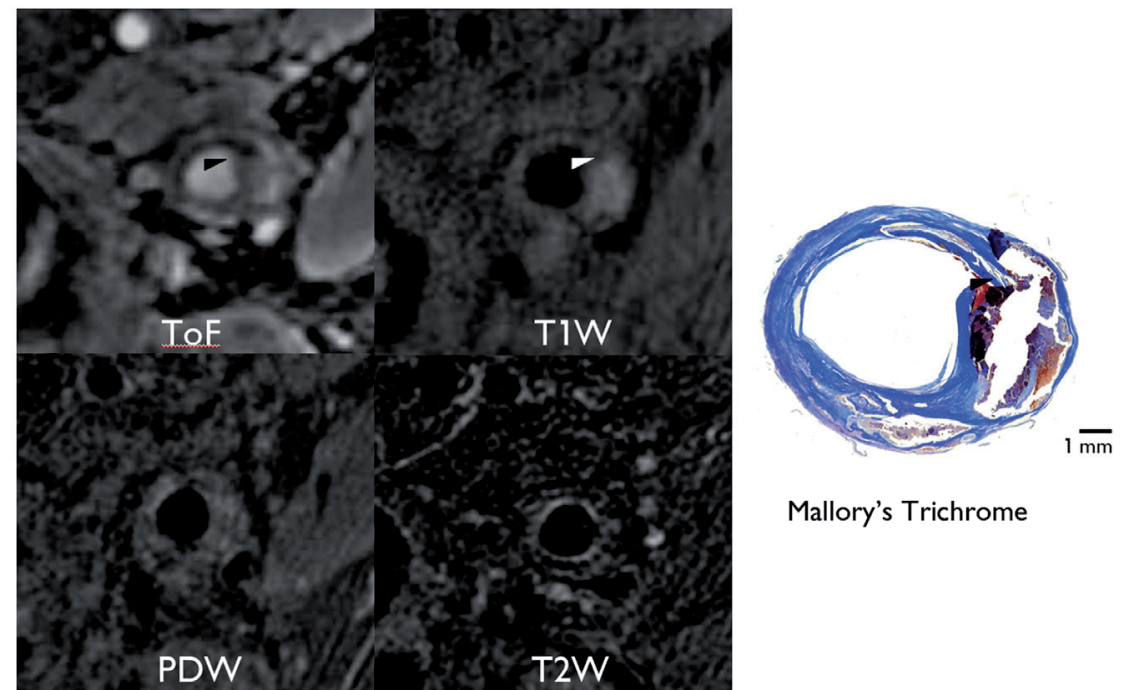

Mallory's Trichrome

Chapter 2 - Figure 2. Example of a luminal contour abnormality. A focal concavity of the luminal surface (arrowhead), best depicted on the ToF and T1-weighted images, correlates with an unstable, ruptured cap on the corresponding histologic section. Reproduced with permission from (50). 

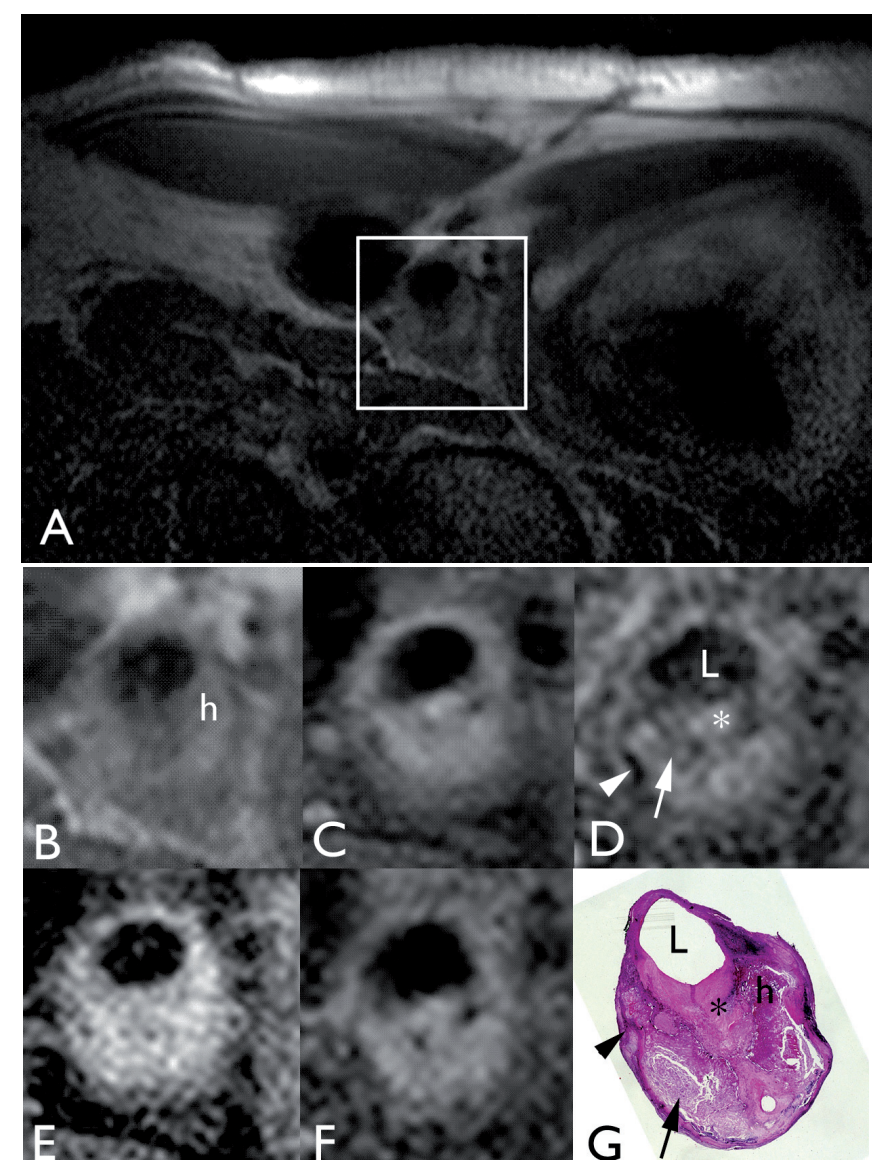

Chapter 2 - Figure 3. Carotid atherosclerotic plaque imaging with multisequence MRI. (A)

T1-weighted TFE overview of the right side of the neck. The box is placed around the internal carotid artery. Different MRI weightings are: T1-weighted TFE (B); PD-weighted TSE (C); T2weighted TSE (D); T1-weighted TSE (E); and Partial T2-weighted TSE (F). The corresponding haematoxylin-eosin stained histological slice (magnified $12.5 \mathrm{x}$ ) is shown in (G). For the T1weighted TFE sequence (B), the in-plane resolution was $0.39 \times 0.49 \mathrm{~mm}$ with a slice thickness of $3.0 \mathrm{~mm}$ and no slice gap. For the other sequences, the in-plane resolution was $0.39 \times 0.39 \mathrm{~mm}$ with a slice thickness of $2.5 \mathrm{~mm}$ and a slice gap of $0.5 \mathrm{~mm}$. Hemorrhage (h) was well differentiated from fibrous (asterisk) tissue (high and iso-intense relative signal intensity, respectively) on the T1-weighted TFE image (B). On the T2-weighted TSE image (D) fibrous tissue (asterisk) has high signal intensity, while calcification has very low signal intensity (arrowhead). Calcification also has very low signal intensity on PD-weighted TSE (C), T1-weighted TSE (E) and Partial T2weighted TSE (F). Lipid core has low signal intensity on T2-weighted TSE (D; arrow) and is low/iso-intense on T1-weighted TFE. 

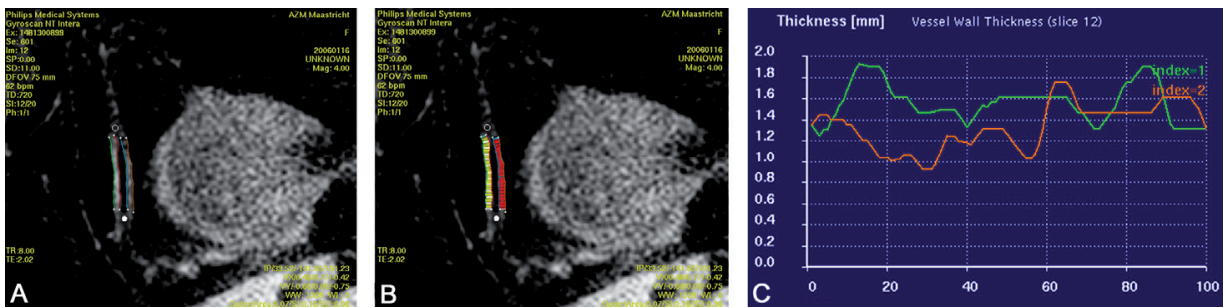

Chapter 4 - Figure 1. Measurement of vessel wall thickness on source images. The anterior and posterior vessel walls are delineated as separate ROIs in segment 2 of the right coronary artery (A). In each ROI 100 measurements are made of the anterior (yellow) and posterior (red) wall thickness (B). The custom made software program calculates wall thickness over the entire length of the measured ROIs for the anterior (index 1 ) and posterior (index 2) vessel wall (C).
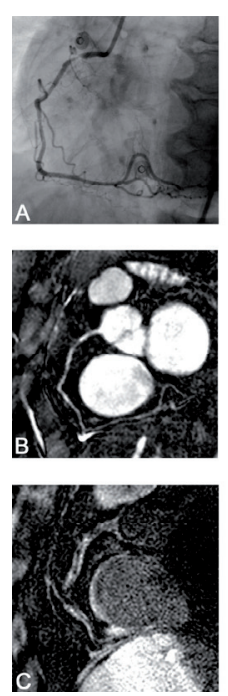
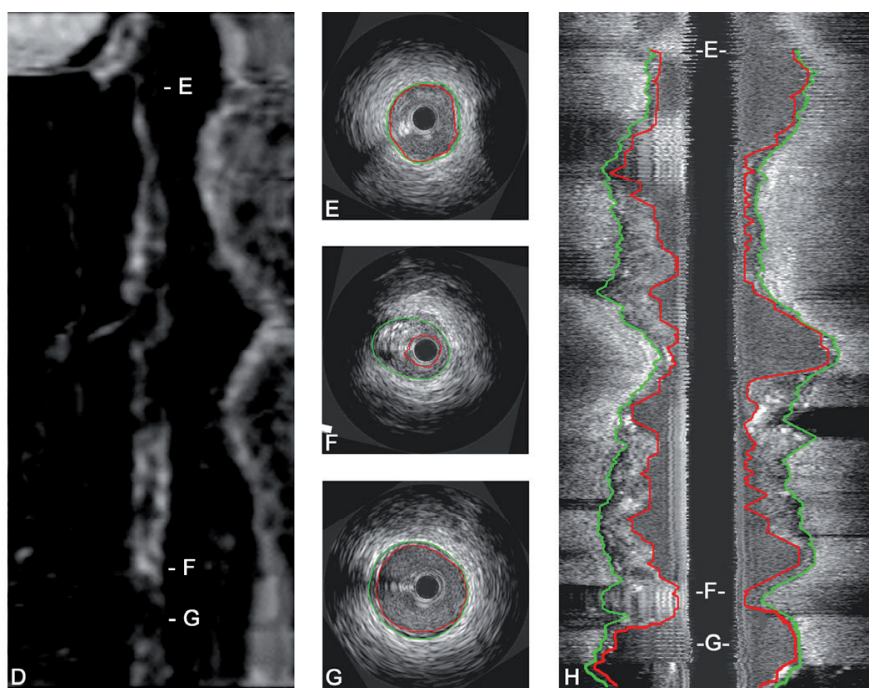

Chapter 4 - Figure 2. 61 y/o female with stable angina. X-ray angiography (A) and coronary MRA (B) demonstrate high grade stenosis in the proximal RCA. C) corresponding MR vessel wall scan demonstrate several area's with vessel wall thickening and high signal intensity. E (distal RCA), F (diseased area) and G (proximal RCA) are cross-sectional IVUS images and refer to the corresponding area's as shown on stretched MPR of the vessel wall scan (D) and the longitudinal IVUS-reformat $(\mathrm{H})$. $\mathrm{F}$ is the area of maximum stenosis. 

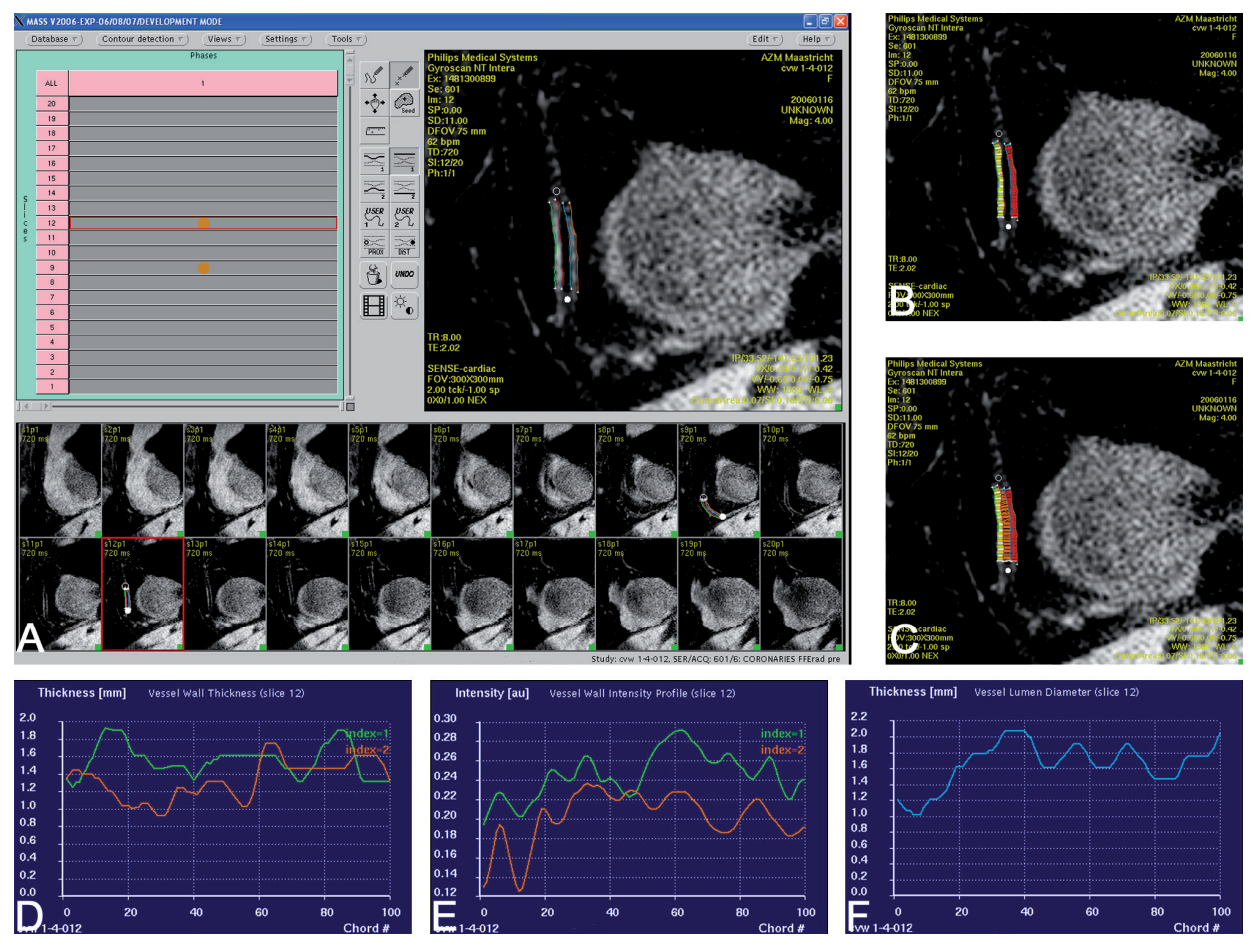

Chapter 5 - Figure 1. Measurement of vessel wall thickness and signal intensity on source images. The anterior and posterior vessel walls are delineated (A). In each segment 100 measurements are made of the thickness and signal intensity of the proximal and distal RCA vessel wall and the diameter of the lumen $(B, C)$. The custom made software program calculates wall thickness, signal intensity, and lumen diameter (D-F) over the entire length of the measured segment. 